\title{
Friction Surface Cladding of AA1050 onto AA2024
}

Parameter study and process window development 


\section{FRICTION SURFACE CLADDING OF AA1050 ONTO AA2024}

PARAMETER STUDY AND PROCESS WINDOW DEVELOPMENT

Shaojie Liu 
Composition of the graduation committee:

Chairman and secretary:

Prof.dr. G.P.M.R. Dewulf

University of Twente

Promoter:

Prof.dr.ir. R. Akkerman

University of Twente

Prof.dr.ir. L.E. Govaert

University of Twente

Co-promoter:

Dr.ir. T.C. Bor

University of Twente

Members:

Prof.dr. I.M. Richardson

Delft University of Technology

Prof.dr.ir. R. Benedictus

Delft University of Technology

Prof.dr.ir. A.H. van den Boogaard

University of Twente

Prof.dr.ir. D.J. Schipper

University of Twente

Friction surface cladding of AA1050 onto AA2024; parameter study and process window development

Shaojie Liu

PhD Thesis, University of Twente, Enschede, The Netherlands

December 2016

ISBN: 978-90-365-4270-8

Copyright ( 2016 by Shaojie Liu, The Netherlands

Printed by Ipskamp Drukkers B.V., Enschede, The Netherlands 


\section{FRICTION SURFACE CLADDING OF AA1050 ONTO AA2024}

PARAMETER STUDY AND PROCESS WINDOW DEVELOPMENT

\section{DISSERTATION}

to obtain

the degree of doctor at the University of Twente, on the authority of the rector magnificus,

Prof.dr. T.T.M. Palstra ,

on account of the decision of the graduation committee,

to be publicly defended

on Wednesday $14^{\text {th }}$ December, 2016 at $12.45 \mathrm{hrs}$

by

Shaojie Liu

born on 13 December, 1987

in Linyi, Shandong, China 
This thesis has been approved by

Promoter:

Prof.dr.ir R. Akkerman

Prof.dr.ir. L.E. Govaert

Co-promoter:

Dr.ir. T.C. Bor 


\section{Summary}

Surface modification is often required in many industries to improve the physical or chemical characteristics of the original product surface. Friction surface cladding (FSC), a relatively new solid state surface modification technique, was developed to deposit thin metallic layers onto substrates to protect the substrates from chemical corrosion. The FSC process employs a specially designed rotating tool containing an opening as the supply channel of the clad material and a specific tool bottom to support the material flow. The process comprises a preheating and a cladding phase.

A feasibility study of depositing commercially pure aluminum AA1050 on substrates of AA2024 has been performed before. It was observed experimentally that continuous and defect free clad layers can be deposited on a substrate. The main FSC process variables identified were the tool rotation rate, the layer dimensions and the size of the tool opening. The objectives of the current thesis are to carry out a systematic analysis of the FSC process, to develop appropriate and validated process models and to determine a model based FSC process window.

The various series of experiments presented in this work show that defect free layers can be manufactured within a large range of process parameters. It is observed that the cladding quality depends strongly on the process temperature, which, in turn, is strongly related to the tool rotation rate and the clad layer width. The normal force exerted by the cladding system on the substrate is very sensitive to all process parameters investigated.

The heat input of the FSC process is estimated using a 3D thermal model by fitting the recorded thermal history. Subsequently, a 2D axisymmetric thermo-mechanical model is set up to explain and calculate the heat generation from viscous dissipation of the strongly deforming clad material. As a start, it is assumed that full sticking of the clad material with the FSC tool and with the substrate occurs. The trends observed from the model results indicate that the heat generation increases with the tool rotation rate and the clad layer width, whereas the clad layer thickness and the size of the tool opening have negligible influence. The normal force exerted on the substrate decreases for larger values of the clad layer thickness, the tool opening diameter and the tool rotation rate, but it increases with larger clad layer widths. These results confirm approximately the experimental trends observed and supply further understanding of the FSC process. A quantitative comparison of the experimental and model results shows that the thermo-mechanical model overestimates the estimated heat generation and it underestimates the measured 
normal force. This is mainly ascribed to the assumed full sticking conditions at the interfaces with the clad layer.

From both thermal models it was observed that variations in the clad layer temperature are relatively small during the cladding phase, which allowed the development of a closed form analytical solution under isothermal conditions. This analytical model also includes a spatially varying sticking factor at the tool-clad material interface, which allows further study of the role of the contact conditions during FSC. Best results were obtained if the sticking conditions vary from full sticking in a region close to the FSC tool opening to almost full slipping at the FSC tool edge. The predicted heat generation rates compare well with the corresponding experimental results, but the calculated normal forces show some deviations from the measured values.

Additional experiments were performed to determine the FSC process window by adjusting the tool rotation rates in the cladding phase. It is found that continuous and defect free layers can be deposited with the substrate temperature between a lower and an upper bound of $317^{\circ} \mathrm{C}$ and $407^{\circ} \mathrm{C}$, respectively. Discontinuous layers may be produced when the substrate temperature is below $317^{\circ} \mathrm{C}$ and mixing of the clad material with the substrate may occur at temperatures higher than $407^{\circ} \mathrm{C}$.

A map of the FSC process window has been determined employing the temperature bounds described above and the 3D thermal model that computes the thermal fields on the basis of the heat input calculated from the analytical model. Proper tool rotation rates leading to continuous and defect free deposition of clad material can be selected directly from this map when certain layer dimensions are required. Minimal changes in the mechanical properties of the substrate occur if temperatures close to the lower bound are selected. The tool rotation rates within the process window can also be adjusted for a temperature controlled FSC process. 


\section{Samenvatting}

In industriële toepassingen is het vaak nodig de fysische en/of chemische eigenschappen van het oppervlak van een product te modificeren. In dit onderzoek is gebruik gemaakt van een relatief nieuwe, vaste stof oppervlaktebehandelingsproces (Friction Surface Cladding, FSC). Hierbij worden dunne metaallagen op een substraat opgebracht ter bescherming van het onderliggende oppervlak tegen bijvoorbeeld chemische corrosie. De techniek maakt gebruik van een speciaal ontwikkeld hol en roterend gereedschap dat het op te brengen metaal aanvoert en op het oppervlak aanbrengt. Het opbrengproces bestaat uit een voorverwarmingsfase en een opbrengfase.

Uit een experimenteel haalbaarheidsonderzoek is gebleken dat continue en defectvrije lagen van zuiver aluminium (AA1050) kunnen worden aangebracht op een in de vliegtuigindustrie veel gebruikte aluminium-koper legering (AA2024). De belangrijkste procesvariabelen waren de rotatiesnelheid van het gereedschap, de afmetingen van de opgebrachte laag en de grootte van de gereedschapsopening. Het doel van dit proefschrift is om na een systematische analyse van het opbrengproces, gevalideerde procesmodellen te ontwikkelen en mede op basis hiervan een procesvenster (process window) te bepalen waarbinnen het proces op betrouwbare wijze kan worden uitgevoerd.

Uit de verschillende uitgevoerde experimenten is gebleken dat defectvrije metaallagen kunnen worden gefabriceerd binnen een relatief breed gebied van procesvariabelen. De kwaliteit van de opgebrachte lagen hangt sterk af van de procestemperatuur. Deze temperatuur hangt vervolgens vooral af van de rotatiesnelheid van het gereedschap en de breedte van de opgebrachte laag. Daarentegen blijkt de door het proces op het substraat uitgeoefende normaalkracht af te hangen van alle onderzochte procesvariabelen.

De hoeveelheid warmte opgewekt tijdens het opbrengproces is eerst afgeschat met behulp van een 3D-thermisch model dat de bepaalde temperatuurverdeling nauwkeurig laat aansluiten bij gemeten temperatuurwaardes. Vervolgens is een 2D-axisymmetrisch thermo-mechanisch model opgesteld dat op basis van viskeuze vervorming de warmteontwikkeling in de op te brengen laag kan verklaren en berekenen. Hierbij is aangenomen dat de dunne metaallaag uitstekend hecht zowel aan het roterende gereedschap aan de bovenzijde van de laag als aan het substraat aan de onderzijde. Volgens dit model blijkt de warmteontwikkeling vooral bepaald te worden door de draaisnelheid van het gereedschap en de laagbreedte, terwijl de laagdikte en de grootte van de gereedschapsopening 
nauwelijks effect hebben. De uitgeoefende normaalkracht op het substraat neemt af met de laagdikte, de grootte van de gereedschapsopening en de draaisnelheid van het gereedschap, maar neemt toe met de laagbreedte. De resultaten van het model komen kwalitatief grotendeels overeen met de experimenten en verbeteren hiermee het begrip van het opbrengproces. Een kwantitatieve vergelijking laat echter zien dat het thermo-mechanische model de warmteontwikkeling overschat en de uitgeoefende normaalkracht onderschat. Dit wordt vooral toegeschreven aan de veronderstelde hechting van de opgebrachte metaallaag aan het substraat en het roterende gereedschap.

De resultaten van beide thermische modellen laten zien dat de temperatuurverschillen in de opgebrachte metaallaag relatief klein zijn tijdens de opbrengfase. Wanneer deze verschillen worden verwaarloosd, is een analytische oplossing van de warmteontwikkeling, het stromingspatroon en het drukverloop in de gemodelleerde metaallaag mogelijk. In het model kan ook de mate van hechting van het op te brengen metaal aan het gereedschap ingesteld en daarmee bestudeerd worden. De beste resultaten worden verkregen indien wordt aangenomen dat in de buurt van de gereedschapsopening een sterke hechting optreedt, terwijl naar de buitenrand van het gereedschap toe, deze hechting sterk afneemt. De voorspelde warmteontwikkeling komt dan goed overeen met de uit experimenten bepaalde waardes alhoewel de berekende normaalkrachten een zekere afwijking ten opzichte van de gemeten waardes blijven vertonen.

Het procesvenster (process window) is bepaald aan de hand van enkele extra experimenten. Hierbij werd de draaisnelheid van het gereedschap tijdens de opbrengfase gevarieerd. Continue en defectvrije lagen werden opgebracht bij een substraattemperatuur tussen een onder- en bovengrens van respectievelijk, $317^{\circ} \mathrm{C}$ en $407^{\circ} \mathrm{C}$. Bij temperaturen beneden $317^{\circ} \mathrm{C}$ bestaat het gevaar voor discontinue lagen, terwijl bij temperaturen boven $407^{\circ} \mathrm{C}$ vermenging van het substraat met het opgebrachte metaal kan plaatsvinden.

Het procesvenster is opgesteld met behulp van de hierboven genoemde temperaturen en het combineren van het reeds eerder opgestelde 3D-thermische model, dat het temperatuurveld berekent op basis van een hoeveelheid warmte, met het 2D-analytische model, dat de benodigde warmte kan bepalen. Met behulp van het zo opgestelde procesmodel kunnen de condities voor het opbrengen van continue en defectvrije lagen direct worden bepaald. Minimale beïnvloeding van de mechanische eigenschappen van het substraat treedt op wanneer temperaturen dicht bij de ondergrens worden geselecteerd. Eventueel kan de draaisnelheid van het gereedschap worden geregeld tijdens de opbrengfase voor een temperatuurgecontroleerd proces. 


\section{Nomenclature}

\section{Abbreviations}

AS Advancing side

CFD Computational fluid dynamics

CL Clad layer

FEM Finite element model

FS Friction surfacing

FSC Friction surface cladding

FSW Friction stir welding

HAZ Heat affected zone

ITCR Ideal thermal contact region

LE Leading edge of the tool

RS Retreating side

TE Trailing edge of the tool

\section{Greek symbols}

$\alpha \quad$ Location parameter of the transition point between sticking and slipping

$\beta_{1} \quad$ Fitting constant for the relation of heat generation and the layer width and the temperature

$\Delta p \quad$ Pressure drop within the clad disk ring subdomain

$\Delta p_{k} \quad$ Pressure different over interval $k$

$\delta_{\theta, k} \quad$ Sticking/slipping factor along the circumferential direction at the $k$ interval

$\delta_{\theta, \min }$ Minimum value of the sticking/slipping factor along the circumferential direction

$\delta_{\theta}, \delta_{\theta}(r)$ Sticking/slipping factor at the contact interface along the circumferential direction 
$\Delta_{F_{n}} \quad$ The ratio of the measured normal force to that calculated by FEM

$\Delta_{Q} \quad$ The ratio of the estimated heat generation to that calculated by FEM

$\delta_{r} \quad$ Sticking/slipping factor at the contact interface along the radial direction

$\dot{\epsilon} \quad$ Strain rate

$\left[\mathrm{s}^{-1}\right]$

$\dot{\epsilon}_{0} \quad$ Initial strain rate

$\left[\mathrm{s}^{-1}\right]$

$\dot{\gamma} \quad$ Shear rate without consideration of the direction

$\left[\mathrm{s}^{-1}\right]$

$\dot{\gamma}_{r z} \quad$ Shear rate along the $r-z$ direction

$\left[\mathrm{s}^{-1}\right]$

$\dot{\gamma}_{z \theta} \quad$ Shear rate along the circumferential direction

$\left[\mathrm{s}^{-1}\right]$

$\gamma_{z \theta} \quad$ Strain along the circumferential direction

$\left[\mathrm{s}^{-1}\right]$

$\Omega \quad$ Tool rotation rate

[rpm]

$\mu \quad$ Viscosity of the clad material

$[\mathrm{Pa} \cdot \mathrm{s}]$

$\omega \quad$ Angular speed of the rotating tool

$[\mathrm{rad} / \mathrm{s}]$

$\rho \quad$ Material density

$\left[\mathrm{kg} / \mathrm{m}^{3}\right]$

$\sigma_{0} \quad$ Flow stress at the initial strain rate

$\sigma_{n} \quad$ Normal stress

$\sigma_{\theta} \quad$ Stress at $\theta$ direction

$\sigma_{e f f} \quad$ Effective stress

$\sigma_{f} \quad$ Flow stress of the material

$\sigma_{r} \quad$ Stress at $r$ direction

$\sigma_{y} \quad$ Yield stress

$\sigma_{z} \quad$ Stress at $z$ direction

$\tau \quad$ Shear stress of the material

$\tau_{r z} \quad$ The $r-z$ component of the shear stress

$\tau_{z \theta} \quad$ The $z-\theta$ component of the shear stress

$\theta_{t} \quad$ Tilt angle of the tool

$\delta, \delta, \delta(r)$ Sticking/slipping factor at the contact interface

\section{Roman symbols}


$<F_{n}>$ Average normal force

$<T_{t}>$ Average tool temperature

u Material flow velocity vector $[\mathrm{m} / \mathrm{s}]$

$\theta \quad \theta$ direction in the cylindrical coordinate system

$A, B$ Constant values in the analytical model

$A_{1} \quad$ Fitting constant

$A_{S} \quad$ Surface area $\left[\mathrm{m}^{2}\right]$

$b^{\prime} \quad$ Distance of thermocouple $T_{t}$ to the tool axis

$C_{1}, C_{2}$ Constants during the derivation of the normal force

$C_{p} \quad$ Specific heat

COF Coefficient of friction

$D_{\text {rod }}$ Diameter of the clad rod

$f^{\prime} \quad$ Derivative of $f(z)$

$f^{\prime \prime} \quad$ Second derivative of $f(z)$

$f(z) \quad$ A function of $z$

$F_{n} \quad$ Normal force

$F_{n, k} \quad$ Calculated normal force exerted by interval $k$ on the substrate

$F_{n-a n a}$ Total normal force calculated by analytical model

$F_{n-\text { disk-center }}$ Calculated normal force at the clad disk center subdomain

$F_{n-\exp }$ Normal force recorded experimentally

$F_{n-F E M}$ Normal force calculated by the FEM

$F_{n-\text { ring }}$ Normal force in the disk ring subdomain calculated by analytical model [N]

H Actual thickness of the deposited layer

$h_{0} \quad$ Nominal layer thickness

$h_{\text {rod }} \quad$ Height of the clad rod

$h_{\text {sub }} \quad$ Thickness of the substrate

$h_{\text {table }}$ Height of the backing plate 
$k \quad k$ interval

$k_{0} \quad$ Fitting constant

[Pa]

$k_{1} \quad$ Fitting constant

$k_{2} \quad$ Fitting constant

$k_{c} \quad$ Thermal conductivity

$[\mathrm{W} /(\mathrm{m} \cdot \mathrm{K})]$

M The applied torque

$[\mathrm{N} \cdot \mathrm{m}]$

$m$ Temperature dependence of the material property

[Pa]

$N \quad$ Finite division of the contact interface

$n \quad$ Power of the material property

$p, p(r)$ Pressure in the material

$P_{e} \quad$ Engine power of the planer machine

$p_{k} \quad$ Pressure at the $k$ interval at the contact interface

$P_{S} \quad$ Average pressure of a sample being analyzed

$p_{\text {disk-center }}$ Pressure in the clad disk subdomain

Q Heat generation rate

$Q_{0} \quad$ Activation energy

$[\mathrm{J} / \mathrm{mol}]$

Qana Total heat generation calculated by analytical model

[Watt]

$Q_{\text {disk-center }}$ Heat generation in the clad disk center subdomain calculated by analytical model

[Watt]

$Q_{\exp } \quad$ Heat generation estimated experimentally

[Watt]

$Q_{F E M}$ Heat generation calculated by the FEM

[Watt]

$Q_{k} \quad$ Heat generation in interval $k$ calculated by analytical model

[Watt]

$Q_{\text {ring }}$ Heat generation in the clad disk ring subdomain calculated by analytical model

[Watt]

$Q_{v h} \quad$ Viscous dissipation

[Watt]

$R \quad$ Half of the layer width

$r \quad$ Radius or radial direction in the clad disk

[m]

$R_{g} \quad$ Gas constant

$[\mathrm{J} /(\mathrm{mol} \cdot \mathrm{k})]$ 
$r_{k} \quad$ Radius at $k$ interval

$R_{\text {disk }} \quad$ Radius of the clad disk

$r_{i} \quad$ Inner radius of the clad disk ring subdomain

$r_{k+1} \quad$ Radius at $k+1$ interval

$r_{o} \quad$ Outer radius of the clad disk ring subdomain

$R_{\text {rod }} \quad$ Radius of the clad rod

$R_{\text {shoulder }}$ Radius of the tool shoulder

$R_{\text {sub }} \quad$ Radius of the substrate

$R_{\text {table }}$ Radius of the backing plate

$R_{t r} \quad$ Transition point between sticking and slipping

$s \quad$ Shape parameter of the sticking/slipping factor

T Transient temperature

$t \quad$ Time

$T_{m} \quad$ Melting temperature of the material

$T_{r} \quad$ Ambient temperature

$T_{t} \quad$ Thermocouple in the tool or tool temperature recorded by the thermocouple in the tool

$T_{\text {in }} \quad$ Calculated peak temperature at the bonding interface

$T_{\text {lower }}$ The lower bound temperature of the FSC process window

$T_{\text {upper }}$ The upper bound temperature of the FSC process window

$\mathrm{TC}_{i} \quad$ The $i$ thermocouple or the temperature recorded by the $i$ thermocouple, $i=1,2,3,4,5$

$T C_{3-\exp }$ Peak temperature measured by $T C_{3}$

$T C_{3-F E M}$ Peak temperature calculated by the FEM at the position of $T C_{3}$

$u_{r} \quad$ Velocity along $r$ direction

$u_{z} \quad$ Velocity along $z$ direction

$u_{\theta} \quad$ Velocity along $\theta$ direction

$u_{r, k} \quad$ Velocity along $r$ direction in interval $k$ 
$V_{f} \quad$ Volumetric supply rate of the clad material $\left[\mathrm{m}^{3} / \mathrm{s}\right]$

$V_{f, k} \quad$ Volumetric supply rate of the clad material through interval $k \quad\left[\mathrm{~m}^{3} / \mathrm{s}\right]$

$v_{t} \quad$ Tool translation speed with respect to the substrate $[\mathrm{m} / \mathrm{s}]$

$W \quad$ Width of the deposited layer [m]

$W_{s} \quad$ Width of the clad layer at mixing point [m]

Z Zener-Hollomon equation [-]

$z \quad z$ direction in the coordinate system $\quad[\mathrm{m}]$ 


\section{Contents}

Summary

Samenvatting $\quad$ v

Nomenclature $\quad x$

1 Introduction 1

1.1 Background and motivation . . . . . . . . . . . . . . . 1

1.2 FSC setup and process . . . . . . . . . . . . . . . 2

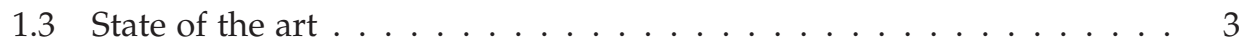

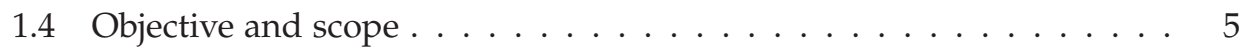

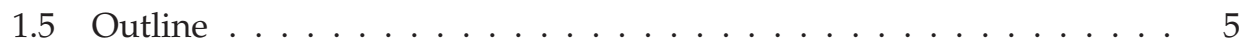

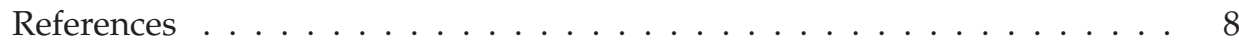

2 The effect of the tool rotation rate 9

2.1 Introduction . . . . . . . . . . . . . . . . . . 9

2.2 Experimental procedure and materials . . . . . . . . . . . . . . 10

2.3 Model description . . . . . . . . . . . . . . . . . . . . . . . . . . . . . . . . . . . . .

2.3 .1 Model setup . . . . . . . . . . . . . . . 13

2.3 .2 Heat input . . . . . . . . . . . . . . . . . 14

2.3 .3 Boundary conditions . . . . . . . . . . . . . . 14

2.4 Results and discussion . . . . . . . . . . . . . . . . 15

2.4.1 Experimental observation . . . . . . . . . . . . . 15

2.4 .2 Determination of the heat input . . . . . . . . . . . 23

2.4 .3 Application of the thermal model . . . . . . . . . . . 28

2.5 Conclusions . . . . . . . . . . . . . . . . . 30

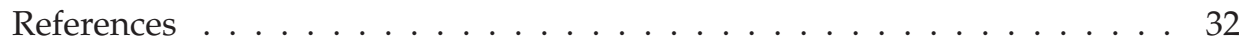


3 Experimental study 33

3.1 Introduction . . . . . . . . . . . . . . . 33

3.2 Experimental procedure . . . . . . . . . . . . . . 34

3.3 Results and discussion . . . . . . . . . . . . . . . . 36

3.3.1 EN-h0.4 series: tool rotation rate study . . . . . . . . . . 36

3.3.2 EH series: layer thickness study . . . . . . . . . . . . . 39

3.3 .3 EW experiment . . . . . . . . . . . . . . . 44

3.3 .4 ED series . . . . . . . . . . . . . . . . 46

3.4 Conclusions . . . . . . . . . . . . . . . . . . . . 49

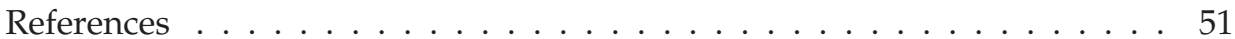

4 Parameter study with an axisymmetric thermo-mechanical model 53

4.1 Introduction . . . . . . . . . . . . . . . . . . . 53

4.2 Model description . . . . . . . . . . . . . . . . . . . . 54

4.2 .1 Model setup . . . . . . . . . . . . . . . 54

4.2 .2 Boundary conditions . . . . . . . . . . . 55

4.2.3 Constitutive equations of the clad material and governing equations ...................... 57

4.3 Results and discussion . . . . . . . . . . . . . . 58

4.3 .1 Example study . . . . . . . . . . . . . 58

4.3.2 Parameter study with the model . . . . . . . . . . . 61

4.3.3 Ratios of the heat generations and the normal forces and COF 64

4.4 Conclusions . . . . . . . . . . . . . . . . . . . 68

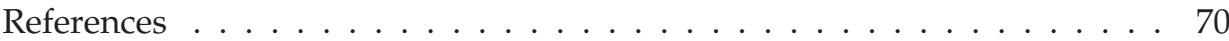

4.A Application of the model . . . . . . . . . . . . . 71

5 Analytical solution to the heat generation and the normal force 77

5.1 Introduction . . . . . . . . . . . . . 77

5.2 Model description . . . . . . . . . . . . . . . . . . . 78

5.2.1 Model background . . . . . . . . . . . . . 78

5.2 .2 Materials .................... 80

5.2.3 Mathematical derivation . . . . . . . . . . . . . 80

5.3 Results and discussion . . . . . . . . . . . . . . . . . 85

5.3.1 Heat generation and normal force contribution of the clad disk center..................... 85

5.3.2 Analytical results at full sticking condition . . . . . . . . . . . 88

5.3.3 Comparison with experiments . . . . . . . . . . . . . 91

5.3.4 The role of the contact status at the tool-clad material interface 92

5.4 Conclusions . . . . . . . . . . . . . . . . . 97 
References .......................... . 99

5.A Validation of the analytical model . . . . . . . . . . . . 100

5.A.1 Material . . . . . . . . . . . . . . . . . . . . . . 100

5.A.2 Model validation . . . . . . . . . . . . . . . . . . . 100

6 Process window determination 103

6.1 Introduction . . . . . . . . . . . . . . . . . . . . . . 103

6.2 Experimental procedure and materials . . . . . . . . . . . . . 104

6.3 Experimental results . . . . . . . . . . . . . . . . 105

6.3.1 Cladding appearance . . . . . . . . . . . . . 105

6.3.2 Temperature, heat generation and normal force . . . . . . . . 108

6.3.3 Normal force . . . . . . . . . . . . . . . . . . . . . . . . 110

6.4 Model based process window . . . . . . . . . . . . . . . . . . . 111

6.5 Temperature controlled process . . . . . . . . . . . . . . . . . . 114

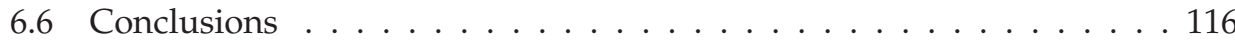

References . . . . . . . . . . . . . . . . . . . . . 117

7 Discussion 119

7.1 Overview of the FSC study . . . . . . . . . . . . . . . . . 119

7.2 Remaining challenges . . . . . . . . . . . . . . . 120

7.2 .1 Experimental controllability . . . . . . . . . . . . . . . . . . . . . . 120

7.2.2 Numerical and analytical models . . . . . . . . . . . . . 121

7.2.3 Material flow and contact area . . . . . . . . . . . . . . . . 121

References . . . . . . . . . . . . . . . . . . . . . . . 124

8 Conclusions and recommendations 125

8.1 Conclusions . . . . . . . . . . . . . . . . . . . . . . . 125

8.2 Recommendations . . . . . . . . . . . . . . . . 127

$\begin{array}{ll}\text { Acknowledgement } & 131\end{array}$

$\begin{array}{ll}\text { Publications } & 133\end{array}$ 



\section{Introduction}

\subsection{Background and motivation}

Many industries including automotive, aerospace and ship building use surface modification technologies to change the surface properties of a product. There is a broad range of industrial processes that can alter the surface of metal products to enhance various properties such as corrosion resistance, wear resistance, chemical resistance and hardness as thoroughly described by Miyamoto et al. (1999). Often, the surface is covered (coated) with a clad layer that is different in composition than the base metal product. Possible surface modification techniques include amongst others physical/chemical vapor deposition, thermal spraying, shielded metal arc and laser beam cladding, galvanizing and friction surfacing. Transfer of the clad material occurs through the gas, the liquid and/or the solid phase, leading to differences in deposition rate, microstructural changes of the base metal product and the area of the surface being covered as discussed in the above reference.

The majority of coating techniques employed currently in industries are fusion based. These techniques require a relatively large heat input to melt the clad material, although the deposition of the material on the substrate involves in general low mechanical loading. Upon subsequent solidification problems may occur due to shrinkage, inhomogeneous cooling and entrapped gas, leading to (micro) cracks and altered substrate microstructures. Solid state approaches form an interesting alternative: the heat input required is much lower, solidification related problems are absent and dimensional and microstructural changes remain modest. This drives research on solid state cladding processes.

Friction surfacing (FS) provides a way to deposit clad materials in the solid state, as reviewed by Gandra et al. (2014). A rotating consumable clad rod is pressed against a metal product/substrate. Friction occurs at the interface leading to local heating and softening of the clad rod. As soon as the clad rod and the substrate are heated up sufficiently, the rotating rod is moved over the substrate surface while being pressed against it. Part of the softened clad rod is transferred to the substrate generating a clad layer. In general, the temperatures occurring in the substrate are much lower than the melting point of the substrate material. This 
prevents fusion defects and limits the extent of the Heat Affected Zone (HAZ). A considerable amount of work has been carried out over the years and a large number of engineering metals can be deposited this way, as reported by Gandra et al. (2014).

A typical problem of FS, and also for fusion based clad processes, is the occurrence of porosities and poor clad material-substrate bonding, as studied by Gandra et al. (2012) in a different paper. These problems may occur especially near the edges of FS deposited layers, hampering reliable application in practice. Another problem in FS is excessive flash formation. The applied pressure on the rotating rod is relatively high compared to the strength of the rod near the clad rod-substrate interface. This leads to severe plastic deformation and the loss of large amounts of clad material. Van der Stelt et al. (2013) introduced a new solid state cladding process, called Friction Surface Cladding (FSC), with the aim of, amongst others, solving the main problems observed in FS. This new technique provides effective control over the deposition of the clad material by using a specially designed cladding tool. The cladding setup and process will be described in the following section.

\subsection{FSC setup and process}

The FSC system comprises an in-house developed tool mounted on a modified planer machine and a hydraulic pumping unit providing controllable amounts of hydraulic fluid to the FSC tool. This tool contains a dedicated cylinder that enables the clad rod to be pressed out from a central tool opening at the tool bottom, as sketched in Fig. 1.1. The tool as well as the clad rod rotate at a preset rotation speed, while the rod is pushed out. The range of a number of FSC parameters is given in Table 1.1

The cladding process generates heat by (1) friction between the rotating, consumable rod and the substrate, (2) friction at the tool interface with the clad layer and (3) dissipation of plastic deformation within the clad material.

Table 1.1 Parameters of the FSC setup.

\begin{tabular}{c|c|c|c|c}
\hline $\begin{array}{c}\text { Engine power } \\
P_{e}[\mathrm{~kW}]\end{array}$ & $\begin{array}{c}\text { Rotation rate } \\
\Omega[\mathrm{rpm}]\end{array}$ & $\begin{array}{c}\text { Translation speed } \\
v_{t}[\mathrm{~mm} / \mathrm{min}]\end{array}$ & $\begin{array}{c}\text { Normal force } \\
F_{n}[\mathrm{kN}]\end{array}$ & $\begin{array}{c}\text { Tilt angle } \\
\theta_{t}\left[{ }^{\circ}\right]\end{array}$ \\
\hline $0-13$ & $250-1500$ & $0-500$ & $0-50$ & $-10-10$ \\
\hline
\end{tabular}

The FSC process consists of a preheating phase (Fig. 1.1(a), (b) and (c)) and a cladding phase (Fig. 1.1(d)). The rotating tool starts from a predefined height above the substrate. In the preheating phase, the clad material contained in the tool is pressed out at a preset supply rate and when it touches the substrate, frictional heating starts. After some time plastic deformation occurs in the clad rod due to the temperature rise and the pressure exerted. The softened clad material is spread laterally through the narrow space between the substrate and the tool bottom. The 
cladding phase begins as soon as the temperatures are high enough. The tool is translated at a certain speed along a predefined trajectory while continuously depositing the clad material. The cladding experiments are performed normally with the cladding tool tilted towards the trailing edge of the tool at an angle of $\theta_{t}$.

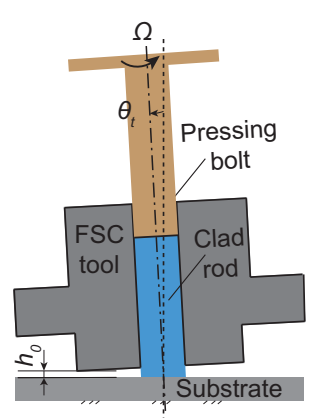

(a)

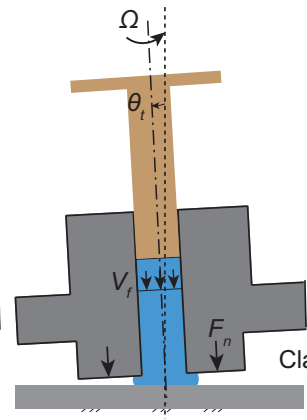

(b)

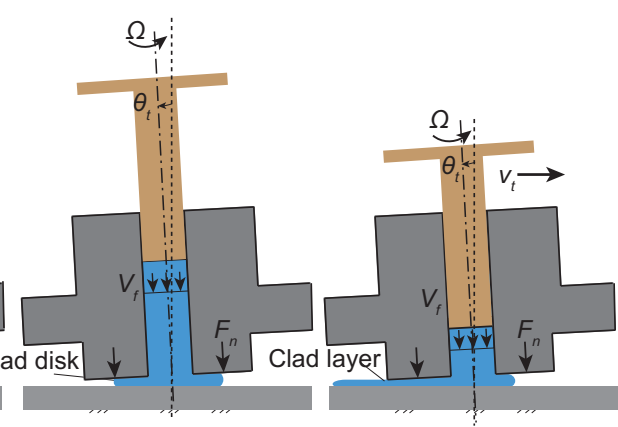

(c)

(d)

Fig. 1.1 Schematic process steps of Friction Surface Cladding (FSC): (a) the cladding tool positioned at required height and start of tool rotation at a rotation rate of $\Omega,(b)$ the clad rod is pressed out with a volumetric flow rate of $V_{f},\left[\mathrm{~mm}^{3} / \mathrm{s}\right],(c)$ frictional preheating of substrate, clad rod and tool and (d) cladding phase: the rotating tool translates with respect to the substrate at translation speed $v_{t}$. Note: the tilt angle $\theta_{t}$ of the tool is exaggerated for clarification.

The cladding steps of the FSC process are similar to those of FS, but the FSC process features some additional potentials. The clearance between the tool bottom and the substrate is used to control the layer thickness. The width of the clad layer deposited is determined by the volume of the clad material supplied per unit of time, the tool translation speed and the clearance between the tool and the substrate. The top surface of the clad layers produced by FSC is generally smoother than that by FS. The FSC process is more suitable for cladding soft metals on substrates in comparison with FS. It is attributed mainly to the presence of the FSC tool which supports a good lateral flow of the clad material on the substrate and a proper bond of the clad layer to the substrate. Other advantages of FSC can be found in Van der Stelt (2014).

\subsection{State of the art}

\section{Solid state bonding}

Solid state bonding takes place at a certain pressure and temperature without liquid or molten phases present at the bonding interface, as described in Kalpakjian and Schmid (2009). A sound bonding strength commonly requires clean surfaces, high pressure, elevated temperatures and relative movements at the bonding interface in the beginning of the process, according to Tylecote (1968). Cold welding, rolling, 
roll bonding, friction stir welding (FSW), FS and the currently presented FSC are some techniques that use the mechanism of solid state bonding.

Surface preparation prior to the bonding process is important to produce a proper bond in the solid state, as described by Tylecote (1968). A typical contaminant on the surface is the oxide film (or layer) which is generally hard and brittle. The oxide layer normally breaks before the initiation of the bonding process, and the fragments of the broken layers may interfere with the bonding quality. A scratchbrushing step can be used to wipe away/remove the majority of the oxide layers, which, to a large extent, reduces the threshold of the deformation required for a solid bond. Degreasing fluids can be used subsequently to remove organic contaminants.

Solid state bonding is mainly based on plastic deformation. The threshold value of deformation to initiate bonding differs for different metals and bonding methods. For instance, $40 \%$ overall deformation is required to cold weld aluminum by roll bonding, as mentioned by Tylecote (1968). The amount of plastic deformation depends highly on the pressure and temperature during the process. High temperature softens the material and also raises the possibility of atomic diffusion. The combination of the high pressure and temperature deforms or even breaks the asperities on the contacting surfaces. This brings the two surfaces even closer, facilitating diffusion of the material across the interface. A permanent bond is formed eventually between the workpieces. The process temperature can be raised by external heat sources, frictional work at the contacting interface and the plastic deformation within the deforming components. In general, the relative motion of the materials to be bonded lowers the required normal pressure, as suggested by Tylecote (1968).

\section{FSC process}

The aforementioned conditions required by the solid state bonding process also apply for FSC. FSC is performed at sufficiently high temperature with severe plastic deformation of the clad material, which enables the bonding.

Van der Stelt (2014) developed the cladding setup, performed a series of various exploratory experiments and confirmed the feasibility of depositing AA1050 on AA2024-T3. The bonding strength and the microstructures of the manufactured samples were also analyzed. Most of these experiments were performed with relatively high tool rotation rates, and the clad layers were often observed mixed with the substrate material. Defect free and non-mixing deposition was observed once from one experiment performed with a tool rotation rate of $450 \mathrm{rpm}$, the lowest possible rotation rate at that time. This indicates that the tool rotation rate has a strong influence on the cladding performance. Unfortunately, no more experiments were performed with low tool rotation rates to further study non-mixing deposition. The correlation between the FSC process parameters and the cladding performance remained unclear. 


\subsection{Objective and scope}

The FSC tool rotation rate may play a significant role in FSC, as described above. Hence, it is prioritized in this research. The FSC process is influenced also by other process parameters such as the volumetric supply rate of the clad material, the tool-substrate distance, the FSC tool translation speed, etc., see also Fig. 1.2. Future application of the FSC process requires a thorough understanding of the influence of all relevant process variables. Hence, a systematic study of the relations between the process variables and the process performance in terms of, for example, layer appearance, bonding strength, layer microstructure and alterations of the microstructure and properties of the substrate, is required. Once these correlations become clear, optimizing the process is also important for industrial application of FSC.

In this thesis the deposition of AA1050 clad layers on top of an AA2024 substrate is studied in depth with the aim to improve the corrosion resistance of the cladded substrate. Furthermore, the process conditions should be optimized, based on validated quantitative thermal flow models, to prevent changes in the microstructure and mechanical performance of the substrate as much as possible.

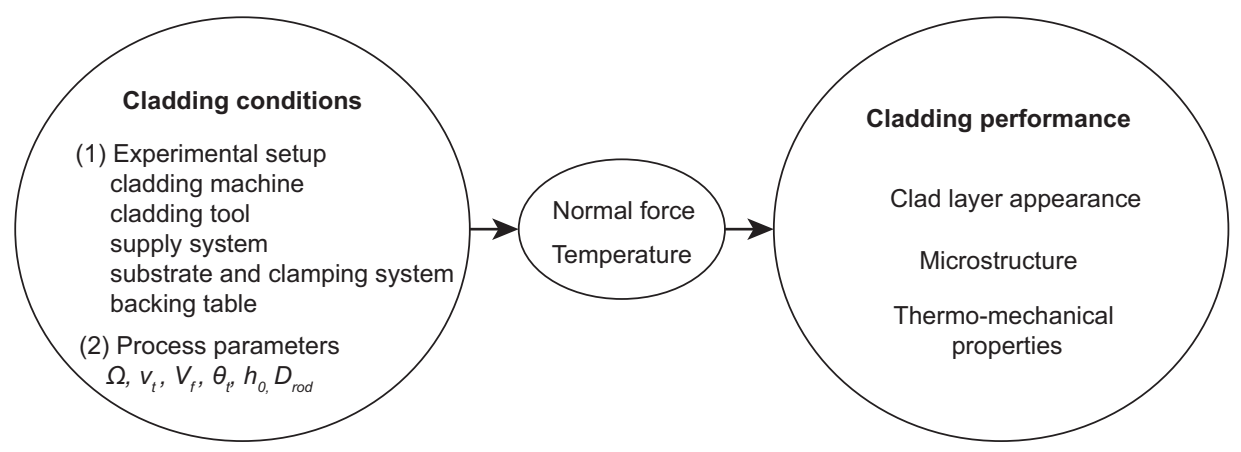

Fig. 1.2 The FSC map: the correlation between the cladding conditions, determined by the process parameters and the experimental setup, through the normal force and tool temperature with the cladding performance as presented by the clad layer appearance and the microstructure and mechanical properties of the substrate and clad layer.

\subsection{Outline}

The best corrosion performance of the deposited AA1050 layers on AA2024 substrates is commonly obtained when the layers are put on top of the substrate without mixing of the clad material and the substrate occurring. The experimental work is dedicated to the construction of a process window indicating relevant process regions, i.e. finding process settings prone to mixing and those that provide unmixed, well bonded clad layers. The clad layer and the substrate are characterized mainly in terms of hardness and their microstructure. 
A major part of the work comprises the modeling of the FSC process. Various models are developed. As a start a 3D thermal model is composed that allows the amount of heat generated during the FSC process to be estimated from the measured thermal fields in the substrate and the tool. This model does not consider the origin of the heat generated, but merely serves as a tool to estimate the heat input, since a dedicated torque measurement device is not present within the current FSC setup. In this way a relation of the process settings with the heat generated can be established.

Subsequently, a more general finite element model is developed that also enables the calculation of the thermal and pressure fields in time and space. The heat generation is based on temperature and strain rate dependent constitutive behavior of the AA1050 clad material. Heat conduction to the FSC tool, the substrate, the backing plate and the ambient environment is included. The finite element model allows the generated heat and normal force to be computed for a range of process parameters and in that sense provides significant understanding of the role of key process parameters. However, the model is not fully capable of handling variations in the boundary conditions at the interface between the FSC tool and the clad material. These boundary conditions may play an important role in a quantitative comparison of the modeled and experimental heating rates and normal forces.

Hence, a different modeling approach is required and here an axisymmetric, isothermal analytical model is developed, which pertains to the clad layer only. Both finite element models developed so far have shown that the spatial temperature variations occurring in the clad layer during the cladding phase are small enough to consider the temperature in the clad layer as isothermal for the current FSC setup and materials selected. The model provides closed form analytical expressions of the heat generation and the normal force exerted in terms of the process parameters and relevant tool dimensions. The role of the boundary condition at the tool-clad layer interface is studied in relation to the results of the various FSC experiments performed. The so-obtained experimental and modeling data are employed to construct a process window, from which optimal conditions for the deposition of AA1050 on top of AA2024 can be derived. The contents of each chapter are shown below in detail.

Chapter 2 contains an exploratory study aimed at depositing continuous and defect free layers as a function of the tool rotation rate. The appearance of the clad layer top surface, the clad layer dimensions and the clad layer-substrate interface are studied. The measured temperatures in the substrate and the FSC tool and the normal forces exerted on the substrate during the cladding process are investigated as well. The deposited clad layer and substrate hardness is measured to reveal the effects of the FSC process on the mechanical properties in both materials. A 3D thermal finite element model is set up to estimate the effective amount of heat generated during the FSC experiments and to relate these quantities to relevant process parameters. Finally, an approach is developed to predict the onset of clad layer-substrate mixing. The next chapter contains the results of additional experiments performed as a function of other process variables and tool dimensions, such as the layer 
thickness and the tool opening diameter (clad rod diameter, see also Fig. 1.1). Characterization of the experiments and resulting clad layers is performed in the same way as in Chapter 2. The combination of experiments from Chapters 2 and 3 form the basis for an in-depth analysis of the heat development and the normal forces exerted in the next two chapters.

In Chapter 4 a transient 2D thermal flow finite element model is established, which aims at understanding the relation between the process parameters and the occurring thermal and pressure fields employing detailed, temperature and strain rate dependent material behavior. The relations obtained between the heat generated and the normal force exerted as a function of various process parameters are compared with those of the experiments. Possible suggestions for observed differences are discussed.

Chapter 5 introduces an analytical solution to the heat generated and the normal force produced in FSC by solving creeping flow equations for an isothermal and stationary case. As a start, full sticking conditions are employed for comparison with the experimental results. The correlation between the heat generation and the normal force on the one side, and the process parameters such as the tool rotation rate and the layer dimensions on the other side, are quantified and discussed. Subsequently, a detailed analysis of the role of the contact conditions between the FSC tool and the clad material is carried out.

The developed process models, along with the results of a number of additional experiments, are employed in Chapter 6 to develop an FSC process window. The experiments are used to establish the upper and the lower bounds of the process temperatures at which continuous and defect free layers can be deposited.

Finally, in Chapter 7 the capabilities and remaining problems of the developed FSC process as well as the process models are thoroughly discussed. Subsequently, in Chapter 8 the final conclusions are drawn and recommendations for future work are provided. 


\section{References}

Gandra, J., Krohn, H., Miranda, R., Vilac, P., Quintino, L., and dos Santos, J. (2014). Friction surfacing: A review. J. Mater. Process. Technol., 214:1062-1093.

Gandra, J., Miranda, R. M., and Vilaça, P. (2012). Performance analysis of friction surfacing. J. Mater. Process. Technol., 212(8):1676-1686.

Kalpakjian, S. and Schmid, S. R. (2009). Manufacturing engineering and technology. Prentice Hall.

Miyamoto, Y., Kaysser, W., Rabin, B., Kawasaki, A., and Ford, R. (1999). Functionally Graded Materials: Design, Processing and Applications. Kluwer Academic Publishers.

Tylecote, R. (1968). The solid phase welding of metals. Edward Arnold.

Van der Stelt, A. (2014). Friction surface cladding; development of a solid state cladding process. PhD thesis, University of Twente.

Van der Stelt, A., Bor, T., Geijselaers, H., Akkerman, R., and van den Boogaard, A. (2013). Cladding of Advanced Al Alloys Employing Friction Stir Welding. ESAFORM 2013, Key Eng. Mater., pages 554-557, 1014-1021. 


\section{CHAPTER 2}

\section{The effect of the tool rotation rate ${ }^{1}$}

\subsection{Introduction}

Friction surface cladding (FSC) is a recently developed solid state process to deposit thin metallic layers on substrates. The principles of the process were first studied by Van der Stelt (2014) and the process was applied to the deposition of commercially pure aluminum (AA1050) on a corrosion sensitive, high strength aluminum alloy (AA2024-T351).

The initial study included FSC tools with different designs, different tool rotation and translation speeds and various tool tilt angles. The best results were obtained with the FSC tool with a central tool opening. The study showed that the tool rotation rate is an important process parameter as it strongly influences the process temperature and, as such, the clad layer appearance, the hardness distribution in the clad region and the resulting microstructure. In most cases the deposited clad material was mixed with the substrate except for one single case performed at the lowest possible tool rotation rate. In that case, it was shown that the clad layer was deposited on top of the substrate without notable defects. The clad layer showed good bonding to the substrate in a bending test and the corrosion properties of the clad layers were shown to be excellent for protection of the underlying AA2024T351 substrate.

This promising result forms the starting point for the current study. Here the influence of the rotation rate on the FSC process is studied systematically and new experiments are performed at even lower tool rotation rates. Hence, a much broader view on the influence of the tool rotation rate on the FSC process can be established.

Furthermore, a 3D thermal finite element model is developed to understand the relation between the temperature development over time in the FSC setup and the response of the cladding process in terms of the surface/interface appearance and the mechanical and microstructural properties of the clad layer and the substrate.

1 Liu, S., Bor, T., Van der stelt, A., Geijselaers, H., Kwakernaak, C., Kooijman, A., Mol, J., Akkerman, R., and Van Den Boogaard, A. (2016). Friction surface cladding: An exploratory study of a new solid state cladding process. J. Mater. Process. Technol., 229:769-784. 
Although it is known that heat generation is based on friction and plasticity processes, as a start, a simple and constant heat source is considered to enable the determination of the magnitude of the heat generation per unit of time. In Chapters 3 and 4 the precise origin of the heat generation is further investigated.

In this chapter also an approach is developed to describe properly the heat conduction at the interface between the substrate and the backing table beneath and in the vicinity of the FSC tool. Finally, the relation between the heat generation rate and the occurrence of mixing is studied.

\subsection{Experimental procedure and materials}

Experiments were performed with the same setup as used by Van der Stelt (2014) as described in Chapter 1 . The setup is equipped with a specially designed tool manufactured from H13 hardened steel. It has a diameter of $30 \mathrm{~mm}$ and contains a $\varnothing 10 \mathrm{~mm}$ opening in the center, as shown in Fig. 2.1. The bottom of the tool (Fig. 2.1(b)) is slightly profiled. At its periphery the tool bottom is manufactured with a shallow angle of $5^{\circ}$ to assist cladding at non-zero tilt angles and to prevent ploughing of the tool outer edge. Near the center region of the tool some space is created to enhance spreading of the clad material over the substrate. In this work, rods of commercially pure aluminum AA1050 are deposited on substrates of AA2024-T351 in the experiments.

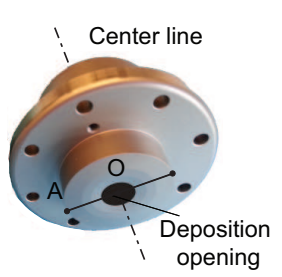

(a)

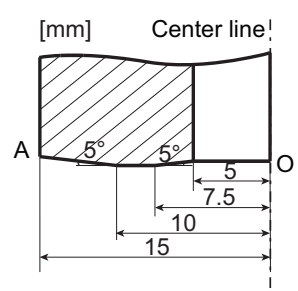

(b)

Fig. 2.1 (a) Friction Surface Cladding tool with a $\varnothing 10 \mathrm{~mm}$ central opening; (b) a detailed view of the tool bottom profile.

A thermocouple $T_{t}$ located at $8 \mathrm{~mm}$ from the tool axis and $2 \mathrm{~mm}$ above the tool bottom was used to measure the tool temperature, as shown in Fig. 2.2(a). The substrates with a length of $300 \mathrm{~mm}$ and a thickness of $4 \mathrm{~mm}$ were cut from larger plates such that the rolling direction of the substrates was perpendicular to the translation direction during the cladding phase. The width of the substrate was $180 \mathrm{~mm}$ or $141 \mathrm{~mm}$, depending on the configurations employed, see Fig. 2.2(b). All the experiments were performed with substrates containing thermocouples $\left(T C_{i}, i\right.$ $=1,2, \ldots, 5)$ to register the temperature development over time. The thermocouples were located in the substrates exactly below the proposed cladding trajectory of the FSC tool at a distance of approximately $2 \mathrm{~mm}$ from the top of the substrate. The 
thermocouples $T C_{i}$ were inserted in $\varnothing 1$ pre-drilled holes either from the bottom (configuration 1) or from the side (configuration 2), see Fig. 2.2(c-d). They were attached to the substrates with Insulcon Thermofix ${ }^{\circledR} 1100{ }^{\circ} \mathrm{C}$ glue. In the case of configuration 1, temperature resistant tape was used to separate the thermocouple wires placed between the substrate and the backing table. The tapes with thickness of $0.12-0.16 \mathrm{~mm}$ hinder to some extent the heat conduction from the substrate on the backing table. More importantly, they also make it difficult to set the nominal layer thickness accurately. The advantages of configuration 2 over 1 are the absence of these tapes and a better view on the cladding process from the side. Both configurations also differ in the way the substrate is clamped to the backing table.

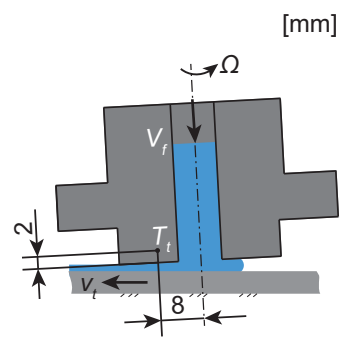

(a) $T_{t}$

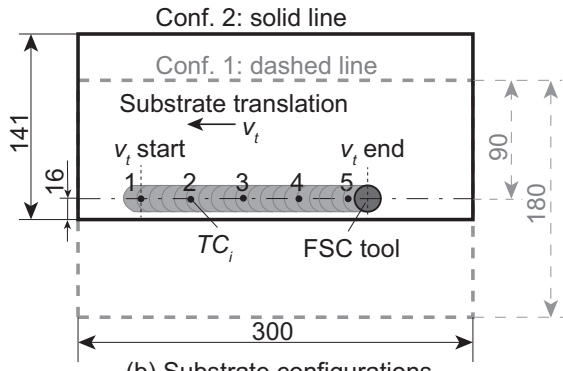

(b) Substrate configurations

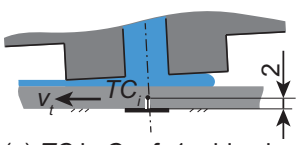

(c) $T C_{i}$ in Conf. 1 , side view

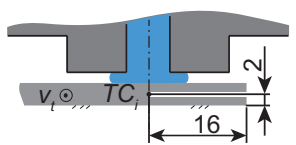

(d) $T C_{i}$ in Conf. 2, front view

Fig. 2.2 The thermocouples in the FSC tool (a) and the substrate (c-d) for both configurations employed; (b) substrate configurations: configuration 1 plotted by dashed line with dimension of $300 \mathrm{~mm} \times 180 \mathrm{~mm}$ and configuration 2 plotted by solid line with dimension of $300 \mathrm{~mm} \times 141 \mathrm{~mm} ; T C_{i}$ being the thermocouples at position $i, i=1,2,3,4,5$. All dimensions in $[\mathrm{mm}]$.

The normal force exerted by the cladding system to the substrate is measured by three load cells fixed on the frame of the planer machine. The supply rate of the clad material is recorded. The nominal layer thickness is the smallest distance between the tool bottom and the substrate top, and it was set manually by using a feeler gauge.

The FSC process is dependent on various process parameters for a given experimental setup. In this chapter mainly the influence of the tool rotation rate has been investigated through the experiments performed with conditions shown in Table 2.1. The tool rotation rate, $\Omega$, was varied from 250 to $600 \mathrm{rpm}$. The tool translation speed and the tool tilt angle were kept constant at $v_{t}=60 \mathrm{~mm} / \mathrm{min}$ and $1^{\circ}$ towards the tool trailing edge from the substrate normal, respectively. These settings follow that used in the experiment which gave the best result from Van der Stelt (2014). The tool-substrate distance, $h_{0}$, was set to a value of $0.2 \mathrm{~mm}$, but the experimental setup did not allow this height to be attained with a high precision $( \pm 0.1 \mathrm{~mm})$. The same holds for the supply rate of the clad material, $V_{f}$, and some variations occurred among the various experiments.

The FSC tool was placed approximately above the first thermocouple $\left(T C_{1}\right)$ before the start of the experiments. After the experiment starts, the substrate and the FSC 
tool are heated up as soon as the clad rod touches the substrate at the rotation rate provided. The translation of the rotating tool with respect to the substrate commences when the tool temperature reaches a value of about $250^{\circ} \mathrm{C}$. The cladding phase stops after translation of $160 \mathrm{~mm}$.

Table 2.1 Process parameters of the performed FSC experiments.

\begin{tabular}{l|c|c|c|c|c}
\hline Exp. & $\begin{array}{c}\Omega \\
{[\mathrm{rpm}]}\end{array}$ & $\begin{array}{c}v_{t} \\
{[\mathrm{~mm} / \mathrm{min}]}\end{array}$ & $\begin{array}{c}h_{0} \\
{[\mathrm{~mm}]}\end{array}$ & $\begin{array}{c}V_{f} \\
{\left[\times 10^{2} \mathrm{~mm}^{3} / \mathrm{min}\right]}\end{array}$ & Substrate \\
\hline EN-h0.2-1 & 250 & 60 & 0.2 & $\mathrm{~N} / \mathrm{A}$ & Configuration 1 \\
\hline EN-h0.2-2 & 300 & 60 & 0.2 & 2.5 & \\
EN-h0.2-3 & 350 & 60 & 0.2 & 2.5 & Configuration 2 \\
EN-h0.2-4 & 400 & 60 & 0.2 & 2.8 & \\
\hline EN-h0.2-5 & 450 & 60 & 0.2 & 3.9 & \\
EN-h0.2-6 & 500 & 60 & 0.2 & 4.4 & \\
EN-h0.2-7 & 550 & 60 & 0.2 & 5.0 & \\
EN-h0.2-8 & 600 & 60 & 0.2 & 4.7 & \\
\hline
\end{tabular}

Note: 'N/A' - data unavailable.

After the cladding experiments the cladded substrates were stored at room temperature for at least two weeks for ageing. Specimens for microstructural characterization were extracted from the substrates using a band saw. The samples were mechanically ground using grit silicon papers up to grade 4000 . Polishing was performed in three steps with a final polishing step using a colloidal silica suspension with a particle size of approximately $0.04 \mu \mathrm{m}$.

The samples were etched by $50 \% \mathrm{NaOH}$ etchant at approximately $70^{\circ} \mathrm{C}$ for 20 to $30 \mathrm{~s}$ for microstructure observation. The bonded interface and the grain structures near the interface were examined with optical microscopy. Vickers hardness measurements were performed with a LECO LM100 automatic micro-hardness measuring device employing a $0.98 \mathrm{~N}$ load for $15 \mathrm{~s}$.

\subsection{Model description}

The total heat generated by the FSC process and the temperature distribution in the FSC setup are obtained employing a 3D thermal finite element model. The model was established with a number of assumptions to determine the heat generation and the temperature distribution.

The following heat equation is solved, based on the conservation of energy, to determine the temperature distribution in the FSC tool, the substrate and the backing table as a function of time $t$ :

$$
\rho C_{p} \frac{\partial T}{\partial t}+\rho C_{p} v_{t} \cdot \nabla T=\nabla \cdot\left(k_{c} \nabla T\right),
$$


where $\rho$ is the material density, $C_{p}$ is the heat capacity and $k_{c}$ is the thermal conductivity. A boundary heat input of $Q$ representing the heat generation rate is prescribed at the tool-clad disk interface.

\subsubsection{Model setup}

The model comprises the FSC tool, the substrate, part of the backing table and the tool holder, as shown in Fig. 2.3(a). The tool in the model has the same dimensions as the one used in the experiments but is modeled with a flat tool bottom. The substrate with one of the two configurations is situated beneath the tool. The substrate clamps are not included in the model. A cylindrical tool holder $(\varnothing 60 \mathrm{~mm}$ $\times 42 \mathrm{~mm}$ ) along with the FSC tool are modeled as one piece, placed above the tool. A simplified table $(500 \mathrm{~mm} \times 396 \mathrm{~mm} \times 79 \mathrm{~mm})$ with clamping grooves is placed beneath the substrates.

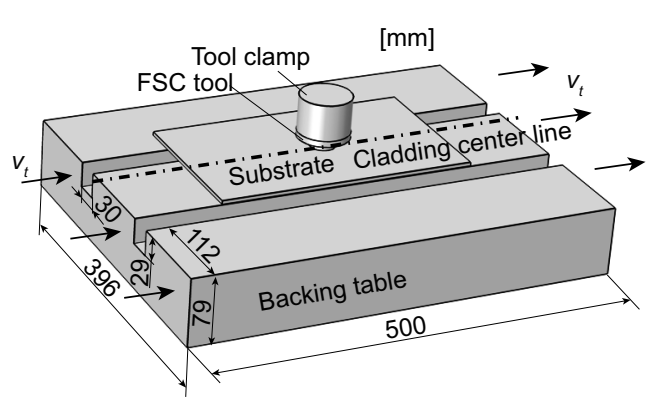

(a) Geometry of the thermal model

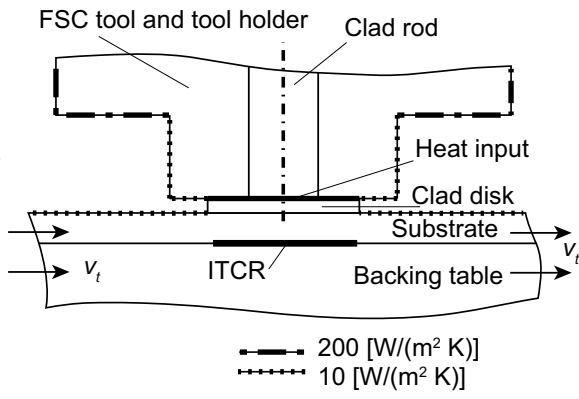

(b) Cross section along the cladding center line

Fig. 2.3 (a) The geometry of the thermal model with substrate configuration 1; (b) The thermal boundary conditions at all surfaces. The boundary heat input is added at the tool-clad disk interface. At the substratebacking table interface the heat conduction is position dependent: below the tool an ideal thermal contact region (ITCR) is present where the heat transfers with no thermal resistance, whereas beyond this zone the effective thermal resistance is modeled with a thin layer of air. The dimensions of the ideal thermal contact region and the thickness of the thin layer of air are determined as part of the modeling efforts.

The model contains a so-called clad disk located in between the tool and the substrate and a clad rod in the tool opening, see Fig. 2.3(b). The clad disk has a diameter equal to the layer width $W$ and is assumed here to be $1 \mathrm{~mm}$ thick instead of the nominal layer thickness of $h_{0}=0.2 \mathrm{~mm}$ to reduce the computational cost caused by relatively fine elements. Both the diameter and the length of the clad rod contained in the model equal $10 \mathrm{~mm}$.

The model is simplified further to limit computational time. The actual flow of the clad material from the FSC tool opening to the substrate is not taken into account. The FSC tool is modeled without a tilt angle and with a flat bottom contacting the clad disk/layer directly. Both the clad material and the cladding tool are considered stationary in the simulation. Average values of the simulated tool temperature are used to compare with the experimental one. 
The average values are obtained at four points in the modeled tool which are located $2 \mathrm{~mm}$ above the tool bottom and $8 \mathrm{~mm}$ away from the tool axis. Two of the four points are located above the cladding center line and the other two are perpendicular to the center line. This, to some extent, balances the temperature deviations at different positions caused by the stationary tool employed in the model.

Further simplifications include that only part of the backing table with a size slightly larger than the substrate is considered. Design details of the backing table in the vicinity of the processing zone are included to improve the simulation quality. In the model the Eulerian frame is used. During the cladding phase the material of the substrate and backing table are modeled to flow from the left side of the model in Fig. 2.3(a) into the respective domains with the substrate translation speed and at ambient temperature.

\subsubsection{Heat input}

A generic surface heat input $Q$ is located in the thermal model at the entire tool-clad disk interface to represent the heat generated in the FSC process zone by plastic deformation of the clad material and friction at the tool-clad material-substrate interfaces. Here, the joint contribution of these heating processes is taken into account without trying to determine the separate contributions of each heating mechanism. The magnitude of the heat input is assumed constant as a function of time. The preheating phase covers $30 \mathrm{~s}$ and the cladding phase $160 \mathrm{~s}$ which is in line with the typical length of a clad layer deposited with the tool translation speed employed (see Section 2.2 and Table 2.1).

The simulated temperature at the mid plane of the substrate along the cladding center line is compared with the value measured by thermocouple $T C_{3}$. The amount of heat input is adjusted to obtain a good fit for both the peak temperatures and the thermal histories.

\subsubsection{Boundary conditions}

The boundary conditions are shown schematically in Fig. 2.3(b). All surfaces exposed to the ambient environment are treated the same, employing an effective heat transfer coefficient of $10 \mathrm{~W} /\left(\mathrm{m}^{2} \mathrm{~K}\right)$. This value is comparable to the one used by Lohwasser and Chen (2010) in the simulation of heat transfer during FSW. An ideal thermal contact region (ITCR) without thermal resistance is assumed below and in the vicinity of the tool due to the locally high pressure. The thermal resistance at the substrate-table interface beyond the ITCR is taken into account by introducing a thin thermally resistive layer. This layer has a thermal conductivity of air at room temperature, $2.57 \times 10^{-2} \mathrm{~W} /(\mathrm{m} \cdot \mathrm{K})$, and its thickness is determined from the simulations. The starting temperature equals the ambient temperature. 
The contact diameter of the tool bottom in contact with the clad layer is set equal to the average width of the produced clad layer. The thermal properties of most components contained in the model are shown in Table 2.2. The temperature dependent specific heat and thermal conductivity of the substrate are shown in Fig. 2.4.

The thermal model was developed in the heat transfer module of the commercial package COMSOL Multiphysics 4.3.

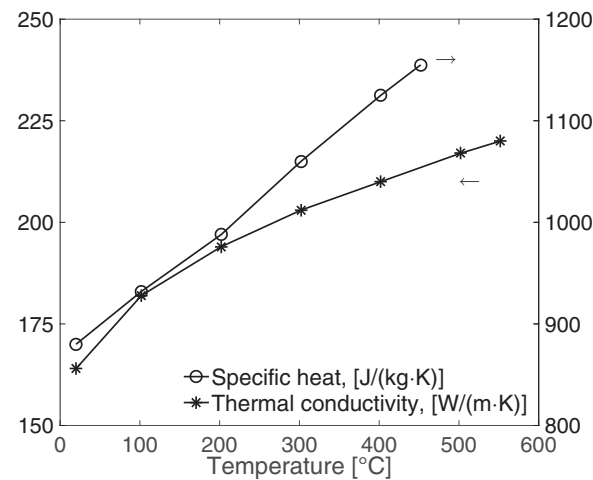

Fig. 2.4 Temperature dependent thermal conductivity and specific heat of AA2024 used by Li et al. (2012).

Table 2.2 Material properties of the components contained in the 3D thermal model.

\begin{tabular}{l|c|c|c}
\hline & $\begin{array}{c}\text { Density } \\
{\left[\mathrm{kg} / \mathrm{m}^{3}\right]}\end{array}$ & $\begin{array}{c}\text { Thermal conductivity } \\
{[\mathrm{W} /(\mathrm{m} \cdot \mathrm{K})]}\end{array}$ & $\begin{array}{c}\text { Heat capacity } \\
{[\mathrm{J} /(\mathrm{kg} \cdot \mathrm{K})]}\end{array}$ \\
\hline Clad material (AA1050) & 2700 & 190 & 900 \\
\hline Substrate (AA2024) & 2780 & see Fig. 2.4 & see Fig. 2.4 \\
\hline Backing table and tool (steel) & 7800 & 45 & 500 \\
\hline
\end{tabular}

\subsection{Results and discussion}

\subsubsection{Experimental observation}

\section{Clad layer appearance}

The FSC experiments were performed with a rotation rate varying between $250 \mathrm{rpm}$ and $600 \mathrm{rpm}$ with intervals of $50 \mathrm{rpm}$. In all cases AA1050 clad material was deposited continuously on the AA2024 substrate, except at a rotation rate of $250 \mathrm{rpm}$. During the cladding process all clad material provided was deposited on top of the substrate; no loss due to flash formation or otherwise took place. An overview of the deposited clad layers is given in Fig. 2.5(A). 
(A)
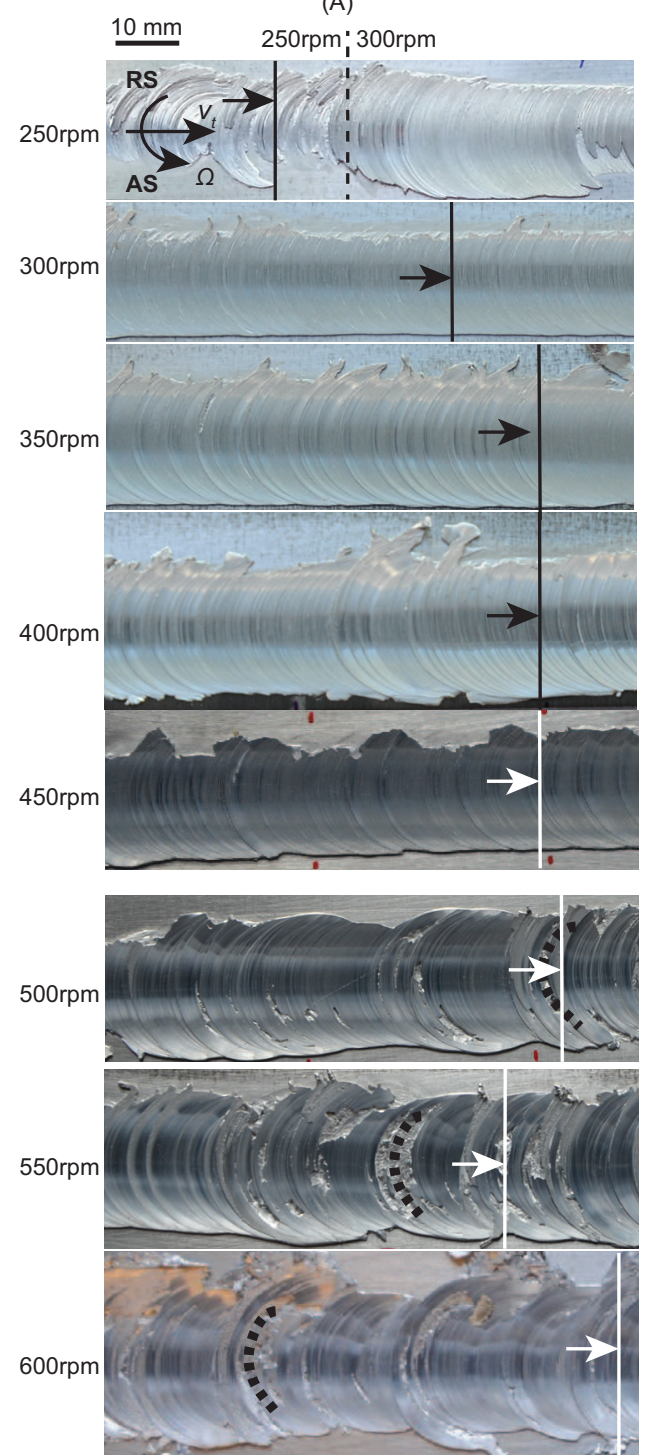

(B)
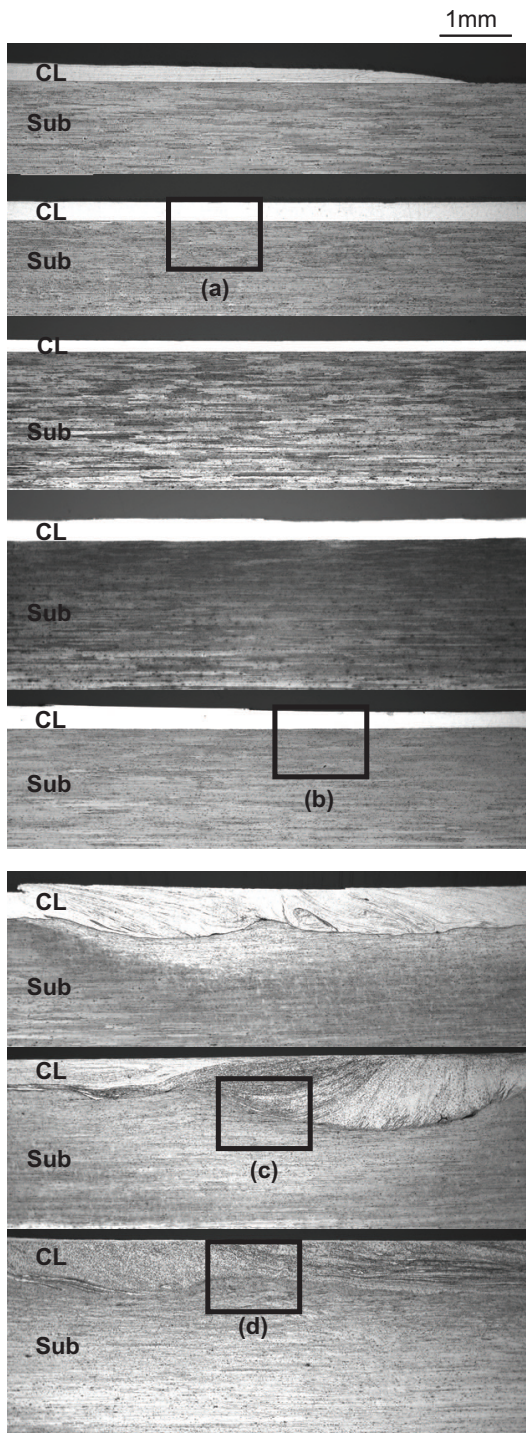

Fig. 2.5 (A) AA1050 clad layers deposited on AA2024 substrates with various tool rotation rates. The tool moved from left to right with respect to the substrate and rotated counterclockwise. (B) The cross sections of the cladded substrates extracted along the vertical lines marked in (A). Details of the sections enclosed by rectangles are displayed in Fig. 2.6. 'CL' = 'Clad layer'; 'Sub' = 'Substrate'; 'RS' = 'Retreating Side'; 'AS' = 'Advancing Side'; Black dashed lines indicate the trailing edge markings where clad material is missing.

A continuous and uniform clad layer with a smooth top surface is produced for rotation rates between $300 \mathrm{rpm}$ and $450 \mathrm{rpm}$. The width of the clad layer is also approximately constant although some variations occur mainly at the retreating 
side (RS) of the clad layer. When the tool rotation rate is $500 \mathrm{rpm}$ or higher, the clad layer does not cover the underlying substrate material uniformly as defects in the clad layer start to appear. Some clad material seems missing at the clad layer along the trailing edge of the tool, see arc markings in Fig. 2.5. At higher rotation rates these defects occur more frequently and furthermore the variation in width of the clad layer increases.

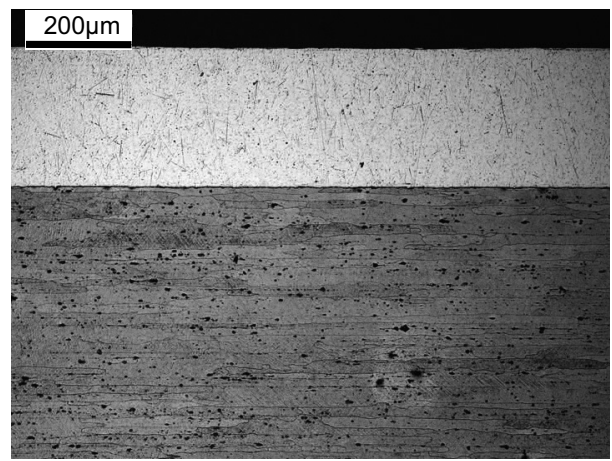

(a) $300 \mathrm{rpm}$

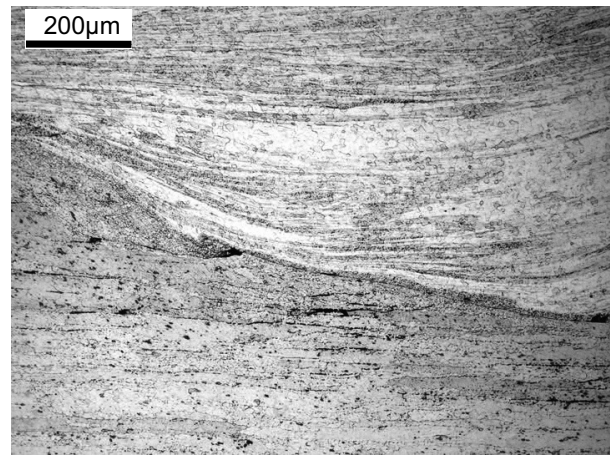

(c) $550 \mathrm{rpm}$

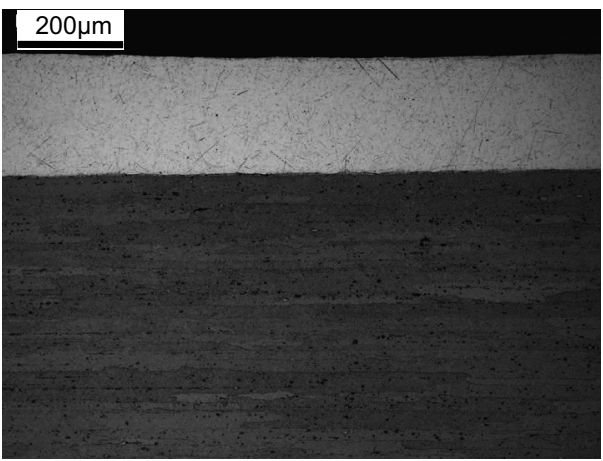

(b) $450 \mathrm{rpm}$

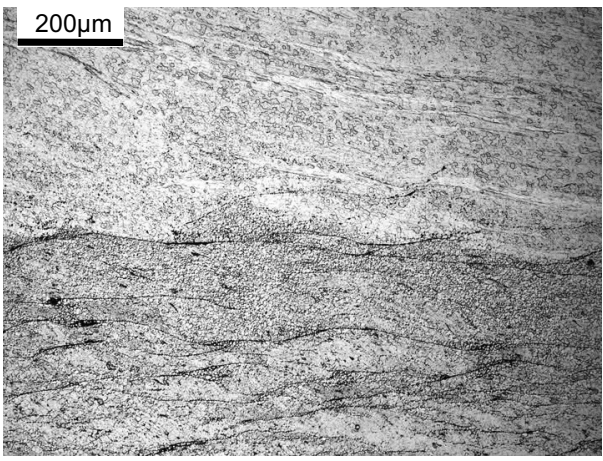

(d) $600 \mathrm{rpm}$

Fig. 2.6 Details of the microstructure at the clad layer-substrate interface after manufacturing at (a) $300 \mathrm{rpm},($ b) $450 \mathrm{rpm},(c) 550 \mathrm{rpm}$ and (d) $600 \mathrm{rpm}$ and a nominal layer thickness of $0.2 \mathrm{~mm}$. See for locations of the interfaces in the respective micrographs of Fig. 2.5(B).

The thickness of the clad layer and the quality of the clad layer-substrate interface are visible in the cross sections of the manufactured samples in Fig. 2.5(B). The bonding interfaces deposited with tool rotation rates between $300 \mathrm{rpm}$ and $450 \mathrm{rpm}$ are straight and no defects or voids are visible. The thickness of the clad layer is fairly constant. Detailed views of the interfaces at the positions marked by rectangles in Fig. 2.5(B) are shown in Fig. 2.6(a) and (b). Clearly, the clad layer is deposited well on top of the substrate and no debonding or mixing occur for the cases with tool rotation rates ranging from $300 \mathrm{rpm}$ to $450 \mathrm{rpm}$.

At tool rotation rates above $450 \mathrm{rpm}$ the appearance of the deposited sample changes, as visible in Fig. 2.5(B). The interface between the clad layer and the 
AA2024 substrate does not remain straight, leading to a somewhat wavy interface. The bonding interface is below the former top surface of the substrate material as can be deduced from an extrapolation of the straight clad material-substrate interface at the far left and right side towards the center of these images. Mixing of the substrate with the clad layer material has occurred in these samples, as is also clearly visible in the detailed micrographs shown in Fig. 2.6(c) (550 rpm) and Fig. 2.6(d) $(600 \mathrm{rpm})$.

\section{Temperature development and FSC tool normal force}

The development of the FSC tool temperature and the normal force exerted on the substrate as a function of time for various experiments are shown in Fig. 2.7. During the start-up phase (preheating phase) of the FSC experiment, the tool is rotating at a fixed position above the substrate. The normal force and the temperature increase quickly as soon as the clad rod is pressed out of the rotating tool and comes into contact with the substrate. Frictional heating causes the temperature to rise. As soon as the tool temperature is high enough, i.e. approximately $250^{\circ} \mathrm{C}$, the cladding phase is started. After some translation distance the temperature either levels off to a roughly constant value or increases slowly over time. Observed tool temperatures in the cladding phase range from about $300^{\circ} \mathrm{C}$ for the experiment performed with the lowest rotation rate up to over $450^{\circ} \mathrm{C}$ for that at $600 \mathrm{rpm}$.

The normal force exerted on the substrate has a maximum during the start-up phase. In this phase the clad rod is still relatively cold and the clad material needs to be spread through the narrow space between the tool and the substrate. This requires relatively high forces. The normal force decreases to an approximately constant value during the cladding phase for the rotation rates between 300 and $450 \mathrm{rpm}$. The translation of the tool with respect to the substrate facilitates the transport of the clad layer from the FSC tool to the substrate.

In some cases the normal force varies strongly, such as shown for the experiment performed at $600 \mathrm{rpm}$. Comparable variations are visible in the temperature signal of the tool. Some arc grooves on the top surface of the clad layer, instead of a smooth surface, are also observed, as mentioned above. These variations may be in a certain way related to each other. No experiments are performed with a tool rotation rate higher than $600 \mathrm{rpm}$ due to the unstable and undesired performance.

During the start-up phase of the experiment performed at $250 \mathrm{rpm}$ the temperature remained substantially lower in comparison with the other experiments. Apparently, the clad material cannot be softened sufficiently for the process to start up properly. Starting the cladding phase in these conditions does not lead to an acceptable clad layer. When the tool rotation rate was increased to $300 \mathrm{rpm}$ during the cladding phase, the cladding process yielded a clad layer with the same quality as the experiment performed at $300 \mathrm{rpm}$ from the start. 


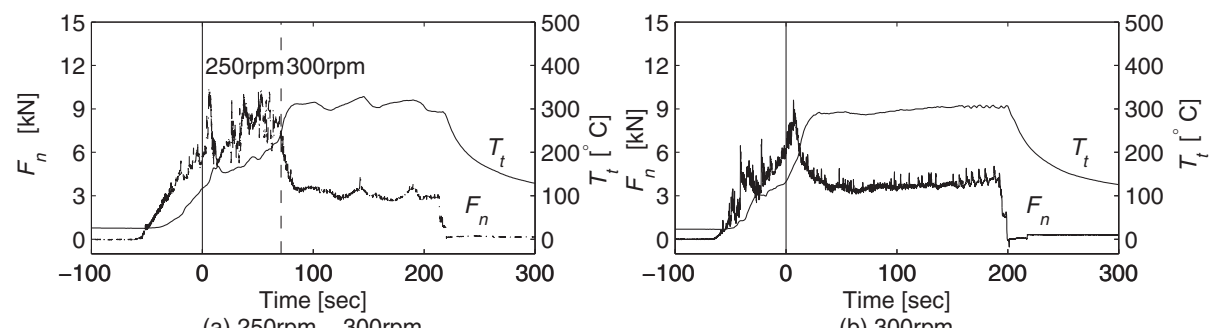

(a) $250 \mathrm{rpm}-300 \mathrm{rpm}$

(b) $300 \mathrm{rpm}$

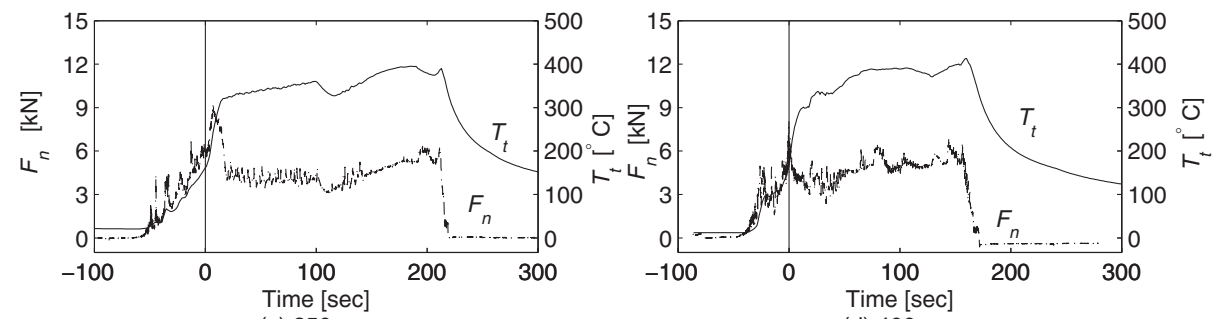

(c) $350 \mathrm{rpm}$

(d) $400 \mathrm{rpm}$

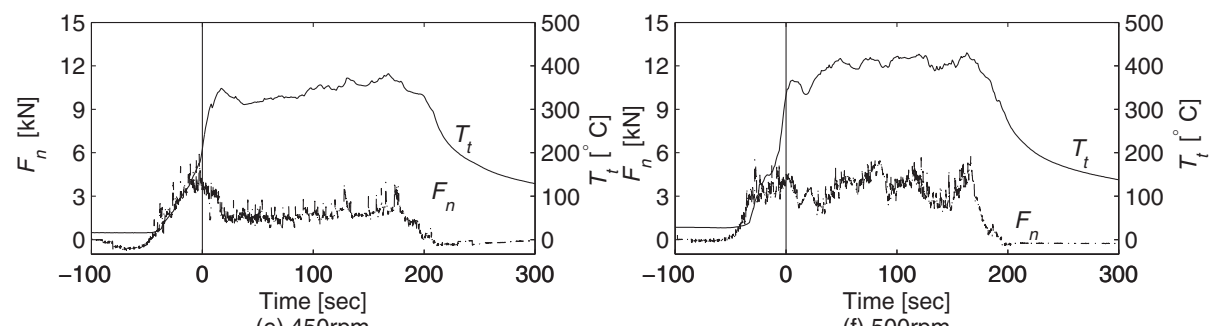

(e) $450 \mathrm{rpm}$

(f) $500 \mathrm{rpm}$

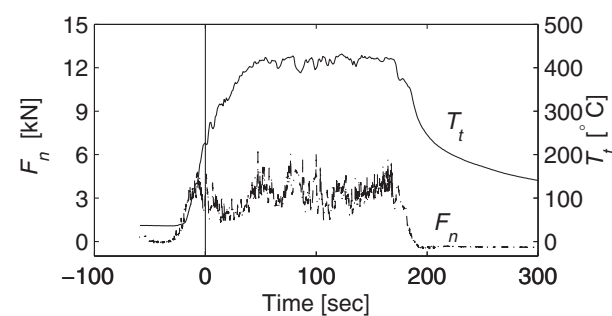

(g) $550 \mathrm{rpm}$

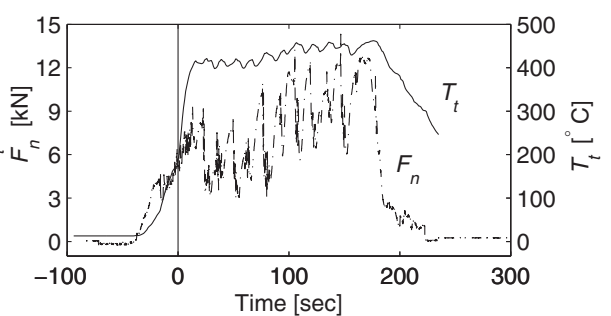

(h) $600 \mathrm{rpm}$

Fig. 2.7 The tool temperature and the normal force distributions of the experiments with tool rotation rate of (a) $250-300 \mathrm{rpm},($ b) $300 \mathrm{rpm},(c) 350 \mathrm{rpm},(d) 400 \mathrm{rpm},(e) 450 \mathrm{rpm},(f) 500 \mathrm{rpm},(\mathrm{g}) 550 \mathrm{rpm}$ and (h) $600 \mathrm{rpm}$. The vertical solid lines indicate the moments when the tool starts to translate with respect to the substrate. The dashed line in (a) is the moment when the tool rotation rate changed from $250 \mathrm{rpm}$ to $300 \mathrm{rpm}$.

The temperatures measured by the various thermocouples in the substrate correspond reasonably well to those measured near the tool bottom. A difference is observed in Fig. 2.8 and this can be explained by the differences in heat conduction of the substrate and tool materials, the geometry of the experimental setup and the thermal boundary conditions. In general, when the tool travels above the location of 
$T C_{i}$, the measured tool temperature is around $20-50^{\circ} \mathrm{C}$ lower than the peak value registered by $T C_{i}$. In a few cases this peak value is lower than the tool temperature without a process related reason, such as the second thermocouple $T C_{2}$ shown in Fig. 2.8. These temperature values are omitted from further analysis as the deviation is probably caused by improper attachment of the particular thermocouple to the substrate leading to a limited heat transfer.

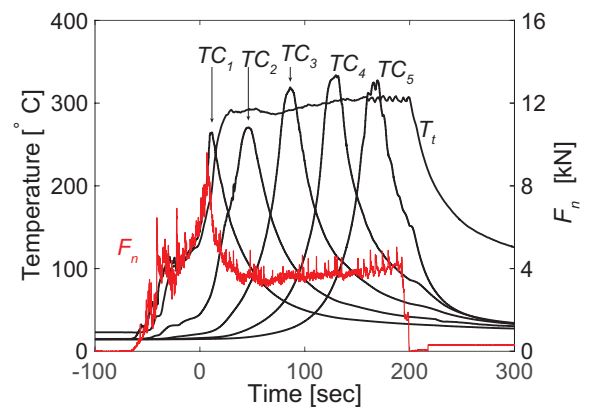

Fig. 2.8 Development of the normal force and temperatures in the FSC tool $\left(T_{t}\right)$ and in the AA2024-T351 substrate $\left(T_{1}-T_{5}\right)$ during deposition of $A A 1050$ at $300 \mathrm{rpm}$.

The average temperature of the FSC tool $\left(<T_{t}>\right)$ during the cladding phase is shown in Fig. 2.9(a) as a function of the tool rotation rate. There is a trend towards a higher tool temperature for increasing rotation rates for both substrate configurations. Larger heat is generated at higher rotation rates during the cladding process leading to higher tool temperatures. A small drop in the respective trend is visible between $400 \mathrm{rpm}$ (configuration 1) and $450 \mathrm{rpm}$ (configuration 2). This may be related to the type of the substrate configuration but the tool temperature may also be influenced by other process parameters, such as the distance between the tool and the substrate (the thickness of the clad layer) and the volume of the clad material supplied per unit of time (the supply rate).

The thickness of the clad layer was determined from the cross sections of the respective samples, such as those shown in Fig. 2.5. For the cases where the clad material was mixed with the substrate, the location of the former substrate top surface was determined from extrapolation of the visible parts of the top surface at the edges of the respective cross sections. The layer thickness near the cladding center line varies from the nominal value of $h_{0}=0.2 \mathrm{~mm}$ between $0.14 \mathrm{~mm}$ and $0.31 \mathrm{~mm}$ as shown in Fig. 2.9(a). Note that the thickness is also influenced by the finite stiffness of the experimental setup in the vertical direction leading to a layer thickness slightly larger than the nominal distance between the tool and the substrate set before the start of the experiment. This is also described by Van der Stelt (2014).

The supply rates of the clad material were monitored and determined after the experiments from the oil flow volumes of the hydraulic pumping unit. The values 
are shown in Fig. 2.9(b). The supply rates were between $2.5 \cdot 10^{2}$ and $2.8 \cdot 10^{2}$ $\mathrm{mm}^{3} / \mathrm{min}$ for $250-400 \mathrm{rpm}$ and increased to $4.0 \cdot 10^{2}-5.0 \cdot 10^{2} \mathrm{~mm}^{3} / \mathrm{min}$ for $450-600 \mathrm{rpm}$. The observed increases of the supply rate and variations of the layer thicknesses are related to the exploratory nature of the experimental setup.

The average normal force $\left\langle F_{n}>\right.$ near $T C_{3}$ decreases with the tool rotation rate in both substrate configurations, see Fig. 2.9(a). An exception occurs at the experiment carried out with $600 \mathrm{rpm}$. The higher tool rotation rate raises the process temperature strongly, which lowers the yield stress of the clad material, as shown by Gilbert Kaufman (1999). Therefore, smaller forces are required in principle to spread the clad material towards the outer edge of the tool. However, the process zone contains both the clad and the substrate materials when mixing occurs, which increases the material strength. Furthermore, more material is required to be deformed under mixing condition and overall it leads to a larger normal force. It is also observed that the experiments are performed with slightly varying layer thicknesses and supply rates. This makes it difficult to derive the correlation between the normal force and the tool rotation rate. It will be further studied in experiments with the tool rotation rate being the only variable in the cladding process, see also Chapter 6.

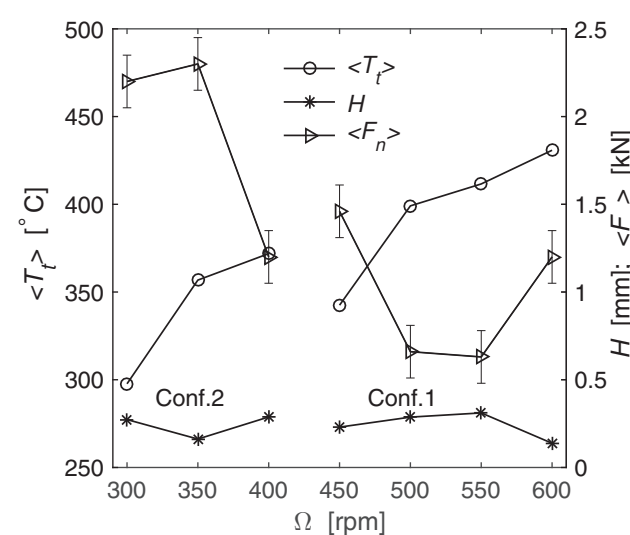

(a)

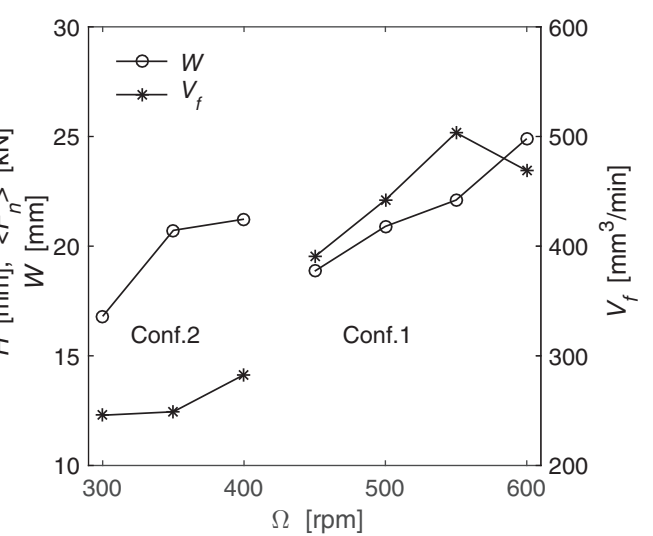

(b)

Fig. 2.9 (a) The average FSC tool temperature $\left.\left(<T_{t}\right\rangle\right)$, the average normal force $\left(<F_{n}>\right)$ near $T C_{3}$ and the clad layer thickness $(H)$ for the experiments performed at $300 \mathrm{rpm}$ to $600 \mathrm{rpm}$. (b) The volumetric supply rate of clad material $\left(V_{f}\right)$ and the average clad layer width $(W)$ for these experiments. 'Conf. $1^{\prime}=$ 'Configuration 1'; 'Conf.2' = 'Configuration 2'.

\section{Hardness in the clad layers and substrates}

An overview of the hardness distributions of the deposited substrates is shown in Fig. 2.10. The hardness differences between the clad layers and the substrates are clearly visible for most cases. For the experiments carried out with tool rotation rates between $300 \mathrm{rpm}$ and $450 \mathrm{rpm}$, the hardness of the clad layers is approximately 
$30 \mathrm{HV}$, whereas that of the substrates is above $100 \mathrm{HV}$. The clad layers deposited at higher tool rotation rates $(\geq 500 \mathrm{rpm})$ are characterized by a hardness between 44 and $100 \mathrm{HV}$, which is higher than the as-received clad material. This is another indication that mixing between the clad material and the substrate material has occurred.

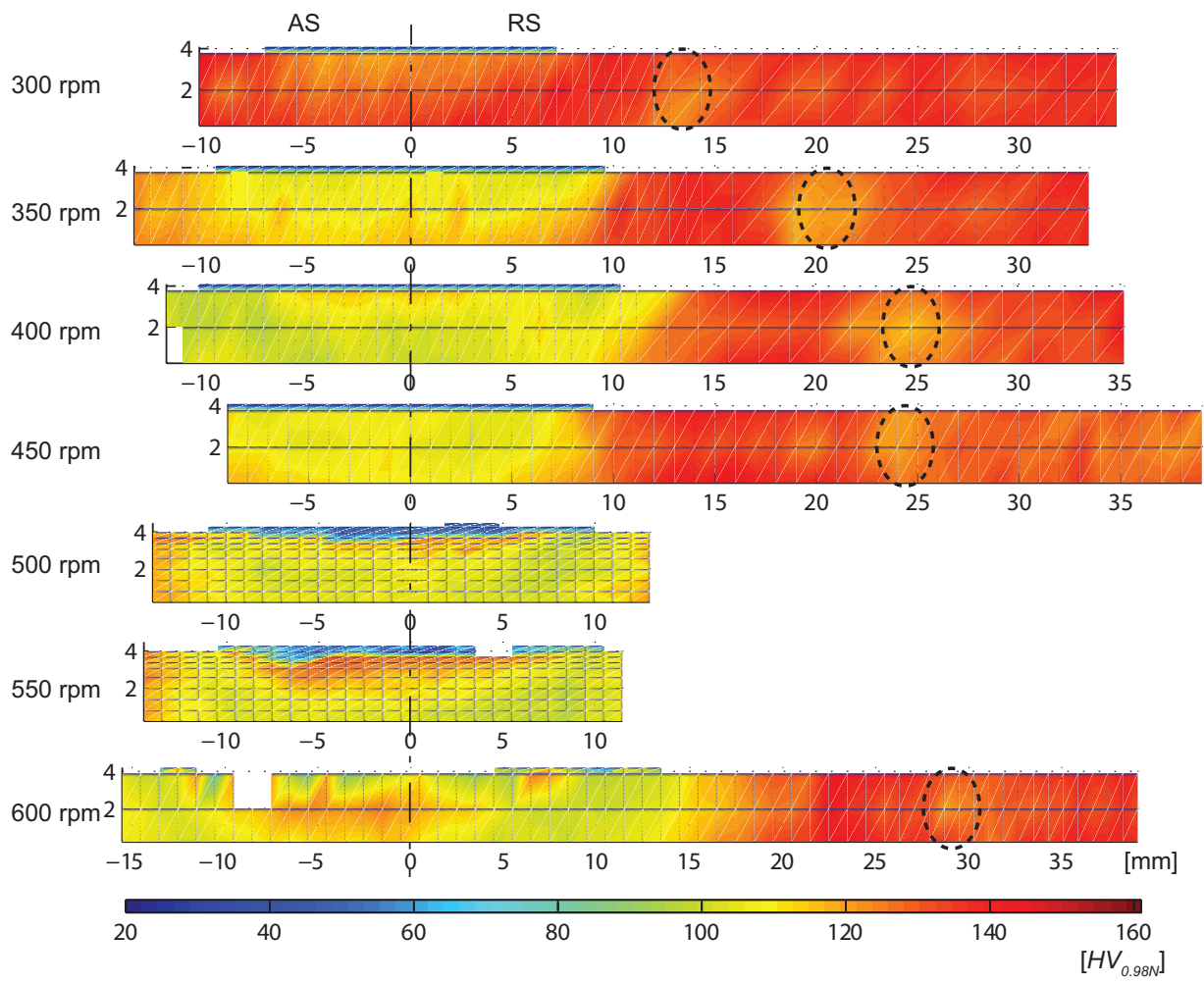

Fig. 2.10 The hardness distributions of experiments with tool rotation rates varying from $300 \mathrm{rpm}$ to $600 \mathrm{rpm}$. The vertical dashed line indicates the cladding center line.

All hardness distributions show a substantial decrease in the hardness from the original as-received value $(140 \mathrm{HV})$ in a zone beneath and in the vicinity of the deposited clad layers, except for the case of $300 \mathrm{rpm}$. Typically, hardness values of approximately $(100 \mathrm{HV})$ are observed. At a relatively large distance from this zone the hardness remained unaffected by the cladding process defining the extent of the heat affected zone. Interestingly, the hardness distributions also contain a fairly narrow zone with a small hardness drop as marked by dashed circles at the RS in Fig. 2.10. The distance between this drop and the cladding center line becomes larger at higher tool rotation rates: from 13 to $25 \mathrm{~mm}$ with substrate configuration 2 (300 rpm - $400 \mathrm{rpm}$ ) and from 23 to $30 \mathrm{~mm}$ with configuration 1 (450 rpm - $600 \mathrm{rpm}$ ). Finally, it is observed that the hardness distributions in the substrates for the highest 
rotation rates show higher hardness values near the cladding center line than for the other cases.

The trends in hardness behavior also become clear from Fig. 2.11, where the hardness values at the mid plane of the substrates (i.e. $2 \mathrm{~mm}$ above the substrate bottom) are shown. The hardness for the $300 \mathrm{rpm}$ sample is hardly decreased, whereas the effects of the cladding process appear more strongly, the higher the tool rotation rate. Furthermore, the tool rotation rate is an important process parameter affecting the tool temperature, as shown in Fig. 2.9(a), suggesting that the tool temperature, as a measure of the process temperature, has a strong effect on the size and extent of the heat affected zone.

The observed changes in the substrate hardness can indeed be explained from the response of AA2024-T351 to the temperature development over time during the cladding process according to Jones et al. (2005) and Khodir et al. (2006). The hardening precipitates start to coarsen at approximately $200^{\circ} \mathrm{C}$, leading to a hardness decrease. At even higher temperatures (approximately $400^{\circ} \mathrm{C}$ ) the precipitates dissolve, but may reprecipitate in time after the cladding process, explaining the hardness recovery found near the cladding center lines of the samples deposited at relatively high rotation rates. From these results it can also be concluded that the FSC temperature should be as low as possible to reduce the size of HAZ. This can be achieved by employing relatively low tool rotation rates to minimize thermal effects on the mechanical properties of the substrate.
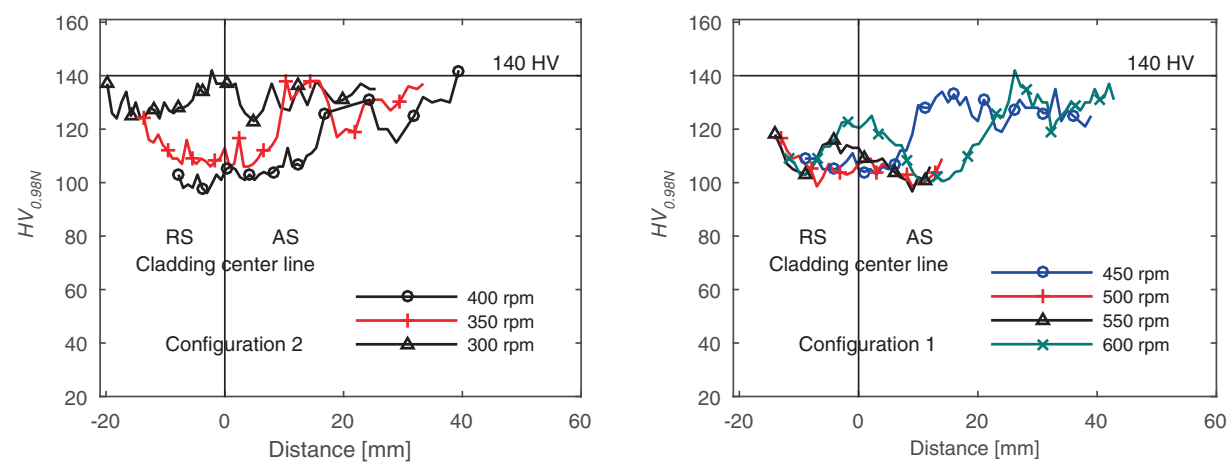

Fig. 2.11 The hardness distributions at the mid plane of the substrates deposited with the tool rotation rate varying from $300 \mathrm{rpm}$ to $600 \mathrm{rpm}$. The vertical lines represent the cladding center lines.

\subsubsection{Determination of the heat input}

\section{Ideal thermal contact region}

A series of thermal simulations was performed to simulate the temperature distribution in the clad layer, the substrate and the FSC tool. In this way also the effective temperature near the tool-substrate interface can be estimated. The 
measured temperature in the third thermocouple $\left(T C_{3}\right)$ was used for comparison. This thermocouple is located at the center of the translation trajectory, where it is assumed that the effects of the start-up process and the finite length of the substrate are of least importance.

The heat input determines to a large extent the maximum temperatures reached within the FSC setup. However, the thermal contact between the substrate and the underlying backing table turned out to be important too and especially for the heating and cooling stages of the substrate. As a start, it was assumed that optimal thermal contact from the substrate to the backing table took place exactly under the tool. In this zone no heat resistance was taken into account while computing the heat flow from the substrate to the table, the so-called ideal thermal contact region (ITCR). However, the size of the ITCR needed to be larger to more accurately fit the measured temperatures $\left(T C_{3}\right)$ over time, especially to more closely follow the shape of the recorded profiles. After some attempts on this, as one possible solution, a larger semicircular zone with a radius of $W$ should be considered on the leading edge of the FSC tool and a smaller semicircular zone with a radius of $0.6 \mathrm{~W}$ on the trailing edge, see Fig. 2.12. The $W$ is then taken to be equal to the layer width of the respective experiment.

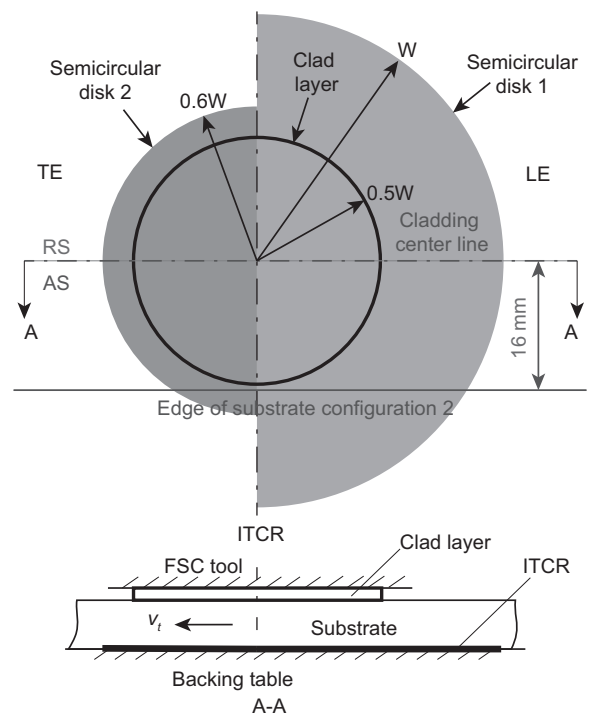

Fig. 2.12 The ideal thermal contact region (ITCR) between the substrate and the backing table. 'TE' = 'trailing edge'; 'LE' = 'leading edge'. Note: The redundant area is eliminated when the ITCR extends beyond the substrate edge at the advancing side. This occurs in the case of substrate configuration 2.

The proposed difference of the semicircle size may be caused through the traction exerted by the FSC tool on the substrate during the cladding phase. The tool translates with respect to the substrate and as the clad material is bonded to the substrate a net shear force is exerted by the tool to the substrate in the translation 
direction. In turn, the shear force generates a moment such that the substrate region in front of the tool is pressed downwards to the table. This increases effectively the size of the region with ideal thermal contact. At the trailing side such an additional normal force is lacking and the region with ideal thermal contact is smaller. The effective thickness of the thin thermally resistive layer between the substrate and the backing table beyond the ideal thermal contact region was optimized concomitantly to be $50 \mu \mathrm{m}$ after varying it from $5 \mu \mathrm{m}$ to $1000 \mu \mathrm{m}$. The aformentioned relations for the radii of the ITCR and the thickness of the thin thermally resistive layer of air held for all experiments from 300 to $600 \mathrm{rpm}$ simultaneously were independent of the respective temperatures and clad layer dimensions.

\section{Heat input and temperature distribution}

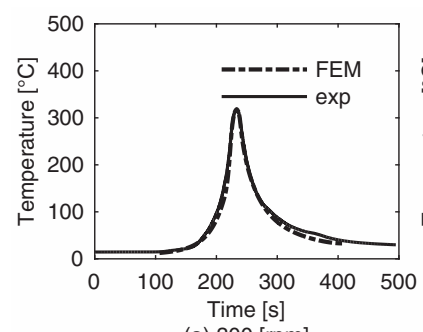

(a) 300 [rpm]

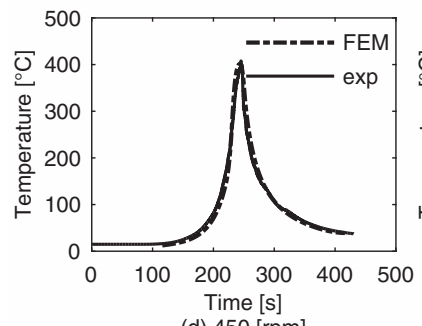

(d) 450 [rpm]

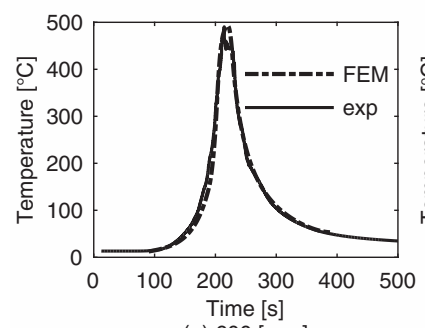

(g) 600 [rpm]

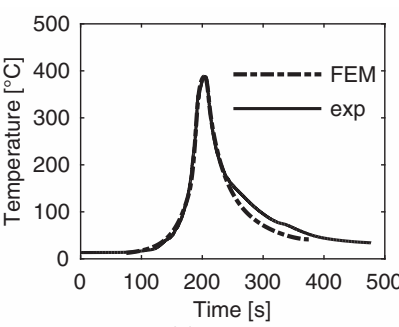

(b) 350 [rpm]

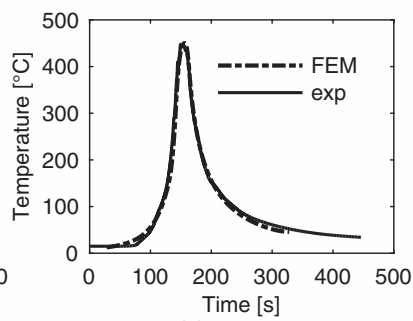

(e) 500 [rpm]

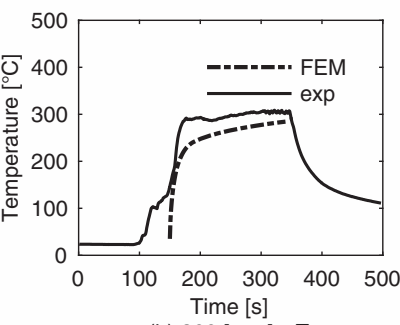

(h) $300[\mathrm{rpm}], T_{t}$

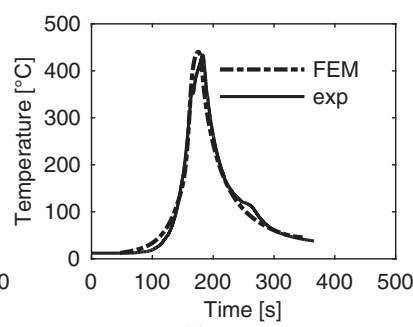

(c) 400 [rpm]

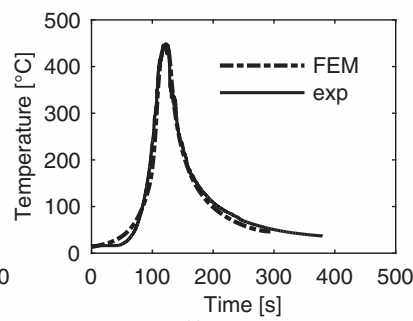

(f) 550 [rpm]

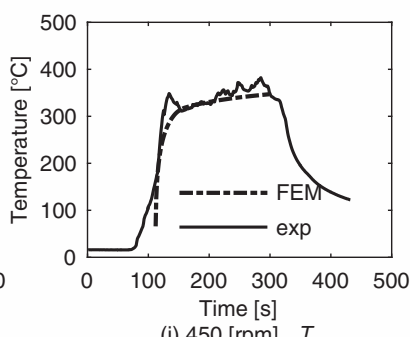

(i) $450[\mathrm{rpm}], T_{t}$

Fig. 2.13 Temperature distributions in the substrate and the tool: $(a-g)$ provide the calculated temperatures at the position of $T C_{3}$ in the substrate compared with the measured ones by $T C_{3}$ in the experiments carried out with the tool rotation from 300 to $600 \mathrm{rpm}$; $(h)$ and (i) show the calculated temperature at the position of $T_{t}$ in the tool compared with the measured tool temperature measured by $T_{t}$ in experiments of 300 and $450 \mathrm{rpm}$. 
Thermal simulations were performed for all experiments carried out with the tool rotation rate rising from 300 to $600 \mathrm{rpm}$. The substrate configuration 1 was applied in the cases with tool rotation rates between $450 \mathrm{rpm}$ and $600 \mathrm{rpm}$, and configuration 2 with $300 \mathrm{rpm}, 350 \mathrm{rpm}$ and $400 \mathrm{rpm}$. The dimensions of the ITCR depend on the width of the deposited clad layers as shown in Fig. 2.12 and described above. The amount of heat generated per unit of time was optimized such that the simulated temperature profiles matched those recorded by the third thermocouple $\left(T C_{3}\right)$ as closely as possible.

In each case a good agreement between the simulated temperature profile and its corresponding measured one is obtained as illustrated by Fig. 2.13(a a g). Particularly, the maximum temperatures, the heating rates and the cooling rates of the simulations are very consistent with the recorded ones at temperatures above $250^{\circ} \mathrm{C}$. This also holds to a large extent for the experimental and simulated tool temperature developments as shown for $300 \mathrm{rpm}$ and $450 \mathrm{rpm}$ in Fig. 2.13(h) and (i). Furthermore, the simulated peak temperatures of $T C_{3}$ are around $20-50^{\circ} \mathrm{C}$ higher than the simulated tool temperatures at the same position for all cases, which is consistent with the corresponding experimental values.

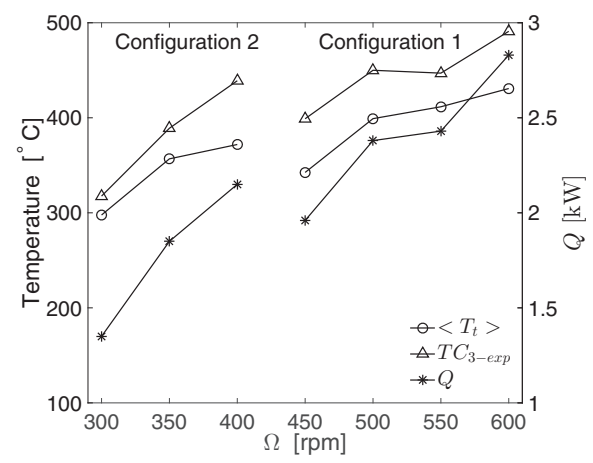

Fig. 2.14 The applied heat inputs in the thermal models, the measured average tool temperature, $\left\langle T_{t}\right\rangle$, and the peak temperature measured by $T C_{3}, T C_{3-e x p}$, in the experiments carried out with tool rotation rate rising from $300 \mathrm{rpm}$ to $600 \mathrm{rpm}$.

The heating rates obtained from the fitting procedure, the experimentally measured temperatures of $T C_{3}$ and the measured average tool temperature $\left.\left(<T_{t}\right\rangle\right)$ are shown for each experiment in Fig. 2.14. Here, the tool temperature is also analyzed because it may serve as the only temperature accessible in real case applications of FSC where embedding of thermocouples in the substrate is unpractical.

The fitted heat input follows the trends of the measured temperatures for each substrate configuration. Higher tool rotation rates raise the tool temperatures, from $\left\langle T_{t}>=320^{\circ} \mathrm{C}\right.$ at $\Omega=300 \mathrm{rpm}$ to $\left\langle T_{t}>=490^{\circ} \mathrm{C}\right.$ at $\Omega=600 \mathrm{rpm}$ and the temperatures measured in the substrate by $T C_{3}$ also follow this trend. However, differences in the tool-substrate distance, the supply rate and the substrate configuration employed among the various experiments, may blur this relation to 
some extent. This probably explains, for example, the reversed order of the data points for $400 \mathrm{rpm}$ and $450 \mathrm{rpm}$.

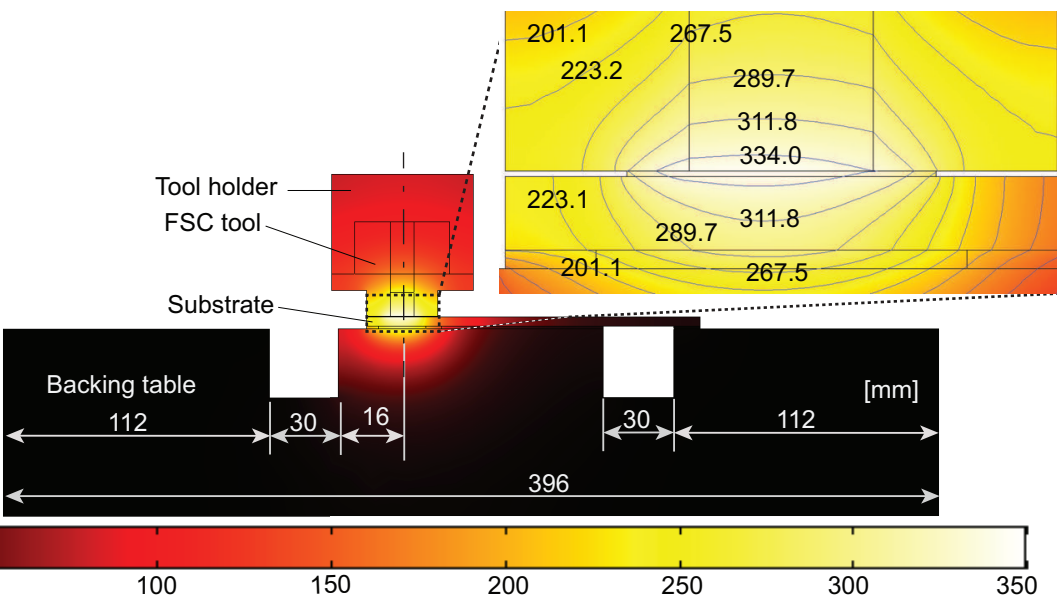

(a) Transverse cross section

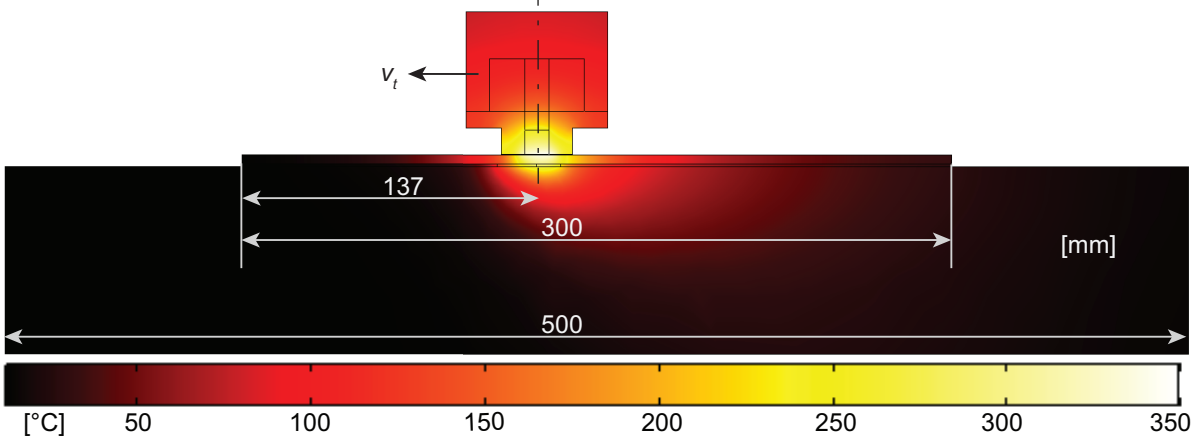

(b) Longitudinal cross section

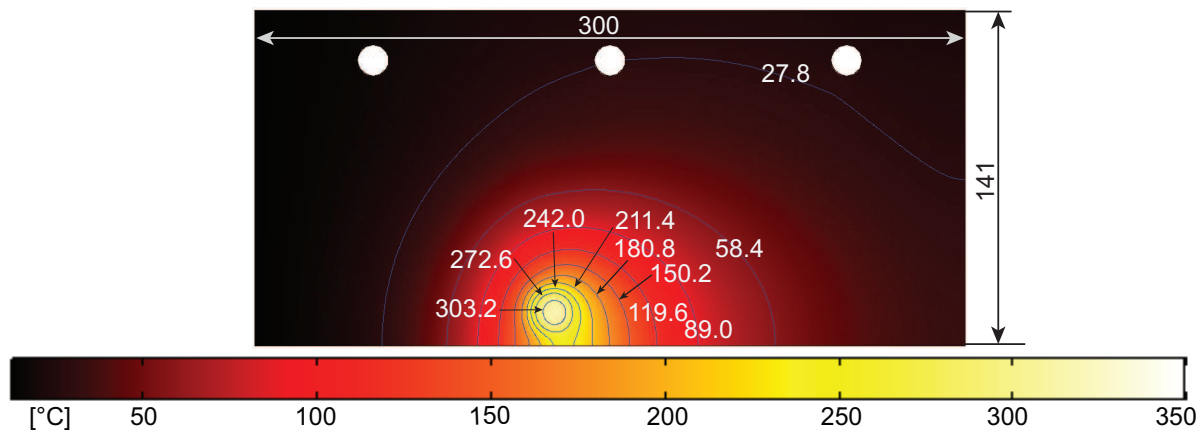

(c) Mid plane of the substrate at $2 \mathrm{~mm}$ above the substrate bottom

Fig. 2.15 Temperature distribution in various cross sections of the FSC tool, the substrate and the backing table for the simulation of the thermal field of $300 \mathrm{rpm}$ when the tool is located exactly above the location of the third thermocouple, $\mathrm{TC}_{3}$ (see also Fig. 2.2): (a) transverse cross section, (b) longitudinal cross section and (c) mid plane of the substrate. 
Apart from the heat generation, the model also calculates the transient temperature distribution for the cladding setup. This provides a way to estimate the thermal effect on the substrate. An example of the thermal field in the FSC tool, the substrate and the backing table calculated with the model for the $300 \mathrm{rpm}$ experiment is shown in Fig. 2.15. The highest temperature of approximately $335^{\circ} \mathrm{C}$ occurs near the heat input region, i.e, the cladding/processing zone. The substrate in the position of $\mathrm{TC}_{3}$ and the tool in the position of $T_{t}$ experienced somewhat lower temperatures of around $320^{\circ} \mathrm{C}$ and $290^{\circ} \mathrm{C}$, respectively. The temperature within the thin clad layer shows relatively little variation, whereas relatively large thermal gradients are observed in the FSC tool and the backing table, which can be largely explained by differences in thermal conductivity of the materials involved. The model also allows to determine the difference between the tool temperature, which serves as a practical measure of the process temperature, and the actual temperature at the clad material-substrate interface in the cladding zone. The differences between both temperature values are mainly caused by the thermal gradient occurring in the FSC tool.

\subsubsection{Application of the thermal model}

\section{Hardness prediction}

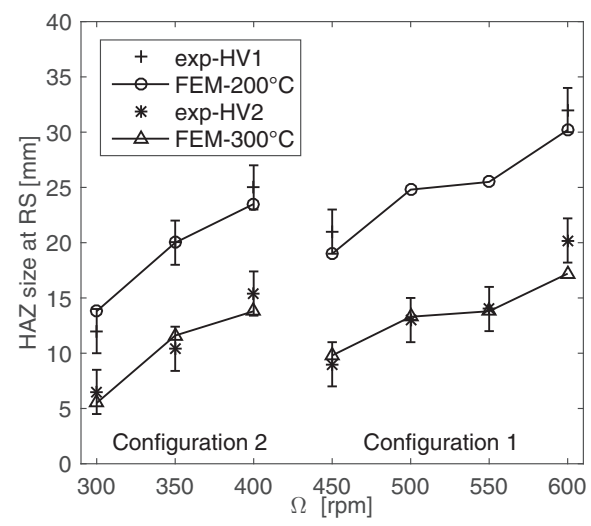

Fig. 2.16 Comparison of two locations (at RS) in the heat affected zone determined from hardness measurements and from simulated thermal profiles in the substrate. The symbols exp-HV1 and exp-HV2 are the distances from the cladding center line till the position where the hardness reaches a relatively high value and starts to drop, respectively. FEM-200 ${ }^{\circ} \mathrm{C}$ and FEM- $300^{\circ} \mathrm{C}$ stand for the distances from the cladding center till the position where temperature drops to $200^{\circ} \mathrm{C}$ and $300^{\circ} \mathrm{C}$, respectively.

The calculated transient thermal distributions can be used to predict the hardness distributions in the substrates. As observed above, the model provides very accurate thermal profiles at the transverse section of the deposited substrate, where the hardness was measured. Therefore, the simulated temperature plotted against 
distance can explain directly the hardness at the corresponding positions and estimate the location and the size of the HAZ.

The precipitates coarsening and the dissolution of precipitates followed by reprecipitation over time after the thermal process occur above $200^{\circ} \mathrm{C}$ and $400{ }^{\circ} \mathrm{C}$, respectively, according to the work on FSW of AA2024 of Jones et al. (2005). The extent of the precipitate growth zone and the precipitate dissolution zone can be determined from the respective isotherms in the simulated temperature fields by employing selected temperature values. A good correspondence between the location of the HAZ, as determined experimentally from the hardness distributions, and both zones determined from the simulation is observed in Fig. 2.16. The values of exp-HV1 and exp-HV2 are the distances from the cladding center line till the position where the hardness reaches a relatively high value and where it starts to drop, respectively. The symbols FEM- $200{ }^{\circ} \mathrm{C}$ and FEM- $300{ }^{\circ} \mathrm{C}$ stand for the distances from the cladding center line till the position where the temperature drops to $200{ }^{\circ} \mathrm{C}$ and $300{ }^{\circ} \mathrm{C}$, respectively. These results confirm the validity of the thermal simulations and the computed heat input $Q$.

\section{Non-mixing/mixing determination}

The fitted values of the heat generation rates $Q$ can be used to analyze the influence of FSC on the workpiece properties by determining the thermo-mechanical loading conditions of the substrate beneath the clad layer being deposited. On the assumption that all mechanical power of the electrical engine connected to the FSC tool is transferred into heat and that the contribution of the translation of the tool with respect to the substrate to the heat generation is negligible, the heat generated may be then set equal to the mechanical power supplied. If stable conditions apply at the clad layer-substrate interface, an average shear stress can be calculated according to the heat generation model derived originally for FSW by Schmidt et al. (2004):

$$
\tau=\frac{Q}{\frac{2}{3} \pi * \frac{2 \pi \Omega}{60} * \frac{W^{3}}{8}}=\frac{360 Q}{\pi^{2} \Omega W^{3}} .
$$

The region of the substrate below the clad layer also supports a normal force exerted by the clad material being pressed out of the FSC tool which is measured by the load cells, leading to an average normal stress $\sigma_{n}$. Therefore, the effective stress $\left(\sigma_{e f f}\right)$ exerted on the substrate material can be calculated according to von Mises stress by:

$$
\begin{aligned}
& \sigma_{n}=F_{n} / A_{s}, \text { with } A_{s}=\pi W^{2} / 4 ; \\
& \sigma_{e f f}=\sqrt{\sigma_{n}^{2}+3 \tau^{2}} .
\end{aligned}
$$

When the effective stress exceeds the yield stress of the substrate material at elevated temperatures, the substrate material may be deformed plastically, leading 
to a wavy clad layer-substrate interface and eventually mixing of the clad material with the substrate. If the effective stress is smaller, the clad layer-substrate interface remains straight. In Fig. 2.17 the ratio of the effective von Mises stress exerted on the substrate material to the yield stress of the substrate at the process temperature is shown. It is assumed that the temperature in the processing zone between the tool bottom and the substrate is $40^{\circ} \mathrm{C}$ higher than the average tool temperature in line with the results of the thermal simulations. The values for the AA2024-T351 yield stress as a function of temperature shown by Gilbert Kaufman (1999) were used. For the experiments performed at tool rotation rates between 300 and $450 \mathrm{rpm}$ the ratio is smaller than 1 and no mixing occurs, in line with the observations shown in Fig. 2.5. For the experiments carried out at higher rotation rates mixing does occur and in those cases the ratio is larger than 1 , indicating that plastic deformation of the substrate occurs, which leads to mixing.

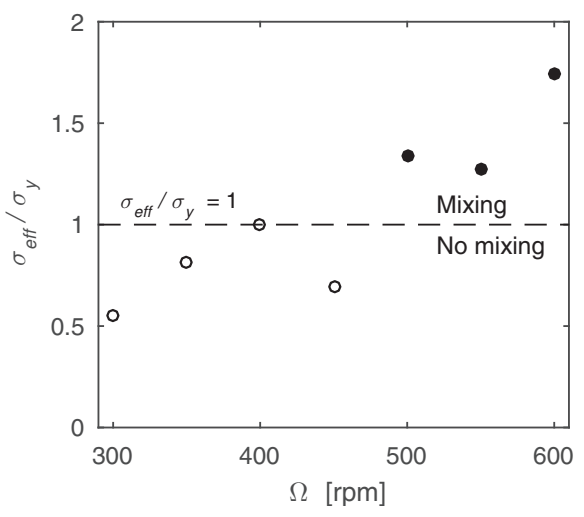

Fig. 2.17 The ratio of the effective von Mises stress $\left(\sigma_{\text {eff }}\right)$ exerted on the AA2024-T351 substrate by the AA1050 clad material being deposited to the yield stress of the substrate $\left(\sigma_{y}\right)$ at the process temperature $(=$ $\left.<T_{t}>+40^{\circ} \mathrm{C}\right)$.

\subsection{Conclusions}

An exploratory study of the friction surface cladding (FSC) process depositing commercially pure AA1050 on an AA2024-T351 substrate in the solid state has been presented. Smooth and defect free clad layers can be manufactured that are bonded well to the substrate.

The clad layer quality is highly dependent on the frictional and plastic deformation heat generated during the deposition process. The heat generated is shown to be strongly related to the tool rotation rate and the volume of the clad material supplied per unit of time. For higher tool rotation rates and supply rates, the generated heat is larger, as also revealed by the higher temperature in the FSC tool bottom and the width of the heat affected zones. High quality clad layers were manufactured with a tool temperature ranging between $300^{\circ} \mathrm{C}$ and $420^{\circ} \mathrm{C}$. At 
temperatures below $300{ }^{\circ} \mathrm{C}$ the FSC process fails to start up properly and above 410 $-430{ }^{\circ} \mathrm{C}$ the clad layers are characterized by the occurrence of surface defects and mixing of the clad layer with the substrate.

The developed 3D thermal model provides a way to determine the heat generation rate from temperature data recorded during the experiments. The thermal contact at the interface between the substrate and the underlying backing table plays an important role. An ideal thermal contact region has been defined comprising two semicircular zones, one beneath the leading edge of the FSC tool and a smaller one beneath the trailing edge, where no thermal resistance is present over the interface. The size of this region scales with the width of the clad layer deposited.

The determined heat generation rates vary almost linearly with the recorded tool temperatures. Also, the occurrence of mixing of the clad material with the substrate can be predicted from the thermal model utilizing the ratio of the effective stress applied to the substrate, as derived from the obtained heat generation rate, to the yield stress of the substrate at elevated temperatures.

The process temperatures also influence the mechanical properties of the AA2024T351 substrate. The extent of the heat affected zone increases at higher tool temperatures. This can also be predicted by the simulated thermal distributions. Experiments performed at relatively low tool rotation rates, where the tool temperature is close to $300^{\circ} \mathrm{C}$, show only a small decrease in the substrates hardness. This provides an important guideline for future applications to minimize the effect of the process temperature on the mechanical properties of the substrate. 


\section{References}

Gilbert Kaufman, J. (1999). Properties of Aluminum Alloys: Tensile, Creep, and Fatigue Data at High and Low Temperatures. ASM International.

Jones, M., Heurtier, P., Desrayaud, C., Montheillet, F., Allehaux, D., and Driver, J. (2005). Correlation between microstructure and microhardness in a friction stir welded 2024 aluminium alloy. Scr. Mater., 52(8):693-697.

Khodir, S. A., Shibayanagi, T., and Naka, M. (2006). Control of hardness distribution in friction stir welded AA2024-T3 aluminum alloy. Mater. Trans., 47(6):1560-1567.

Li, W., Zhang, Z., Li, J., and Chao, Y. J. (2012). Numerical analysis of joint temperature evolution during friction stir welding based on sticking contact. J. Mater. Eng. Perform., 21(9):1849-1856.

Lohwasser, D. and Chen, Z. (2010). Friction Stir Welding: From Basics to Applications. Woodhead Publishing.

Schmidt, H., Hattel, J., and Wert, J. (2004). An Analytical Model for the Heat Generation in Friction Stir Welding. Model. Simul. Mater. Sci. Eng., 12(1):143-157.

Van der Stelt, A. (2014). Friction surface cladding; development of a solid state cladding process. PhD thesis, University of Twente. 


\section{CHAPTER 3}

\section{Experimental study}

\subsection{Introduction}

In the previous chapter exploratory experiments were carried out to study the effect of the tool rotation rate on the cladding performance. It was confirmed that commercially pure aluminum can be deposited on an AA2024-T351 substrate employing FSC without mixing between the clad material and the substrate. Experiments should be done at relatively low tool rotation rates to limit the heat input and the associated rise of the process temperature. The experiments also showed that continuous layers cannot be deposited when the heat input is too low. Then, non-continuous clad layers are deposited as the clad material is insufficiently softened. Hence, the results obtained in Chapter 2 form an interesting starting point to investigate the extent of the process window for defect free deposition of clad layers without mixing with the underlying substrate for corrosion protection purposes.

The main process and tool parameters that will be analyzed are the tool rotation rate, the clad layer thickness, the clad layer width and the opening diameter of the FSC tool. The tool rotation rate was already studied in Chapter 2, but it turned out to be difficult to maintain a constant layer thickness with the prototype FSC setup employed. Hence, these experiments are repeated but aimed at a larger layer thickness to decrease the relative effects of variations in the layer thickness. Furthermore, the effects of the layer dimensions are studied. The relation of the layer thickness to the heat generation during the FSC process and the normal force exerted on the substrate is analyzed by employing a number of experiments with increasingly thicker clad layers. The effect of the layer width is examined by modifying the volumetric supply rate of the clad material during a single experiment. Finally, the feasibility of FSC tools with larger tool opening diameters is investigated and the influence of the opening diameter on the FSC process will be established.

The various parameters described above are explored in a similar way as the tool rotation rate described in Chapter 2. In this chapter, each variable will be studied with one dedicated series of experiments which is adjusted to produce defect free 
layers. The cladding appearance, the actual dimensions of the deposited layers, the process temperatures and the normal forces will be analyzed to discover the trends in the relation between the cladding performance and the process and tool parameters.

\subsection{Experimental procedure}

The FSC experiments were performed on the same setup as that employed in Chapter 2. The tool rotation rate, the layer dimensions and the tool opening size were studied in a separate series of experiments, as shown in the overview presented in Table 3.1. In these experiments the tool translation rate and the tool tilt angle remained the same as in Chapter 2.

The EN-h0.4 series of experiments were performed with a nominal layer thickness of $0.4 \mathrm{~mm}$ to confirm the observations described in Chapter 2. The experiments performed in that chapter employed a nominal layer thickness of $0.2 \mathrm{~mm}$, but it turned out to be difficult to maintain this value and variations in layer thickness occurred from experiment to experiment. The variations were inherent to the accuracy with which the tool height could be realized in practice and variations of $0.1 \mathrm{~mm}$ took place. The aim of this series is to reduce the relative influence of these variations by increasing the layer thickness. The tool rotation rates were varied from $300 \mathrm{rpm}$ to $600 \mathrm{rpm}$. Some variation in the supplied volume of clad material may still occur, as also experienced in Chapter 2, causing some variation in layer width.

The second series of experiments was carried out to study the influence of the layer thickness on the FSC process. The nominal layer thickness of the EH series increased from $0.2 \mathrm{~mm}$ to $0.8 \mathrm{~mm}$ with the volumetric supply rate adjusted accordingly. In the experiment EH-08 the supply rate was initially not set correctly, but after about 50 s during the cladding phase, the supply rate was increased to the proper value and remained constant until the end of the experiment. The tool rotation rate was constant during each experiment, but it was adjusted from experiment to experiment to deposit layers at approximately the same process temperature.

The third series of experiments was performed with a nominal layer thickness of $0.2 \mathrm{~mm}$ and was aimed to study the influence of the clad layer width. The EW experiment was performed employing a single experiment where, during the cladding phase, the volumetric supply rate was manually modified. In this way the results between several parts of the clad layer with different layer widths can be studied more easily as the layer thickness and tool rotation rate remain unaltered.

The first three series of experiments were performed with a tool opening diameter of $10 \mathrm{~mm}$ employing the $\varnothing 10$ tool. Two more tools have been developed with opening diameters of 15 and $20 \mathrm{~mm}$ corresponding to the $\varnothing 15$ tool and $\varnothing 20$ tool, respectively. The dimensions of these tools are shown in Fig. 3.1. The $\varnothing 10$ tool served as a reference in the ED series, where ED10A and ED10B were performed at tool rotation 
rates of 300 and $350 \mathrm{rpm}$, respectively. Two experiments, ED15A-1 and ED15A2 , were performed with the $\varnothing 15$ tool at $300 \mathrm{rpm}$ to compare with ED10A. Then, experiments ED20B-1 and ED20B-2 were carried out with the $\varnothing 20$ tool at $350 \mathrm{rpm}$ to compare with ED10B.

Table 3.1 Experimental settings of the experiments performed with different process variables.

\begin{tabular}{l|ccccc}
\hline Exp. & $\begin{array}{c}\text { Parameter } \\
\text { to study }\end{array}$ & $\begin{array}{c}D_{\text {Rod }} \\
{[\mathrm{mm}]}\end{array}$ & $\begin{array}{c}h_{0} \\
{[\mathrm{~mm}]}\end{array}$ & $\begin{array}{c}\Omega \\
{[\mathrm{rpm}]}\end{array}$ & $\begin{array}{c}V_{f} \\
{\left[\mathrm{~mm}^{3} / \mathrm{min}\right]}\end{array}$ \\
\hline EN-h0.4-1 & & & 0.4 & 300 & 558 \\
EN-h0.4-2 & & & 0.4 & 425 & 442 \\
EN-h0.4-3 & $\Omega$ & 10 & 0.4 & 500 & 365 \\
EN-h0.4-4 & & & 0.4 & 600 & 338 \\
\hline EH-02 & & & 0.2 & 300 & 246 \\
EH-04 & & & 0.4 & 400 & 339 \\
EH-06 & $h_{0}$ & 10 & 0.6 & 450 & 459 \\
EH-08 & & & 0.8 & 450 & 772 \\
\hline EW & $W$ & 10 & 0.2 & 300 & $\downarrow \uparrow \downarrow$ \\
\hline ED10A & & 10 & 0.2 & 300 & 246 \\
ED15A-1 & & 15 & 0.2 & 300 & 311 \\
ED15A-2 & & 15 & 0.2 & 300 & 360 \\
ED10B & $D_{\text {rod }}$ & 10 & 0.2 & 350 & 249 \\
ED20B-1 & & 20 & 0.2 & 350 & 355 \\
ED20B-2 & & 20 & 0.2 & 350 & 199 \\
\hline
\end{tabular}

Note: arrows $\uparrow$ and $\downarrow$ mean, respectively, that the supply rate of the clad material rises and drops with time. In this table EH-02 and ED10A are the same experiment.

The temperature development in the substrate and the tool during the FSC process were measured in the same way as explained in Chapter 2. The tool temperatures were also measured in the $\varnothing 15$ and $\varnothing 20$ tools employing incorporated thermocouples, but the radial position of the thermocouples is slightly different due to the opening diameter of the tool. The thermocouples are located at $2 \mathrm{~mm}$ above the tool bottom and $b^{\prime}$ away from the tool axis, where the value of $b^{\prime}$ equals $8 \mathrm{~mm}$, $10.5 \mathrm{~mm}$ and $12.5 \mathrm{~mm}$ for the $\varnothing 10, \varnothing 15$ and $\varnothing 20$ tools, respectively. The type of tool selected does not alter the way the normal force is measured (see Chapter 2).

The experiments are performed depositing pure aluminum, AA1050, with a rod diameter appropriate to the FSC tool selected on top of an AA2024-T351 substrate with configuration 2 (see Chapter 2). The preparation of the clad rods and the substrate remained unchanged. The rod lengths are equal to $20 \mathrm{~mm}$ for the $\varnothing 10$ tool and are slightly shorter for the other tools. The preparation of the microscopical samples after the cladding process and the subsequent hardness measurement were all carried out in a way identical to those described in Chapter 2. 


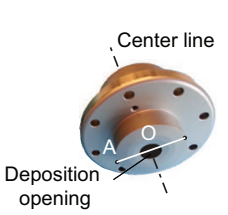

(a) FSC tool

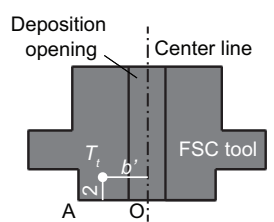

(b) Cross section of FSC tool

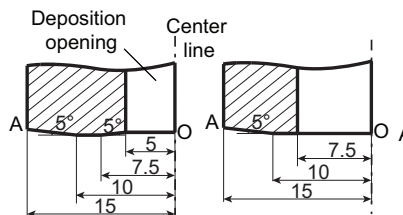

(B) $\varnothing 15$

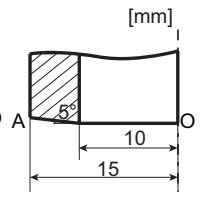

(C) $\varnothing 20$

Fig. 3.1 FSC tool with a central opening (a) and its cross section (b); the configurations of the tool bottoms with different openings: (A) $10 \mathrm{~mm},(B) 15 \mathrm{~mm}$ and (C) $20 \mathrm{~mm}$.

\subsection{Results and discussion}

\subsubsection{EN-h0.4 series: tool rotation rate study}

\section{Cladding appearance}

(A)

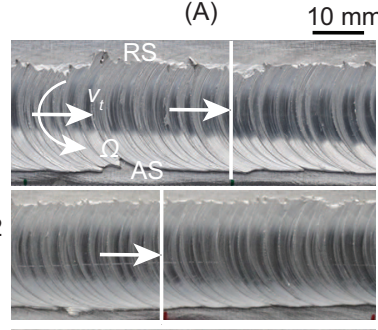

(c) EN-h0.4-3 near $\mathrm{TC}_{4}$ $500 \mathrm{rpm}$

(d) EN-h0.4-4 near $\mathrm{TC}_{2}$ $600 \mathrm{rpm}$
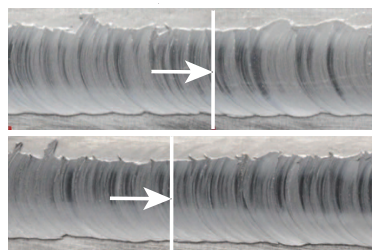

(B)
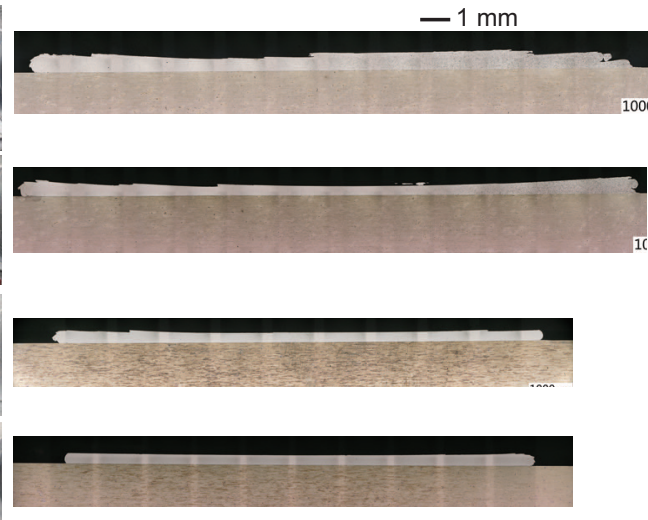

Fig. 3.2 (A) Top views of the produced layers; (B) transverse cross sections extracted along the lines shown in (A) for the EN-h0.4 series of experiments.

Homogeneous and defect free clad layers were deposited successfully on the substrates in the EN series of experiments. The clad layer appearance as visible from the top surface and through the cross sections of the deposited samples near $T C_{3}$ is shown in Fig. 3.2. The substrate is covered fully by the clad material and 
no surface voids are visible. The layer edge at the AS is rather straight along the cladding track, whereas a more wavy edge is observed at the RS. This effect has been observed before in Chapter 2. The clad layer-substrate interface is straight for each sample independent of the tool rotation rate as visible from the micrographs of Fig. 3.2(B). Even for the highest tool rotation rates used, $500 \mathrm{rpm}$ and $600 \mathrm{rpm}$, no mixing of the clad material with the substrate is visible. At the lowest tool rotation rate the top surface shows some arc-like markings giving the surface a larger roughness, but this effect disappears for higher tool rotation rates giving the clad layers a smoother appearance.

The dimensions of the layers produced in this series are shown as a function of the tool rotation rate in Fig. 3.3(a). The actual layer thickness, $H$, is the average value obtained from the respective cross sections shown in Fig. 3.2(B). It is observed that the layer thickness is somewhat larger than $0.4 \mathrm{~mm}$ for the lower rotation rates and somewhat smaller for the high rotation rates. The layer width varies between 16 and $20 \mathrm{~mm}$ indicating that the current supply system does not allow the volumetric supply rate to be set accurately, as also experienced in Chapter 2.

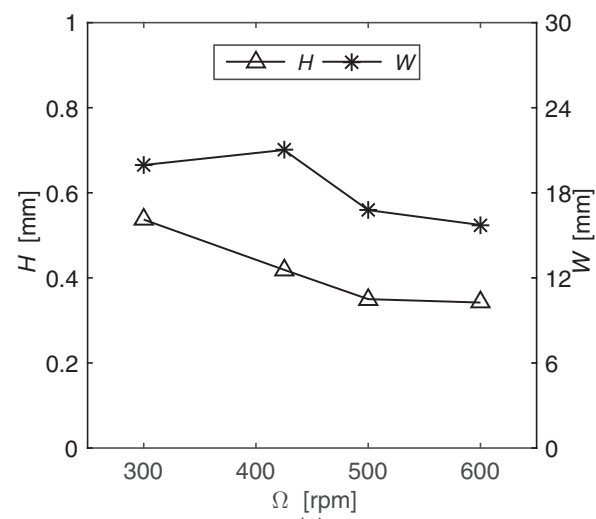

(a)

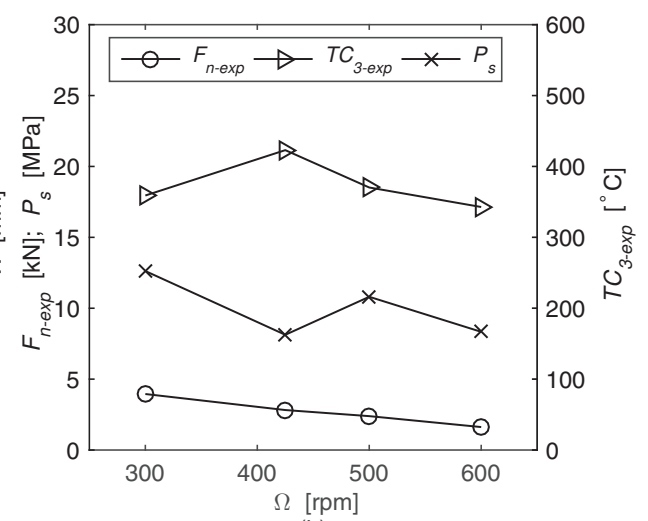

(b)

Fig. 3.3 (a) The actual thickness $(H)$ and the width $(W)$ of the layers produced; $(b)$ the measured average normal forces $\left(F_{n-\exp }\right)$, the average pressures at the substrate $\left(P_{s}\right)$ and the peak temperatures $\left(T C_{3-\exp }\right)$ near the analyzed cross sections in Fig. 3.2 for the EN-h0.4 series of experiments.

\section{Temperature and normal force}

The recorded process temperatures as a function of time for this series of experiments are shown in Fig. 3.4. In all cases the tool temperature $T_{t}$ rises strongly during the preheating phase (i.e. time $<0$ in Fig. 3.4), but the temperature rise visible for experiments EN-h0.4-2 and EN-h0.4-4 after about $80 \mathrm{~s}$ is stronger than usually observed. A probable cause seems a change in the layer width which is not further studied here. Unfortunately, the tool temperature signal was temporarily lost during the experiments at $300 \mathrm{rpm}$ and $600 \mathrm{rpm}$. 


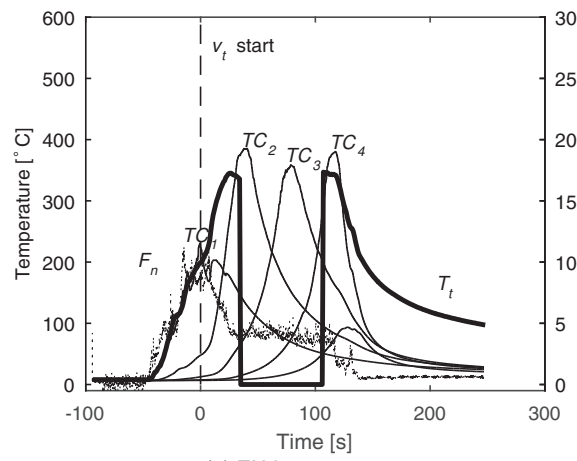

(a) EN-h0.4-1, $300 \mathrm{rpm}$

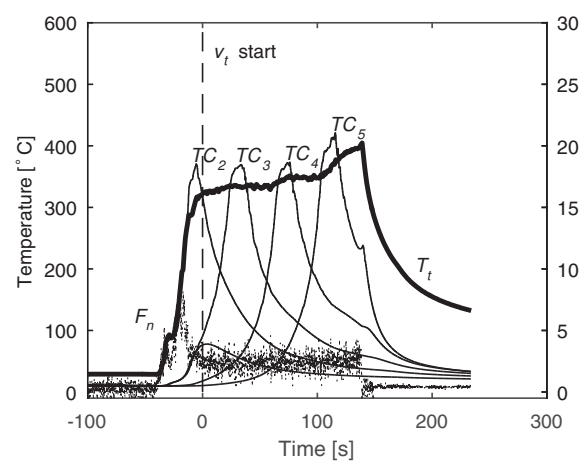

(c) EN-h0.4-3, $500 \mathrm{rpm}$

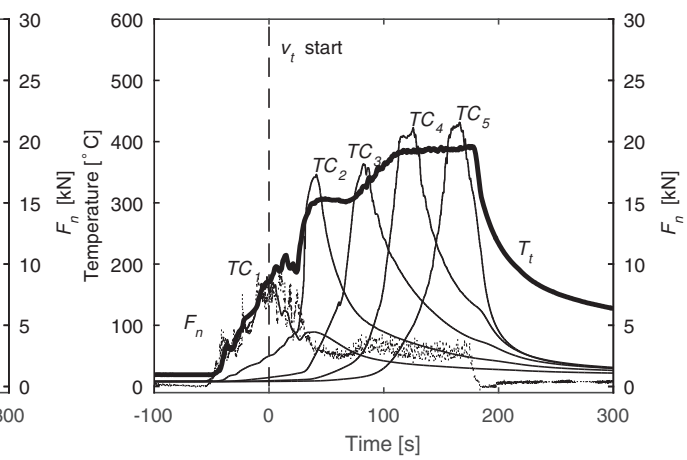

(b) EN-h0.4-2, $425 \mathrm{rpm}$

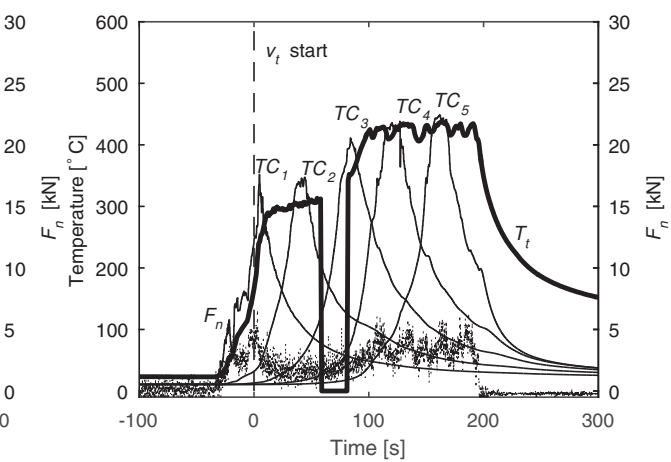

(d) EN-h0.4-4, $600 \mathrm{rpm}$

Fig. 3.4 The tool temperature, $T_{t}$, the temperatures in the mid plane of the substrate, $T C_{1}-T C_{5}$, and the normal force, $F_{n}$, of the EN-h0.4 series of experiments.

The peak values of the substrate temperatures measured by the thermocouples located near the analyzed samples shown in Fig. 3.2(B) are proximately $350{ }^{\circ} \mathrm{C}$ for this series of experiments with an exception of EN-h0.4-2, see Fig. 3.3(b). According to experimental and modeling results of Chapter 2, the process temperatures increase with the tool rotation rates, but are also affected by the layer width. Apparently, the layer width in this case is sufficiently small at $500 \mathrm{rpm}$ and $600 \mathrm{rpm}$ to prevent mixing of the clad layer with the substrate as did occur at these rotation rates in Chapter 2 for the $0.2 \mathrm{~mm}$ layer thickness. In fact, the widest layer deposited at $425 \mathrm{rpm}$ may explain the highest substrate temperature observed for this series.

The measured normal forces shown in Fig. 3.4 are approximately constant after the initial start-up peak during the cladding phase in experiments EN-h0.4-1, EN-h0.42 and EN-h0.4-3. This, to some extent, indicates that the cladding phase is stable over time for these experiments. The normal force in the experiment EN-h0.4-4 is only more or less constant before the tool passes $T C_{3}$, but afterwards it increases and shows some oscillations that may also indicate the occurrence of mixing as observed in Chapter 2. 
The average normal forces determined at the location of the cross sections shown in Fig. 3.2(B) are displayed in Fig. 3.3(b). They seem to decrease roughly linearly with increasing tool rotation rates. This relation could not be observed from the results shown in Chapter 2 due to concomitant variations in the clad layer dimensions. Here, the experimental conditions during experiments EN-h0.4-1, EN-h0.4-3 and EN-h0.4-4 led to similar process temperatures. The effect of the slightly changing layer width may be handled by plotting the average pressure as a function of the rotation rate employing $P_{s}=4 F_{n-\exp } /\left(\pi * W^{2}\right)$. Then, a decreasing trend of the pressure applied on the substrate with higher tool rotation rates is observed. The data point for the experiment EH-h0.4-2 does not fit so nicely in the expected behavior, but this is ascribed to the relatively high process temperature. The clad material is softened significantly in this case, which apparently requires a smaller pressure to distribute the clad material.

\section{Hardness}

The hardness values at the mid planes of the substrates measured at the selected cross sections (see Fig. 3.2(B)) are consistent with the recorded tool and substrate temperatures, see Fig. 3.5. The hardness remains above $100 \mathrm{HV}$ for all experiments of this series. The highest peak temperature observed in experiment EH-h0.4-2 and the lowest one in EH-h0.4-4 lead to the lowest and highest hardness values near the cladding center line, respectively, see also Fig. 3.3. The thermal history of experiments EH-h0.4-1 and EH-h0.4-3 is very similar, leading to similar hardness distributions.

\subsubsection{EH series: layer thickness study}

\section{Cladding appearance}

Homogeneous and defect free clad layers were also deposited on the substrates in the EH series of experiments. The appearance of the clad layer from the top surface and through the cross sections near $T C_{3}$ is shown in Fig. 3.6. Full coverage of the substrate with clad material is visible also in this case. The layer width is approximately uniform $(16 \mathrm{~mm}-18 \mathrm{~mm})$ regardless of the layer thickness. The layer edge at the AS is very straight along the cladding track, whereas a more wavy edge is observed at the RS. The effect seems to be stronger for layers with a larger thickness. Nevertheless, the clad layer-substrate interface is straight for each sample independent of the layer thickness as visible from the micrographs of Fig. 3.6(B).

The cross sections extracted along the vertical straight lines marked in Fig. 3.6(A) reveal well bonded clad layers with uniform layer thickness, see Fig. 3.6(B). The bonding interface between the clad layer and the substrate is rather straight along the entire layer width and extends till the edge of the clad layer, see also Fig. 3.7. Clearly, no mixing between the clad layer and the substrate material has occurred. 


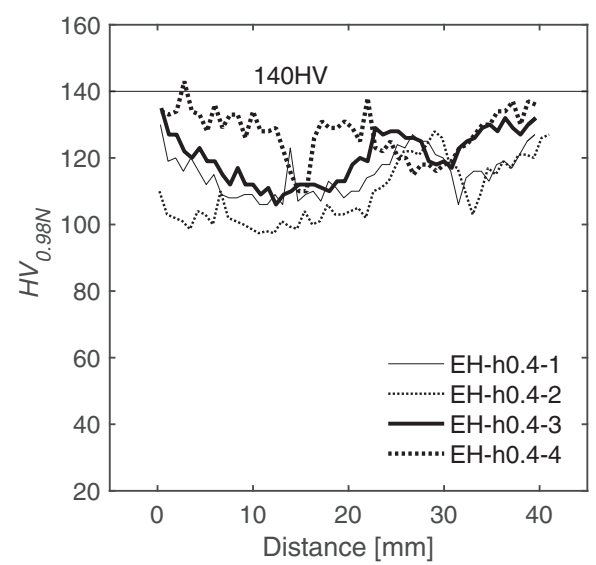

Fig. 3.5 The hardness at the mid plane of the substrate measured at the cross sections shown in Fig. 3.2.

$10 \mathrm{~mm}$ (A)
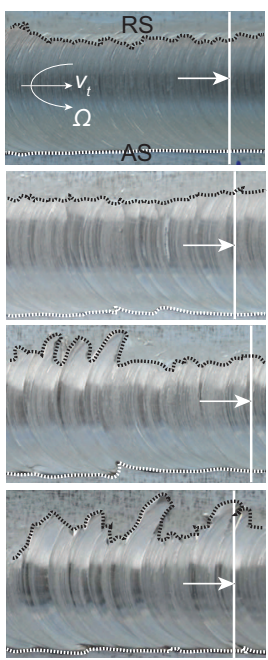

(B)

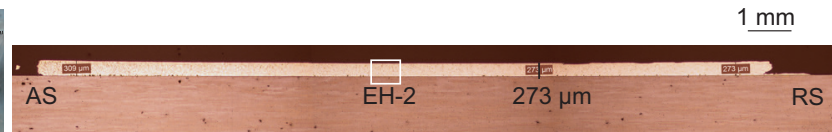

(a) $\mathrm{EH}-02$

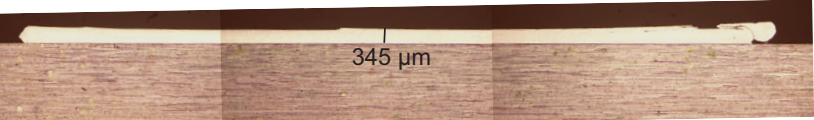

(b) $\mathrm{EH}-04$

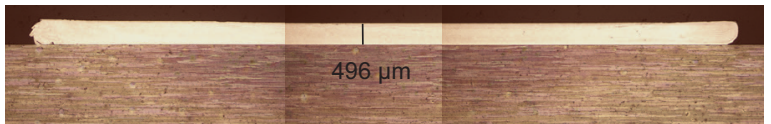

(c) $\mathrm{EH}-06$

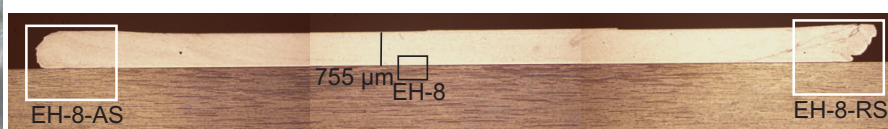

(d) $\mathrm{EH}-08$

Fig. 3.6 The top view of the clad layers (A) and their cross sections in the experiments EH-02, EH-04, EH-06 and EH-08 (B) performed with a nominal layer thickness $h_{0}$ from 0.2 to $0.8 \mathrm{~mm}$. Cross sections were taken at positions marked by the vertical white lines in (A). They closely correspond to the location of thermocouple $T C_{3}$.

The clad layers are characterized by fine grains with a grain size of approximately $5 \mu \mathrm{m}$ near the bonding interfaces, similar to the observations in Van der Stelt (2014); hence, these are not shown again. Full dynamic recrystallization occurred in the clad layer next to the bonding interface due to the large plastic deformation of the clad material under the influence of the rotating (and translating) tool at relatively high temperatures. The grains in the clad rod further away from the 
bonding interface are slightly larger in size. This region may have experienced less plastic deformation, possibly leading to less dynamic recrystallization and in turn to somewhat fewer fine grains as discussed by Robinson and Ring (2005). The substrate microstructure is characterized by large and elongated grains. The FSC process conditions selected are such that no changes to the AA2024 substrate grain structure takes place.
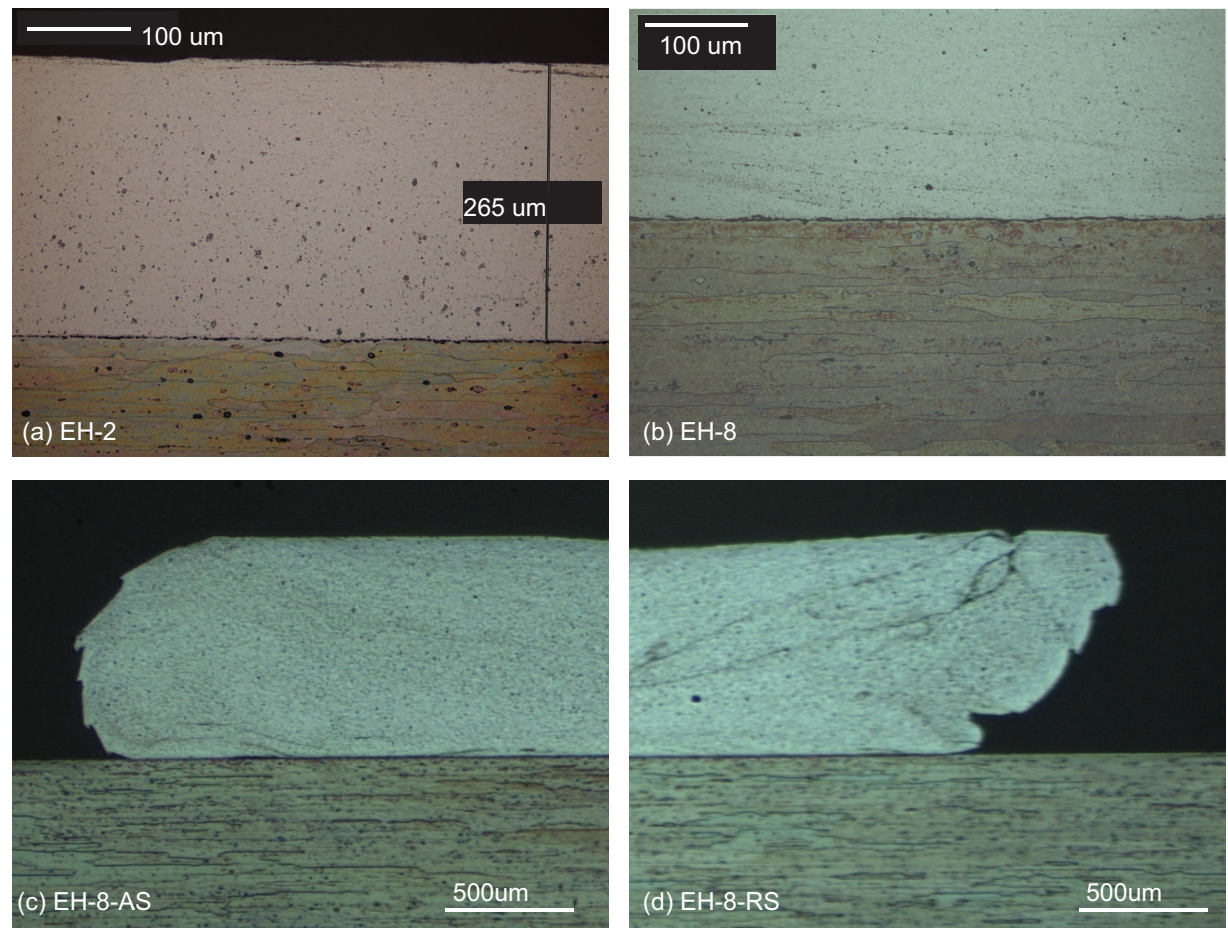

Fig. 3.7 The bonding interface near the cladding center line for EH-02 (a) and EH-08 (b) and near the edge (AS and RS) of clad layer in EH-08 (c-d) marked in Fig. 3.6(B).

The measured dimensions of the manufactured clad layers are shown in Fig. 3.8. The thickness deviates somewhat from the nominal values, especially at the smallest layer thickness in experiment EH-02. Here, the actual thickness is about $0.3 \mathrm{~mm}$ against a nominal value of $0.2 \mathrm{~mm}, 50 \%$ of deviation. The deviation drops to less than $3 \%$ in experiment EH-08. The average layer width is more or less constant at $17 \mathrm{~mm}$.

\section{Temperature and normal force}

The recorded process temperatures for this series of experiments are shown in Fig. 3.9. In all cases the tool temperature $T_{t}$ rises during the preheating phase 
(i.e. time $<0$ in Fig. 3.9) and continues to rise further during the first stages of the translation phase (time $>0$ ) up to a more or less constant value near the location of the third thermocouple $\left(\mathrm{TC}_{3}\right)$. In the experiment $\mathrm{EH}-08$, the initial value of the volumetric supply rate of the clad material was too small and it was increased afterwards at about time $=50 \mathrm{~s}$. Then, the tool temperature reached a value comparable to the other experiments. The tool temperature $\left(T_{t}\right)$ near the location of the third thermocouple $\left(T C_{3}\right)$ is always around $290^{\circ} \mathrm{C}-300^{\circ} \mathrm{C}$, which is about $30^{\circ} \mathrm{C}$ lower than that measured by the thermocouple $T C_{3}$ in the substrate. The observed differences between the tool and substrate temperatures have been explained in Chapter 2. The tool temperature is seen to rise again for experiments EH-02, EH-04 and EH-06 during the last stages of the cladding phase, after the tool passed the location of $T C_{3}$ as has been observed before with the previous series of experiments and in Chapter 2. Nevertheless, the peak values of the temperatures measured by the thermocouple $\mathrm{TC}_{3}$ are approximately constant $\left(325^{\circ} \mathrm{C}-330^{\circ} \mathrm{C}\right)$ for all experiments in this series, see Fig. 3.8(b). In this way, these experiments can be studied further without considering the temperature differences.

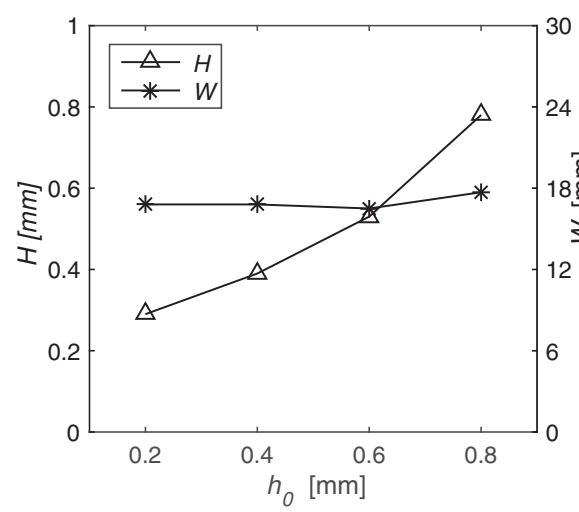

(a)

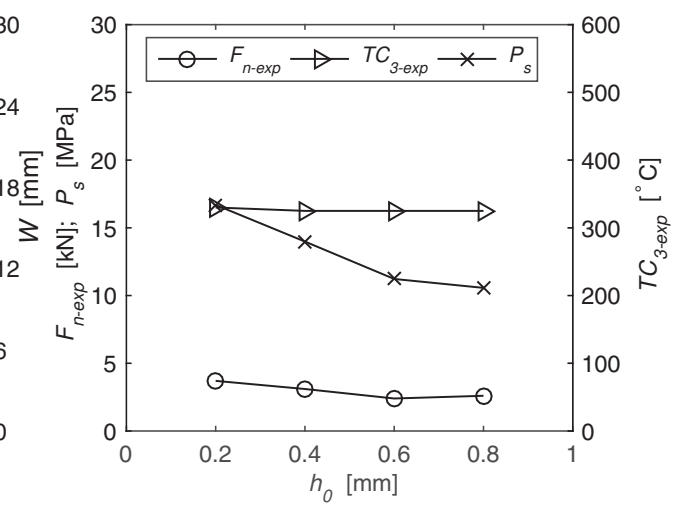

(b)

Fig. 3.8 (a) The actual thickness $(H)$ and width $(W)$ of the deposited layers; $(b)$ the average normal force $\left(F_{n}\right)$, the average pressure $\left(P_{s}\right)$ and the peak temperatures recorded by $T C_{3}\left(T C_{3-e x p}\right)$ near the analyzed cross sections in Fig. 3.6 for the EH series of experiments.

The average normal force $\left(F_{n-\text { exp }}\right)$ obtained near the $T C_{3}$ position shows a decreasing trend as a function of the layer thickness, see Fig. 3.8(b). The average pressure is calculated in the same way as in the previous section and shows a similar trend as the normal force. Apparently, the normal force drops as a function of the layer thickness under these conditions where the process temperature and layer width are approximately constant. This is also confirmed by comparing the results of EN-h0.4-2 $\left(\Omega=425 \mathrm{rpm} ; W=21 \mathrm{~mm} ; F_{n-\exp }=2.8 \mathrm{kN}\right)$ with the experiment performed with $400 \mathrm{rpm}$ in Chapter $2\left(h_{0}=0.2 \mathrm{~mm} ; W=21.2 \mathrm{~mm} ; F_{n-\exp }=4.8 \mathrm{kN}\right)$. The process temperatures are of the same order of magnitude, but in the case of the larger layer thickness, the normal force is strongly reduced. 

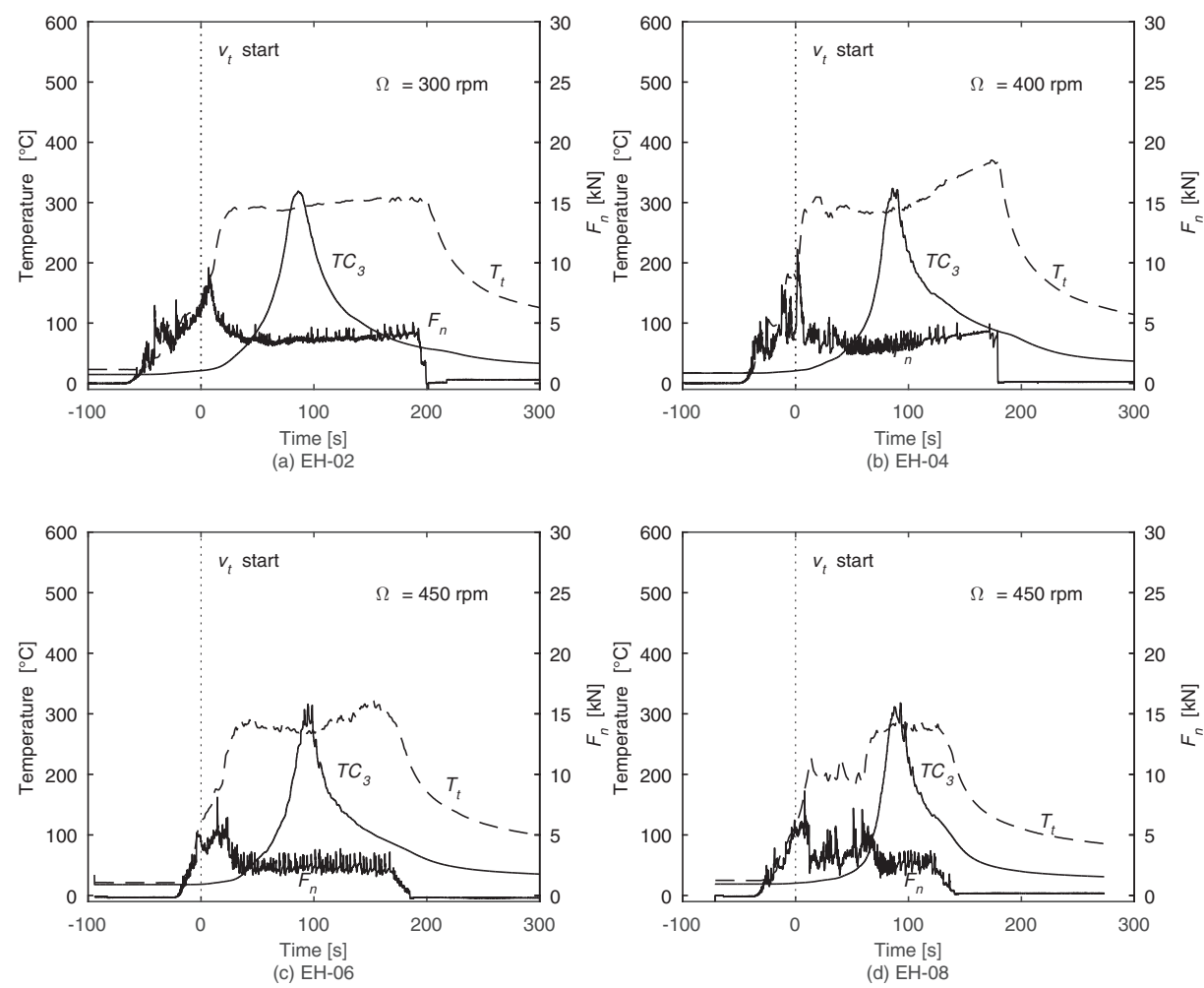

Fig. 3.9 The tool temperature $T_{t}$, the substrate temperature measured at the mid plane of the substrate by thermocouple $\mathrm{TC}_{3}$ and the normal force $F_{n}$ for the experiments EH-02, EH-04, EH-06 and EH-08 operated with nominal layer thickness $h_{0}$ from $0.2 \mathrm{~mm}$ to $0.8 \mathrm{~mm}$.

\section{Hardness}

The measured temperatures $T C_{3}$ of these experiments show roughly the same maximum values. This is also reflected by the measured hardness distributions, as shown in Fig. 3.10. The hardness is measured at the cross sections shown in Fig. 3.6(B). The hardness at the mid plane of the substrates $(z=2 \mathrm{~mm})$ beneath the cladding area is around $130 \mathrm{HV}$, less than $10 \%$ lower than the original value of $140 \mathrm{HV}$. This is in line with the similar and relatively low process temperatures experienced by all deposited samples near $T C_{3}$, see Fig. 3.8(b). The hardness changes can be explained in the same way as in the previous chapter. The lowest hardness $(\approx 120 \mathrm{HV})$ is observed along the cladding center line close to the clad layer interface at $z=3.8 \mathrm{~mm}(0.2 \mathrm{~mm}$ below the substrate top $)$ for experiments $\mathrm{EH}$ 02 and $\mathrm{EH}-04$. The hardness for experiments $\mathrm{EH}-06$ and $\mathrm{EH}-08$ at this position is higher $(\approx 130 \mathrm{HV})$.

The hardness in all clad layers is $20-30 \mathrm{HV}$ which is smaller than the value $(40 \mathrm{HV})$ of the as-received, cold deformed AA1050 rods. Apparently, the thermo-mechanical 
conditions of the FSC process have brought about a reduction of the dislocation density in the clad material, leading to a reduction of its hardness. The concomitant decrease in the grain size of the material, which is known to increase the material hardness, as also discussed by Qiao et al. (2009) for this material, has, however, no decisive influence.

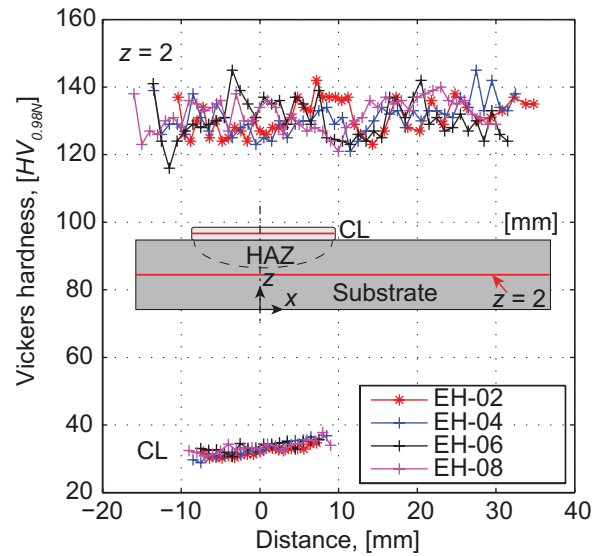

(a) HV at CL and $z=2 \mathrm{~mm}$

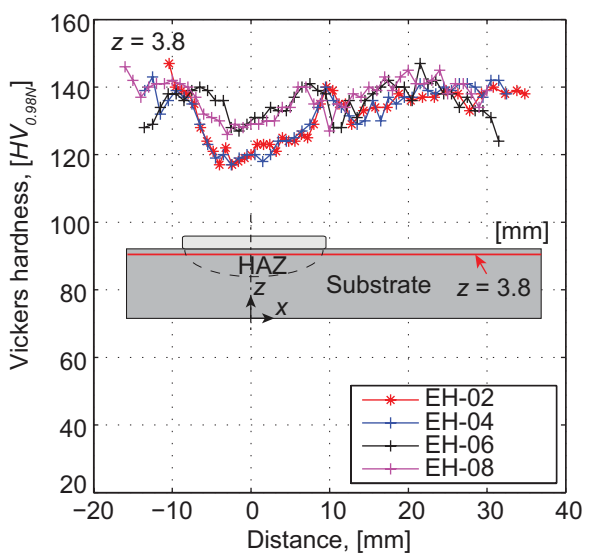

(b) HV at $z=3.8 \mathrm{~mm}$

Fig. 3.10 Hardness profiles of the experimental samples at different positions: (a) mid plane of the substrate with $z=2 \mathrm{~mm}$ and mid plane of the clad layer; $(b)$ substrate directly beneath the clad layer with $z=3.8 \mathrm{~mm}$.

\subsubsection{EW experiment}

\section{Cladding appearance}
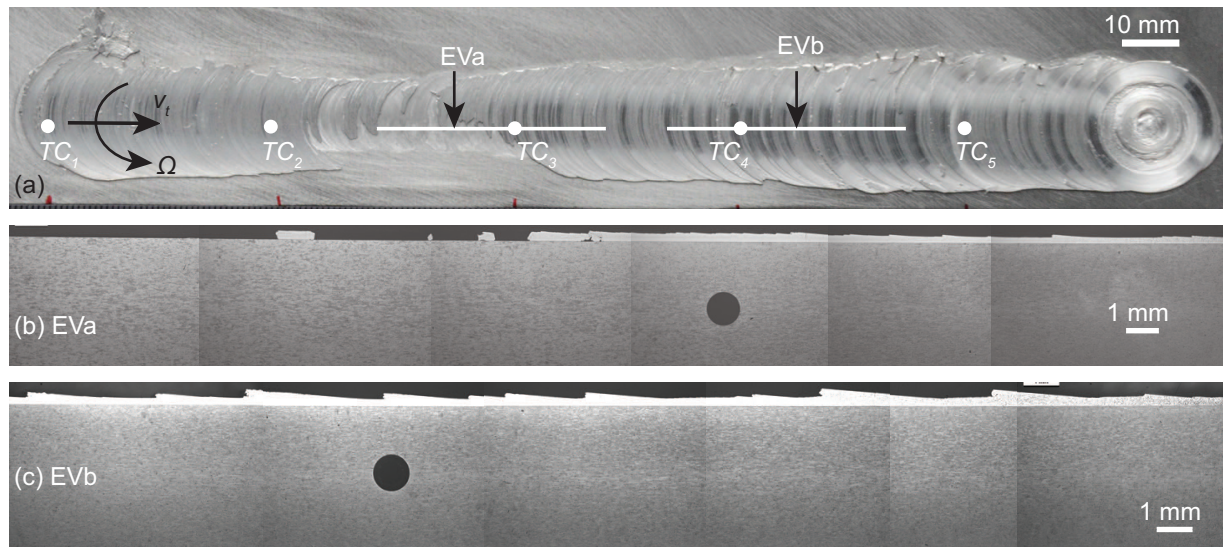

Fig. 3.11 Cladding performance of the sample deposited in experiment EW: (a) The top view of the clad layer; $(b)$ and $(c)$ the microstructure of sample EVa and EVb marked by the white lines in (a). 
The top view of the so-deposited layer along the entire cladding track is shown in Fig. 3.11(a). After the preheating phase the volumetric flow rate is held constant for a short period and then the flow rate is significantly reduced leading to a concomitant reduction of the layer width. The amount of clad layer material supplied per unit of time is now too small to cover the substrate completely. A discontinuous clad layer is produced which is also visible on the left side of the cross section shown in Fig. 3.11(b). As soon as the volumetric supply rate is increased again the clad layer covers the substrate completely, as also shown at the right side of Fig. 3.11(b) and in Fig. 3.11(c) for even larger supply rates.

The substrate-clad material interface remains straight, indicating that no mixing occurs between the layer and the substrate. The layer thickness is macroscopically constant along the cladding direction, with some local fluctuations of around 0.1 $0.2 \mathrm{~mm}$.

\section{Temperature and normal force}

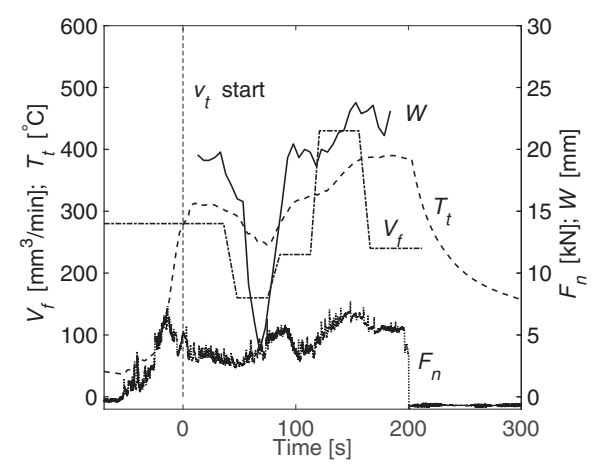

Fig. 3.12 The tool temperature $\left(T_{t}\right)$ and the normal force $\left(F_{n}\right)$, the layer width $(W)$ and the supply rate of the clad material $\left(V_{f}\right)$ in experiment $E W$.

The measured tool and substrate temperatures and the normal force approximately follow the magnitude of the supply rate of the clad material, and as such, the layer width, see Fig. 3.12. When insufficient clad material is supplied, the contact area between the FSC tool and the clad layer becomes relatively small. In this situation little material experiences frictional and/or dissipative heating, leading to relatively low process temperatures. The clad material insufficiently softens under this condition and it hardly flows laterally. This even induces a larger normal force (after approximately $90 \mathrm{~s}$ ). When more material is supplied, the temperature increases and the normal force drops again (after $100 \mathrm{~s}$ ). As soon as the volumetric supply rate is increased once again, the layer width also grows larger, leading to a concomitant increase in tool temperature and normal force. Apparently, the volume of clad material deposited is so large that the normal force grows further despite the additional softening of the clad material at the increased process temperatures. 


\section{Hardness}

The hardness distributions at the mid plane of the substrate measured at the cross sections EVa (small width) and EVb (large width) are shown in Fig. 3.13. The layer width and the hardness are correlated clearly. The deposition of wider clad layers leads to a stronger reduction in the hardness of the substrate due to the higher cladding process temperature.

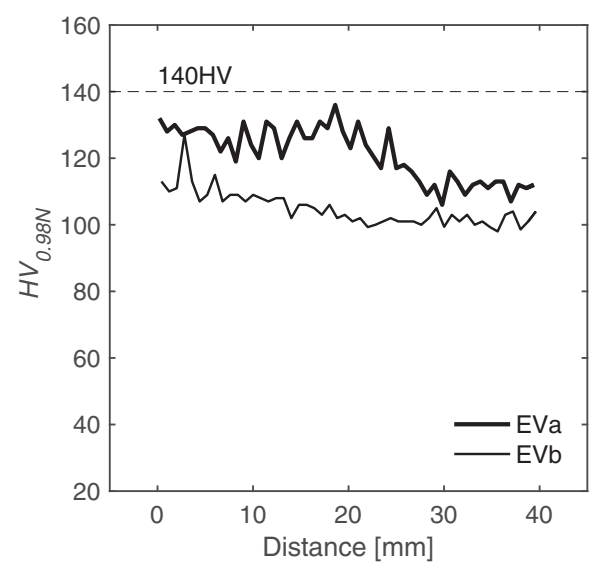

Fig. 3.13 Hardness distributions at the mid plane of the substrate measured from the samples EVa (thick line) and EVb (thin line) shown in Fig. 3.11.

\subsubsection{ED series}

\section{Cladding performance}

All the experiments carried out to study the effect of the diameter of the tool opening produce continuous clad layers without defects. Three representative examples from the ED series: experiments ED10-B, ED15A-2 and ED20B-1 are shown in Fig. 3.14. The rest of this series (experiments ED10-A, ED15A-1 and ED20B-2) present similar cladding performance and are not shown here. All clad layers fully cover the substrate within the cladding trajectory and feature porosity free top surfaces featuring some local roughness arcs as also observed in previous experiments.

The tool with larger openings seems to produce layers with slightly smoother edges. Fig. 3.14(A) shows that the layer edge at the RS of experiment ED20B-1 fluctuates less than that of ED10B. One explanation might be that when the diameter of the tool opening is larger, the clad material pressed out of the opening travels a shorter radial distance in the clearance between the tool and the substrate to reach a constant layer width. This may lead to a more even flow pattern near the layer edge and a clad layer that is straighter along the translation direction. 


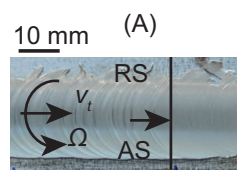

$1 \mathrm{~mm}$

(B)

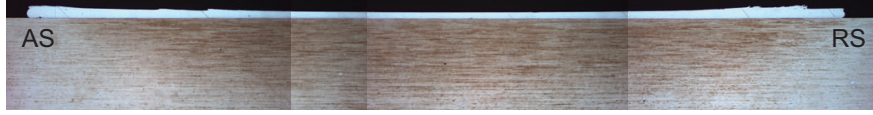

(a) ED10B
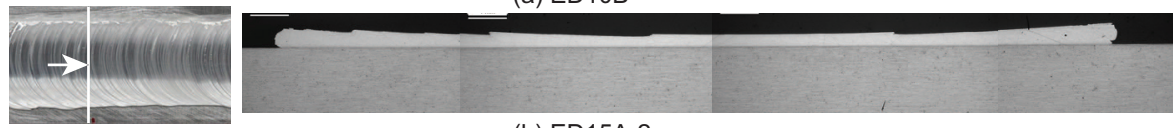

(b) ED15A-2
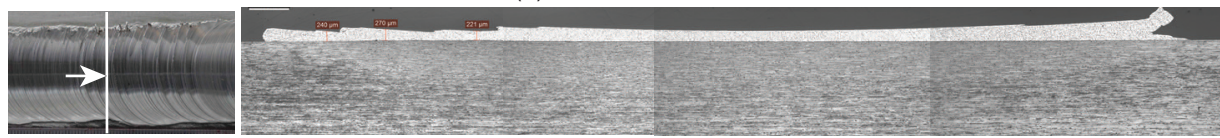

(c) ED20B-1

Fig. 3.14 (A) The top views of the clad layers deposited in experiments ED10B, ED15A-2 and ED20B-1; $(B)$ the corresponding cross sections extracted along the vertical lines in (A).

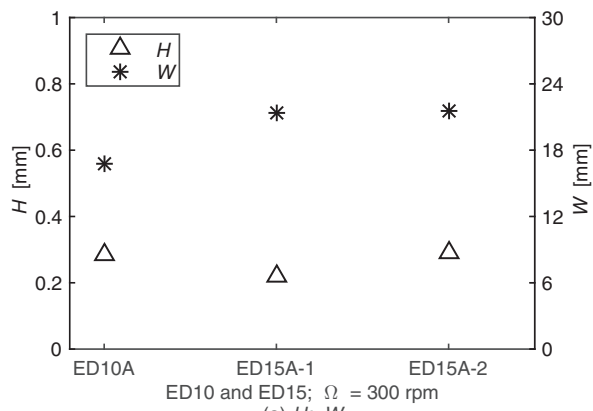

(a) $H ; W$

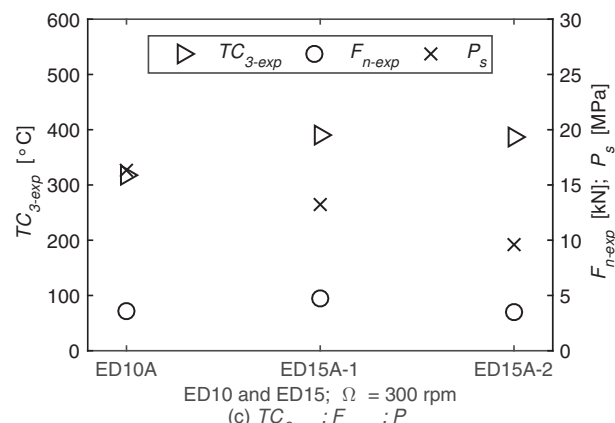

(c) $T C_{3-\exp } ; F_{n-\exp } ; P_{s}$

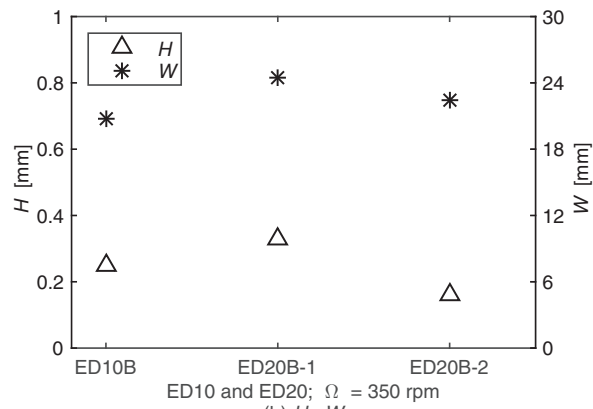

(b) $H ; W$

Fig. 3.15 $(a-b)$ The layer dimensions $(H$ and $W) ;(c-d)$ the peak temperatures measured by $T C_{3}\left(T C_{3-e x p}\right)$, the average normal forces near the positions of $T C_{3}\left(F_{n-\text { exp }}\right)$ and average pressures $\left(P_{s}\right)$ for the ED series of experiments.

The dimensions of the deposited layers near the position of $T C_{3}$ for this series of experiments are shown in Figs. 3.15(a) and (b). The actual thickness of the layers deviates from the preset values, which has been explained previously. The layer 
widths produced by the tools with larger openings are somewhat larger than those by the tools with smaller openings. It is difficult to judge whether this is related to the tool opening diameter or to the variations in experimental conditions.

\section{Temperature and normal force}

The recorded temperatures $\left(T_{t}\right.$ and $\left.T C_{3}\right)$ during the cladding process of experiments ED10B, ED15A-2 and ED20B-1 are shown in Fig. 3.16. The measured tool temperature rises gradually over the cladding time due to the changing thermal conditions as explained before. A small dip in the tool temperature profile near $\mathrm{TC}_{3}$ in experiment ED10B is observed for reasons that are unclear. The tool temperature of experiment EB20B-1 is unavailable. The peak values of the temperatures measured by $T C_{3}$ for all experiments in this series are shown in Fig. 3.15(c-d). These values seem to be correlated to the layer widths as shown in Fig. 3.15(a-b). Wider layers correlate with higher substrate temperatures in line with the observations of the EW experiment. It suggests that the influence of the tool opening diameter is small.

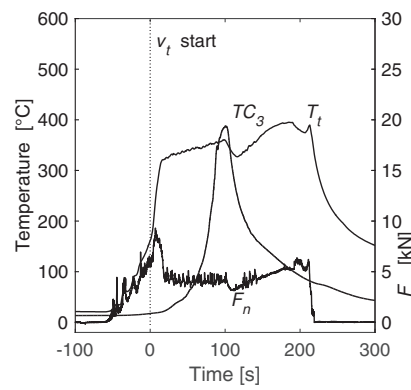

(a) ED10B

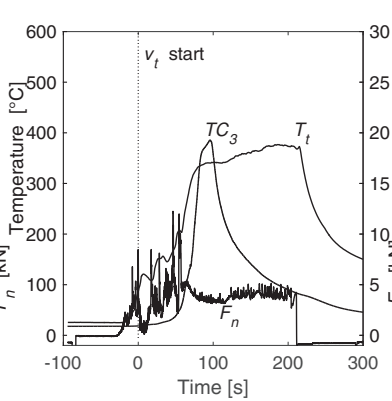

(b) ED15A-2

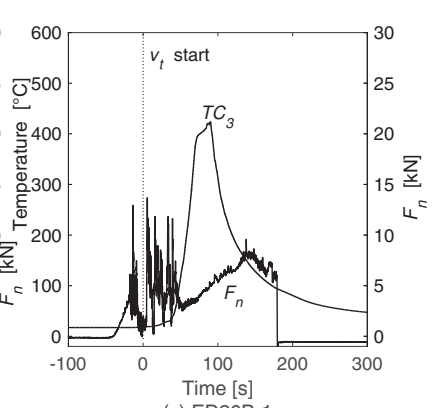

(c) ED20B-1

Fig. 3.16 The temperature and normal force distributions of the experiments ED10B, ED15A-2 and ED20B-1.

The normal forces measured during the cladding processes are shown in Fig. 3.16 too. The profiles are in line with those observed previously except for the end of experiment ED20B-1. The normal force rises strongly in the second half of the cladding phase. The temperature also increases with time in this part of the experiment, which leads to mixing at the end of the cladding phase.

The average normal forces near $T C_{3}$ of these experiments of the ED series do not show clearly a link with the tool opening. However, if the average pressure exerted on the substrate is calculated instead (see previous sections), it seems clear that this pressure decreases with the size of the tool opening. Apparently, the clad material will flow more easily in a lateral fashion with a larger tool opening. 


\section{Hardness}

The hardness values at the mid plane of the substrates are observed from the cross sections extracted near the $T C_{3}$ position, see Fig. 3.17. The hardness profiles of the experiments performed at a tool rotation rate of $300 \mathrm{rpm}$ (ED10A, ED15A-1 and ED15-2) are shown in Fig. 3.17(a) and Fig. 3.17(b) shows those at $350 \mathrm{rpm}$ (ED10B, ED20B-1 and ED20B-2). The lowest process temperature in experiment ED10A leads to the highest hardness which equals approximately $90 \%$ of the as-received value. The hardness of the other samples is lower due to the higher temperatures experienced during the cladding phase.

In Fig. 3.17(b), the hardness values near the cladding center line are $100-110 \mathrm{HV}$, which is in line with the respective recorded temperature profiles. A peak region of the hardness profiles around $15 \mathrm{~mm}$ away from the cladding center line is commonly seen in all experiments.

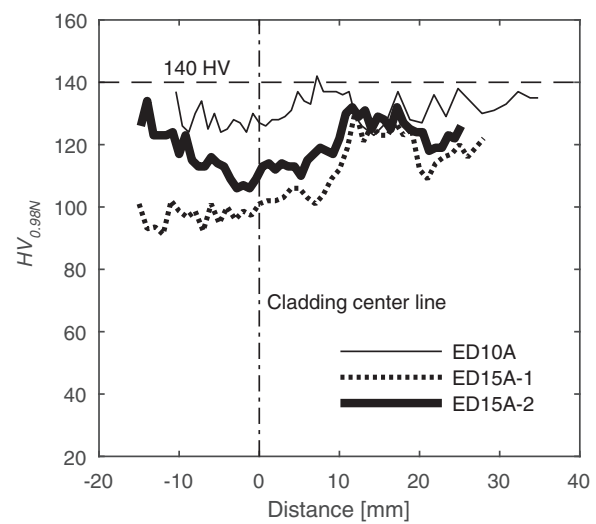

(a) $300 \mathrm{rpm}$

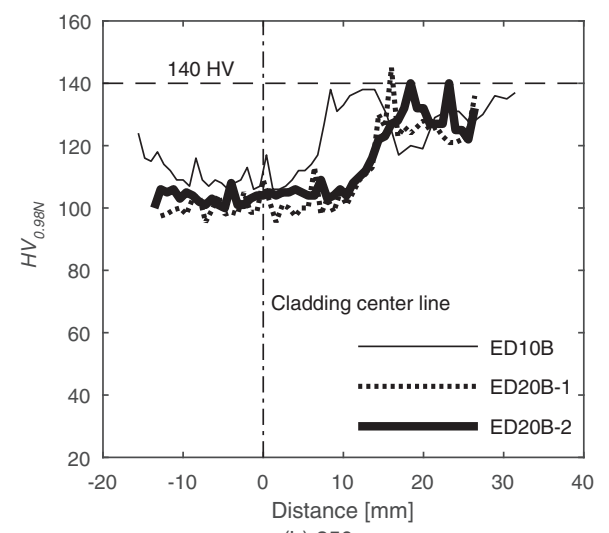

(b) $350 \mathrm{rpm}$

Fig. 3.17 The hardness distributions in the mid plane of the substrates deposited in the ED series of experiments.

\subsection{Conclusions}

The various series of experiments presented in this chapter show that homogeneous and defect free layers of commercially pure aluminum can be deposited well on an AA2024 substrate within a relatively broad process window. Layers with a thickness between 0.2 and $0.8 \mathrm{~mm}$ can be produced well. Tools equipped with a larger tool opening diameter can also be employed well, allowing a larger supply of clad material.

In general, the process temperature, as characterized by both the FSC tool temperature and the temperatures recorded in the substrate, and the normal force exerted on the substrate are influenced by process parameters and tool design. 
The process temperature is an important indicator for the occurrence of mixing. The FSC process temperature depends strongly on the tool rotation rate and the layer width. The influence of the layer thickness on the process temperature could not be determined clearly. The influence of the tool design, i.e. the tool opening diameter, does not appear to be large.

The normal force exerted on the substrate beneath the FSC tool is very sensitive to the process temperature. It increases with the clad layer width, but it decreases with the layer thickness and the tool opening diameter. These conclusions are based on the developments of the average pressure exerted on the substrates, where the contact area is determined on the basis of the actual layer width. In this way variations in clad layer width occurring from experiment to experiment can be compensated for.

The variations in the hardness distributions observed at the cross sections of the samples extracted near the location of the third thermocouple, positioned half way along the cladding phase, can be explained from the known behavior of AA2024T351 as a function of temperature and time. 


\section{References}

Qiao, X., Starink, M., and Gao, N. (2009). Hardness inhomogeneity and local strengthening mechanisms of an Al1050 aluminium alloy after one pass of equal channel angular pressing. Mater. Sci. Eng. A, 513-514:52-58.

Robinson, T. and Ring, B. (2005). Reduction of Annealing Times for Energy Conservation in Aluminum. Technical report.

Van der Stelt, A. (2014). Friction surface cladding; development of a solid state cladding process. PhD thesis, University of Twente. 


\section{Parameter study with an axisymmetric thermo-mechanical model}

\subsection{Introduction}

The performance of friction surface cladding depends on the setup and many process variables, as described in Chapter 1 . With the current cladding device, the main process parameters, including the tool rotation rate, the layer thickness and width and the size of the tool opening have been studied experimentally in Chapters 2 and 3. Correlations between these parameters and the FSC process temperature, the normal force exerted on the substrate and the substrate hardness have been observed. These may provide a useful guideline for future cladding operations. However, the correlations described above were obtained in an exploratory and experimental way. Some parameters, such as the layer dimensions, could not be controlled with a high precision. As a consequence, several variables may vary unintendedly in one series of cladding experiments aimed at studying a single variable. This complicates the parameter study and leads to deviations from the true underlying relations between the parameters and the observed correlations in the experiments performed.

Hence, an FSC process model is required that predicts the heat generation and the normal force exerted on the substrate as a function of the process parameters and the tool design. The model should also provide knowledge on the temperature distribution within the tool and the clad layer and the heat flow to the substrate and the backing table as a function of time to be able to make a comparison with experimentally observed temperature developments. Furthermore, detailed understanding of the pressure distribution required to distribute the clad material through the narrow gap between the FSC tool and the substrate is necessary to understand the origin of the normal force exerted on the substrate.

In this chapter a thermo-mechanical finite element model is set up to compute the thermal and pressure fields and to study and understand the experimental trends. The model is based on a computational fluid dynamics (CFD) approach, utilizing the fact that the behavior of the AA1050 clad material at relatively 
high temperatures and strain rates can be described as a creeping, high viscosity material. Such an approach has been applied before by Colegrove and Shercliff (2005) and Schmidt and Hattel (2005) in a study of the material flow behavior during friction stir welding (FSW).

A relatively simple 2D axisymmetric thermo-mechanical model is employed to characterize the heat production and normal force development during the FSC process. The main purpose of the model is to determine the strength of the general heat source employed in the model of Chapter 2, that did not take the origin of the heat development into account. The developed model is also applied to a parameter study of the FSC process to gain in-depth understanding of the relations between the heat generation, the tool and substrate temperatures and the normal force exerted on the substrate with the process parameters and tool design.

\subsection{Model description}

\subsubsection{Model setup}

The FSC process comprises a preheating and a cladding phase, as described in Chapter 1. The developed process model is intended to compute the heat generation and the normal force development during the cladding phase. The preheating phase is not studied. During the FSC process the clad material is pressed out of the tool opening and flows into the narrow gap between the tool and the substrate. It is distributed laterally away from the tool opening through the applied pressure. The clad material experiences considerable heating during the FSC process through intense plastic deformation and frictional heating at the tool-clad material interface. The temperature increase caused in the clad material significantly decreases the clad material strength. Under these conditions the clad material can be considered as a creeping flow under the compression and rotation of the FSC tool.

The generation of heat and the normal force exerted on the substrate are computed employing a 2D axisymmetric thermo-mechanical model under the following assumptions. (i) In the cladding phase the FSC experiments are commonly performed with a high ratio of the tool rotation rate to the tool translation speed. The contribution of the tool translation speed to the heat generation is relatively small and can be neglected. (ii) The flow of clad material and the viscous /dissipative heat generation occur primarily in the (clad disk) zone between the tool and the substrate. Heat transfer from this zone primarily occurs to the tool situated above and the substrate and backing table located below it. Hence, the heat transfer is mainly oriented parallel to the FSC tool axis. (iii) The tool bottom is simplified to a flat bottom and the small inclination angle between the tool axis and the substrate surface normal is neglected. Hence, for symmetry reasons a 2D axisymmetric model suffices.

A sketch of the model including the FSC tool, the clad material being deposited and parts of the substrate and backing table, is shown in Fig. 4.1. The thickness $\left(h_{0}\right)$ and 
the width $\left(W=2 R_{\text {disk }}\right)$ determine the clad layer dimensions. The diameter of the clad rod $\left(D_{\text {rod }}=2 R_{\text {rod }}\right)$ equals the tool opening diameter. The length of the modeled clad rod is $h_{\text {rod }}=10 \mathrm{~mm}$, which is approximately the rod length at the location of $T C_{3}$ during the experiments, see Chapters 2 and 3 . The tool has an opening with a diameter of either $10 \mathrm{~mm}, 15 \mathrm{~mm}$ or $20 \mathrm{~mm}$ in line with the tools available, see also the previous chapter. Other dimensions of the modeled tool remain the same as those used in Chapters 2 and 3. The substrate and the backing table are simplified as cylinders, placed coaxially with the tool. The substrate has a radius of $R_{s u b}=$ $90 \mathrm{~mm}$ and a thickness of $h_{\text {sub }}=4 \mathrm{~mm}$, whereas the backing table has a radius of $R_{\text {table }}=45 \mathrm{~mm}$ and a height of $h_{\text {table }}=30 \mathrm{~mm}$. The clad material flows in at the inlet at a specified supply rate $v_{f}(\mathrm{~mm} / \mathrm{min})$ and it leaves the process at the outlet where $p$ is set to zero. The tool holder and the clamps to fix the substrates are not considered in this model.

The 2D thermo-mechanical model solves the continuity equation and the momentum conservation equations of the creeping flow in the cylindrical coordinate system along with the heat equation. Inertia effects in the clad material are neglected. The occurrence of mixing of the clad material with the substrate material is also not considered. The model computes the pressure field in the clad material and the temperature fields in the various parts of the model setup. The model is established in COMSOL Multiphysics 5.2.

The 3-node triangular meshes are used to mesh each component of the model. Fine elements are used in the clad layer and larger ones in the other parts.

\subsubsection{Boundary conditions}

Boundary conditions are provided to determine the clad material flow through the FSC tool and the heat conduction to the different model parts and the heat loss to the environment.

The clad material moves through the domains of the clad rod and the clad disk as shown in Fig. 4.1. The clad material flows into the tool opening via the clad rod with a linear supply rate of $v_{f}(\mathrm{~mm} / \mathrm{min})$ or a volumetric supply rate of $V_{f}\left(\mathrm{~mm}^{3} / \mathrm{min}\right)$, $V_{f}=v_{f} \pi R_{\text {rod }}^{2}$, which is connected to clad layer thickness and width through $V_{f}$ $=W h_{0} v_{t}$. Full sticking is assumed for the circumferential velocity component of the clad material in contact with the FSC tool. The clad material rotates with the same rotational speed as the FSC tool at any interface where the clad material is in contact with the tool, i.e. $u_{\theta}=r \omega$ with $\omega$ the tool rotation rate in $[\mathrm{rad} / \mathrm{s}]$. For the axial velocity component ( $z$ direction), at the vertical interface of the clad rod domain (see Fig. 4.1) a frictionless sliding wall condition is assumed. At the vertical tool-clad material interface the clad material moves at $\left(u_{r}, u_{\theta}, u_{z}\right)=\left(0, r \omega_{1} v_{f}\right)$. A fillet with a radius of $0.5 \mathrm{~mm}$ is incorporated to smoothen the material flow from the central FSC tool opening to the clad disk domain in between the tool and the substrate. The $u_{r}$ and $u_{z}$ components of the clad material flow tangential to the fillet surface in the $r-z$ plane (in the plane of the drawing) are modeled such that 


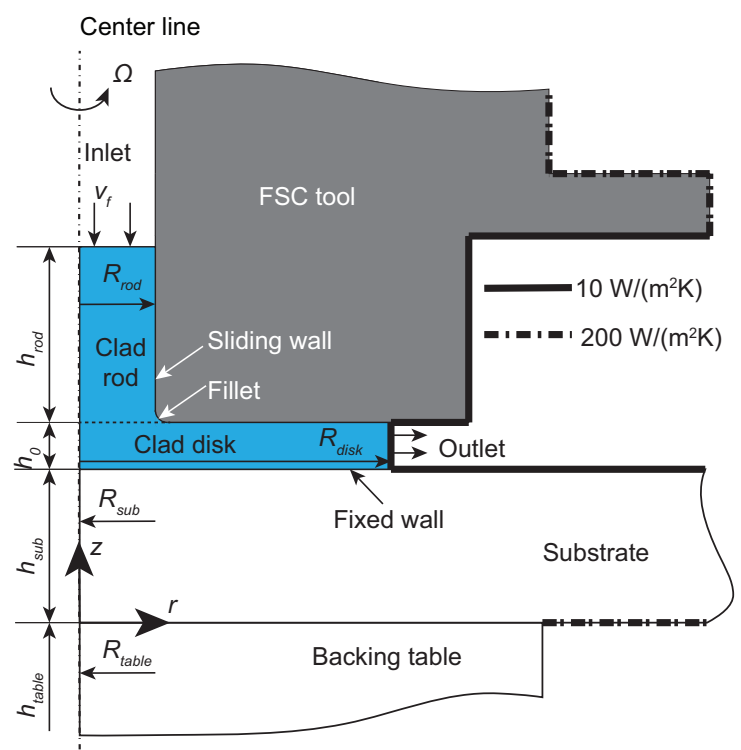

(a) $[\mathrm{mm}]$

\begin{tabular}{l|ll}
\hline $\begin{array}{l}\text { Domain 1 } \\
\text { Clad rod }\end{array}$ & $h_{\text {rod }}$ & 10 \\
& $R_{\text {rod }}$ & $5,7.5,10$ \\
\hline $\begin{array}{l}\text { Domain 2 } \\
\text { Clad disk }\end{array}$ & $h_{0}$ & Varying \\
& $R_{\text {disk }}$ & Varying \\
\hline Substrate & $h_{\text {sub }}$ & 4 \\
& $R_{\text {sub }}$ & 90 \\
\hline Table & $h_{\text {table }}$ & 30 \\
& $R_{\text {table }}$ & 45 \\
\hline
\end{tabular}

(b)

Fig. 4.1 Sketch of the 2D axisymmetric thermo-mechanical model. The dimensions of the clad rod, the clad disk, the substrate and the backing table are $R_{\text {rod }} \times h_{\text {rod }}, R_{\text {disk }} \times h_{0}, R_{\text {sub }} \times h_{\text {sub }}$ and $R_{\text {table }} \times$ $h_{\text {table, }}$ respectively (see the corresponding values in $(b)$ ). The parameters $v_{f}$ and $\Omega$ are the supply rate in $[\mathrm{mm} / \mathrm{min}]$ of the clad material and the tool rotation rate in $[\mathrm{rpm}]$, respectively. The heat transfer coefficient of $10 \mathrm{~W} /\left(\mathrm{m}^{2} \mathrm{~K}\right)$ or $200 \mathrm{~W} /\left(\mathrm{m}^{2} \mathrm{~K}\right)$ at the model boundaries are indicated by the line types. All remaining surfaces are isolated.

the magnitude of the tangential flow drops linearly from $v_{f}$ to 0 with the arc length of the fillet to prevent unrealistic sudden velocity changes. Despite the relative motion of the clad material and the FSC tool at the fillet interface, any frictional heat generation is neglected. The clad material contacting the horizontal portion of the tool bottom rotates at the same rate as the tool ( $\theta$ direction) but without radial slip ( $r$ direction), i.e. $\left(u_{r}, u_{\theta}, u_{z}\right)=(0, r \omega, 0)$. Further, at the interface between the clad material and the substrate, full sticking is assumed for all components of the clad material velocity at the interface assuming the materials are firmly bonded. Finally, due to these imposed boundary conditions, viscous dissipation, $Q_{v h}$, produced by the creeping clad material under shearing and compression, is the only heat source in the model. Under other contact conditions, both viscous and frictional heat will contribute to the total heat generated.

The thermal boundary conditions of the model consist of contacting interfaces between the tool, the clad material, the substrate and the backing table and of all surfaces exposed to the ambient environment. Both the heat conduction within parts of the setup and the convective heat transfer to the surroundings are considered, see Fig. 4.1. For the surfaces of the upper part of the FSC tool that are in contact with the tool holder, a heat transfer coefficient of $200 \mathrm{~W} /\left(\mathrm{m}^{2} \mathrm{~K}\right)$ is used, comparable to the value used by Dickerson et al. (2003) for non-ideal thermal 
contact of tool holders in FSW. The heat transfer to the ambient environment from the FSC tool, the side surface of the clad material and the top surface of the substrate is modeled employing a (generally used) heat transfer coefficient of $10 \mathrm{~W} /\left(\mathrm{m}^{2} \mathrm{~K}\right)$, as mentioned by Lohwasser and Chen (2010) for example. Perfect thermal contact, without thermal resistance, is assumed to occur between the FSC tool and the substrate due to the anticipated large pressure present at this interface. The same holds for the interface between the clad material and the substrate. For the interface between the substrate and the backing table perfect thermal contact is only assumed beneath and in the vicinity of the FSC tool axis where large normal forces are present, in line with the modeled ideal thermal contact region in Chapter 2. A smaller heat transfer coefficient of $200 \mathrm{~W} /\left(\mathrm{m}^{2} \mathrm{~K}\right)$, as used by Jain et al. (2014) and Hamilton et al. (2008) in FSW, is applied to the substrate bottom further away from the tool axis taking the same reasoning as explained in Chapter 2. All remaining surfaces are isolated. The general thermal properties of each component included in the model remain the same as those used in the 3D thermal model described in Chapter 2, see Table 2.2 in Chapter 2. The CFD simulations of the thermomechanical model are performed for a more or less arbitrarily chosen duration of the cladding phase of $30 \mathrm{~s}$. It is assumed that the FSC tool is completely filled with clad material at the start of the cladding phase. At that moment all parts of the model have a temperature equal to the ambient temperature. The influence of the clad phase duration on the simulation results will further be discussed in Section 4.3.2.

\subsubsection{Constitutive equations of the clad material and governing equations}

The constitutive equation describing the material behavior of the AA1050 clad material is based on the experimental data from Prasad and Sasidhara (1997). The experimental data is extended to wider strain rates and temperature ranges in this thesis. The clad material is assumed incompressible. The flow stress-strain rate constitutive law of the clad material is developed as a Zener-Hollomon based equation,

$$
\sigma_{f}=\left(\sigma_{0}+k_{0} \ln \frac{\dot{\epsilon}+\dot{\epsilon}_{0}}{\dot{\epsilon}_{0}}\right) \cdot \exp \left(k_{1} \frac{T_{m}-T}{T_{m}-T_{r}}\right) \cdot \sinh ^{-1}\left(\left(\frac{Z}{A_{1}}\right)^{k_{2}}\right),
$$

with

$$
Z=\dot{\epsilon} \exp \left(\frac{Q_{0}}{R_{g} T}\right)
$$

The temperature dependence $(T)$ of the flow stress of the clad material, $\sigma_{f}$, is considered both in Eq. (4.1) and Eq. (4.2). The symbols $Q_{0}$ and $R_{g}$ represent the activation energy and the gas constant, respectively; $\sigma_{0}$ is the flow stress at the initial strain rate of the clad material, $\dot{\epsilon}_{0}$, which is set to $\dot{\epsilon}_{0}=0.1 \mathrm{~s}^{-1}$ to avoid an infinite flow stress at $\dot{\epsilon}_{0}=0$. The melting temperature of the clad material is $T_{m}$ and 
$T_{r}$ is the ambient temperature. Here, $A_{1}, k_{0}, k_{1}$ and $k_{2}$ are fitting constants. The values of the other variables and constants are listed in Table 4.1 .

Table 4.1 The values of the relevant variables and constants in Eq. (4.1) and Eq. (4.2).

\begin{tabular}{c|c|c|c|c|c|c|c}
\hline $\begin{array}{c}\sigma_{0} \\
{[\mathrm{MPa}]}\end{array}$ & $\begin{array}{c}k_{0} \\
{[\mathrm{MPa}]}\end{array}$ & $k_{1}$ & $\begin{array}{c}Q_{0} \\
{[\mathrm{~kJ} / \mathrm{mol}]}\end{array}$ & $\begin{array}{c}A_{1} \\
{\left[\mathrm{~s}^{-1}\right]}\end{array}$ & $k_{2}$ & $\begin{array}{c}T_{m} \\
{\left[{ }^{\circ} \mathrm{C}\right]}\end{array}$ & $\begin{array}{c}T_{r} \\
{\left[{ }^{\circ} \mathrm{C}\right]}\end{array}$ \\
\hline 17.0 & 0.11 & 2.1 & 156 & $3.02 \cdot 10^{10}$ & 0.15 & 646 & 15 \\
\hline
\end{tabular}

The set of Zener-Hollomon based stress-strain curves of the clad material is shown for various temperatures by the solid lines in Fig. 4.2 and forms a rather good approximation of the experimental data.

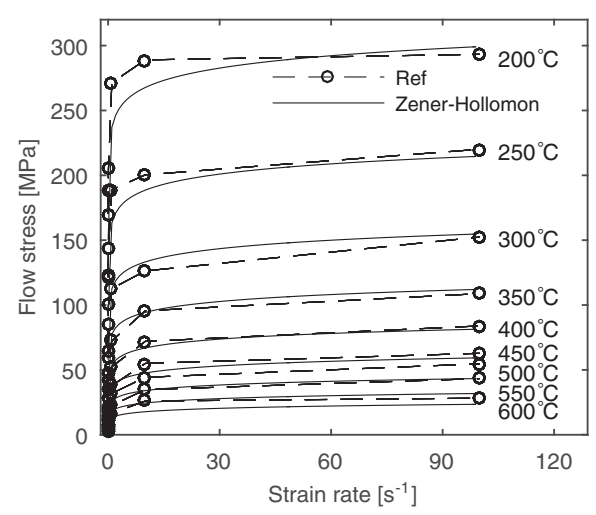

Fig. 4.2 The strain rate and temperature dependent flow stress of commercially pure aluminum AA1050. The dashed curves with markers represent the experimental data from Prasad and Sasidhara (1997); set of solid lines represent the Zener-Hollomon based stress from Eq. (4.1). The experimental data with strain rate being higher than $100 \mathrm{~s}^{-1}$ is unavailable.

The melting point of the AA2024-T351 substrate material is not considered in this model. This may, however, control the highest temperature in reality because it has a lower melting point than the clad material.

\subsection{Results and discussion}

\subsubsection{Example study}

With the axisymmetric thermo-mechanical model the temperature, the velocity and the pressure fields for the case of $h_{0}=0.2 \mathrm{~mm}, W=16.8 \mathrm{~mm}, \Omega=300 \mathrm{rpm}$ and $D_{\text {rod }}=10 \mathrm{~mm}$, corresponding to the experimental conditions of experiment EH-02 are calculated (see Figs. 4.3, 4.4 and 4.5). The temperature field of this example is shown in Fig. 4.3. The highest temperature of approximately $408^{\circ} \mathrm{C}$ occurs in the clad disk near the FSC tool bottom, see Fig. 4.3(c). The difference between the 
maximum and the minimum temperatures in the $0.2 \mathrm{~mm}$ thick clad layer is around $30{ }^{\circ} \mathrm{C}$ in this case, which is comparably small as for the example shown in Fig. 2.15 in Chapter 2 which applied to the same case. The tool temperature in this example rises quickly at first, but then levels off, see Fig. 4.4. At higher tool temperatures apparently the heat generation rate becomes smaller and more and more equal to the rate at which heat is lost through heat transfer to the FSC tool, the substrate, the backing table and the environment. Hence, only a small tool temperature increase over time remains.

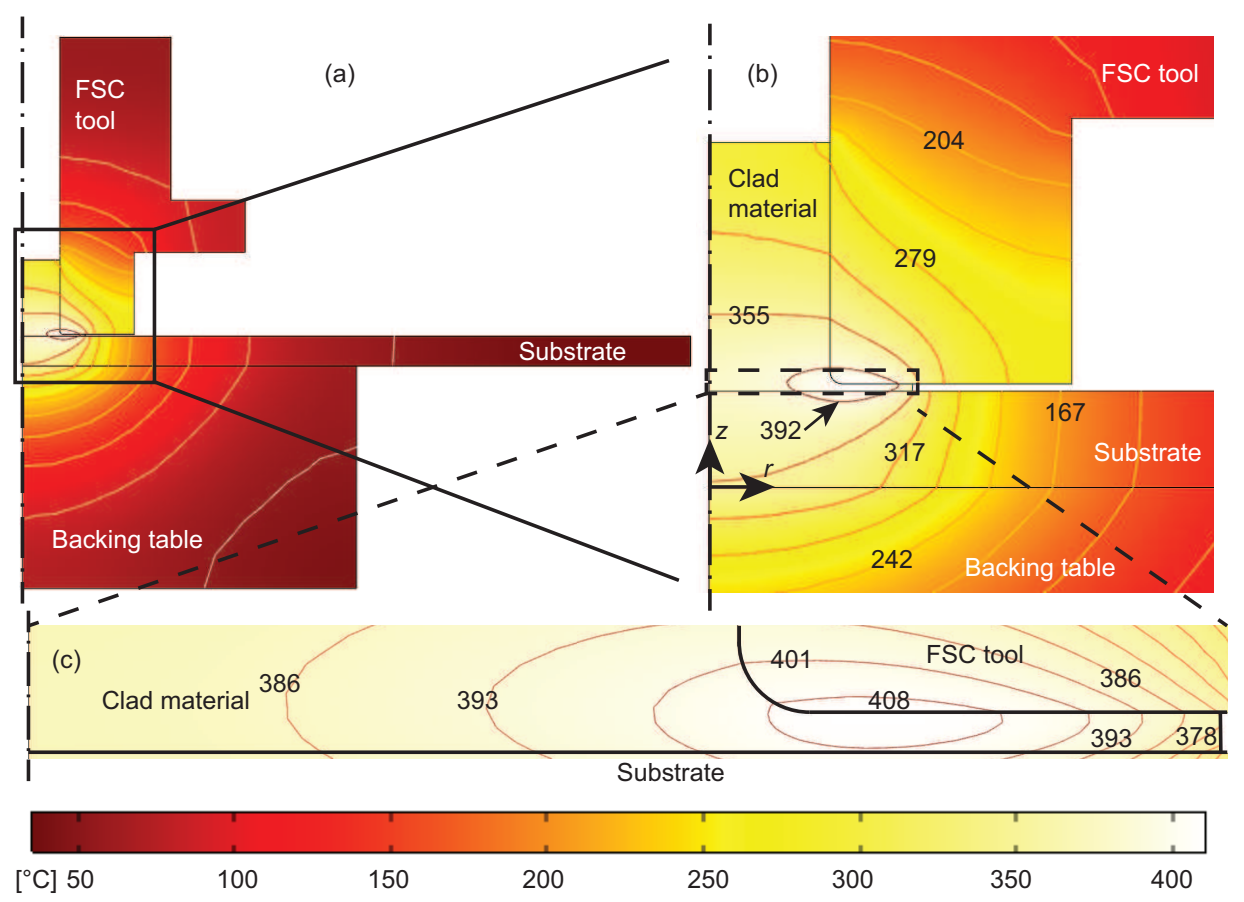

Fig. 4.3 Temperature distribution at time $=30 \mathrm{~s}$ for the case of $\Omega=300 \mathrm{rpm}, h_{0}=0.2 \mathrm{~mm}, W=16.8 \mathrm{~mm}$ and $D_{\text {rod }}=10 \mathrm{~mm}$.

The velocity magnitudes of the $r$ and $z$ components of the clad material at time $=$ $30 \mathrm{~s}$ for the calculated example are shown in Figs. 4.5(a) and (A). The value of the circumferential speed component $\left(u_{\theta}\right)$ is excluded here. In this way the velocity distribution in the vertical $(z)$ and radial $(r)$ direction can be better studied. The vertical velocity $\left(u_{z}\right)$ drops dramatically after the clad material enters the clad disk domain. Hence, the radial velocity $\left(u_{r}\right)$ dominates the flow pattern in this domain and it decreases with the radial distance from the tool axis. The speed distribution within this domain is approximately symmetric about the mid plane of the clad layer in thickness. This is in line with the full sticking boundary conditions at the top and bottom interfaces of the clad layer within this domain and is also related to the pressure distribution which is approximately constant over height within this 


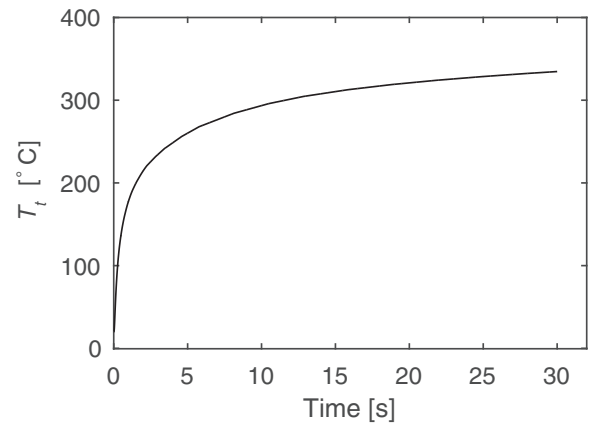

(a)

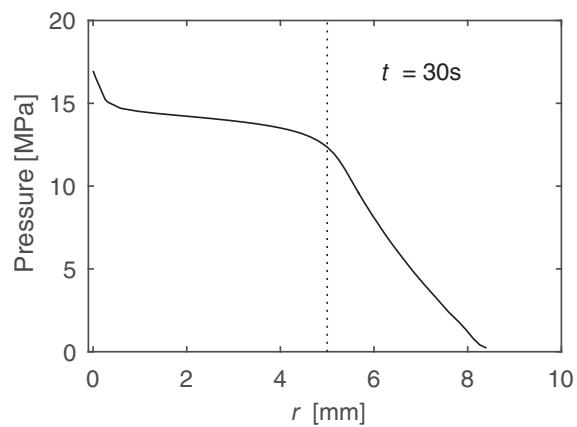

(b)

Fig. 4.4 Tool temperature over time (a) and radial distribution of pressure exerted at the substrate beneath the FSC tool at time $=30 \mathrm{~s}(b)\left(\Omega=300 \mathrm{rpm}, h_{0}=0.2 \mathrm{~mm}, W=16.8 \mathrm{~mm}\right.$ and $\left.D_{\text {rod }}=10 \mathrm{~mm}\right)$.

(a) Velocity $\left(u_{r}, u_{z}\right)$
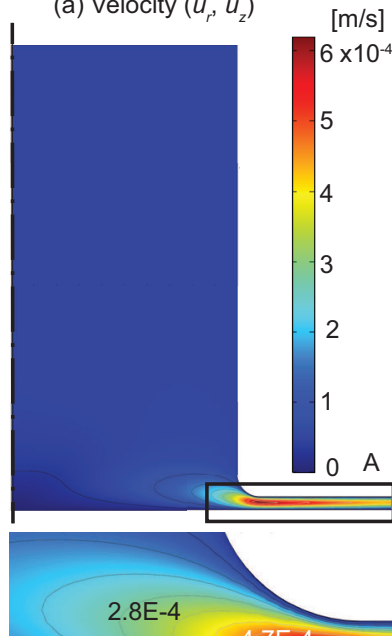

(b) Shear rate $\dot{\gamma}$

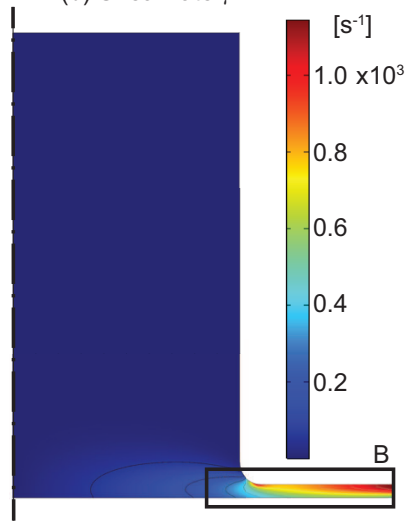

(A) Velocity $\left(u_{r}, u_{z}\right)$ (c) Pressure

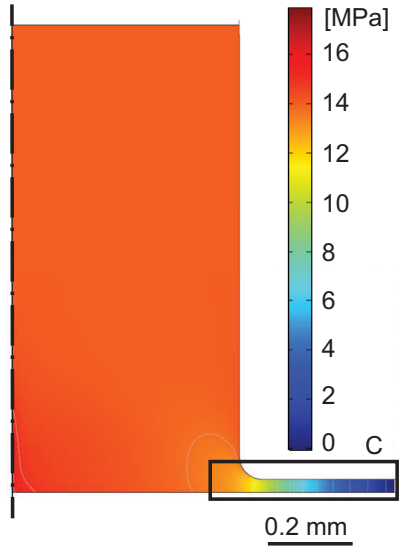

$[\mathrm{m} / \mathrm{s}]$

\section{$4.7 E-4 \quad 5.9 E-4 \quad 5.3 E-4$}

4.0E-4

$3.4 \mathrm{E}-4$

$2.2 \mathrm{E}-4$

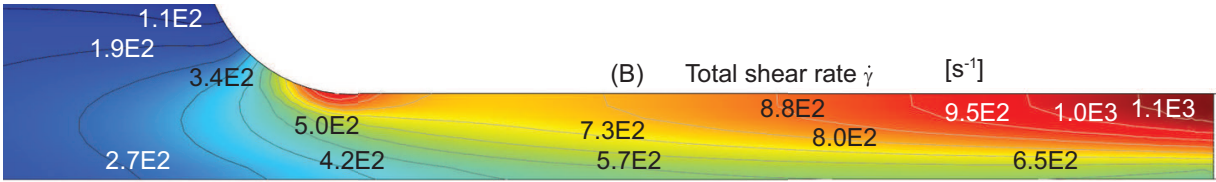

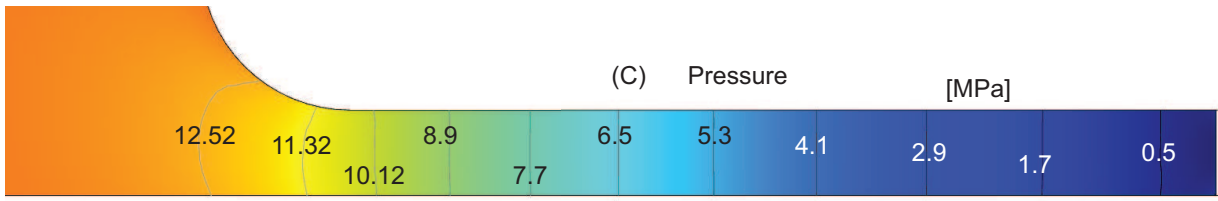

Fig. 4.5 The magnitude of the radial and vertical velocity ( $r$ and $z$ components), the total shear rate and the pressure distributions in the clad material at time $=30 \mathrm{~s}\left(\Omega=300 \mathrm{rpm}, h_{0}=0.2 \mathrm{~mm}, W=16.8 \mathrm{~mm}\right.$ and $\left.D_{\text {rod }}=10 \mathrm{~mm}\right)$. This shear rate is out of the region of the experimental data available for flow stress. 
region (see Fig. 4.4(b)).

The total shear rate of the clad material is shown in Figs. 4.5(b) and (B). The shear rate increases both in radial direction and, especially in the narrow space between the tool and the substrate, also in axial direction in line with the boundary conditions imposed. The maximum value observed is over $1000 \mathrm{~s}^{-1}$, which is significantly higher than the values found experimentally in FSW by Nandan et al. (2008).

Figs. 4.5(c) and (C) show the pressure distribution and contours in the clad material at time $=30 \mathrm{~s}$. In the clad disk domain the pressure distribution seems independent of the $z$ direction. The clad rod witnesses a high and nearly identical pressure within the central tool opening. The highest pressure calculated by this model occurs near the tool axis where the material experiences a high viscosity not only due to low strain rates, see Figs. 4.5(b) and (B), but also due to the pressure buildup in the relatively small opening between the substrate and the clad layer. The calculated pressure in the clad disk domain at the interface with the substrate drops approximately linearly with the radius to zero at the outlet opening of the model.

\subsubsection{Parameter study with the model}

In this subsection the trends of the heat generation and the normal force as a function of the FSC process variables calculated by the model are first observed and compared with the experimental observations in a qualitative sense. A quantitative comparison between the modeling and experimental results is made at the end of this subsection.

The influence of the main process variables of the FSC process including the tool rotation rate, the layer dimensions and the diameter of the tool openings is studied with the axisymmetric thermo-mechanical model. In this way useful trends between the process parameters, the tool design and the generated heat and normal force may be obtained. The viscous dissipation and the normal force are calculated for various cases. The model also enables a straightforward view of the thermal distributions in all of the involved components and also at the clad layersubstrate interface (i.e. bonding interface), where the temperature cannot currently be measured experimentally. The viscous heat $\left(Q_{F E M}\right)$, the normal force $\left(F_{n-F E M}\right)$ and the temperatures in each simulation case are studied as a function of one single process parameter, and the results are shown in Fig. 4.6. The symbols $T C_{3-F E M}$ and $T_{\text {in }}$ represent the peak temperatures at the mid plane of the substrate and that at the bonding interface, respectively. Apart from the data points shown in Fig. 4.6, a large number of other cases have been calculated as well to support the study, see Appendix 4.A.

The viscous dissipation increases approximately linearly with the tool rotation rate when the layer dimensions and the cladding tool remain constant, as visible in Fig. 4.6(a). This behavior is in line with the heat generation equation derived by Schmidt et al. (2004) for FSW. The temperatures in the substrate and at the clad 


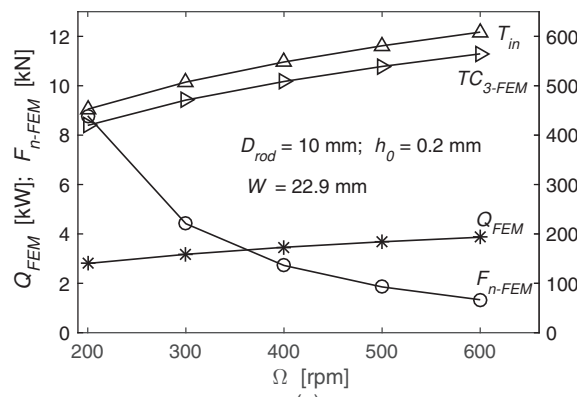

(a)

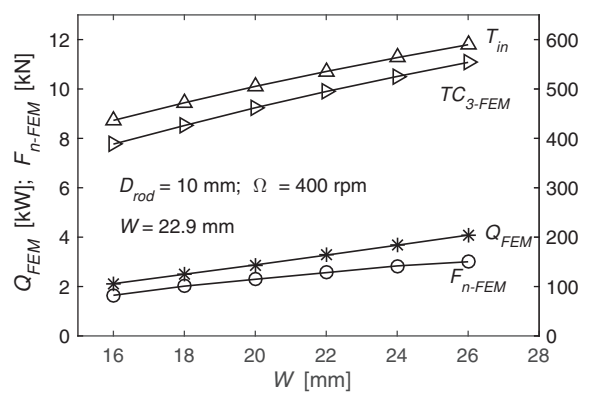

(c)

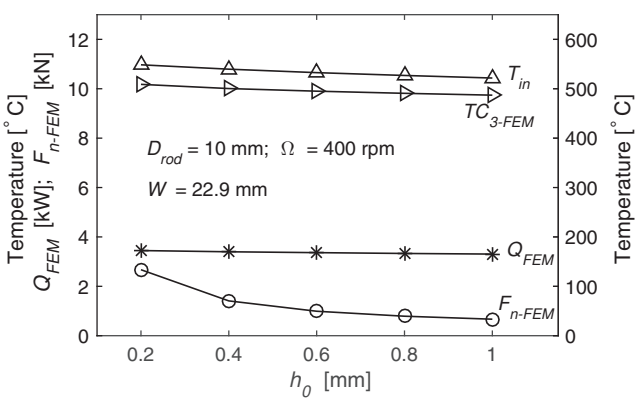

(b)

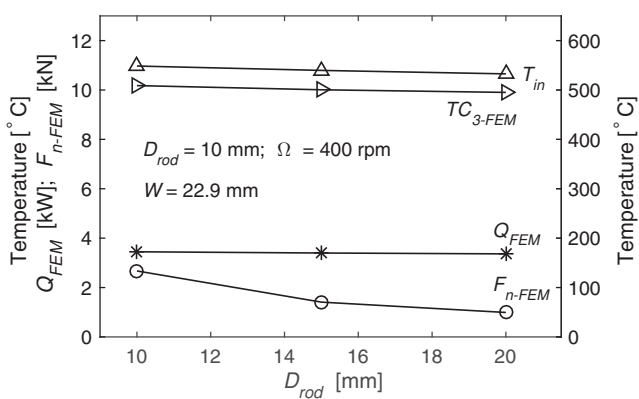

(d)

Fig. 4.6 Influence of the FSC parameters (a) the tool rotation rate $\Omega$, (b) the nominal layer thickness $h_{0}$, (c) the layer width $W$ and $(d)$ the tool opening diameter $D_{\text {rod }}$ on the heat generation $Q_{F E M}$, the normal force $\left(F_{n-F E M}\right)$, the peak temperature at the cladding interface $T_{i n}$ and the peak temperature at the mid plane of the substrate $T_{3}-F E M$ calculated by FEM using the clad material properties in Eq. (4.1).

layer-substrate interface follow roughly the trend of the heat generation. The ENh0.2 series of experiments shows similar behavior between the fitted heat input and the measured temperatures and the tool rotation rates for each substrate configuration, see Fig. 2.14 in Chapter 2. However, for the EN-h0.4 series of experiments, the substrate temperature does not rise linearly with the tool rotation rate at a nominal layer thickness of $0.4 \mathrm{~mm}$, see Fig. 3.3 in Chapter 3. The layer width produced in this series varies from experiment to experiment, which may explain the absence of a clear trend as a function of tool rotation rate. Apparently, the influence of the layer width on the heat generation is important too.

In Fig. 4.6(a) it can also be observed that the normal force exerted on the substrate decreases with higher tool rotation rates. This behavior is also visible to a certain extent in both the EN-h0.2 and EN-h0.4 series of experiments when no mixing between the clad material and the substrate takes place, see Fig. 2.9 in Chapter 2 and Fig. 3.3 in Chapter 3. At relatively low tool rotation rates heat generation is relatively small yielding relatively low temperatures and thereby a high flow stress of the clad material. This requires a larger force to deform the clad material and to deposit the clad material on the substrate beneath the FSC tool. When the clad material is softened more at higher temperatures due to the higher rotation rates, 
the normal force becomes accordingly smaller and the deposition becomes easier.

The influence of the layer thickness on the FEM calculated viscous heat and temperatures in the tool and the substrate is very small according to Fig. 4.6(b), whereas the simulated normal force decreases with the layer thickness. The measured temperature profiles, normal forces and pressures in the $\mathrm{EH}$ series of experiments mostly confirm these simulation results, see Fig. 3.8 in Chapter 3. The experimental normal force and average pressure exerted on the substrate also show a decreasing trend with the layer thickness, although the rotation rates in these experiments are adjusted to maintain a constant substrate temperature. In fact, the tool rotation rate was increased as a function of the layer thickness, but this is in line with the trend observed in Fig. 4.6(b), where the tool and substrate temperatures show a slightly decreasing trend as a function of layer thickness.

The influence of the layer width on the heat generation and the normal force is shown in Fig. 4.6(c). At larger layer widths more heat is generated as the temperature is seen to increase relatively strongly with increasing layer width. Despite the higher temperatures and associated decrease in the flow stress of the clad material, the normal force also increases with the layer width. The clad material needs to be transported over a larger distance from the central tool opening towards the edge of the FSC tool, explaining this behavior. The strong influence of the layer width is also observed clearly in the EW experiment, see Fig. 3.12 in Chapter 3, where the tool temperature and normal force increase in line with concomitant changes of the clad layer width. Its influence also became apparent in the EN-h0.4 series of experiments where the substrate and tool temperatures even decreased as a function of tool rotation rate due to relatively small changes in the layer width, see Fig. 3.3. The same holds for the EN-h0.2 series discussed in Chapter 2. Here, the influence of the tool rotation rate on the heat generation seems to be strong, but in fact the layer width also shows a relatively strong increase for this series.

The simulation results displayed in Fig. 4.6(d) show that the increasing opening size of the tool has no effect on the viscous heat generation but decreases the normal force significantly. The corresponding experiments, ED series of experiments, cannot confirm directly the relation between the measured temperature and the opening diameter. The layer widths produced with larger openings are generally larger than those with smaller openings due to the amount of the clad material supplied. This may dominate the profiles of the temperature registered, according to Fig. 4.6(c). The pressure profiles of the ED series of experiments confirm the relation between the simulated force and the diameter of the tool opening, see also Fig. 3.15.

In short, the tool and substrate temperatures measured in the experiments described in Chapters 2 and 3 show trends as a function of the process variables and FSC tool design comparable to those obtained from the axisymmetric thermo-mechanical model. This also holds for the experimentally measured and simulated normal forces. Hence, in a qualitative sense the simulations are in agreement with the experiments.

However, the actual values of the tool temperature, substrate temperature and 
normal force measured experimentally do not compare in a quantitative sense to the respective ones calculated by the model. Compare, for example, the temperature distribution calculated in the FSC tool, the clad material, the substrate and the backing table visible in Fig. 2.15 with the temperature distribution in Fig. 4.3. The temperature in the latter case is much higher for all parts of the FSC setup. The origin of the difference does not lie only in the more or less arbitrarily duration of the simulation of $30 \mathrm{~s}$, see Section 4.2.2. Even if the duration had been optimized towards, for example, an identical average temperature in the clad layer for the experiment and the simulation, significant differences in heat generation would still have been revealed. If the simulation of this case is repeated for a simulation duration of $200 \mathrm{~s}$, using the same clad layer dimensions, tool rotation rates and tool opening dimension, Fig. 4.7 is obtained. The simulated viscous heat, $Q_{F E M}$, is always larger than the experimental heat input, $Q_{\text {exp }}$, which is estimated using the $3 \mathrm{D}$ thermal model in Chapter 2, regardless of the substrate temperature, $T C_{3-F E M}$. And when $Q_{F E M}$ is close to $Q_{\exp }$, the simulated temperature becomes too high, see Fig. 4.7(a). At the same time the simulated normal force, $F_{n-F E M}$, is too small in comparison with the experimental value, $F_{n-\exp }$, as visible in Fig. 4.7(b). These deviations hold for all experimental cases. It can be concluded that in a qualitative sense the thermo-mechanical model predicts the trends as a function of process variables and tool opening dimensions rather well. However, the model fails to predict accurately the behavior in a quantitative sense regardless of the simulation duration selected.

One possible explanation for the discrepancy between the experimental and simulation results is the type of boundary condition chosen at the interface between the FSC tool and the clad material in the clad disk domain. Here, a full sticking condition has been assumed (see Section 4.2.2), such that the clad material rotates at the same rate as the FSC tool. It leads to very high strain rates near the outer edge of the FSC tool (see Section 4.3.1). However, from this figure it is clear that the pressure is also strongly reducing towards the outer edge of the tool and some degree of slip of the tool with respect to the clad material is more likely to occur under these conditions. Effectively, this will reduce the heat generated and as such the average temperature in the clad layer. In turn, it will also increase the normal force exerted on the substrate as the effective viscosity of the clad material is increased at lower temperatures. The role of slip is further studied in Chapter 5.

\subsubsection{Ratios of the heat generations and the normal forces and COF}

The comparison made in the previous section showed that the simulated results deviate from the experimental values. This section will compare all experiments (the EN-h0.2 series of experiments described in Chapter 2 and the EN-h0.4 series, the EH series and the ED series in Chapter 3) with their corresponding simulation cases to quantify the deviation. The EW experiment described in Chapter 3 is not used here as the heat generated is difficult to obtain under the changing 


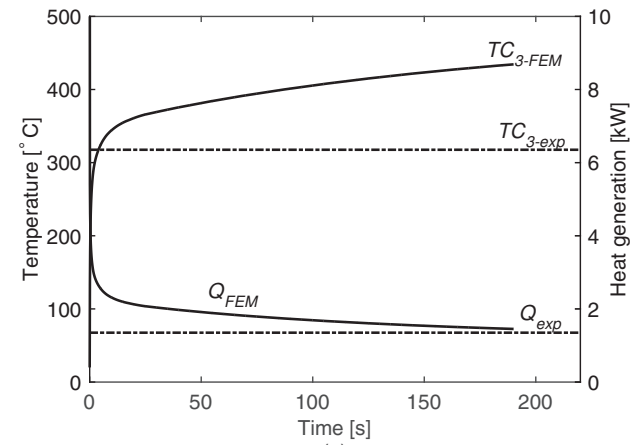

(a)

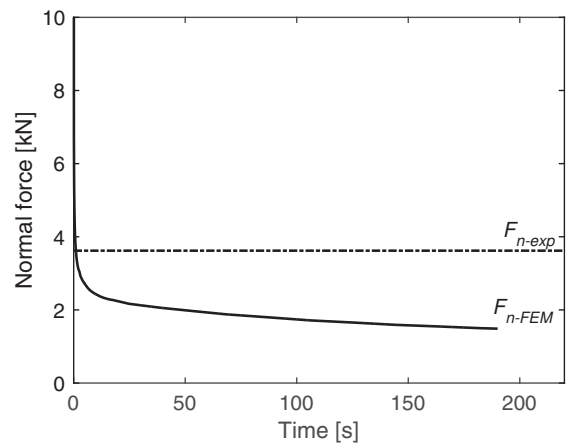

(b)

Fig. 4.7 The heat generation estimated based on the measured temperature $\left(Q_{\text {exp }}\right)$, the normal force measured $\left(F_{n-\text { exp }}\right)$ and the temperature registered in the substrate $\left(T C_{3-e x p}\right)$ compared with the values $\left(Q_{F E M}, F_{n-F E M}\right.$ and $\left.T C_{3-F E M}\right)$ calculated with the axisymmetric thermo-mechanical model for the case of $\Omega=300 \mathrm{rpm}, h_{0}=0.2 \mathrm{~mm}, W=16.8 \mathrm{~mm}$ and $D_{\text {rod }}=10 \mathrm{~mm}$.

process conditions. In each simulation case the actual dimensions ( $W$ and $H$ ) of the deposited layer and the tool rotation rate employed during the experiment are used to calculate the heat generated and the force exerted on the substrate. The simulations run for $30 \mathrm{~s}$, as with all simulations carried out up to now. The symbols used in the following context have the same meaning as the ones shown in Fig. 4.7.

\section{Ratio of heat generation}

Fig. 4.8(a) shows the ratios of the experimentally estimated heat generations to the model calculated values, $\Delta_{Q}=Q_{\exp } / Q_{F E M}$. The ratios are approximately constant for all cases considered and their average value equals 0.66. The EN-h0.2 and ENh0.4 series of experiments confirm that the ratio is independent of the tool rotation rate, regardless of the nominal layer thickness. The diameter of the tool opening also has negligible influence on this ratio, as shown by the ED series. The EH series suggests a slightly decreasing trend of the ratio with the nominal layer thickness. However, the differences between the ratios in this series are very small.

The value of $\Delta_{Q}$ obtained in this work is very comparable with the sticking factor of 0.65 used by Atharifar et al. (2009) in their CFD simulation for FSW of AA6061. However, the value of $\Delta_{Q}$ is also dependent on the duration time of the simulations. Therefore, a direct comparison of the sticking factor defined in this chapter with those presented in the literature is not valid. Apart from the type of interface condition (stick/slip), the value of $\Delta_{Q}$ depends also on other variables such as the shape of the contact area, the tool design, the inclination angle of the tool, etc. Furthermore, the actual sticking factor in FSC may not have the same value as those typically found for FSW. Its value will be one of the topics in Chapter 5. 


\section{Ratio of normal force}

The ratios of the measured normal forces $F_{n-\exp }$ to the values calculated by the axisymmetric thermo-mechanical model, $F_{n-F E M}, \Delta_{F_{n}}$, show more scatter than $\Delta_{Q}$, see Fig. 4.8(b). The values of $\Delta_{F_{n}}$ are different in each series of experiments, see Fig. 4.8(b). The EH and EN-h0.2 series of experiments show a large scatter of $\Delta_{F_{n}}$. However, the experiments performed with relatively low tool rotation rates in the EN-h0.2 series, for which mixing of the clad material with the substrate material does not occur, and the ED series of experiments show a value of approximately 2 . A value of approximately 3 is observed for the EN-h0.4 series.

For the calculation of the $\Delta_{F_{n}}$ the actual value of the layer thickness is required to compute $F_{n-F E M}$. It is difficult to determine its value accurately. Not only is it difficult to set its value before the start of an FSC experiment (see Chapter 2), it is also challenging to determine a correct value as, due to the small inclination angle of the FSC tool, the post clad layer thickness is not completely constant over the cross section. Also, the top surface of the deposited layer is not always perfectly flat, causing errors in the layer thickness determination depending on the fortuitously selected location of the cross section. Furthermore, the normal force is also seen to be more sensitive to small variations in the actual value of the layer thickness than the heat generation is, as visible in Fig. 4.6(b). Hence, the determination of $\Delta_{F_{n}}$ is inherently associated with more scatter than $\Delta_{Q}$. This becomes even more clear when mixing occurs (see last three data points of $\Delta_{F_{n}}$ in the EN-h0.2 series of experiments). Given this relatively high sensitivity to the layer thickness, the EN-h0.4 series of experiments has been performed, aimed at lowering the relative difference between the nominal layer thickness and the actual value after the cladding experiments. The advantage of this approach is visible by the approximately uniform value of $\Delta_{F_{n}}$ for this series. In the case of the EH series of experiments relatively large deviations are observed that cannot be explained by the occurrence of mixing.

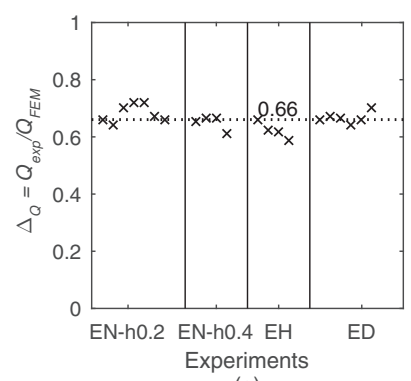

(a)

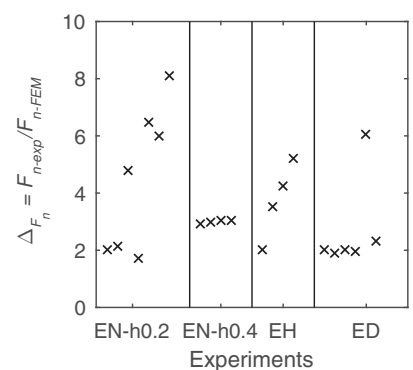

(b)

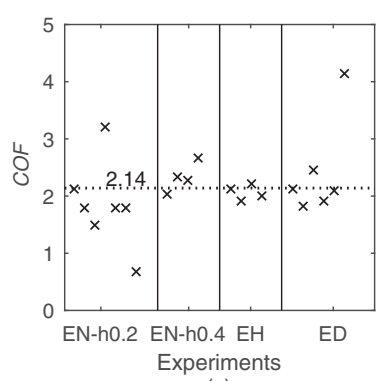

(c)

Fig. 4.8 (a) The ratio of $Q_{\exp }$ to $Q_{F E M}, \Delta_{Q}=Q_{\exp } / Q_{F E M}$; (b)the ratio of $F_{n-\exp }$ to $F_{n-F E M}, \Delta_{F_{n}}=$ $F_{n-\exp } / F_{n-F E M}$; and $(c)$ the coefficient of friction, COF, calculated for all experiments listed in Table 2.1 in Chapter 2 and Table 3.1 except experiment EW in Chapter 3.

Nevertheless, the axisymmetric heat generation model, based on plastic dissipation 
within a creeping flow, is applicable to a broad range of FSC process conditions and tool opening diameters. The model provides a good qualitative understanding of the relation between the process parameters, the dissipated heat and the normal force exerted on the substrate surface.

\section{Coefficient of friction}

The maximum shear rate obtained in the modeling results (see for example Fig. 4.5) is more than $1000 \mathrm{~s}^{-1}$ and occurs near the outer edge of the clad disk. This is much higher than values found for FSW which is mainly attributed to the full sticking condition employed in the model. It is more likely that some degree of slipping occurs at the tool-clad layer interface, suggesting that friction occurs at the FSC tool-clad material interface. The effective value of an average coefficient of friction $(\mathrm{COF})$ is determined utilizing the heat generation, as estimated by the approach in Chapter 2, and other experimental data only. The values are independent of the modeling approach developed in this chapter. It is assumed that all power provided by the electrical engine driving the FSC tool is transferred into heat, as described in Chapter 2, and the FSC tool can be represented by a solid cylinder with a flat bottom. The average coefficient of friction can be estimated with the experimental heat generation,

$$
Q_{\exp }=\omega M,
$$

where $\omega$ is the angular speed of the tool, $\omega=2 \pi \Omega / 60$, and $M$ is the applied torque, $M=\int_{0}^{W / 2} \tau_{\text {eff }} 2 \pi r^{2} d r=\frac{\pi}{12} \tau_{\text {eff }} W^{3}$. Here, the shear stress $\tau_{\text {eff }}$ at the tool-clad material interface is an effective, average value. When slipping occurs, the shear stress is related to the normal pressure according to

$$
\tau_{e f f}=C O F \cdot P_{s}
$$

Combining Eqs. (4.3) and (4.4) yields the following expression for the COF

$$
C O F=\frac{90 Q_{\exp }}{\pi \Omega F_{n} W}
$$

The values of COF for all experiments being analyzed in this chapter are shown in Fig. 4.8(c). The values are mainly in the range of $1.5-2.6$, with an average value of 2.1. This value is slightly larger than 1.75 found by Wang et al. (2009) during the ball-on-disk test of AA7475 with $\mathrm{H} 11$ tool steel ball at the temperature of $350{ }^{\circ} \mathrm{C}-500^{\circ} \mathrm{C}$. It is also larger than the value of 1.4 observed by Kumar et al. (2009) at a temperature higher than $200^{\circ} \mathrm{C}-250{ }^{\circ} \mathrm{C}$ in FSW of high strength aluminum employing a die steel tool. However, the values are comparable to those found by Widerøe and Welo (2012) in hot deformation of AA6060 on tool steel at temperatures between $300^{\circ} \mathrm{C}$ and $450^{\circ} \mathrm{C}$.

The larger COF obtained in this work might be related to the seizure behavior, as discussed by Reddy et al. (1995). The clad material employed here is much softer 
than the high strength aluminum, which could make the seizure more severe. The resistance of shear reduces with the hardness, and thus the clad material can be more easily deformed and move with the tool. In this case, the contact status may change from full slipping to partial slipping (or sticking). This can be observed from some clad material being stuck on the tool bottom after the cladding experiments. When the process temperature is higher, the shear strength and the hardness of the clad material reduces, this may cause further seizure and thereby a higher sticking fraction and a larger COF.

The value of the COF may also differ from the contact position at the clad materialtool interface. Figs. 4.5(c) and 4.5(C) show that the pressure decreases with the distance from the tool axis. The high pressure leads to larger shear stress and thereby a more severe seizure. This may make the COF at the locations closer to the tool opening larger than the average value of 2.1. However, more slipping occurs under lower pressure. Therefore, the value of the COF may be smaller near the FSC tool edge.

The COF at the substrate-clad material interface is not calculated here. However, Van der Stelt (2014) observed values of 1 - 4 in bonding strength tests of AA1050 and AA2024 at process temperatures of $150^{\circ} \mathrm{C}-350^{\circ} \mathrm{C}$. These values are higher than those between the pure aluminum (clad material) and the tool steel. This is also apparent from the observation that a bond is obtained at the clad materialsubstrate interface and not at the tool-clad material interface.

\subsection{Conclusions}

In this chapter a thermo-mechanical FSC process model is introduced to study the heat generation during FSC and the influence of the process parameters and tool opening diameter on the FSC process. The model is applied to the deposition of commercially pure AA1050 clad material onto an AA2024-T351 substrate. The constitutive law of the clad material is described by a Zener-Hollomon based equation which includes the temperature and strain rate dependence of the flow stress.

The model results show that the tool rotation rate and the layer width raise the calculated heat nearly linearly due to the temperature dependence and the shear thinning behavior of the clad material. The diameter of the tool opening and the layer thickness have a negligible effect on the heat generation. The normal force calculated by the model decreases with the tool rotation rate, with the layer thickness and with the tool opening, whereas it increases with the layer width.

The calculated trends are to a large extent confirmed by experimental observations showing that the developed model is capable of predicting in a qualitative sense the relevant relations between the process variables, the tool opening diameter, the generated heat and the normal force. In fact, the ratio of the experimentally estimated heat generation to the model calculated one is observed as constant for 
all experiments performed. Such a ratio calculated for the normal force exerted on the substrate is less uniform, which is ascribed, amongst others, to the relatively large sensitivity of the normal force calculation to small changes in the clad layer dimensions and the occurrence of mixing under certain conditions.

A quantitative comparison of the model results shows that the model overestimates the generated heat that is necessary to explain the measured temperatures in the FSC tool and the substrate. It underestimates the measured normal force exerted on the substrate surface beneath the FSC tool regardless of the thermal boundary conditions used. A possible cause for these deviations is the contact condition at the FSC tool-clad material interface. The assumption of full sticking causes unrealistically high strain rates near the outer edge of the FSC tool, where, given the relatively low pressure exerted locally on the clad material, some degree of slip seems not unlikely. In such case the simulated heat generation and normal force exerted on the substrate would get closer to the experimental results. If some degree of slipping is assumed to occur, an average value of the apparent coefficient of friction of 2.1 is shown to reasonably describe the experimental results. This value is in accordance with the literature. 


\section{References}

Atharifar, H., Lin, D., and Kovacevic, R. (2009). Numerical and experimental investigations on the loads carried by the tool during friction stir welding. $J$. Mater. Eng. Perform., 18(4):339-350.

Colegrove, P. A. and Shercliff, H. R. (2005). 3-Dimensional CFD modelling of flow round a threaded friction stir welding tool profile. J. Mater. Process. Technol., 169(2):320-327.

Dickerson, T., Shi, Q.-Y., and Shercliff, H. R. (2003). Heat flow into friction stir welding tools. 4th Int. Symp. Frict. Stir Welding, USA, (May):11.

Hamilton, C., Dymek, S., and Sommers, a. (2008). A thermal model of friction stir welding in aluminum alloys. Int. J. Mach. Tools Manuf., 48(10):1120-1130.

Jain, R., Pal, S. K., and Singh, S. B. (2014). Finite Element Simulation of Temperature and Strain Distribution in A12024 Aluminum Alloy by Friction Stir Welding. In 5th Int. 26th All India Manuf. Technol. Des. Res. Conf. (AIMTDR 2014), pages 3-7.

Kumar, K., Kalyan, C., Kailas, S. V., and Srivatsan, T. S. (2009). An Investigation of Friction During Friction Stir Welding of Metallic Materials. Mater. Manuf. Process., 24(4):438-445.

Lohwasser, D. and Chen, Z. (2010). Friction Stir Welding: From Basics to Applications. Woodhead Publishing.

Nandan, R., DebRoy, T., and Bhadeshia, H. K. D. H. (2008). Recent advances in Friction-stir welding - Process, weldment structure and properties. Prog. Mater. Sci., 53(6):980-1023.

Prasad, Y. and Sasidhara, S. (1997). Hot Working Guide: A Compendium of Processing Maps. ASM International.

Reddy, A. S., Bai, B. N. P., and Biswas, S. K. (1995). Mechanism of seizure of aluminium-silicon against steel. Wear, 183.

Schmidt, H. and Hattel, J. (2005). Modelling heat flow around tool probe in friction stir welding. Sci. Technol. Weld. Join., 10:176-187.

Schmidt, H., Hattel, J., and Wert, J. (2004). An Analytical Model for the Heat Generation in Friction Stir Welding. Model. Simul. Mater. Sci. Eng., 12(1):143-157.

Van der Stelt, A. (2014). Friction surface cladding; development of a solid state cladding process. PhD thesis, University of Twente.

Wang, L., Cai, J., Zhou, J., and Duszczyk, J. (2009). Characteristics of the friction between aluminium and steel at elevated temperatures during ball-on-disc tests. Tribol. Lett., 36(2):183-190.

Widerøe, F. and Welo, T. (2012). Conditions for Sticking Friction between Aluminium Alloy AA6060 and Tool Steel in Hot Forming. Key Eng. Mater., 491:121-128. 


\section{A Application of the model}

The model can be used to analyze the trends for different process parameters. Fig. 4.A.1 shows the relations between the heat generation and the tool rotation rate for varying layer dimensions and $D_{\text {rod }}=10 \mathrm{~mm}$. Clear trends are observed for these data points. The normal forces of these data also present identical profiles, see Fig. 4.A.2. The natural logarithm scale of the forces and tool rotation rates provides linear relations. When the ratio of the layer width to the diameter of the tool opening, $W / D_{\text {rod }}$, is larger than approximately 1.1 , the lines of the natural logarithm of the normal forces fall on top. This may be, to some extent, related to the shear thinning behavior of the clad material. However, it also indicates that the model may not be able to handle the normal force with a high precision when the value of $W / D_{\text {rod }}$ is very close to 1 .

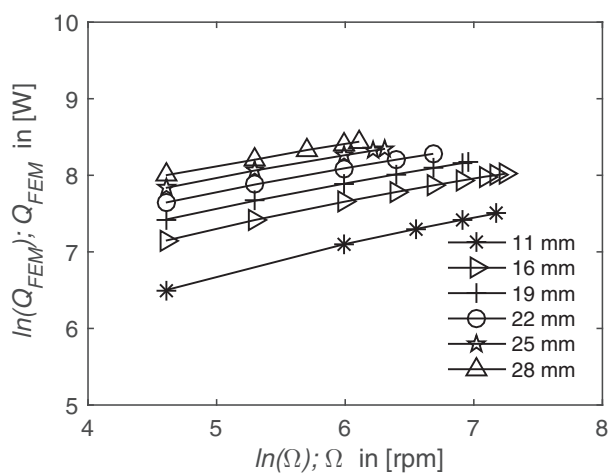

(a) $D_{\text {rod }}=10 \mathrm{~mm} ; h_{0}=0.2 \mathrm{~mm}$

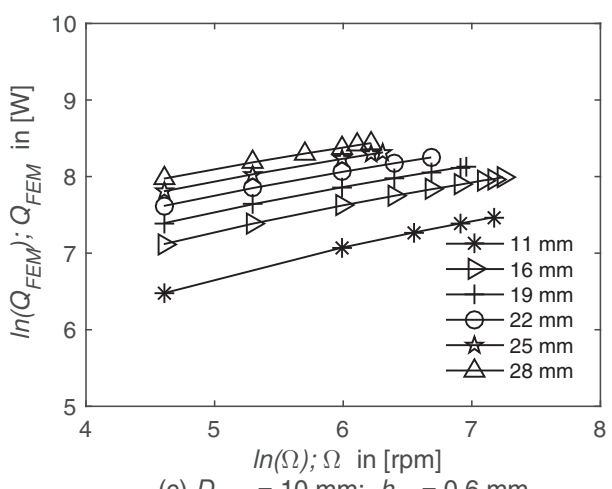

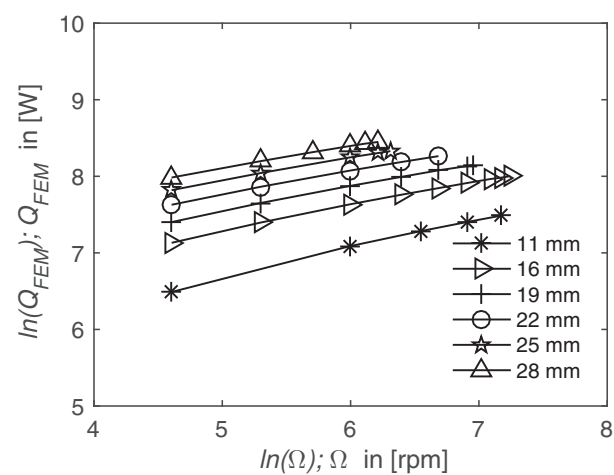

(b) $D_{\text {rod }}=10 \mathrm{~mm} ; h_{0}=0.4 \mathrm{~mm}$

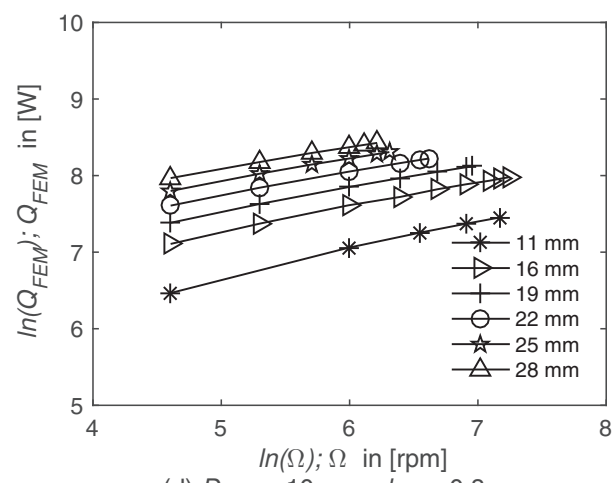

(d) $D_{\text {rod }}=10 \mathrm{~mm} ; h_{0}=0.8 \mathrm{~mm}$

Fig. 4.A.1 The heat generations calculated by the axisymmetric thermo-mechanical model for the $\varnothing 10$ tool with certain layer dimensions and tool rotation rates.

Based on these regular patterns observed above, the viscous dissipation and the normal forces of the process variables which are not calculated directly can be 
estimated by interpolation of these known data. The process window of the heat generation can also be established using these data, which will be discussed in Chapter 5. Other data points calculated for other tools $\left(D_{\text {rod }}=15 \mathrm{~mm}\right.$ and $\left.20 \mathrm{~mm}\right)$ are shown in Figs. 4.A.3 - 4.A.6. Similar trends are observed as those for $D_{\text {rod }}=$ $10 \mathrm{~mm}$.

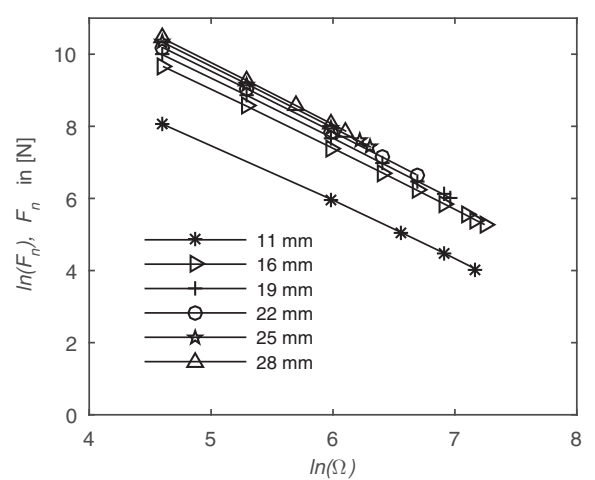

(a) $D_{\text {rod }}=10 \mathrm{~mm} ; h_{0}=0.2 \mathrm{~mm}$

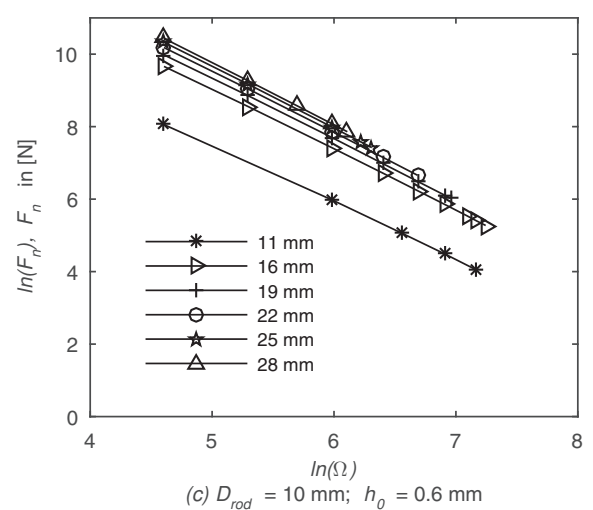

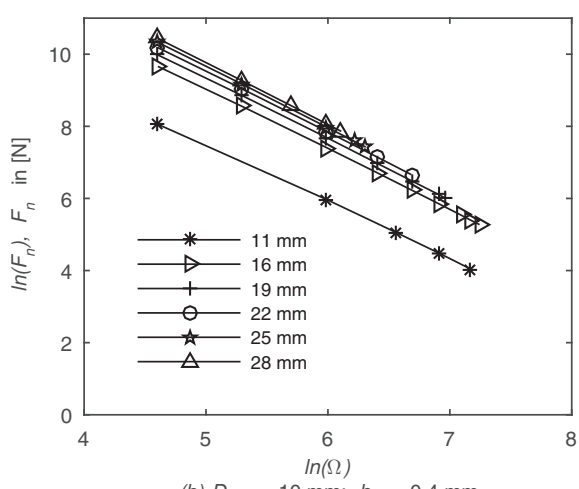

(b) $D_{\text {rod }}=10 \mathrm{~mm} ; h_{0}=0.4 \mathrm{~mm}$

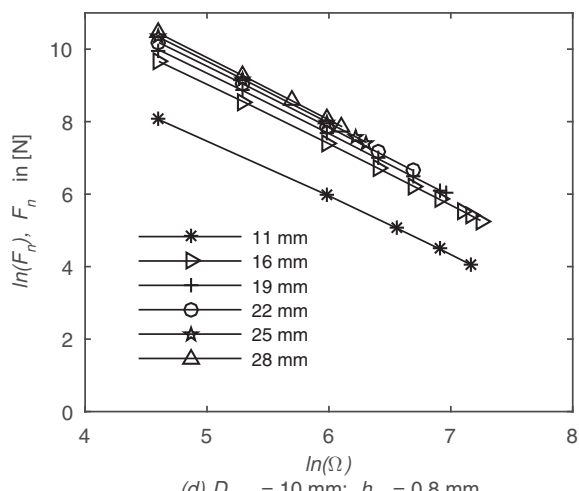

(d) $D_{\text {rod }}=10 \mathrm{~mm} ; h_{0}=0.8 \mathrm{~mm}$

Fig. 4.A.2 The normal forces calculated by the axisymmetric thermo-mechanical model for the $\varnothing 10$ tool with certain layer dimensions and tool rotation rates. 


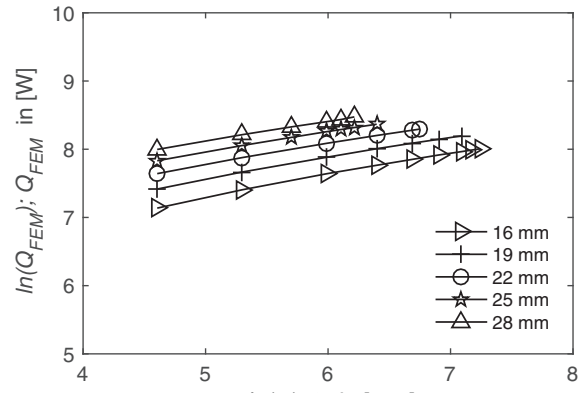

(a) $D_{\text {rod }}=15 \mathrm{~mm} ; h_{0}=0.2 \mathrm{~mm}$

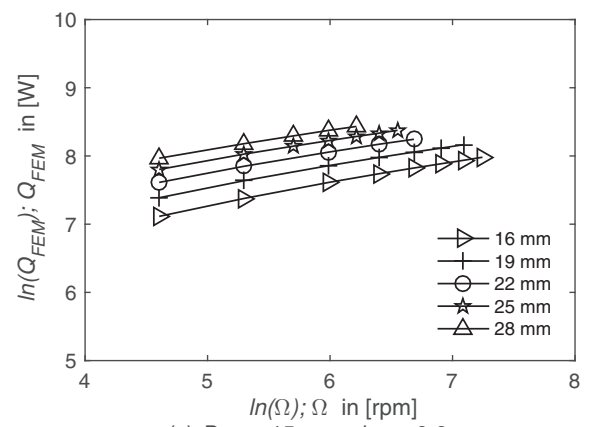

(c) $D_{\text {rod }}=15 \mathrm{~mm} ; h_{0}=0.6 \mathrm{~mm}$

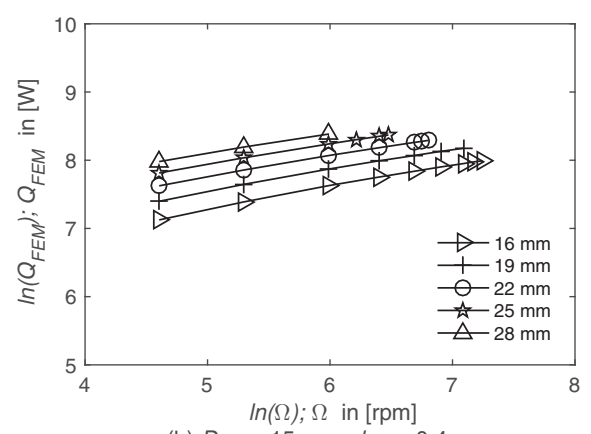

(b) $D_{\text {rod }}=15 \mathrm{~mm} ; h_{0}=0.4 \mathrm{~mm}$

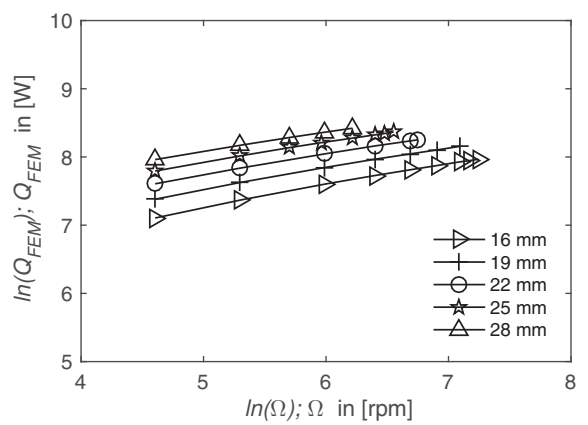

(d) $D_{\text {rod }}=15 \mathrm{~mm} ; h_{0}=0.8 \mathrm{~mm}$

Fig. 4.A.3 The heat generations calculated by the axisymmetric thermo-mechanical model for the $\varnothing 15$ tool with certain layer dimensions and tool rotation rates. 


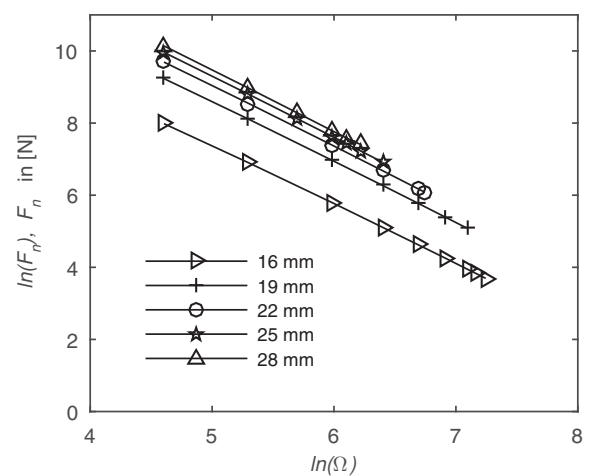

(a) $D_{\text {rod }}=15 \mathrm{~mm} ; h_{0}=0.2 \mathrm{~mm}$

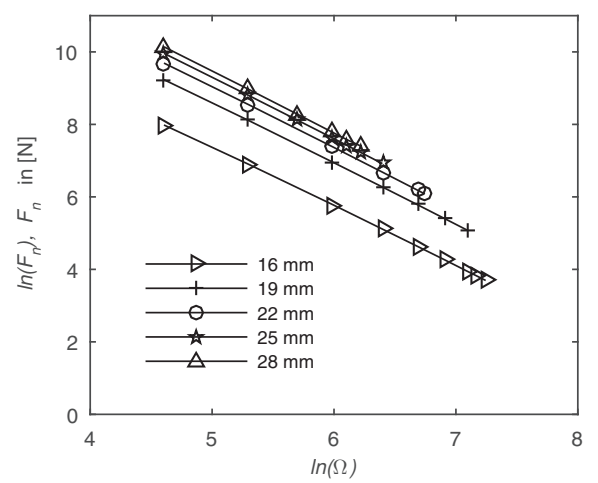

(c) $D_{\text {rod }}=15 \mathrm{~mm} ; h_{0}=0.6 \mathrm{~mm}$

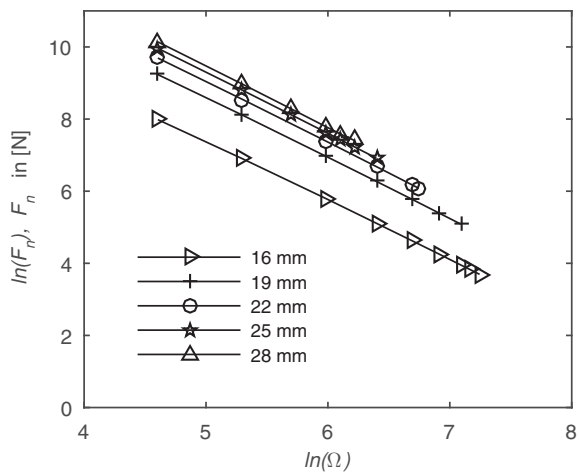

(b) $D_{\text {rod }}=15 \mathrm{~mm} ; h_{0}=0.4 \mathrm{~mm}$

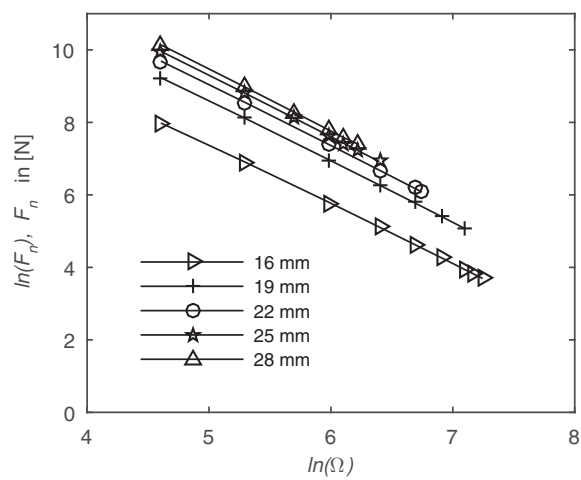

(d) $D_{\text {rod }}=15 \mathrm{~mm} ; h_{0}=0.8 \mathrm{~mm}$

Fig. 4.A.4 The normal forces calculated by the axisymmetric thermo-mechanical model for the $\varnothing 15$ tool with certain layer dimensions and tool rotation rates. 


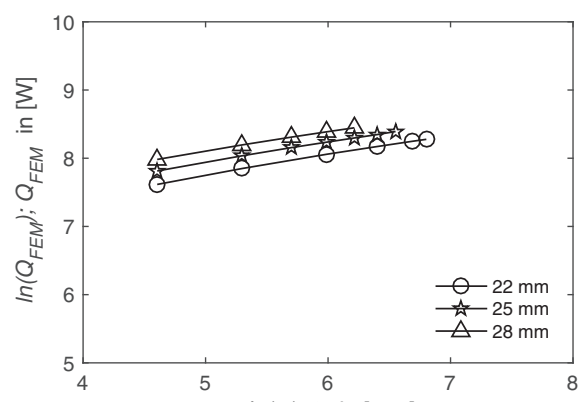

(a) $D_{\text {rod }}=20 \mathrm{~mm} ; h_{0}=0.2 \mathrm{~mm}$

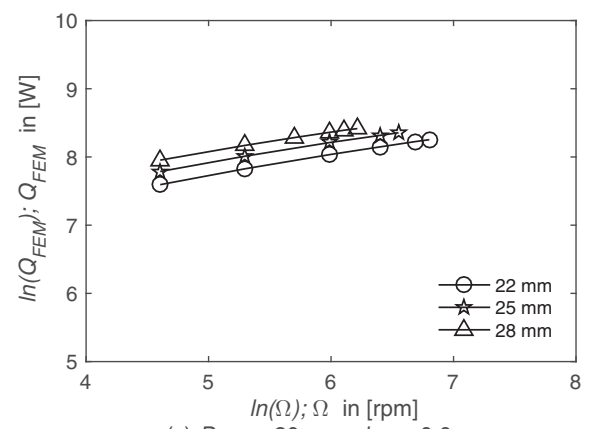

(c) $D_{\text {rod }}=20 \mathrm{~mm} ; h_{0}=0.6 \mathrm{~mm}$

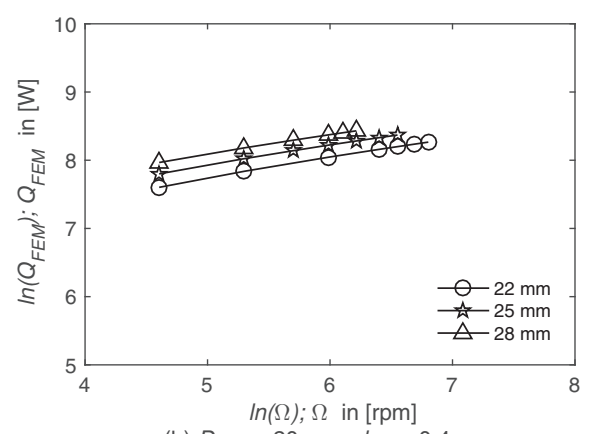

(b) $D_{\text {rod }}=20 \mathrm{~mm} ; h_{0}=0.4 \mathrm{~mm}$

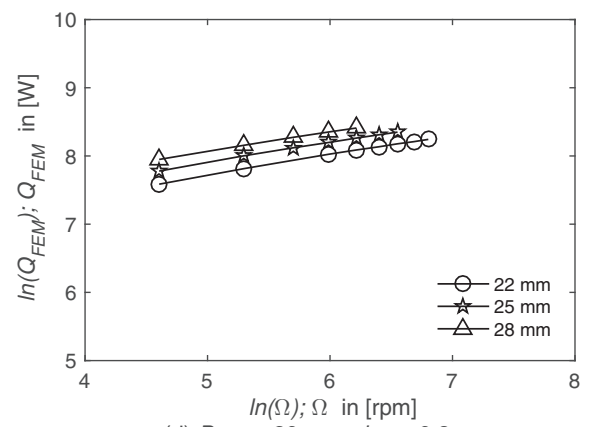

(d) $D_{\text {rod }}=20 \mathrm{~mm} ; h_{0}=0.8 \mathrm{~mm}$

Fig. 4.A.5 The heat generations calculated by the axisymmetric thermo-mechanical model for the $\varnothing 20$ tool with certain layer dimensions and tool rotation rates. 


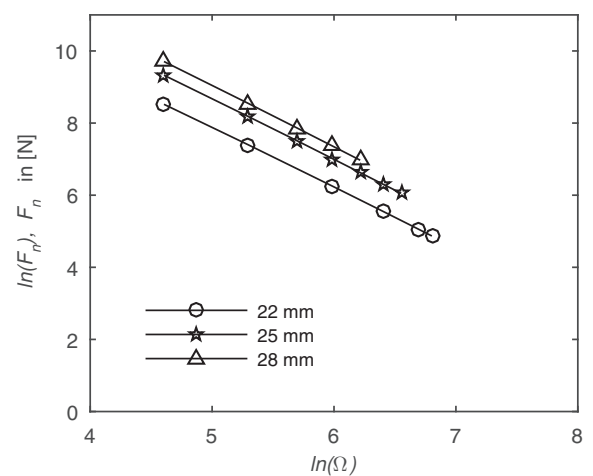

(a) $D_{\text {rod }}=20 \mathrm{~mm} ; h_{0}=0.2 \mathrm{~mm}$

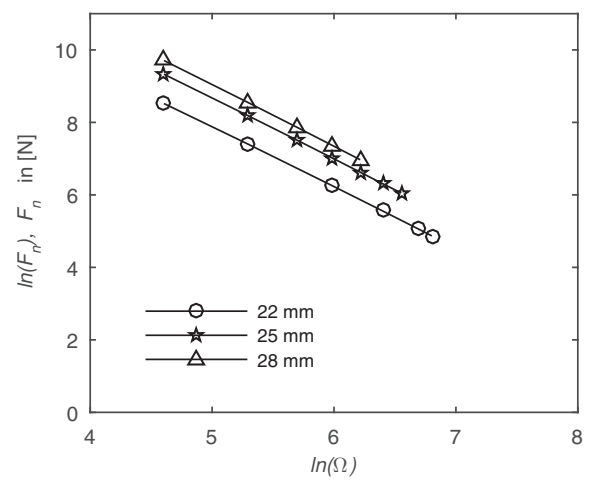

(c) $D_{\text {rod }}=20 \mathrm{~mm} ; h_{0}=0.6 \mathrm{~mm}$

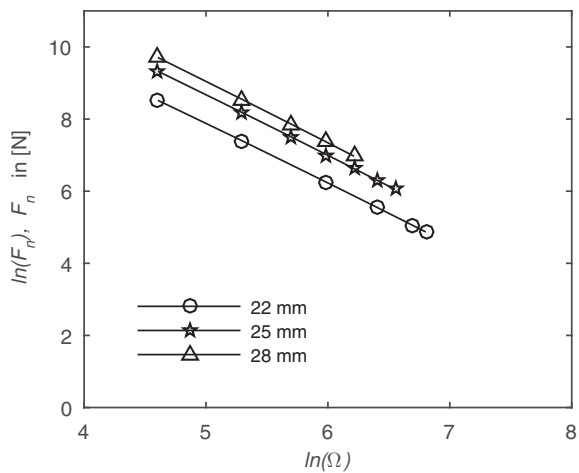

(b) $D_{\text {rod }}=20 \mathrm{~mm} ; h_{0}=0.4 \mathrm{~mm}$

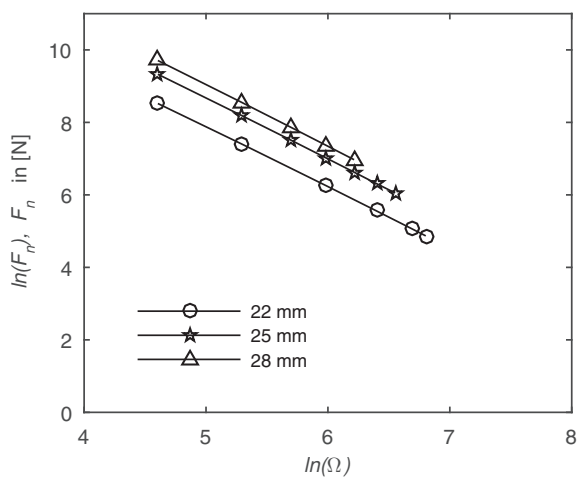

(d) $D_{\text {rod }}=20 \mathrm{~mm} ; h_{0}=0.8 \mathrm{~mm}$

Fig. 4.A.6 The normal forces calculated by the axisymmetric thermo-mechanical model for the $\varnothing 20$ tool with certain layer dimensions and tool rotation rates. 


\section{CHAPTER 5}

\section{Analytical solution to the heat generation and the normal force}

\subsection{Introduction}

The friction surface cladding process has been studied experimentally in Chapters 2 and 3. The influence of various process parameters, such as the tool rotation rate, the layer width and the layer thickness, along with the tool opening diameter has been investigated. Different trends between these parameters and the heat generated and the normal force exerted on the substrate beneath the tool have been identified. In Chapter 4 a numerical approach was followed to deepen the understanding of the underlying relations between the process parameters, the heat input and the normal force. Although the numerical model confirmed the observed trends, it was not capable of making quantitatively correct predictions of the heat generated and normal force exerted on the substrate.

A possible origin for the difference is the contact condition at the interface between the clad material and the FSC tool. In Chapter 4 it was assumed that full sticking occurred at this interface, which led to high heat inputs and higher temperatures in the FSC setup than measured experimentally. In turn, the normal force computed was lower than measured experimentally.

The assumption of full sticking also has a strong influence on the strain rate distribution in the clad layer. At the edge of the FSC tool, where the clad material exits the space between the tool and the substrate, the strain rates are computed highest, with values over $1000 \mathrm{~s}^{-1}$. However, in the experiments, the clad material leaving the tool is moving with the substrate, which suggests that the clad material that moves towards the edge of the rotating FSC tool should experience some degree of slip to accommodate the large differences in relative speed.

In other work on solid state processes employing rotating tools, such as friction stir welding (FSW) and friction stir spot welding (FSSW), various ways have been developed to deal with the uncertainties about the contact condition at the interface [Arora et al. (2009), Schmidt et al. (2004)]. In some cases the effective contact 
area between the rotating tool and the substrate is made artificially smaller to compensate for too high rates of heat generation. Others use frictional contact described with a constant friction coefficient, which is unlikely to be realistic to completely describe the friction behavior.

A different approach has recently been proposed by Reilly et al. (2015) for FSSW. They proposed a radially varying circumferential velocity profile that matched the tool velocity near the tool center line and they made the circumferential material velocity fall to zero at the edge of the tool for continuity with the surrounding workpiece. The interface condition resembles that of full sticking near the tool center line and, as soon as the material departs from the tool, it becomes intermediate between stick and slip. At the tool edge a state of full slip is present. In the paper the authors employed the proposed kinematic model to successfully explain observed material flow phenomena.

In this chapter the role of the contact status at the tool-clad material interface will be thoroughly investigated. A closed form analytical solution is derived first based on the assumption of a constant temperature within the clad layer. From the temperature distributions presented in the previous chapter, it was learned that the temperature within the clad layer in between the FSC tool and the substrate was indeed relatively uniform.

The model will first be applied to the case of full sticking at the tool-clad layer interface to investigate the role of the various process parameters on the heat generated and the normal force exerted. Then, the contact conditions at the toolclad layer interface will be adapted to better describe the contact behavior and to obtain values of generated heat and normal force in line with those observed experimentally.

\subsection{Model description}

\subsubsection{Model background}

The analytical FSC process model calculates the generated heat and normal force for a significantly deforming clad material located between a quickly rotating and undeformable hollow tool and an undeformable solid substrate. The deposited layer is generally very thin and narrow in comparison with the other components in the cladding setup such as the tool and the substrate. Hence, the thermal gradients within the clad layer are small, which can also be observed from Fig. 2.15 in Chapter 2 and Fig. 4.3 in Chapter 4. The experiments described in Chapters 2 and 3 also show that the temperature and the normal force measured during the cladding process in general reach stable or slowly varying values after some cladding time.

Given this, an analytical model considering the clad material as isothermal in a steady state is presented. The isothermal condition also indicates that the components involved in heat transfer in the cladding setup can be neglected. Other 
assumptions are similar to those employed in the axisymmetric thermo-mechanical model described in Chapter 4. Hence, the model is established as an axisymmetric case and contains only the clad material with a flat top surface disregarding the profiled shape of the tool bottom and the small inclination of the tool with respect to the substrate surface normal.

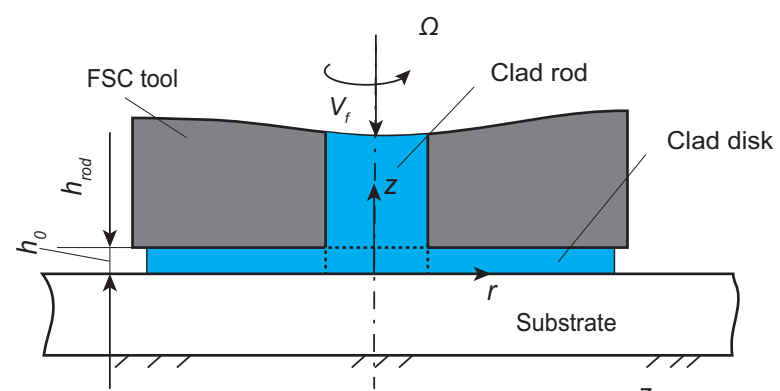

(a) Cross section

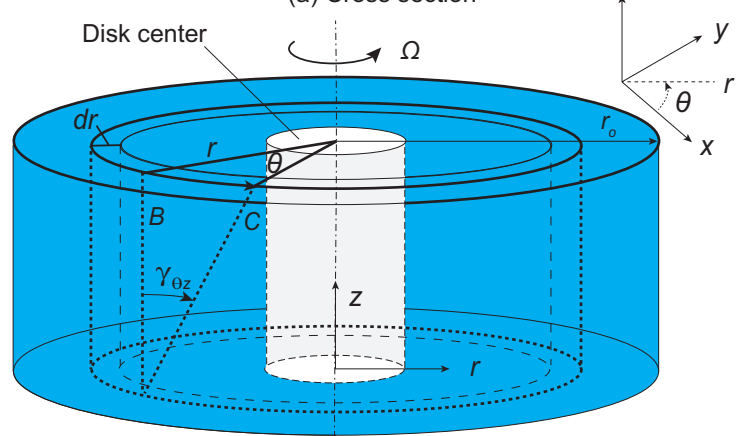

(c) Clad disk

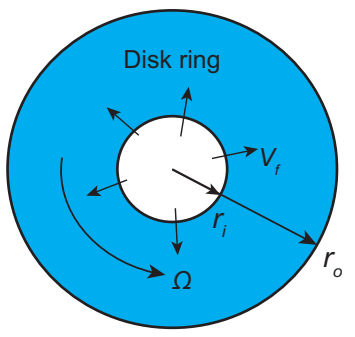

(b) Top view of a disk ring

\begin{tabular}{|l|l|}
\begin{tabular}{|l|l|}
\hline Domain 1 & Subdomain 1 \\
Clad rod (rod) & $\leq r \leq r_{i} ;$ \\
$h_{0} \leq z \leq h_{0}+h_{\text {rod }}$ & $\begin{array}{l}\text { Susk center } \\
\text { Disk } \\
0 \leq r \leq r_{i} ; \\
0 \leq z \leq h_{0}\end{array}$ \\
\hline Domain 2 & $\begin{array}{l}\text { Subdomain 2 } \\
\text { Clad disk } \\
0 \leq r \leq r_{0} ; \\
0 \leq z \leq h_{0}\end{array}$ \\
\hline
\end{tabular}$\quad \begin{array}{l}\text { Disk ring (ring) } \\
r_{i} \leq r \leq r_{o} ; \\
0 \leq z \leq h_{0}\end{array}$ \\
\hline
\end{tabular}

Fig. 5.1 (a) Cross section of the FSC process: a cladding tool rotating at $\Omega$ and clad material flowing through the tool opening at volumetric supply rate of $V_{f}$ to the substrate with a clad layer formed; $(b)$ top view of the cylindrical disk ring used in the analytical solution with the clad material flowing into the ring at $r=r_{i}$ with $V_{f}$ and (c) the shear deformation of the clad material in the cylindrical disk ring.

The clad material comprises two domains: a clad rod with radius $r_{i}$ and length $h_{\text {rod }}$ and a clad disk with radius $r_{o}\left(r_{o}=W / 2\right)$ and thickness $h_{0}$ as shown schematically in Fig. 5.1. The clad disk domain consists of two subdomains: (i) a central part, the disk center $\left(0 \leq r \leq r_{i}\right)$, and (ii) an outer part, the disk ring $\left(r_{i} \leq r \leq r_{0}\right)$. In the experiments the material moves in from the top of the tool, i.e. the top of the clad rod and moves through the clad rod domain and the clad disk domain towards the outer edge of the clad disk ring. This flow is very complicated to describe in an analytical way. Here, the model is further simplified by neglecting the contribution of the vertical flow through the clad rod domain. Only the flow in the clad disk ring subdomain will be considered, assuming laminar flow in this subdomain. The contribution of the ring center will be discussed in Section 5.3.2. 


\subsubsection{Materials}

The temperature and strain rate dependent behavior of the clad material is described by a Zener-Hollomon based equation in the axisymmetric thermomechanical model. However, this equation is too complicated to be employed in the analytical derivation. Given this, the clad material response to temperature and strain rate, $\dot{\gamma}$, is re-described by that of a power law fluid with viscosity $(\mu)$ and shear stress $(\tau)$ defined, following Winter (1975), as,

$$
\begin{aligned}
& \mu=m \dot{\gamma}^{n-1} ; \\
& \tau=\mu \dot{\gamma}=m \dot{\gamma}^{n} .
\end{aligned}
$$

The symbols $m$ and $n$ are temperature dependent material constants ${ }^{1}$, with their values shown in Fig. 5.2. The flow stress of the clad material $\left(\sigma_{f}=\sqrt{3} \tau\right)$ described in this way agrees well with the experimental data from Prasad and Sasidhara (1997) and the Zener-Hollomon model, see the comparison shown in Fig. 5.A.1 in Appendix 5.A.

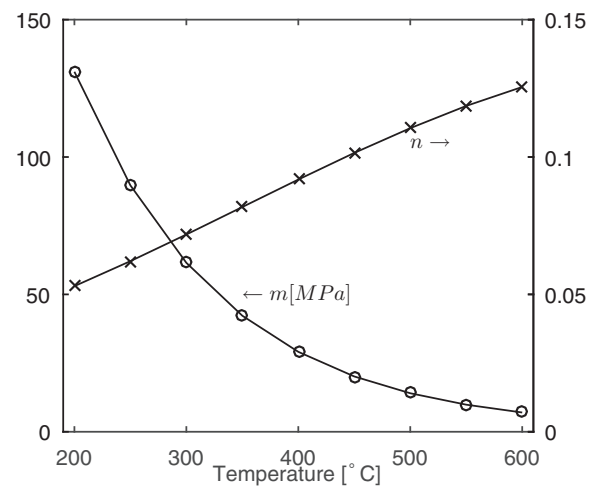

Fig. 5.2 The temperature dependent values of $m$ and $n$ in the power law based material properties of AA1050 shown in Eq. (5.1).

\subsubsection{Mathematical derivation}

The clad material flow through the disk ring subdomain is calculated by solving the continuity and the momentum equations assuming that the material viscosity is determined by Eq. (5.1). Hence, the problem reduces to the flow of a power law fluid in between two circular rings.

$1 \quad$ Formally, the strain rate term in the equation, $\dot{\gamma}$, should be replaced by $\dot{\gamma} / \dot{\gamma}_{0}$ for the units to be correct. However, this is commonly neglected. 
The flow behavior is strongly dependent on the contact conditions at the interfaces of the clad material with the tool and the substrate. The well-bonded nature of the clad material to the substrate, as observed in Chapters 2 and 3 within a broad range of experimental conditions, allows the assumption of full sticking at the clad material-substrate interface. At the interface of the clad material with the tool a position and direction dependent sticking factor is adopted. The degree of slip at the tool-clad layer interface is described by a sticking factor $\delta$, which is given in the form of a vector with components in the circumferential and radial direction, $\delta=\left(\delta_{\theta}, \delta_{r}\right)$, where each component is defined between 0 and 1 and a value of 1 indicates full sticking. The axisymmetric nature of the model makes the sticking factor dependent only on the radial position.

The clad material is incompressible and the continuity equation reads for this case

$$
\frac{\partial}{\partial r}\left(r u_{r}\right)=0
$$

Inertia forces are not considered due to the high viscosity of the clad material. Therefore, the flow behavior is considered as a creeping flow. The pressure is generated from the normal stress in all directions: $\sigma_{r}=\sigma_{\theta}=\sigma_{z}=-p$. The momentum equation after the aforementioned simplification becomes

$$
-\frac{\partial p}{\partial r}+\frac{\partial \tau_{r z}}{\partial z}=0
$$

Only the $r$ component is calculated due to the axisymmetric nature of the model and as no flow is involved in the $z$ direction within the disk ring subdomain. A similar approach was followed by $\mathrm{Na}$ and Hansen (1967).

The contribution of the disk ring to the heat generation and the normal force is considered based on the assumption of full sticking or partial sticking/slipping contact at the tool-clad material interface. The combination of the tool rotation rates, the clad disk dimensions and the volumetric supply rates of the clad material employed typically in the cladding experiments provides a generic shear rate distribution for FSC. The shear rate in the clad material caused by the circumferential flow is always much larger than that by the radial flow. This holds as long as the slip rate at the tool-clad material interface is not too large.

If the circumferential component of the shear rate $\left(\dot{\gamma}_{\theta z}\right)$ becomes of the same order of magnitude as the radial component $\left(\dot{\gamma}_{r z}\right)$, for example in the case of very small values of the circumferential sticking factor, an adapted approach should be followed.

Apart from the above mentioned exception, it can be assumed that the effective material viscosity is dependent solely on the circumferential component of the shear rate,

$$
\begin{aligned}
& \dot{\gamma}_{z \theta}=\frac{d \gamma_{z \theta}}{d t}=\frac{r}{z} \frac{d \theta}{d t}=\frac{\delta_{\theta}(r) r \omega}{h_{0}} ; \\
& \mu=m \dot{\gamma}_{z \theta}^{n-1},
\end{aligned}
$$


with $\omega$ the angular tool rotation speed with unit of $\mathrm{rad} / \mathrm{s}$, related to $\Omega$ by $\omega=$ $2 \pi \Omega / 60$.

From Eq. (5.2), it becomes clear that the term $r u_{r}$ is independent of $r$. From the axisymmetric nature it also follows that this term is independent of $\theta$. Hence, a function $f(z)$ with independent variable $z$ can be defined,

$$
r u_{r}=f(z) .
$$

The $r-z$ component of the shear stress $\left(\tau_{r z}\right)$, according to Eq. (5.1) and Eq. (5.5), becomes

$$
\begin{aligned}
& \tau_{r z}=\mu \dot{\gamma}_{r z} ; \\
& \dot{\gamma}_{r z}=\frac{\partial u_{r}}{\partial z}=\frac{f^{\prime}}{r} .
\end{aligned}
$$

Hence, it follows from Eqs. (5.3) - (5.6):

$$
\frac{\partial p}{\partial r}=\frac{\partial \tau_{r z}}{\partial z}=A r^{n-2} \delta_{\theta}^{n-1} f^{\prime \prime},
$$

with

$$
A=m\left(\frac{\omega}{h_{0}}\right)^{n-1}
$$

The symbols $f^{\prime}$ and $f^{\prime \prime}$ are the first and second derivative of the newly introduced function $f(z)$ in Eq. (5.5), respectively.

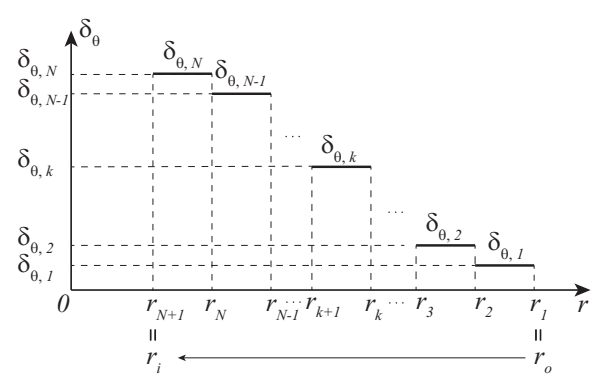

Fig. 5.3 The piecewise constant sticking factor $\delta_{\theta}(r)$ which is only valid for the circumferential flow.

The integration of the right-hand side of Eq. (5.7) cannot be readily performed. It is dependent on the value of the circumferential sticking factor $\delta_{\theta}(r)$. Without further ado a piecewise constant function is introduced as shown schematically in Fig. 5.3 to describe the sticking factor $\delta(r)$. It is valid within the distance from the opening radius $r=r_{i}$ to the outer edge of the clad layer $r=r_{0}$. The distance is divided into $N$ intervals and both components of the sticking factor remain constant within each interval. Note, that the interval numbering starts from the outside inwards.

The derivation is continued first for a separate interval $k$, with $r_{k+1} \leq r \leq r_{k}$, and subsequently the contributions of each interval are added up to completely describe 
the clad material flow in between the rotating circular tool bottom and the stationary circular substrate top. The integration of Eq. (5.7) for interval $k$ with a constant value of sticking factor, $\delta_{\theta, k}$, yields the following expression for the pressure distribution within the $k^{\text {th }}$ interval,

$$
p_{k}(r)=\frac{A \delta_{\theta, k}^{n-1} f^{\prime \prime}}{n-1}\left(r_{k}^{n-1}-r^{n-1}\right)+p_{k-1}\left(r_{k}\right),
$$

where the last term on the right-hand side of the equation expresses the pressure at the interface with the neighboring interval located closer to the outer edge of the FSC tool. As the clad material flows from the inside outwards, the pressure at $r=r_{o}$ is set to 0 . The total pressure difference over interval $k$ can now be expressed as

$$
\Delta p_{k}=p_{k}\left(r_{k+1}\right)-p_{k-1}\left(r_{k}\right)=A B_{k} f^{\prime \prime},
$$

with

$$
B_{k}=\delta_{\theta, k}^{n-1} \frac{r_{k+1}^{n-1}-r_{k}^{n-1}}{n-1}
$$

From Eq. (5.10), it follows

$$
f^{\prime \prime}=\frac{\Delta p_{k}}{A B_{k}}
$$

The radial component of the velocity distribution, $u_{r}$, is related to $f(z)$ according to Eq. (5.5). The function $f(z)$ can be obtained from Eq. (5.12) by double integration with respect to $z$ :

$$
f=\frac{\Delta p_{k}}{2 A B_{k}} z^{2}-C_{1} z+C_{2}
$$

with $C_{1}$ and $C_{2}$ constants depending on the boundary conditions. At the clad material-substrate interface (at $z=0$ ) full sticking is assumed as explained above. At the tool-clad material interface (at $z=h_{0}$ ) the degree of slip may vary between full sticking and full slipping. The function $f(z)$ can be expressed for these cases as:

$$
f= \begin{cases}\frac{\Delta p_{k}}{2 A B_{k}}\left(z^{2}-h_{0} z\right) & \text { full-sticking } \\ \frac{\Delta p_{k}}{2 A B_{k}}\left(z^{2}-2 h_{0} z\right) & \text { full-slipping }\end{cases}
$$

A sticking factor in the radial direction, $\delta_{r}$, for intermediate cases can be defined with the help of the shear rates at the tool-clad material interface at $z=h_{0}$ for both 
extreme cases:

$$
\left.\frac{\partial u_{r}}{\partial z}\right|_{z=h_{0}}=\frac{f^{\prime}}{r}= \begin{cases}\frac{\Delta p_{k}}{2 A B_{k} r} h_{0} & \text { full-sticking } \\ 0 & \text { full-slipping }\end{cases}
$$

Hence, intermediate cases of sticking/slipping can be described with the radial sticking factor $\delta_{r}$ according to

$$
\left.\frac{\partial u_{r}}{\partial z}\right|_{z=h_{0}}=\frac{\Delta p_{k}}{2 A B_{k} r} h_{0} \delta_{r}, \text { with } 0 \leq \delta_{r} \leq 1,
$$

where $\delta_{r}=0$ represents full slipping and $\delta_{r}=1$ full sticking as mentioned before.

Based on the boundary conditions described with Eq. (5.16), the function $f(z)$ can be given with $\delta_{r}$ as a parameter,

$$
f(z)=\frac{\Delta p_{k}}{2 A B_{k}}\left(z^{2}+\left(\delta_{r}-2\right) h_{0} z\right) .
$$

The combination of Eq. (5.5) and Eq. (5.17) provides an expression for the radial velocity of the clad material within interval $k$ :

$$
u_{r, k}=\frac{f(z)}{r}=\frac{\Delta p_{k}}{2 A B_{k} r}\left(z^{2}+\left(\delta_{r}-2\right) h_{0} z\right) .
$$

The volumetric supply rate of the clad material through interval $k$ equals $V_{f, k}$ and can be calculated from Eq. (5.18) by integration of the radial flow over any cross section at radius $r$, such that

$$
V_{f, k}=\int_{0}^{h_{0}} u_{r, k} 2 \pi r d z=\frac{\pi \Delta p_{k} h_{0}{ }^{3}}{6 A B_{k}}\left(3 \delta_{r}-4\right) .
$$

By combining Eqs. (5.8) and (5.19), the pressure difference $\Delta p_{k}$ in Eq. (5.10) can be expressed as a function of the volumetric supply rate, the tool rotation rate, the layer thickness and the material properties of the clad material at the process temperature,

$$
\Delta p_{k}=\frac{6 m B_{k} \omega^{n-1} V_{f}}{\pi h_{0}^{n+2}\left(3 \delta_{r}-4\right)}
$$

The pressure distribution expressed in Eq. (5.9), together with Eq. (5.17), can be used to calculate the total normal force exerted by interval $k$ on the underlying substrate from integration of the pressure distribution within the interval from $r_{k+1} \leq r \leq r_{k}$,

$$
\begin{aligned}
& F_{n, k}=\int_{r_{k+1}}^{r_{k}} p_{k}(r) 2 \pi r d r \\
& =-\frac{6 m V_{f} \delta_{\theta, k}}{\omega^{1-n} h_{0}^{2+n}\left(3 \delta_{r}-4\right)}\left[\frac{2\left(r_{k}^{1+n}-r_{k+1}^{1+n}\right)}{n^{2}-1}-\frac{r_{k}^{n-1}\left(r_{k}^{2}-r_{k+1}^{2}\right)}{n-1}\right]+\pi p_{k-1}\left(r_{k}\right)\left(r_{k}^{2}-r_{k+1}^{2}\right) .
\end{aligned}
$$


The volumetric heat generation is calculated on the basis of the assumptions stated at the beginning that only the circumferential component of the shear rate significantly contributes to the viscous dissipation. The circumferential component of the shear stress, according to Eq. (5.4), is

$$
\tau_{z \theta}=\mu \dot{\gamma}_{z \theta}
$$

The total heat generation within interval $k$ follows from

$$
Q_{k}=\int_{r_{k+1}}^{r_{k}} 2 \pi \omega \delta_{\theta, k} r^{2} \tau_{z \theta} d r=\frac{2 \pi \omega^{n+1} \delta_{\theta, k}^{n+1} m}{(n+3) h_{0}^{n}}\left(r_{k}^{n+3}-r_{k+1}^{n+3}\right) .
$$

The total heat generated within the clad disk ring subdomain and the total force exerted by this subdomain on the underlying substrate are obtained from the sum of the contributions of each interval, respectively:

$$
\begin{aligned}
& Q_{\text {ring }}=\sum_{k=1}^{N} Q_{k} ; \\
& F_{n-\text { ring }}=\sum_{k=1}^{N} F_{n, k} .
\end{aligned}
$$

For the case of full sticking on the tool-clad material interface (i.e. $\delta_{\theta}=\delta_{r}=1$ ) the number of intervals is reduced to one and the integration of the heat generation can be performed from $r=r_{i}$ to $r=r_{o}$. Then, the following expression for the heat generated is obtained

$$
\begin{aligned}
& \left.Q_{\text {ring }}\right|_{\text {full-sticking }}=\int_{r_{i}}^{r_{o}} 2 \pi \omega r^{2} \tau_{z \theta} d r \\
& =2 \pi m \frac{\omega^{1+n}\left(r_{o}^{3+n}-r_{i}^{3+n}\right)}{(3+n) h_{0}^{n}} .
\end{aligned}
$$

Similarly, the normal force for this case can be calculated from

$$
\begin{aligned}
& \left.F_{n-\text { ring }}\right|_{\text {full-sticking }}=\int_{r_{i}}^{r_{o}} p(r) 2 \pi r d r \\
& =\frac{6 m V_{f}}{\omega^{1-n} h_{0}^{2+n}}\left[\frac{2\left(r_{o}^{1+n}-r_{i}^{1+n}\right)}{n^{2}-1}-\frac{r_{o}^{n-1}\left(r_{o}^{2}-r_{i}^{2}\right)}{n-1}\right] .
\end{aligned}
$$

\subsection{Results and discussion}

\subsubsection{Heat generation and normal force contribution of the clad disk center}

In the previous section expressions for the heat generation in the disk ring subdomain and the normal force exerted on the substrate were derived. With 
the help of the numerical approach presented in Chapter 4, expressions can be developed for the entire clad disk including the contribution of the disk center.

\section{Heat generation}

The clad material in the clad disk center also contributes to the total heat generation as it is in contact with the substrate and is strongly deformed by the rotation of the FSC tool. It is assumed that the clad material in the clad disk center at height $z=$ $h_{0}$ (see Fig. 5.1), rotates at the same angular speed as the tool. This condition can then also be described as full sticking. The contribution of the clad disk center to the heat generation can therefore be expressed as, using Eq. (5.25),

$$
Q_{\text {disk-center }}=2 \pi m \frac{\omega^{1+n} r_{i}^{3+n}}{(3+n) h_{0}^{n}} .
$$

The validity of this approach has been tested by comparing the results of the analytical model with the numerical model presented in the previous chapter for the case of full sticking, see Fig. 5.A.2 in Appendix 5.A. The thermo-mechanical model was adjusted to enable the simulation under the same conditions as valid for the analytical model. In this case both models provide the same amount of total heat generation, proving that the contribution to the heat generation of the disk center can indeed be modeled in the way described above.

Further, finite element computations have also been performed to ensure the validity of the approach for the range of process variables investigated in Chapter 4 . The contribution of the disk center to the overall heat generation is relatively small and takes less than $10 \%$ of the total heat generated and it also depends on the geometry of the tool and the layer dimensions. The relatively small circumferential velocity of the clad material in the disk center explains the low fraction.

The total heat generation of the clad disk for full sticking conditions, including the contributions of the disk ring and the disk center, follows from summation of Eqs. (5.25) and (5.27):

$$
Q_{a n a}=2 \pi m \frac{\omega^{1+n} r_{0}^{3+n}}{(3+n) h_{0}^{n}} .
$$

\section{Normal force}

The normal force in the clad disk center also contributes to the normal force exerted by the whole clad disk on the substrate. Based on the pressure distribution simulated by the axisymmetric thermo-mechanical model of Chapter 4, see Fig. 4.4(b), it is assumed that the pressure calculated at the inner surface of the disk ring at $r=r_{i}$ is equal to the pressure in the disk center, $p_{\text {disk-center }}=p\left(r_{i}\right)$. According to this assumption, the pressure distribution in the whole clad disk 
domain $\left(0 \leq r \leq r_{o}\right)$ for the case of full sticking becomes

$$
p(r)= \begin{cases}p\left(r_{i}\right) & 0 \leq r \leq r_{i} \\ \frac{6 m V_{f}\left(r_{o}^{n-1}-r^{n-1}\right)}{\pi(n-1) \omega^{1-n} h_{0}^{2+n}\left(3 \delta_{r}-4\right)} & r_{i} \leq r \leq r_{o}\end{cases}
$$

Fig. 5.4 shows the pressure distributions defined by Eq. (5.29) and the one calculated by the numerical model. Close resemblance of both pressure distributions is visible.

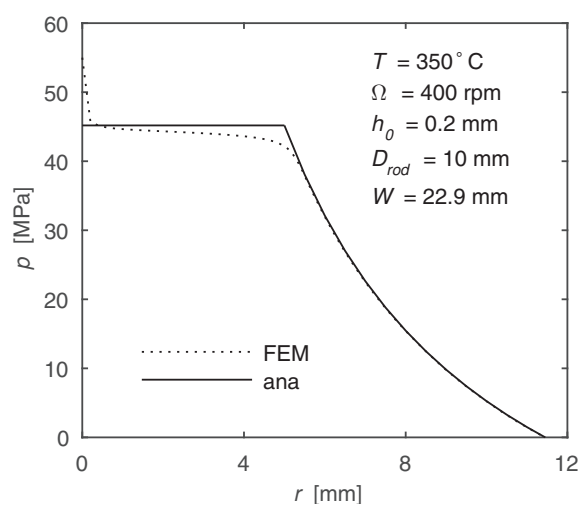

Fig. 5.4 The pressure distributions from $r=0$ to $r=W / 2$ for the analytical solution and the thermomechanical model at $350^{\circ} \mathrm{C}$ with $m=42 \mathrm{MPa}, n=0.0818, h_{0}=0.2 \mathrm{~mm}, \Omega=400 \mathrm{rpm}$ and $W=22.9 \mathrm{~mm}$.

The total normal force exerted by the clad disk on the substrate with $r$ from $r=$ 0 to $r=r_{0}, F_{n-a n a}$, can be calculated for the case of full sticking by integrating the pressure distribution over the clad disk center and ring area, as described by Eq. (5.29), leading to the following expression

$$
F_{n-a n a}=\frac{6 m V_{f}\left(r_{o}^{n+1}-r_{i}^{n+1}\right)}{(1+n) \omega^{1-n} h_{0}^{2+n}} .
$$

The total normal force exerted by the disk center and the disk ring as calculated by the analytical approach is also validated with the same adapted thermo-mechanical model as described above, see Fig. 5.A.3 in Appendix 5.A. Again, the results of both approaches are very similar, confirming the validity of the calculation of the contribution of the disk center to the total normal force.

It is found that the normal force in the disk center calculated by $F_{n \text {-disk-center }}=$ $p\left(r_{i}\right) \pi r_{i}^{2}$ may take a great fraction of the total normal force. Its contribution can be over $50 \%$, depending on the ratio of the layer width $\left(W=2 r_{0}\right)$ to the diameter of the clad rod $\left(2 r_{i}\right)$. The large contribution of the center region to the total force can also be deduced from the pressure distribution shown in Fig. 5.4. 


\subsubsection{Analytical results at full sticking condition}

In this section the influence of the various process parameters and the tool opening diameter on the heat generation and the normal force are calculated for the case of full sticking. This case serves as a reference for the next section, where partial sticking/slipping at the tool-clad material interface is introduced.

\section{Total heat generation}

The relations between the total heat generated $\left(Q_{a n a}\right)$ and the tool rotation rate, the layer thickness, the layer width and the size of the tool opening are shown in Fig. 5.5 for $300^{\circ} \mathrm{C}, 400^{\circ} \mathrm{C}$ and $500{ }^{\circ} \mathrm{C}$ for the case of full sticking. The volumetric supply rates are adjusted accordingly to provide the required volume of clad material per unit of time according to the dimensions of the clad layer. The tool translation speed is $60 \mathrm{~mm} / \mathrm{min}$ in all cases.

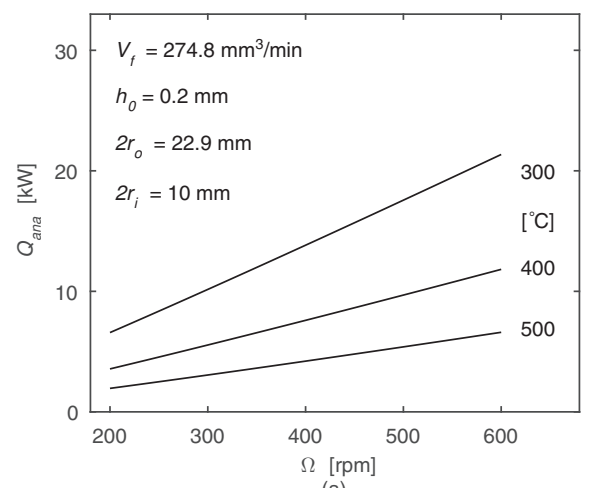

(a)

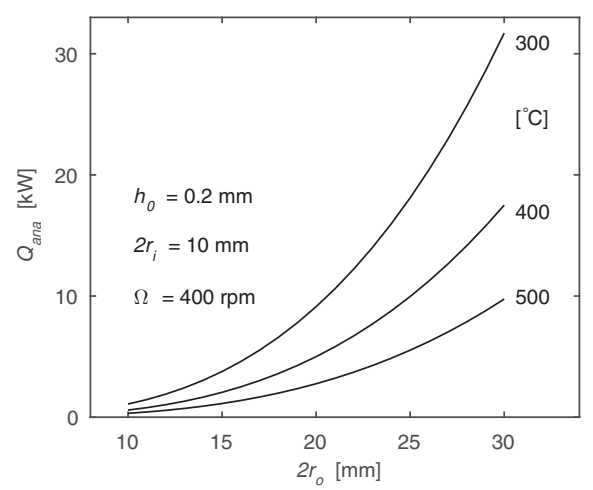

(c)

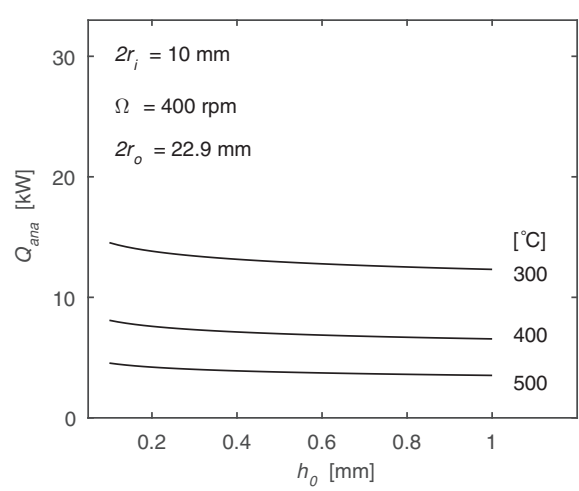

(b)

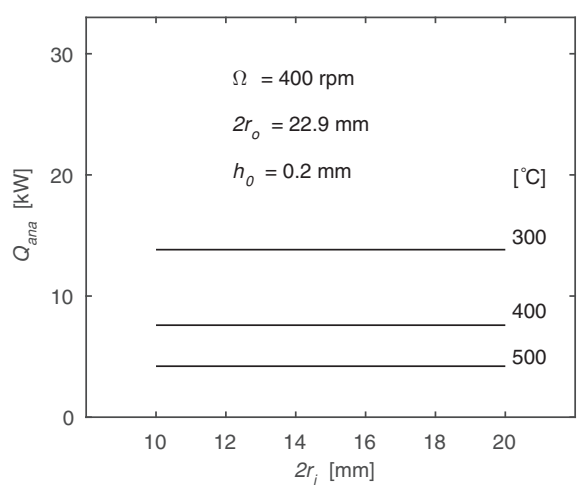

(d)

Fig. 5.5 The influence of the tool rotation rate $(a)$, the layer dimensions $(b, c)$ and the diameter of the tool opening (d) on the total heat generated in the clad disk according to Eq. (5.28) at $300^{\circ} \mathrm{C}, 400^{\circ} \mathrm{C}$ and $500^{\circ} \mathrm{C}$. 
It is observed in Fig. 5.5(a) that the heat generation rises nearly linearly with the tool rotation rate at each selected temperature. The trend can be explained from the power of $\omega$ in Eq. (5.28), $1+n$, which is approximately equal to 1 as the value of $n$ is in general small. For each separate temperature, it agrees well with the corresponding trend simulated by the axisymmetric thermo-mechanical model of Chapter 4, see Fig. 4.6(a). The differences in the heat generations between the various temperatures can be explained from the dependence of the flow stress on the temperature.

The effect of the layer thickness on the generated heat for various temperatures is very small as visible in Fig. 5.5(b): the generated heat is almost constant for each temperature. This is again in line with the numerical result, see Fig. 4.6(b) in Chapter 4. Inspection of Eq. (5.28) shows that the generated heat is inversely proportional to the layer thickness to the power $n$. As mentioned above, the value of $n$ is rather small, making $Q_{a n a}$ almost insensitive to the layer thickness. For materials exhibiting a constant flow stress at a given temperature independent of the strain rate (i.e. $n=0$ ), the shear rate, as expressed by Eq. (5.4), scales inversely proportional with the layer thickness $h_{0}$. However, as the volume of the clad material scales proportionally with $h_{0}$, the integration of the generated heat over the domain (see Eq. (5.28)) for a constant temperature (i.e. a constant $m$ and thus a constant $\tau$ ) becomes independent of $h_{0}$.

The layer width $\left(W=2 r_{0}\right)$ bears a strong effect on the heat generation as shown in Fig. 5.5(c). The power of the layer width is much larger than that of the tool rotation rate in Eq. (5.28), indicating that the layer width exerts a larger effect on the heat generation than the tool rotation rate. The slope of the heat generation curve calculated by the analytical model is much larger compared with the one by the axisymmetric thermo-mechanical model, see Fig. 4.6(c) in Chapter 4. The temperatures in the numerical model become much higher than those in the analytical one. Hence, the effective flow stress value in the numerical model is smaller, decreasing the net heat generation rate and explaining the differences between both slopes.

The tool opening diameter has no influence on the heat generation as visible from Fig. 5.5(d). This is in line with the observations of the axisymmetric thermomechanical model in Chapter 4, see Fig. 4.6(d). The tool opening diameter, or related, the tool opening radius $r_{i}$, is not part of Eq. (5.28) due to the assumptions underlying the derivation of this equation.

\section{Total normal force}

The influence of the tool rotation rate, the layer dimensions and the size of the tool opening on the normal force at the bottom of the clad disk is shown in Fig. 5.6 for $300^{\circ} \mathrm{C}, 400^{\circ} \mathrm{C}$ and $500^{\circ} \mathrm{C}$ assuming full sticking conditions. For each temperature the normal force decreases substantially with the tool rotation rate, the layer thickness and the diameter of the tool opening, whereas it increases 
significantly with the layer width. These results are comparable with the simulated results shown in Fig. 4.6 in Chapter 4.

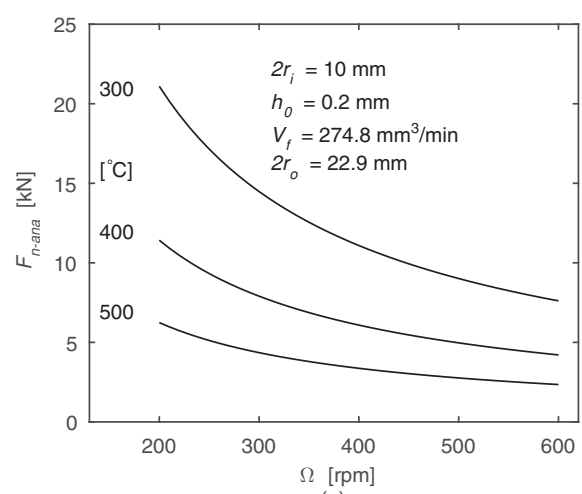

(a)

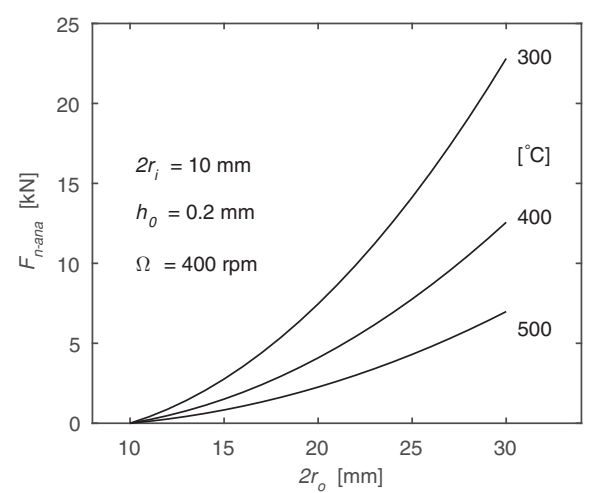

(c)

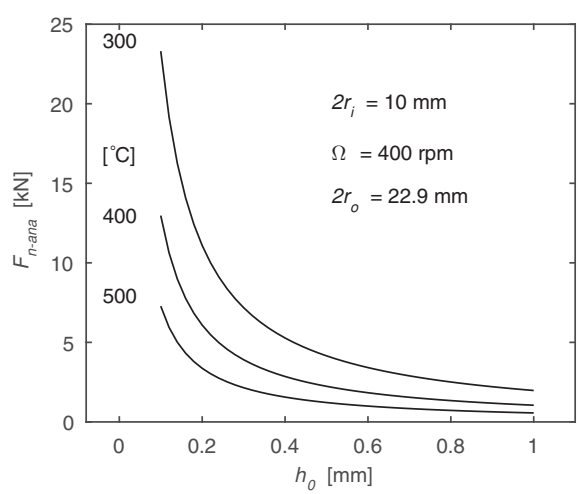

(b)

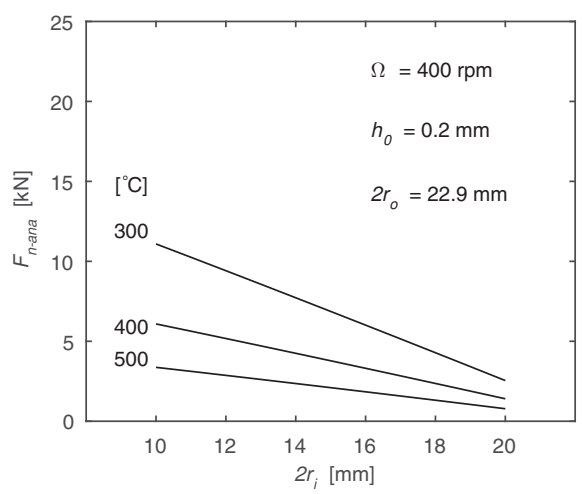

(d)

Fig. 5.6 The influence of the tool rotation rate (a), the layer dimensions $(b, c)$ and the diameter of the tool opening (d) on the normal force in the clad disk according to Eq. (5.30) at $300^{\circ} \mathrm{C}, 400^{\circ} \mathrm{C}$ and $500^{\circ} \mathrm{C}$.

Inspection of Eq. (5.30) shows that the normal force is inversely proportional to the angular tool rotation rate to the power $1-n$. It is a consequence of the effective viscosity of the material being related to the shear rate with the same power $(\mu=$ $m / \dot{\gamma}_{z \theta}^{1-n}$ ), see Eq. (5.1). As the clad material is highly shear thinning (i.e. $n$ is small) an increase in the tool rotation rate, i.e. an increase in the shear rate (see Eq. (5.4)), will decrease the effective viscosity significantly. Hence, it requires less force to distribute the clad material beneath the tool, leading to a decrease in the normal force exerted on the substrate.

The relation of the normal force with the layer thickness and width is not directly obvious from Eq. (5.30) as the volumetric supply rate $V_{f}$ also changes with the layer dimensions. Incorporation of volume consolidation, $V_{f}=h_{0} W v_{t}$ leads to the following expression that shows the relation between the normal force and the clad 
layer dimensions more clearly,

$$
F_{n-a n a}=\frac{12 m v_{t} r_{o}\left(r_{o}^{1+n}-r_{i}^{1+n}\right)}{(1+n) \omega^{1-n} h_{0}^{1+n}} .
$$

It is observed that the normal force is inversely proportional to the layer thickness to the power $1+n$ explaining the large decrease in the normal force observed in Fig. 5.6(b). This seems somewhat counter-intuitive: despite the fact that more material needs to be supplied if a clad layer with larger thickness is deposited and knowing that the effective shear rate decreases for larger $h_{0}$ (see Eq. (5.4)) and therefore the effective viscosity (see Eq. (5.1)) increases, still the normal force decreases. Apparently, the influence of the layer thickness is inherently very large to counteract the effects of the increase in volumetric flow rate and viscosity upon an increase in layer thickness. This is also observed by Huang and Tzou (2002) in the compression forming of a rotating disk and by Sutera and Skalak (1993) in Hagen Poiseuille flow.

The effect of the layer width is to increase the normal force which is understandable from the fact that more material needs to be deposited over a larger area, effectively increasing the required pressure for clad material distribution. Hence, a more than linear increase in the normal force occurs as a function of the layer width as can also be deduced from Eq. (5.31).

\subsubsection{Comparison with experiments}

As a first step the heat generation $\left(Q_{a n a}\right)$ and the normal force exerted on the substrate $\left(F_{n-a n a}\right)$ are calculated for the case of full sticking using the actual layer dimensions, tool rotation rates and temperatures of each experiment. Here, the temperature of thermocouple $T C_{3}$ is selected to estimate the temperature of the clad material. From Chapters 2 and 4 it is learned that a thermal gradient exists between the clad layer and the center of the substrate in all experiments. On average the temperature within the clad layer is about $30^{\circ} \mathrm{C}$ higher than that measured within the substrate by thermocouple $T C_{3}$. Therefore, the model calculations are performed with a temperature equal to $T C_{3-\exp }+30^{\circ} \mathrm{C}$.

The results are plotted in Fig. 5.7 for all experiments in terms of the ratio of the experimental values to the modeled values. The ratio of $Q_{\exp }$ to $Q_{a n a}, \Delta_{Q}=$ $Q_{\text {exp }} / Q_{a n a}$, shows some scatter around an average value of 0.45 , whereas the ratio of $F_{n-\exp }$ to $F_{n-a n a}, \Delta_{F_{n}}=F_{n-\exp } / F_{n-a n a}$, shows considerably more scatter. The same type of figure was shown in the previous chapter, where the results of the thermo-mechanical model were compared with the experiments, see Fig. 4.8.

The approximately constant ratio between $Q_{\exp }$ and $Q_{a n a}$ suggests that the full sticking analytical model overestimates the heat generation by a constant factor more or less independent of the actual clad layer dimensions, tool rotation rates and FSC tool opening diameters. This ratio may be conceived as an efficiency factor of the FSC process for the current case. This important result will form the basis 
for the prediction of the process window in Chapter 6. It also suggests that the incorporation of a more detailed description of the sticking/slipping behavior at the tool-clad layer interface should also be possible in a rather general way, at least when concentrating on the heat generation.

The ratio of $F_{n-\exp }$ to $F_{n-a n a}$ is strongly varying from experiment to experiment. Possible causes for the observed variations in the ratio were made in Section 4.3.3 and will not be repeated here.

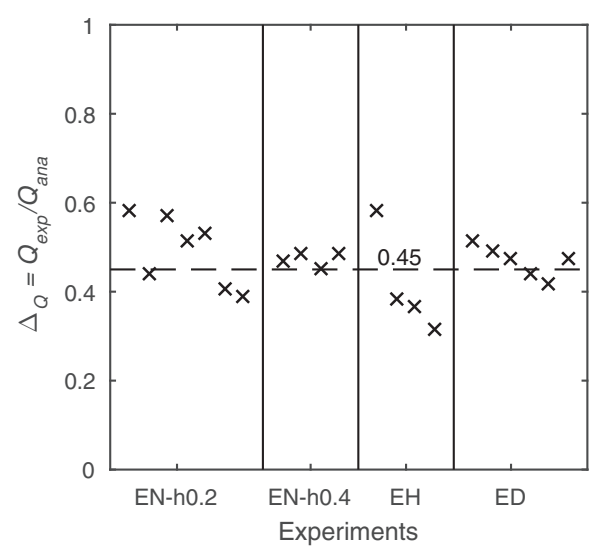

(a)

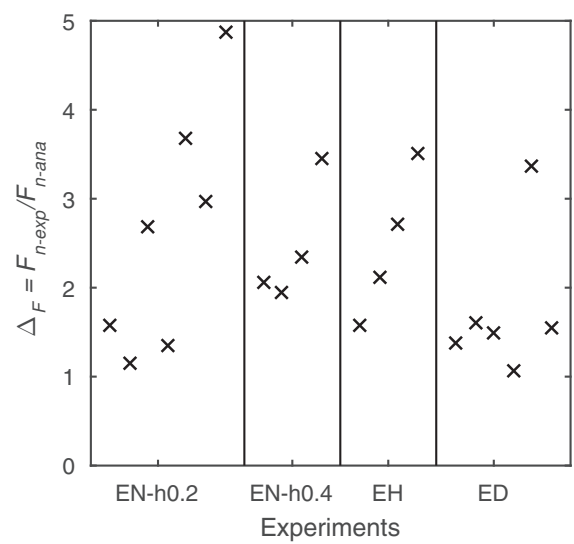

(b)

Fig. 5.7 (a) The ratio of $Q_{\exp }$ to $Q_{a n a}, \Delta_{Q}=Q_{\exp } / Q_{a n a}$; and (b) the ratio of $F_{n-\exp }$ to $F_{n-a n a}, \Delta_{F_{n}}=$ $F_{n-\exp } / F_{n-a n a}$, calculated assuming full sticking in the circumferential and radial direction at the tool-clad material interface for all experiments listed in Table 2.1 in Chapter 2 and Table 3.1 except experiment EW in Chapter 3.

\subsubsection{The role of the contact status at the tool-clad material interface}

The analytical model overestimates the heat generation when full sticking occurs at the tool-clad material interface as shown in the previous section. A better estimate of the heat generation can be obtained if some degree of slip at the tool-clad material interface is introduced. However, this strongly depends on spatial knowledge of the contact status. Some suggestions regarding the sticking/slipping behavior at this interface can be obtained from FSC experiments stopped before all clad material was deposited on the substrate.

A cross section of such a substrate with the clad layer on top and the leftover of the clad rod bonded to substrate is shown in Fig. 5.8 for the case of experiment EH-04. The interface of the clad material with the tool, i.e. the top of the layer, is non-uniform and typically two regions are visible characterized by a transition point at $r=R_{T r}=\alpha r_{0}$. The constant $\alpha$ determines the position of this point with respect to the layer width $\left(r_{o}=W / 2\right)$. The interface has a rough appearance for $R_{\text {rod }}$ 
$\leq r \leq R_{T r}$, indicating that some material was torn away when the tool was lifted with respect to the substrate and suggesting a high degree of adhesion of the clad material to the tool. Therefore, a high degree of sticking or even full sticking may occur for $r \leq R_{T r}$. In the region with radii larger than $R_{T r}$, the interface is smooth and fairly straight ${ }^{1}$. No clad material remained attached to the tool suggesting that the adhesion was poor and more slip occurred than that for $r \leq R_{T r}$. These observations are in line with the typical pressure distributions present in the clad material during FSC, see an example shown in Fig. 5.4. Slip occurs if the generated shear stress (i.e. friction stress) at the tool-clad material interface is smaller than the shear stress exerted by the clad material. Such a condition is easier to achieve in the region near the outer edge of the tool where the normal pressure is usually relatively low.

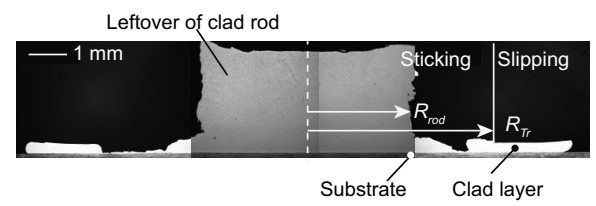

Fig. 5.8 A representative cross section extracted from the end of the cladding path in experiment EH-04. Note: The substrate is located beneath the clad layer and only a small part of the substrate is visible here.

The influence of the contact status at the tool-clad layer interface on the generated heat and the normal force is explored as follows. The experimental observations made above (see Fig. 5.8) indicate that full sticking or a high ratio of sticking to slipping occurs at the tool-clad layer interface for $R_{\text {rod }} \leq r \leq R_{T r}$. Here, full sticking is assumed in this region, i.e. $\delta_{\theta}=\delta_{r}=1$. For radii beyond the transition point, i.e. $R_{T r} \leq r \leq r_{o}$, slipping may occur. Here, it is assumed that the degree of slip at the tool-clad material interface in the circumferential direction under FSC conditions is pressure dependent, which is incorporated in a radius dependent function of the sticking factor. It attains a value equal to $\delta_{\theta}=1$ at $r \leq R_{T r}$, representative of full sticking and $\delta_{\theta, \min }$ at $r=r_{0}$. The value of $\delta_{\theta, \min }$ should be small enough to prevent significant heat generation at the tool edge and provide a smooth kinematic transition of the clad material moving out of the clad disk domain. In the radial direction the shear rates are in general orders of magnitude smaller than in the circumferential direction, see also Section 5.2. The same holds for the shear stresses in the respective directions. Hence, as soon as some slip occurs in the circumferential direction, full slipping is assumed for the radial direction. Therefore, the contact status at the tool-clad layer interface is described by

$$
\delta\left(\delta_{\theta}, \delta_{r}\right)= \begin{cases}\delta_{\theta}=1, \delta_{r}=1 & r<\alpha r_{o} \\ \delta_{\theta}=\left(\frac{r-r_{o}}{\alpha-r_{o}}\right)^{s}\left(1-\delta_{\theta, \text { min }}\right)+\delta_{\theta, \text { min }}, \delta_{r}=0 & \alpha r_{o} \leq r \leq r_{o}\end{cases}
$$

1 The bottom of the FSC tool is slightly profiled. Therefore, the tool-clad material interface may not be perfectly straight, see also Chapter 2 . 
where $s$ represents the shape parameter of the functional behavior of $\delta_{\theta}$ between $\alpha r_{o}$ and $r_{0}$. If $\alpha r_{o}$ is smaller than the radius of the tool opening, $r_{i}$, the value of $\alpha$ is made equal to $r_{i} / r_{0}$, such that the transition from sticking to slipping does not occur within the clad rod.

The influence of the transition from full sticking towards partial slip at $r=\alpha r_{0}$ is studied for an example case with $h_{0}=0.2 \mathrm{~mm}, W=16.8 \mathrm{~mm}, \Omega=300 \mathrm{rpm}$ and $D_{\text {rod }}$ $=10 \mathrm{~mm}$, corresponding to the experimental conditions of experiment EH-02. This case has also been studied in Section 4.3.1. An average temperature of $390^{\circ} \mathrm{C}$ in the clad layer beneath the FSC tool is adopted. Furthermore, $\delta_{\theta}$ is described by a transition from full sticking to partial slip at $\alpha=0.65$, in line with experimental observations (see Fig. 5.8), $s=1.5$ and $\delta_{\theta, \min }=0.01$.

(A) Velocity $\left(u_{r}, u_{z}\right)[\mathrm{m} / \mathrm{s}]$

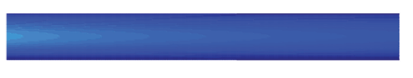

(B) Total shear rate $\left[\mathrm{s}^{-1}\right]$

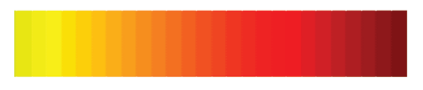

(C) Pressure $[\mathrm{MPa}]$
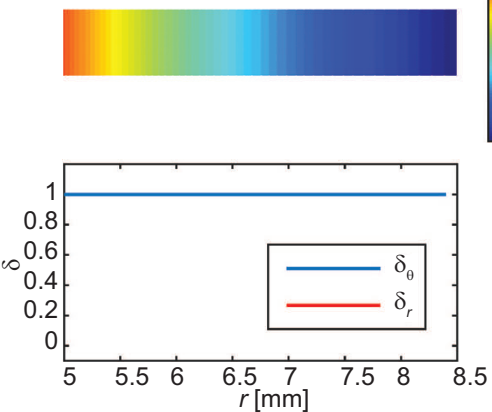

(a) Full sticking
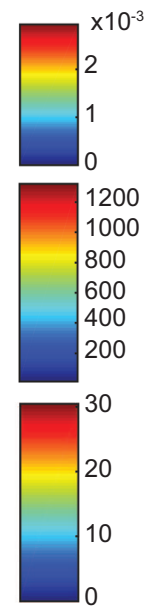

(A) Velocity $\left(u_{r}, u_{z}\right)[\mathrm{m} / \mathrm{s}]$

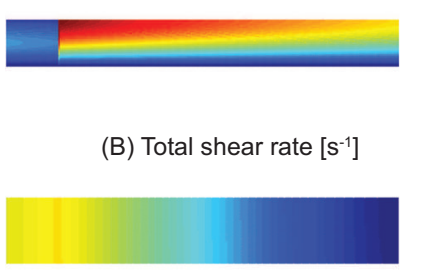

(C) Pressure [MPa]
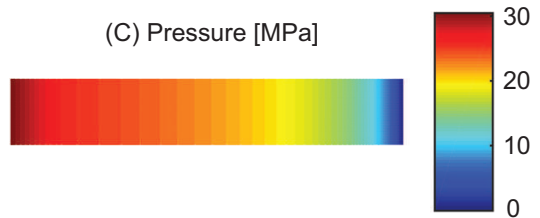

(b) Full sticking

Fig. 5.9 The magnitude of the radial and vertical velocity ( $r$ and $z$ components), the total shear rate, the pressure distributions in the clad material and the $\delta$ distributions in the clad disk ring subdomain calculated for an example at $\Omega=300 \mathrm{rpm}, h_{0}=0.2 \mathrm{~mm}, W=16.8 \mathrm{~mm}$ and $D_{\text {rod }}=10 \mathrm{~mm}$ : (a) full sticking; (b) partly sticking/slipping.

The results are shown in Fig. 5.9 where the case of full sticking is shown in the left column and the results where some slip at the tool-clad material interface is included in the right column. The top row of images in the figure shows the velocity magnitude of the $r$ and $z$ components of the clad material beyond $R_{T r}$. The transition from full sticking to partial slipping in the circumferential direction and to 
full slipping in the radial direction is clearly visible. The transition also has a strong effect on the total shear rate distribution as shown by the second row of images. The high strain rates at the outer edge of the FSC tool, with values above $1000 \mathrm{~s}^{-1}$ for the full sticking case, do not appear when considerable slip occurs near the outer edge, see the right-hand side image at the second row. This is in line with experimental results. Consequently, the pressure distribution is also modified towards higher values when slipping occurs. The lower total shear rate levels in the clad disk domain that occur for this case lead, for the strongly shear thinning AA1050 clad material, effectively to higher viscosities, explaining the observed pressure rise.

In conclusion, the incorporation of slip at the tool-clad material interface leads to substantial changes in the total shear rate and pressure distributions. In turn, the smaller magnitude of the total shear rate causes a significant decrease in the total generated heat, whereas the increase in the pressure causes a concomitant increase in the normal force. The comparison of the model results with the experimental results in Fig. 5.7 already indicated that the assumption of full sticking led to an overestimation of the heat generated by a factor of more than two. Hence, with a suitable description of the sticking/slipping conditions at the tool-clad material interface the estimated generated heat can be decreased to acceptable values. Similarly, the normal force exerted at the substrate surface can be increased to values that are closer to those measured experimentally, although the large scatter observed in the normal force values may obscure such a trend.

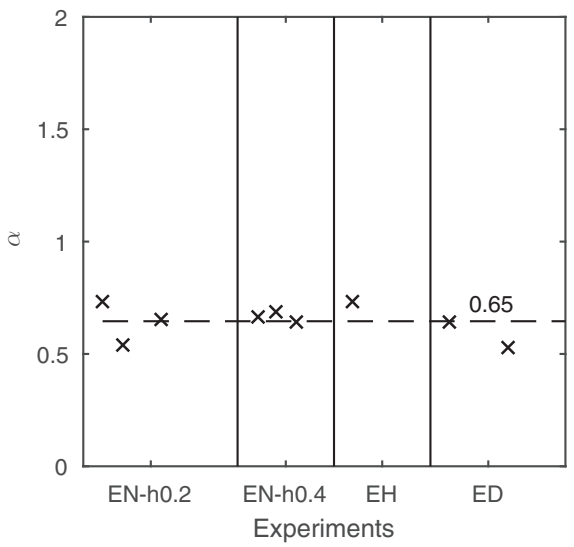

(a)

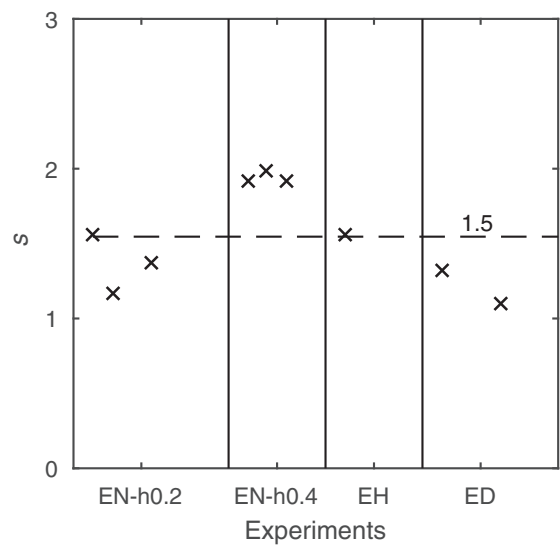

(b)

Fig. 5.10 The values of $\alpha(a)$ and $s(b)$ describing the functional relation of $\delta_{\theta}$ for all experiments where the generated heat and normal force can be fitted to the respective values determined from the experiments.

Subsequently, the functional description of the sticking factors for all experiments has been optimized. The values of the $\alpha$, indicating the relative position of the transition from full sticking to partial slip, and the shape factor $s$ of the function describing the circumferential component of $\delta$ are varied, such that the calculated generated heat and normal force exerted on the substrate are equal to the values 
determined from the respective experiments. In all cases the actual clad layer dimensions, tool rotation rates and tool opening diameters have been used. The average temperature in the clad layer is not available, but the temperature measured by $T C_{3}$ is used along with the earlier mentioned estimated temperature difference between the $T C_{3}$ temperature and the average temperature in the clad layer, see above. The value of $\delta_{\theta, \min }$ also remained unchanged. The results are shown in Fig. 5.10.

The best values of $\alpha$ and $s$ can only be determined for a limited number of cases, as visible in Fig. 5.10. For these cases the range of values of $\alpha$ are in reasonable agreement with the position of transition points in experiments, such as those shown in Fig. 5.8. The values of $s$ are typically between 1 and 2. Further analysis of these results requires deeper understanding of the phenomena occurring at the tool-clad material interface during the FSC experiments.

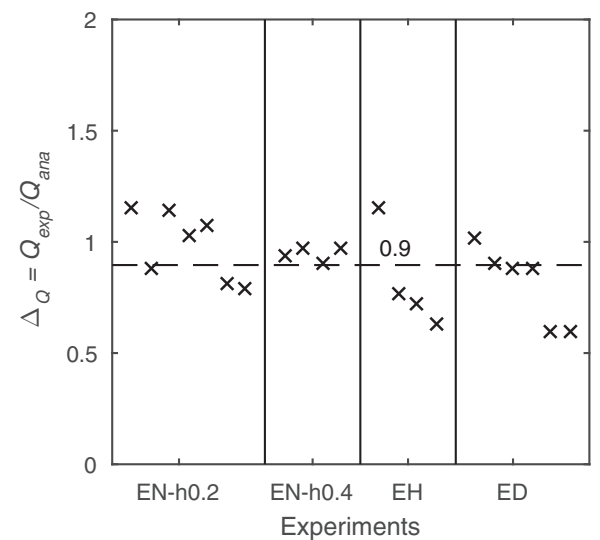

(a)

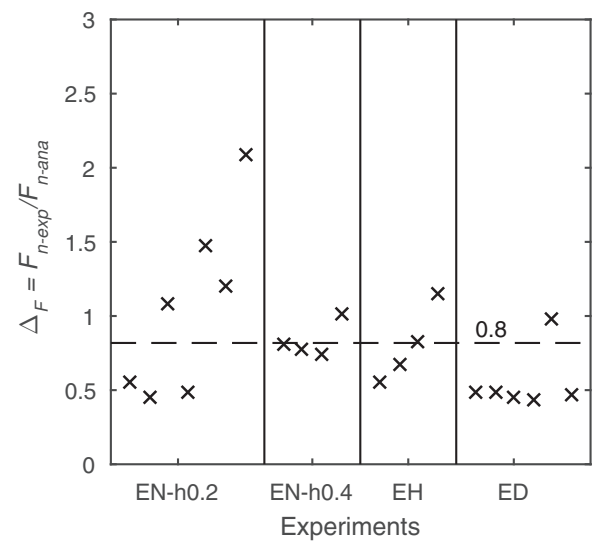

(b)

Fig. 5.11 (a) The ratio of $Q_{\exp }$ to $Q_{a n a}, \Delta_{Q}=Q_{\exp } / Q_{a n a}$; and (b) the ratio of $F_{n-\exp }$ to $F_{n-a n a}, \Delta_{F_{n}}=$ $F_{n-\exp } / F_{n-a n a}$ calculated with the contact status as described by Eq. (5.32) and $\alpha=0.65$ and $s=1.5$.

As a final step, the averages of the values of $\alpha$ and $s$ have been used to calculate the heat generation and normal force exerted of all experiments. All input data to the model remained the same as described above, except the average values for $\alpha$ and $s$ have been adopted to all experiments. The comparison is shown in Fig. 5.11. Despite the fact that only a limited number of experimental results allowed optimization of the functional behavior of the interface contact status (Fig. 5.10), a fairly good estimate of the heat generation can be made for all experiments. Apparently, the heat generation is less sensitive to small variations in experimental and interfacial contact conditions than the normal force. In the latter case some ratios $\Delta_{F_{n}}$ deviating from one can be explained from the occurrence of mixing, such as the last three data points of the EN-h0.2 series. Other possible cases will also be discussed in Chapter 7. Nevertheless, it is encouraging that the results for the EN-h0.4 experiments are predicted rather well, also for the normal force. 
So, the nature of the model does not yet allow a complete quantitative comparison with the experimental results, but it does provide understanding of the role of the contact status on the generated heat and the normal force. The true contact status may depend on the process conditions (tool rotation rate and translation speed) and layer dimensions (the width and thickness) as well as the process temperature and the tool design.

\subsection{Conclusions}

In this chapter a closed form, axisymmetric, isothermal friction surface cladding model has been presented that has been applied to the cladding of commercially pure aluminum on an AA2024 substrate. The clad material behavior is described by that of a power law fluid, where AA1050 shows shear thinning behavior. The model calculates the generated heat in the clad material and the normal force exerted by the clad material to the substrate under steady state conditions. The contact status at the interface between the FSC tool and the clad material can be adapted as well through variation of the degree of stick/slip in both the circumferential and radial direction.

Under full sticking conditions at the tool-clad material interface it is shown that the heat generation increases with the layer width and the tool rotation rate, whereas the influence of the layer thickness is small. The normal force exerted by the clad layer on the substrate also increases substantially with the layer width, but it decreases with the layer thickness and the tool rotation rate. This last effect follows from the aforementioned shear thinning behavior of the clad material employed.

A comparison of the heat generation predicted by the model, assuming a full sticking condition at the tool-clad material interface, and the heat determined from experiments shows that the model consistently overestimates the heat generation. However, it does so with a more or less constant factor which is equal to approximately 0.45 for the current FSC setup and experiments performed. The modeled normal force exerted on the substrate is in general underestimated as compared to the values recorded experimentally.

A better description of the deformation behavior of the clad material beneath the FSC tool is obtained when slip is allowed to occur at the tool-clad material interface. A relatively straightforward description of the stick/slip behavior at the interface has been proposed. It includes a transition from full sticking to partial stick/slip at some distance from the tool opening, in line with experimental observations, and a gradual decrease towards practically a state of full slipping near the FSC tool edge. Optimization of the contact status description for the FSC tool with the $10 \mathrm{~mm}$ opening diameter has shown that the transition from full sticking to partial slip typically occurs at values corresponding to about 0.65 times the clad layer width. Employing this value for the prediction of the heat generation shows that the model results compare well with the corresponding experimental results. 
The prediction of the normal force with the current analytical FSC model is somewhat cumbersome. The model does provide normal force values that are of the same order of magnitude as those observed experimentally, but further study is required as to the causes of the observed differences between experimental and model results. 


\section{References}

Arora, A., Zhang, Z., De, A., and DebRoy, T. (2009). Strains and strain rates during friction stir welding. Scr. Mater., 61(9):863-866.

Huang, M. and Tzou, G. (2002). Study on compression forming of a rotating disk considering hybrid friction. J. Mater. Process. Technol., 125-126:421-426.

Na, T. Y. and Hansen, A. G. (1967). Radial flow of viscous non-Newtonian fluids between disks. Int. J. Non. Linear. Mech., 2:261-273.

Prasad, Y. and Sasidhara, S. (1997). Hot Working Guide: A Compendium of Processing Maps. ASM International.

Reilly, A., Shercliff, H., Chen, Y., and Prangnell, P. (2015). Modelling and visualisation of material flow in friction stir spot welding. J. Mater. Process. Tech., 225:473-484.

Schmidt, H., Hattel, J., and Wert, J. (2004). An Analytical Model for the Heat Generation in Friction Stir Welding. Model. Simul. Mater. Sci. Eng., 12(1):143-157.

Sutera, S. P. and Skalak, R. (1993). The History of Poiseuille Law. Annu. Rev. Fluid Mech., 25:1-19.

Winter, H. H. (1975). Approximate calculation and measurement of the pressure distribution in radial flow of molten polymers between parallel discs. Polym. Eng. Sci., 15:10. 


\section{A Validation of the analytical model}

\section{A.1 Material}

The clad material is temperature and strain rate dependent and is defined as a power law fluid shown in Eq. (5.1). The flow stress of the clad material calculated with the values of $m$ and $n$ shown in Fig. 5.2 agrees well with the experimental data and the Zener-Hollomon based one, see Fig. 5.A.1.

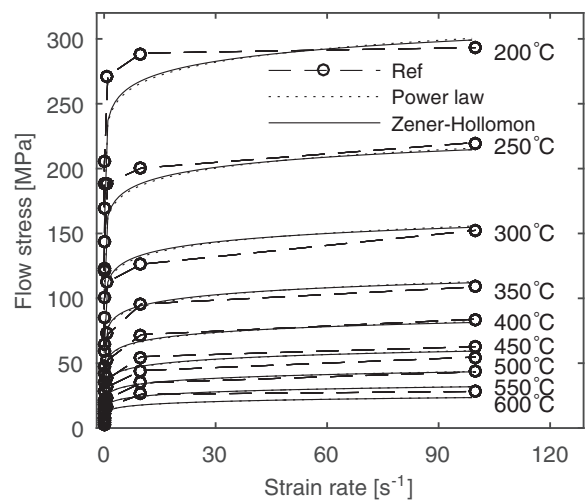

Fig. 5.A.1 The strain rate and temperature dependent flow stress of commercially pure aluminum AA1050. The curves with markers represent the experimental data from Prasad and Sasidhara (1997); set of solid lines without markers represent the Zener-Hollomon based stress in Eq. (4.1) in Chapter 4 and the dotted lines are the power law defined flow stress.

\section{A.2 Model validation}

The total heat generation and the normal force calculated by the analytical model presented are validated by the axisymmetric thermo-mechanical model described in Chapter 4. The power law defined material properties are used in the validation, and thus the clad material is isothermal. Both models provide identical results of the heat generation and the normal force, see Figs. 5.A.2 and 5.A.3, respectively. This confirms the accuracy of the analytical approach. 


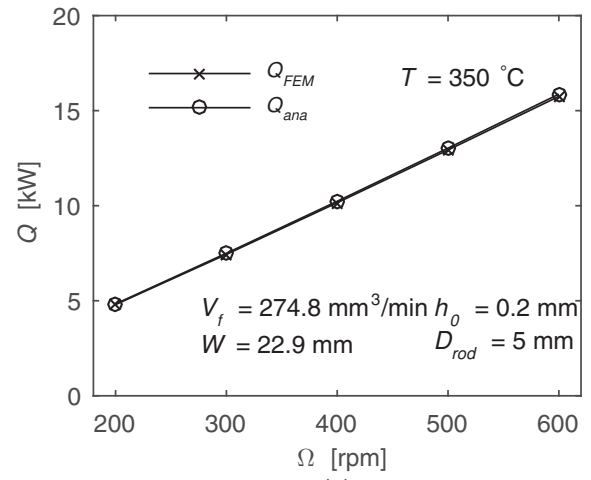

(a)

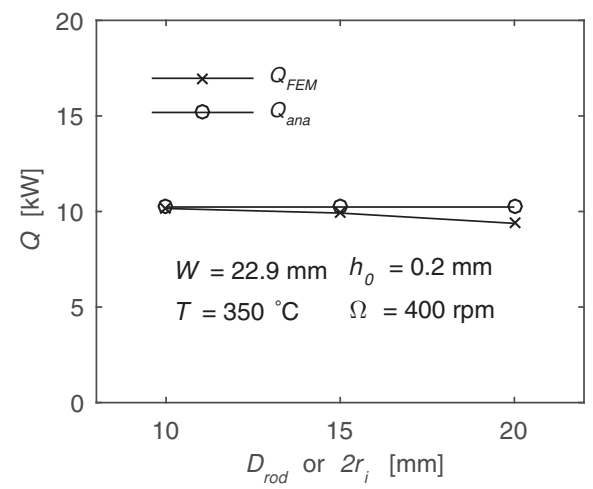

(c)

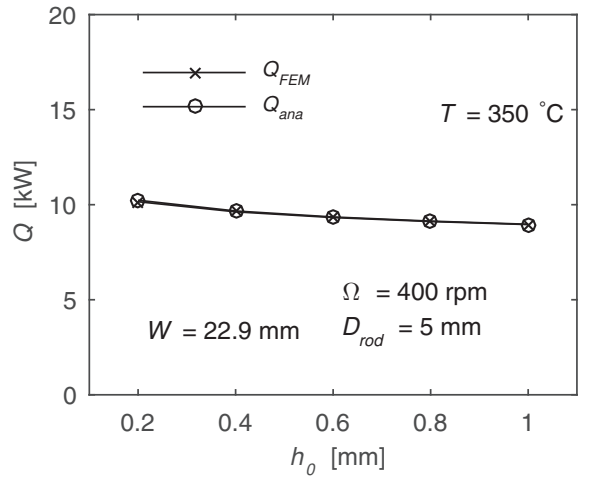

(b)

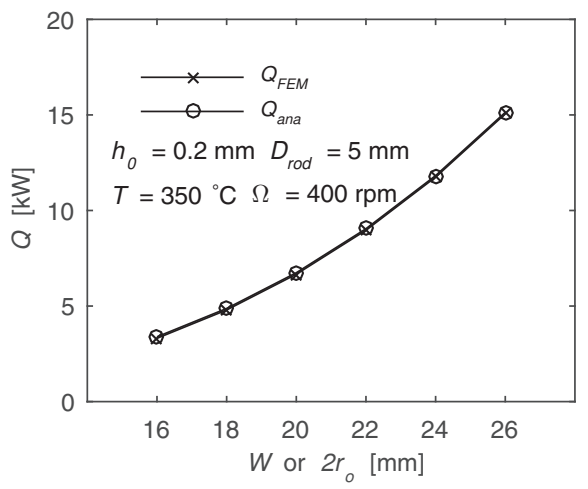

(d)

Fig. 5.A.2 The total heat generation calculated by the FEM $\left(Q_{F E M}\right)$ and the analytical solution ( $\left.Q_{a n a}\right)$ at $350^{\circ} \mathrm{C}(m=42 \mathrm{MPa}, n=0.0818)$. 


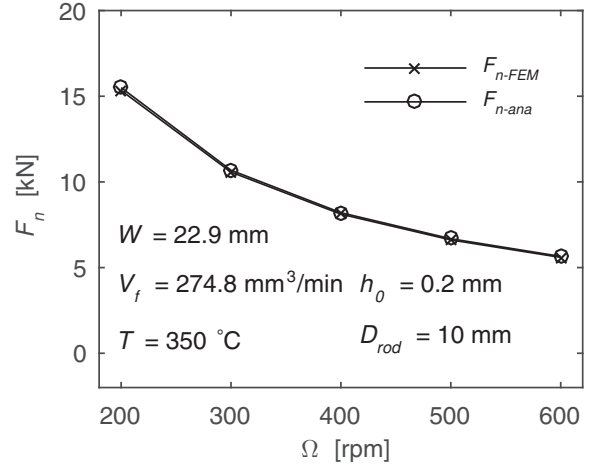

(a)

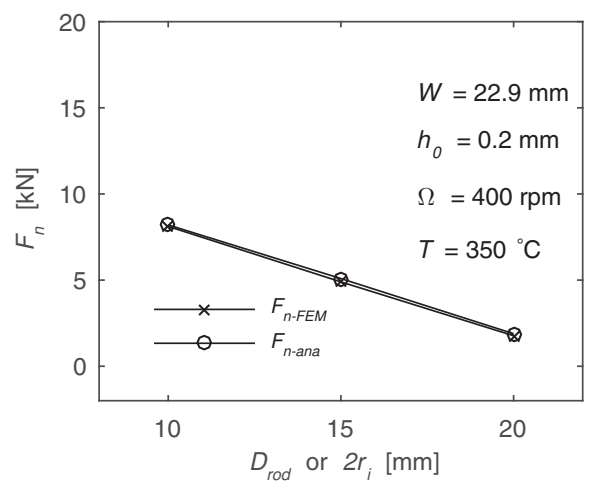

(c)

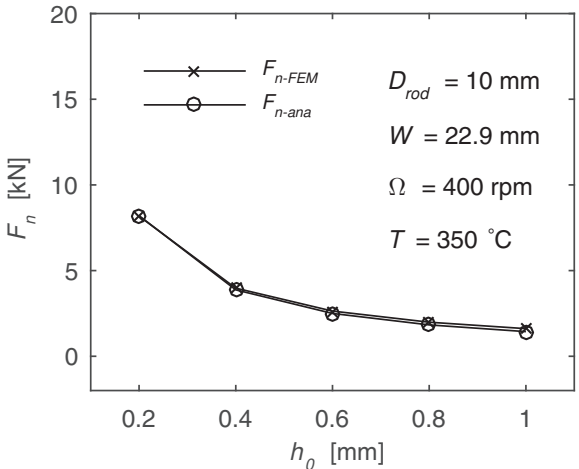

(b)

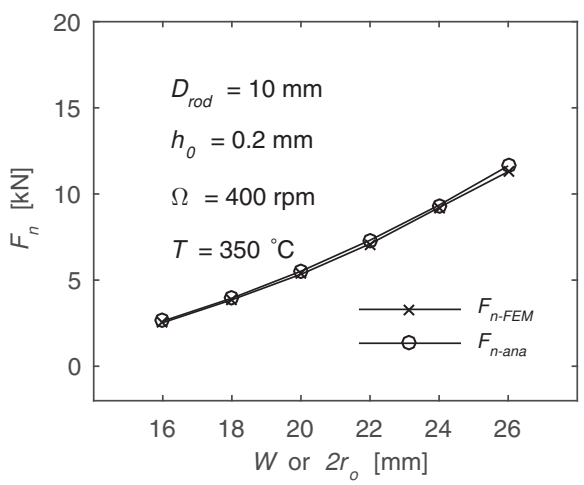

(d)

Fig. 5.A.3 The total normal force calculated by the FEM $\left(F_{n-F E M}\right)$ and the analytical solution $\left(F_{n-a n a}\right)$ at $350{ }^{\circ} \mathrm{C}(m=42 \mathrm{MPa}, n=0.0818)$. 


\section{СHAPTER 6}

\section{Process window determination}

\subsection{Introduction}

The friction surface cladding process is developed to deposit thin metallic layers on a substrate, which may be used, for example, for surface protection. Then, the substrate beneath the cladding trajectory should be covered completely with continuous and defect free layers to improve the resistance against corrosion. Meanwhile, the temperatures and pressures generated during the manufacturing process should have a negligible effect on the dimensions and mechanical properties of the substrate. Dedicated FSC process windows should form a guide towards meeting these requirements.

In the previous chapters (Chapters 2, 3, 4 and 5) the influence of the FSC process parameters on the cladding performance has been studied with experimental, numerical and analytical approaches. The studies show that the tool rotation rate, the layer dimensions and the size of the FSC tool opening each affect the heat generation and the normal force generated during the FSC process in specific ways. The heat generation increases with higher tool rotation rates and larger layer widths, whereas the layer thickness and the size of the tool opening have negligible effect. The normal force increases with the layer widths, but decreases with the tool rotation rates, the layer thicknesses and the diameters of the tool openings. Here, the tool rotation rate and the size of the tool opening are selected as the adjustable process parameters for the development of the process window.

The experiments described in Chapter 2 determined, to some extent, the FSC process window. Defect free layers can only be deposited with the tool rotation rate ranging between $300 \mathrm{rpm}$ and $450 \mathrm{rpm}$ for a nominal layer thickness of $0.2 \mathrm{~mm}$ and the $\varnothing 10 \mathrm{~mm}$ FSC tool. Layers tend to be discontinuous when the tool rotation rate is too low, and mixing occurs when the tool rotation rate is too high. It shows that the heat generation has a strong effect on the cladding behavior, see Fig. 2.14 in Chapter 2. The experiments were performed with a constant tool rotation rate during the cladding phase. This makes process control very straightforward and simple. However, the cladding conditions such as the supply rate of the clad material and the nominal layer thickness varied amongst the experiments. It is more 
appropriate for the determination of the process window to keep all conditions constant and vary only one variable. Here, this is achieved through a change of the tool rotation rate during the cladding phase of a single experiment.

In this chapter the FSC boundaries of the process window are first determined experimentally employing FSC tools with different tool openings. Then, the analytical model developed in the previous chapter is used along with the 3D thermal model developed in Chapter 2 to provide a functional description of the boundaries as a function of process parameters. The feasibility of the approach followed and the quality of the determined process window is investigated with two experiments performed with different process settings.

\subsection{Experimental procedure and materials}

A series of experiments is performed with different tool designs and tool rotation rates to explore the FSC process window, see Table 6.1. Three tools ( $\varnothing 10$ tool, $\varnothing 15$ tool and $\varnothing 20$ tool, see Fig. 3.1 in Chapter 3) are used in the experiments. The tool rotation rate is adjusted manually in each cladding process.

Table 6.1 The settings of experiments performed to determine the FSC process window and additional experiments performed for temperature control.

\begin{tabular}{l|c|cccc}
\hline Exp. & $\begin{array}{c}\text { Parameter } \\
\text { to study }\end{array}$ & $\begin{array}{c}D_{\text {rod }} \\
{[\mathrm{mm}]}\end{array}$ & $\begin{array}{c}h_{0} \\
{[\mathrm{~mm}]}\end{array}$ & $\begin{array}{c}\Omega \\
{[\mathrm{rpm}]}\end{array}$ & $\begin{array}{c}V_{f} \\
{\left[\mathrm{~mm}^{3} / \mathrm{min}\right]}\end{array}$ \\
\hline EP10-L & & 10 & 0.2 & $\uparrow$ & 253 \\
EP10-U & Process & 10 & 0.2 & $\uparrow \downarrow$ & 243 \\
EP15-U & window & 15 & 0.2 & $\uparrow$ & 103 \\
EP20-U & & 20 & 0.2 & $\uparrow$ & 355 \\
\hline EN-1 & $\Omega$ & 10 & 0.2 & $\downarrow$ & 264 \\
EN-2 & & 10 & 0.4 & $\downarrow$ & 380 \\
\hline
\end{tabular}

The arrows $\uparrow$ and $\downarrow$ respectively mean that the tool rotation rate rises and drops over time during the cladding process.

The lower bound of the process window is determined by experiment EP10-L performed with the $\varnothing 10$ tool and continuously increasing tool rotation rate. The upper bound of the process window for the $\varnothing 10$ tool is determined with experiment EP10-U. The tool rotation rate in this experiment increases first, followed by a decrease, to observe the influence of the tool rotation rate on the cladding performance. Experiments EP15-U and EP20-U are carried out to explore the upper bound of the process window for the $\varnothing 15$ and $\varnothing 20$ tools, respectively. The nominal layer thicknesses of all these experiments is $h_{0}=0.2 \mathrm{~mm}$.

Based on the determined process window, two additional experiments EN- 1 and EN-2 are performed with the $\varnothing 10$ tool and a layer thickness of $0.2 \mathrm{~mm}$ and $0.4 \mathrm{~mm}$, 
respectively, aimed at keeping the process temperature constant during the entire cladding phase.

The tool translation speed, the inclination angle of the tool, the supply rate of the clad material and the metallographic analysis methods such as microstructure studies and hardness measurement remain the same as described in Chapters 2 and 3 . The process window is determined to deposit commercially pure aluminum AA1050 on AA2024 substrates.

\subsection{Experimental results}

The process window of FSC comprises a lower bound and an upper bound in the temperature or heat generation domain. The lower bound is the lowest temperature or the smallest amount of heat required to deposit continuous layers. Discontinuity of the layers occurs when the temperature or the heat is below this bound, see for example Fig 2.5(A) in Chapter 2. The upper bound is defined as the highest temperature or the highest heating rate before mixing occurs. The range between the lower and the upper bound allows for fabrication of defect free layers.

\subsubsection{Cladding appearance}

The quality of the manufactured clad layers becomes clearly apparent from the top surfaces of the clad layers, see Fig. 6.1. It is observed that in experiment EP10-L discontinuities occur to the clad layer in the first $60 \mathrm{~mm}$ of the cladding distance, see Fig. 6.1(A-a). The appearance of the clad layer becomes better after the location of $T C_{2}$.

Both the temperature and the extent of plastic deformation are important for a solid state bonding process, as described by Tylecote (1968). The low process temperature (below $200^{\circ} \mathrm{C}$, see Fig. $6.1(\mathrm{~A}-\mathrm{b})$ ) induced by the low tool rotation rate of $250 \mathrm{rpm}$ (see Fig. 6.1(A-c)) employed in the beginning of the cladding phase may be responsible for the discontinuous layer. The clad material is softened insufficiently at low temperatures. Then, it is difficult to deform and press the hard clad material evenly in the narrow gap between the tool and the substrate. The clad layer appears fragmented, non-homogeneous and poorly bonded to the substrate leaving the underlying substrate in an unacceptable state, vulnerable to corrosion.

When the tool rotation rate in EP10-L is increased to $300 \mathrm{rpm}$, this improves the cladding performance greatly. A continuous and defect free layer with a layer thickness of approximately $0.2 \mathrm{~mm}$ and a layer width of $16.8 \mathrm{~mm}$ is obtained. The experiment EP10-L with a constant tool rotation rate of $300 \mathrm{rpm}$ is repeated to ensure that continuous layers can be manufactured well under these conditions. Further information on this experiment is provided in Chapter 2, see the experiment EN-h0.2-2. 
The clad layer deposited in experiment EP10-U is shown in Fig. 6.1(B-a). A defect free clad layer is observed in the beginning of the cladding track, followed by an undesired layer with some grooves where the clad material appears to be missing near the position of $T C_{3}$ when the tool rotation rate was increased. Some flash also forms at the edges of the layer especially at the RS. The clad layer recovers to a defect free layer again when the tool rotation rate is reduced at the end of the cladding phase.

The bonding interfaces from the cross sections, EP10UA and EP10UB, extracted along the cladding center line of experiment EP10-U are shown in Fig. 6.1(B-d) and (B-e). The straight bonding interface at section EP10UA indicates that the clad layer remains pure and mixing with the substrate is absent. The layer thickness is around $0.15 \mathrm{~mm}$. However, at section EP10UB part of the bonding interface is below the substrate top. This implies that some substrate material has been torn away from the substrate base and mixed with the clad material.

The cladding behavior is highly related to the tool rotation rate and the temperature. Mixing occurs at the high process temperature resulting from the relatively high tool rotation rates, see Figs. 6.1(B-b) and (B-c). At such high temperatures, the yield stress of the substrate material drops to a very low level. Moreover, the clad material during the cladding process experiences relatively high strain rate, which raises its flow stress. These two factors may lead to a yield stress of substrate being comparable with the flow stress of the clad material, indicating the point where mixing may initiate, see also Chapter 2.

When the shear stress of the material in the clad layer becomes very low, the rotating tool can drag the material to the layer edge or other positions. This may lead to flash formation and non-uniform layer dimensions. When mixing occurs, the clad layer contains both the pure aluminum and the alloying elements of AA2024. This is also unacceptable for surface protection, like the discontinuous layer in experiment EP10-L. At lower temperature, the substrate remains stronger and thus mixing disappears.

Experiments EP15-U and EP20-U are carried out with only increasing tool rotation rates. The top surfaces of the layers have a better appearance than that in experiment EP10-U, see Figs. 6.1(C-a) and (D-a). Some scratch marks on top of the layer produced in experiment EP15-U become visible in the region of M15. In experiment EP20-U, mixing starts to appear when the tool passes the position of $T C_{4}$, comparable to the observation of the surface of experiment EP10-U near $T C_{3}$.

The occurrence of the mixing phenomenon is often visible from the top surface of the layer, see the regions where scratch marks occur or clad material is absent at the substrate surface. However, mixing may start earlier than the moment when the defect becomes visible on the top surface of the layer, because it normally starts from the bonding interface and gradually extends to the top surface of the clad layer. Considering this, investigation of the cross sections in a large area before the visible mixing region is required to determine the real mixing positions. 


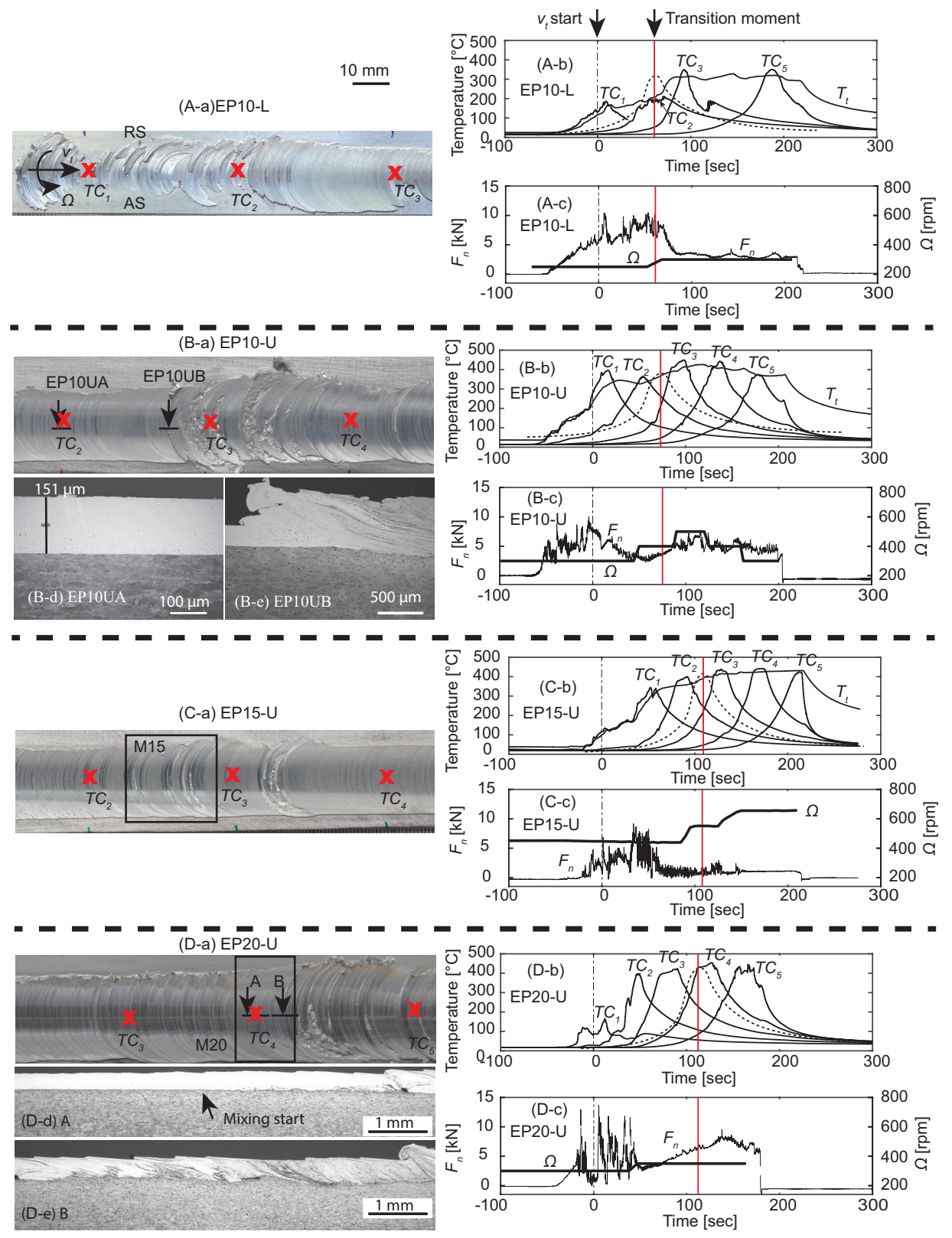

Fig. 6.1 The top views of the clad layers (left-hand column), the temperatures, the normal forces and the tool rotation rates (right-hand column) of the experiments EP10-L, EP10-U, EP15-U and EP20-U. In the top view images, markers ' $X$ ' show the positions of the thermocouples in the substrate. Note: Only part of the layers are shown. The black and the red vertical lines in the images on the right-hand side indicate the start of the cladding phase and the moment at which the transition to mixing occurs, respectively. 
An example to determine the transition point from non-mixing to mixing deposition, i.e. the mixing start moment, is shown in Figs. 6.1(D-d) and (De). Samples A and B are extracted from experiment EP20-U and they show the cladding performance near the bonding interface. The substrate top (i.e. bonding interface) starts to wave locally in the middle of section A (see the arrow pointing at this location in Fig. 6.1(D-d)), indicating that the substrate material starts to be plastically deformed. Further mixing occurs in the position of section B. This position pointed by the arrow in section $\mathrm{A}$ is thus considered as the transition point from non-mixing to mixing for experiment EP20-U. The cross sections in experiment EP15-U show similar results to those in EP20-U.

The mixing region contains alloying elements of the substrate, thus it is relatively easier to be etched chemically in comparison with the pure aluminum. As a result, the extent of mixing can be detected approximately by the etched darker area in the clad layer. This is the approach being used in this work to detect the mixing start moment. The red solid lines in the corresponding graphs on the right-hand side of Fig. 6.1, indicate the respective transition points to mixing. A more precise detection requires the chemical composition of the deposited layer to be determined along the interface, such as has been done by Van der Stelt (2014).

The tool rotation rate, the measured temperature and the corresponding post-clad layer dimensions at the mixing start moment are used in the following sections to determine the heat generation for the upper bound of the process window.

\subsubsection{Temperature, heat generation and normal force}

\section{Temperature distribution}

The distributions of the recorded temperatures can be explained well by the tool rotation rates employed, see the corresponding values of experiment EP10-L in Figs. 6.1(A-b) and (A-c). The value of $T_{t}$ remains below $200{ }^{\circ} \mathrm{C}$ in the first one third of the cladding phase and rises to over $300^{\circ} \mathrm{C}$ in the later part of the cladding track. The tool temperature is approximately $208^{\circ} \mathrm{C}$ at the transition of discontinuous to continuous clad layers marked by a solid vertical red line. The substrate temperature $T C_{2}$ seems to be unreliable since its peak value is lower than the tool temperature at the same moment. In the repeated experiment EP10-L much higher peak temperatures are observed, $290^{\circ} \mathrm{C}$ and $317^{\circ} \mathrm{C}$ registered by the thermocouples in the tool and the substrate, respectively. This is mainly related to the higher tool rotation rates applied from the beginning of the cladding process. The temperature recorded from the repeated EP10-L is eventually selected as the lower bound of the temperature to ensure the deposition of continuous layers: $T_{\text {lower }}=317^{\circ} \mathrm{C}$.

The temperature profiles of the experiments performed to determine the upper bound of the cladding process are shown in Fig. 6.1(B, C and D). The tool and the substrate temperature at the mixing start point of the experiment EP10-U are around $390^{\circ} \mathrm{C}$ and $407^{\circ} \mathrm{C}$ ( $\left.T_{\text {upper }}\right)$, respectively. A tool temperature of $390^{\circ} \mathrm{C}$ and a substrate temperature of around $417^{\circ} \mathrm{C}$ are observed in the experiment EP15-U. 
A substrate temperature of $427^{\circ} \mathrm{C}$ is found for the experiment EP20-U. The tool temperature is unavailable for this experiment. These experimental observations show that mixing occurs at a roughly constant temperature, regardless of the tool opening diameter. This, to some extent, confirms the previous study that the tool opening diameter plays a negligible role in the heat generation and the temperature. The lowest substrate temperature among these experiments is considered as the upper bound temperature of the FSC process window to ensure non-mixed clad layers, $T_{\text {upper }}=407^{\circ} \mathrm{C}$.

All the experiments performed for the process window exploration present almost identical process temperatures at the mixing start points. However, the tool rotation rates employed at these points differ from one experiment to another, see Fig. 6.2. This is related mainly to the layer width deposited by each experiment. To generate the same amount of heat, wider layers require lower tool rotation rates (see EP20-U; $\Omega=350 \mathrm{rpm}, W_{s}=24 \mathrm{~mm}$ ) and higher tool rotation rates to produce smaller layer widths (see EP15-U; $\Omega=550 \mathrm{rpm}, W_{s}=19 \mathrm{~mm}$ ). The results are in line with the thermo-mechanical model results in Chapter 4 and the analytical model results in Chapter 5. Nevertheless, upper and lower bounds of the heating rates are still good indicators for the development of a process window as will be shown next.

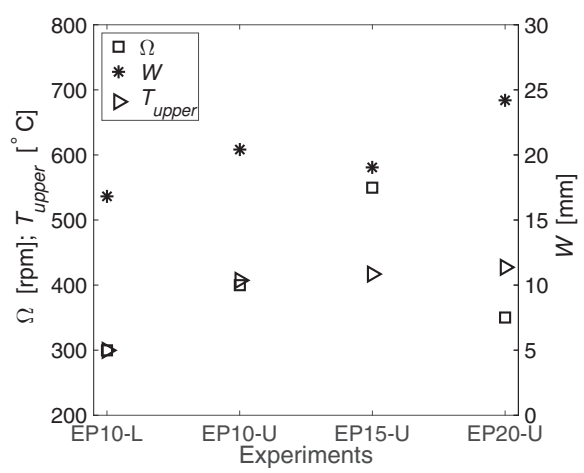

Fig. 6.2 The average layer width $(W)$, the tool rotation rate $(\Omega)$ and the substrate temperature at the mid plane $\left(T_{\text {upper }}\right)$ near the mixing points in these experiments.

\section{Estimation of heat generation}

The 3D thermal model described in Chapter 2 provides an approach to estimate the effective heat generation for the experiments. The heat input is obtained by fitting the simulated temperatures to the measured ones using the actual layer widths. The temperature distributions in the substrate at the transition points of experiments EP10-L, EP10-U, EP15-U and EP20-U can also be estimated, see the data in Fig. 6.3. It is found that experiment EP20-U requires most heat, $2.33 \mathrm{~kW}$, to explain the highest temperatures as compared to EP10-U $(1.93 \mathrm{~kW})$ and EP15-U $(1.97 \mathrm{~kW})$. The smallest heat generation of these experiments, $1.93 \mathrm{~kW}$, is selected as the upper 
bound of the heat generation process window to ensure non-mixing, see the top edge of the gray area in Fig. 6.3. The lower bound is $1.35 \mathrm{~kW}$, obtained from the repeated experiment EP10-L, which defines the bottom edge of the gray area.

The experiments presented in Chapter 2, to some extent, also show the process window for FSC. It is observed that defect free layers can be produced with tool rotation rates between $300 \mathrm{rpm}$ and $450 \mathrm{rpm}$. The largest heat generation estimated for the experiments in this range of the tool rotation rates occurred in experiment EN-h0.2-3 $(\Omega=400 \mathrm{rpm}), 2.15 \mathrm{~kW}$. It is between $1.93 \mathrm{~kW}$ and $2.33 \mathrm{~kW}$, the minimum and maximum heat for experiment EP10-U, EP15-U and EU20-U, bearing a close resemblance.

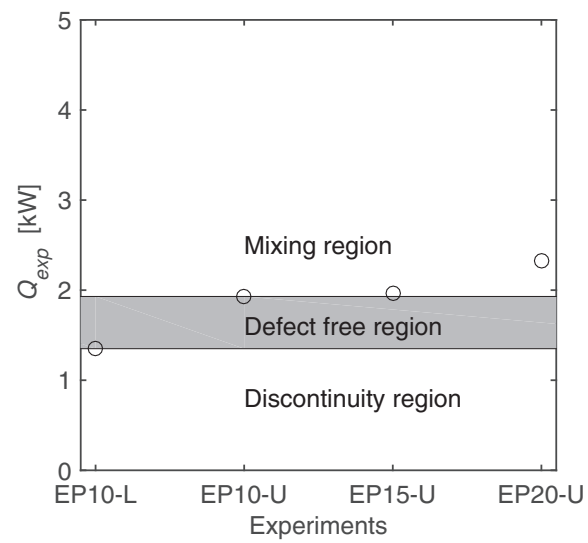

Fig. 6.3 The heat generation, $Q_{\text {exp }}$, of experiments EP10-L, EP10-U, EP15-U and EP20-U calculated by the 3D thermal model in Chapter 2. The two horizontal lines with the process window in between are the upper and lower bound for desired deposition.

\subsubsection{Normal force}

The measured normal forces vary substantially over time in the cladding phase of the EP series of experiments in line with the variation of the rotation rate and, in line with the parameter study discussed in Chapters 4 and 5.

A simple model to determine the mixing transition for the experiments performed was introduced in Chapter 2, see Eqs. (2.2) and (2.3). Here, this model is used again to study the relation of the mixing behavior with the normal force, the heat generation and the tool rotation rate. The yield stresses of the substrate used here to calculate the ratio of $\sigma_{e f f} / \sigma_{y}$ are the values measured by Prasad and Sasidhara (1997) from a compression test. Since the substrate is also under compression in the FSC process, these values may be more suitable than the ones used in Chapter 2, where were obtained by Gilbert Kaufman (1999) from a tensile test. The yield stresses used here should be the values at the temperature of the bonding interface, which, however, are currently unavailable. Given this, the yield stresses at $300^{\circ} \mathrm{C}$ and $350{ }^{\circ} \mathrm{C}$, which may represent the temperature to initiate the bonding, are used 
to calculate the ratio for the lower bound of deposition and the values at $400{ }^{\circ} \mathrm{C}$ and $450^{\circ} \mathrm{C}$ are used to calculate the ratio for the mixing point.

The values of $\sigma_{e f f} / \sigma_{y}$ at the transition points of each experiment (transition from discontinuity to continuity for experiment EP10-L and from non-mixing to mixing for experiments EP10-U, EP15-U and EP20-U) are shown in Fig. 6.4. The ratio $\sigma_{e f f} / \sigma_{y}<1$ is observed for experiment EP10-L, indicating no mixing. The ratios of the other three experiments equal approximately 1 , indicating mixing of the clad material with the substrate. These are in line with the experimental observations.

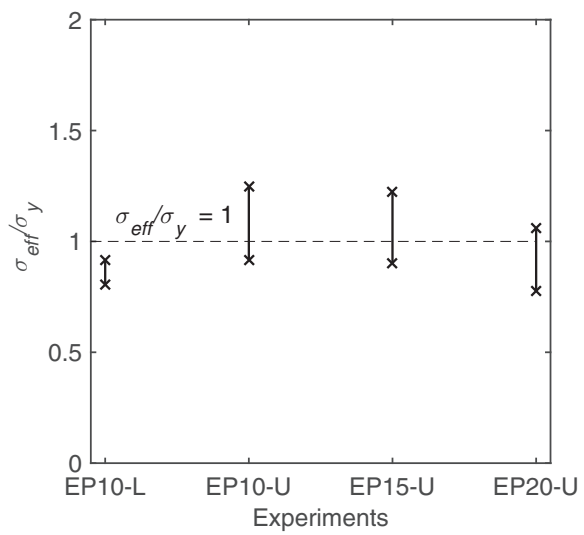

Fig. 6.4 The ratio of the applied effective stress $\sigma_{\text {eff }}$ to the yield stress of the substrate material $\sigma_{y}$ obtained at low strain and strain rate from Prasad and Sasidhara (1997). The upper and lower values for each experiment are calculated with yield stresses of the substrate material at $300^{\circ} \mathrm{C}$ and $350^{\circ} \mathrm{C}$ for the experiment EP10L, and $400^{\circ} \mathrm{C}$ and $450^{\circ} \mathrm{C}$ for the experiments EP10U, EP15U and EP20U.

\subsection{Model based process window}

It is known that both low process temperature and small normal force are required to limit the effect exerted by the cladding process on the mechanical properties of the substrate. A process window considering both the heat generation and the normal force should be established to provide a proper guideline for future work. However, the cladding performance is less sensitive to the normal force than to the heat generation. Defect free layers can be deposited with the measured normal force varying from $1.5 \mathrm{kN}$ to $5 \mathrm{kN}$. When the layer becomes thicker or the diameter of the tool opening becomes larger, the normal force can even be lower. Though the normal force reaches $5 \mathrm{kN}$, mixing may still not occur when the temperature is low. Therefore, in this section the process window will be determined mainly using the temperature and the heat generation.

The process window of the heat generation can be connected to the process parameters. The 3D thermal model described in Chapter 2 can be used to build a relation between the heat generation $\left(Q_{\text {exp }}\right)$, the layer width and the substrate 
temperature $\left(T C_{3}\right)$. It can be described as,

$$
Q_{\exp }=\beta_{1} \cdot T C_{3} \cdot \sqrt{W}
$$

with $\beta_{1}=33.35$ being a fitting constant ${ }^{1}$, see Fig. 6.5 . The heat generation is derived with the analytical model in Chapter 5 as

$$
Q_{a n a}=\pi m \frac{\omega^{1+n} W^{3+n}}{2^{n+2}(3+n) h_{0}^{n}} .
$$

It presents the correlation between the produced heat and the process variables. The heat generation obtained by these two approaches is related with a factor of $Q_{\text {exp }} / Q_{\text {ana }} \approx 0.45$, see Chapter 5 .

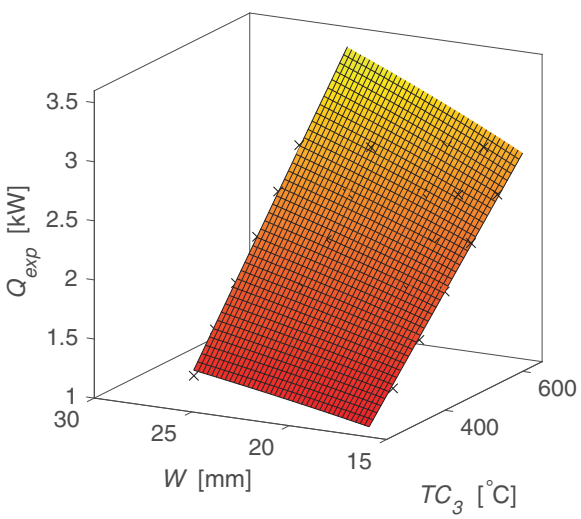

Fig. 6.5 The relation (see Eq. (6.1)) between the layer width, the peak substrate temperature and the heat generation obtained from the $3 D$ thermal model in Chapter 2.

The temperature $T C_{3}$ in Eq. (6.1) is the peak value of the substrate temperature. However, the temperature of the clad layer is required to determine the values of $m$ and $n$ for the calculation of the heat generation in Eq. (6.2). The thermal models in Chapters 2 and 4 show that the temperature in the clad layer is around $30{ }^{\circ} \mathrm{C}$ higher than the peak value in the substrate as mentioned before. This value can be used here to estimate the temperature in the clad layer. With the observed lower and upper temperatures in the experiments, $T_{\text {lower }}$ and $T_{\text {upper }}$, respectively, the process window can be determined based on the models, see Fig. 6.6. The temperature measured by $T C_{3}$ should be higher than $T_{\text {lower }}=317^{\circ} \mathrm{C}$ and lower than $T_{\text {upper }}=407^{\circ} \mathrm{C}$ to ensure both continuous and non-mixing layers, as mentioned in Section 6.3.2.

The two curves with labels of $T_{\text {lower }}=317^{\circ} \mathrm{C}$ and $T_{\text {upper }}=407^{\circ} \mathrm{C}$ in Fig. 6.6 show the lower and upper bound of the FSC process window, respectively. The lowest tool rotation rate is limited to $250 \mathrm{rpm}$ by the current cladding setup, see the vertical

$\overline{1}$ The units in Eq.6.1 are not modified, and the unit of $Q_{\exp }$ is $[\mathrm{kW}], \mathrm{TC}_{3}\left[{ }^{\circ} \mathrm{C}\right]$ and $W[\mathrm{~mm}]$. 
line. As a result, the area between the two curves on the right-hand side of the vertical line is the optimal region within the process window for manufacturing of defect free clad layers.

The experiments described in Chapters 2 and 3 are also shown in Fig. 6.6. Mixing occurs in the EN-h0.2 series of experiments carried out with the tool rotation rates of $500 \mathrm{rpm}, 550 \mathrm{rpm}$ and $600 \mathrm{rpm}$, represented by markers with black faces. The experiment ED20B-1 is shown by the yellow marker, and mixing occurs at the end of this experiment. The experiment carried out with $300 \mathrm{rpm}$ in the EN-h0.2 series is located nearly on the lower bound of the process window, see the green marker. No mixing is observed experimentally in the experiments represented by the markers with red faces, which, however, are located above the upper bound of the process window. This deviation is related to the selected upper bound of the temperature which is the smallest value of the mixing temperatures observed in the EP series of experiments to ensure non-mixing. When the process temperature is slightly higher than the upper bound, mixing may still not happen, which can be seen from the EP20-U experiment where mixing occurs at $427^{\circ} \mathrm{C}$. Nevertheless, the current cladding quality of most experiments performed can be predicted well by the process window.

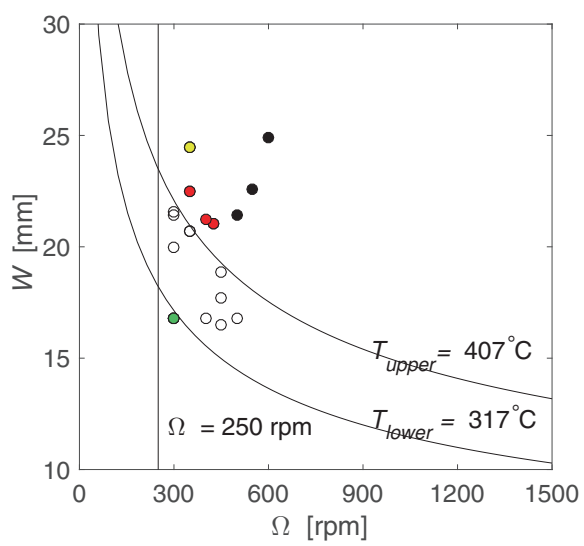

Fig. 6.6 Map of the model based process window of FSC. The circles are the experiments described in Chapters 2 and 3. The values of $h_{0}=0.2 \mathrm{~mm}$ and $D_{\text {rod }}=10 \mathrm{~mm}$ are used in the estimation of the process window.

The process window shown in Fig. 6.6 is calculated using the layer thickness of $0.2 \mathrm{~mm}$ and the diameter of the tool opening of $10 \mathrm{~mm}$. According to the study in Chapters 2 and 4, both the layer thickness and the opening size exert negligible effects on the heat generation. Therefore, the determined process window can be used for a large range of layer thicknesses and tool opening sizes. 


\subsection{Temperature controlled process}

The model based process window shown in Fig. 6.6 indicates that defect free layers can be produced with the tool rotation rates and the layer widths between the two curves bounds. Accordingly, both parameters can also be adjusted during the cladding process to optimize the cladding performance. For instance, the preheating phase takes, in general, $100 \mathrm{~s}$ to heat the cladding system to a proper temperature, see Chapters 2 and 3. This can be shortened by applying higher tool rotation rates in this phase. Lower tool rotation rates can be used in the cladding phase to lower and stabilize the process temperature. The layer width can be controlled by adjusting the supply rate of the clad material. However, a constant supply rate is normally required to produce a uniform layer width. Moreover, the current setup allows a better control of the tool rotation rate than that of the supply rate. Given these conditions, the cladding process can best be controlled with varying tool rotation rates and a constant supply rate of the clad material.

Experiments EN-1 and EN-2 with nominal layer thicknesses of $0.2 \mathrm{~mm}$ and $0.4 \mathrm{~mm}$, respectively, are performed based on the theory stated above. Both layers are characterized by smooth top surfaces, uniform layer dimensions and no defects, see Fig. 6.7. The employed tool rotation rates are illustrated in Fig. 6.8. The rotation rates of around $400 \mathrm{rpm}$ and $420 \mathrm{rpm}$ are used in the preheating phases of EN-1 and EN-2, respectively. They drop to around $300 \mathrm{rpm}$ after the tool starts to translate, followed by slower reduction in the cladding phase. The cross sections of these two experiments are similar to the desired ones as shown in Fig. 6.1(B-d), but with different layer thickness.

$10 \mathrm{~mm}$

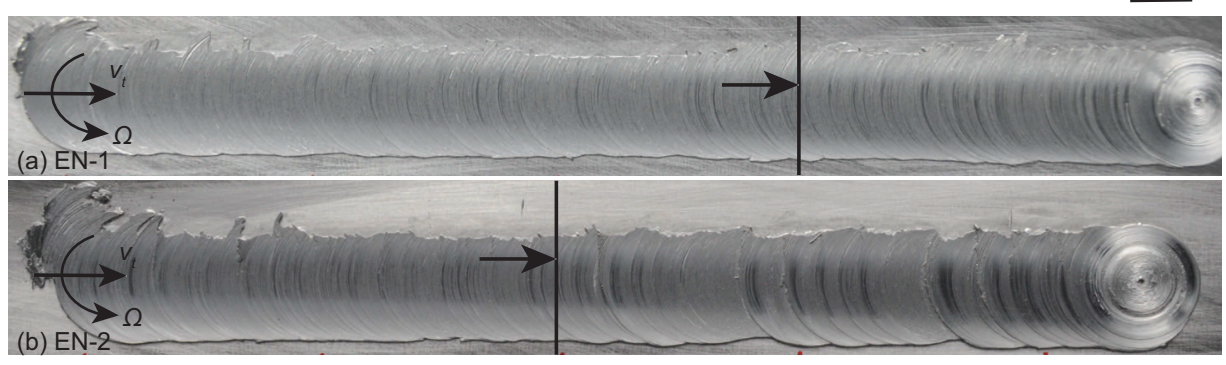

Fig. 6.7 The top views of the clad layers deposited in experiments EN-1 (a) and EN-2 (b). The vertical lines represent the positions of the cross sections for hardness measurement shown in Fig. 6.9.

The measured temperatures both in the tool and in the substrates remain fairly constant in the entire cladding process, see Fig. 6.8. The tool rotation rates are adjusted manually in these two experiments and this explains the uniform temperature distributions over time. The decreasing tool rotation rates also make the measured normal forces increase for both experiments, which is in agreement with the relations observed in Chapter 5, see Fig. 5.5. The clad material behaves 
identically under constant cladding temperatures, enabling a constant FSC process.

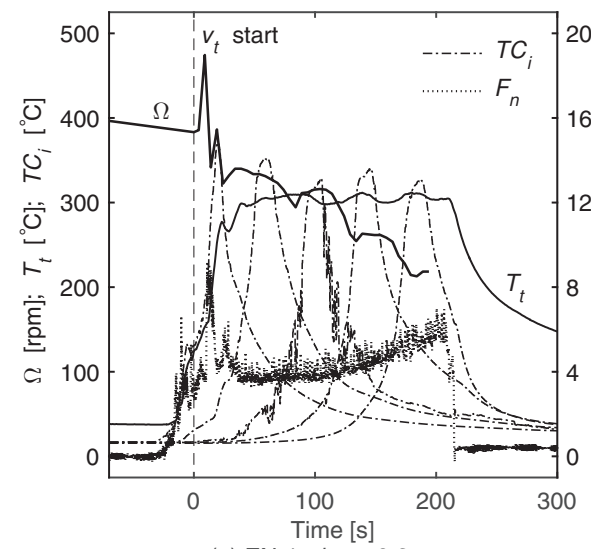

(a) EN-1; $h_{0}=0.2 \mathrm{~mm}$

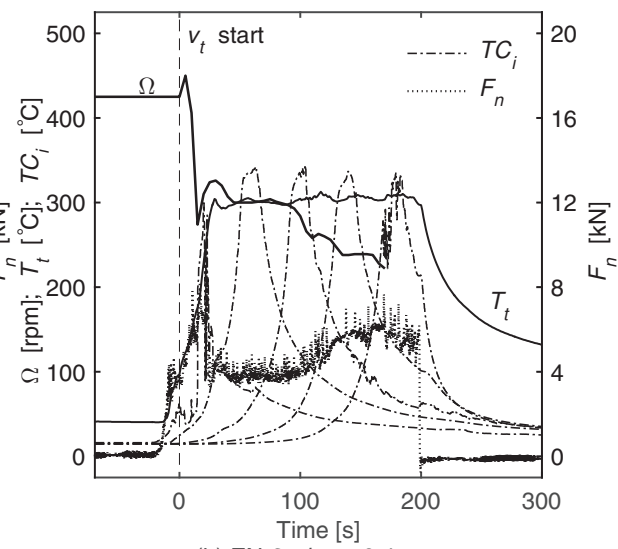

(b) $\mathrm{EN}-2 ; h_{0}=0.4 \mathrm{~mm}$

Fig. 6.8 The temperatures $\left(T C_{i}\right.$ with $i=1,2,3,4,5$ and $\left.T_{t}\right)$, the normal forces $\left(F_{n}\right)$ and the tool rotation rates $(\Omega)$ of experiments $E N-1(a)$ and $E N-2(b)$.

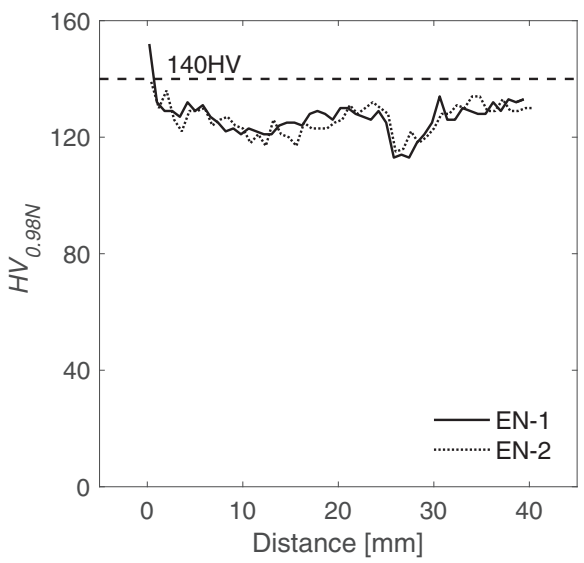

Fig. 6.9 The hardness distributions at the mid planes of the substrates deposited in experiments EN-1 and EN-2 as a function of the distance of the point measured to the substrate edge at the AS.

Fig. 6.9 shows the hardness at the mid planes of the substrates measured from the transverse sections extracted along the vertical solid lines marked in Fig. 6.7. The identical temperatures of these two experiments explain well the uniform hardness distributions. The relatively low process temperature ensures limited hardness reduction, $<15 \%$. The correlation between the hardness and the thermal history discovered by Jones et al. (2005) and Khodir et al. (2006) explains the hardness distributions. 


\subsection{Conclusions}

In this chapter the FSC process window has been determined mainly based on the temperature and the heat generation from a series of experiments performed with a layer thickness of $0.2 \mathrm{~mm}$ and three different FSC tools. The tool rotation rate is the only variable in each cladding track. It is found that the substrate temperature should be above $317^{\circ} \mathrm{C}$ to deposit a continuous clad layer without defects. This is considered as the lower bound of the temperature process window. Mixing may occur when the substrate temperature is higher than $407^{\circ} \mathrm{C}$, which is defined as the upper bound temperature. The experiments carried out with different tools disclose an identical FSC process window.

The heat generations and the normal forces at the transition points from discontinuous to continuous clad layers and from non-mixing to mixing in the clad layer are in line with the corresponding values (EN-h0.2-2 and EN-h0.2-5) found in Chapter 2. The mixing start moment is also confirmed by the value of $\sigma_{e f f} / \sigma_{y}$ calculated based on the estimated heat generation and the recorded normal forces. These observations confirm the reliability of the explored process window.

A map of the process window is established based on the 3D thermal model, the analytical derivation of the heat generation and the observed temperature bounds. Proper tool rotation rates leading to continuous and defect free deposition with a minimum thermal effect exerted by the cladding process on the mechanical properties of the substrate can be selected directly from this map when certain layer dimensions are required. This process window map can also be used for different tools, but in principle it holds only for the deposition of pure aluminum AA1050 on the AA2024 substrates, although the approach is set up in a general way. The mixing behavior of the experiments presented in Chapters 2 and 3 can be predicted well by this map.

The two concluding practical experiments carried out with varying tool rotation rates witness a stable cladding process, constant temperatures and defect free layers with uniform layer dimensions. This indicates that adjusting the tool rotation rate is an effective approach to control the cladding process; higher tool rotation rates can be used in the preheating phase to heat up the FSC system, the clad material and the substrate efficiently. Subsequently, lower rates can be employed in the cladding phase to keep the process temperature constant and low. 


\section{References}

Gilbert Kaufman, J. (1999). Properties of Aluminum Alloys: Tensile, Creep, and Fatigue Data at High and Low Temperatures. ASM International.

Jones, M., Heurtier, P., Desrayaud, C., Montheillet, F., Allehaux, D., and Driver, J. (2005). Correlation between microstructure and microhardness in a friction stir welded 2024 aluminium alloy. Scr. Mater., 52(8):693-697.

Khodir, S. A., Shibayanagi, T., and Naka, M. (2006). Control of hardness distribution in friction stir welded AA2024-T3 aluminum alloy. Mater. Trans., 47(6):1560-1567.

Prasad, Y. and Sasidhara, S. (1997). Hot Working Guide: A Compendium of Processing Maps. ASM International.

Tylecote, R. (1968). The solid phase welding of metals. Edward Arnold.

Van der Stelt, A. (2014). Friction surface cladding; development of a solid state cladding process. PhD thesis, University of Twente. 


\section{CHAPTER 7}

\section{Discussion}

\subsection{Overview of the FSC study}

The friction surface cladding process has been developed to deposit thin metallic layers on a metallic substrate. In this thesis the deposition of AA1050 onto an AA2024-T3 substrate was studied in detail to improve corrosion properties. The presence of a defect free layer of (commercially) pure aluminum completely covering the surface of the substrate strongly supports the corrosion protection of the substrate. Important requirements for the applicability of this process are the following: (i) during the manufacturing of the clad layer changes in the mechanical properties of the substrate should remain as small as possible and (ii) good bonding of the clad layer to the substrate should be achieved. Hence, thorough understanding of the thermo-mechanical processes that occur during the manufacturing process is necessary to obtain continuous and defect free clad layers meeting the requirements mentioned.

The main FSC variables comprise process and tool design parameters such as the tool rotation rate, the clad layer dimensions and the size of the tool opening. The influence of these parameters has been analyzed experimentally, numerically and analytically to study the effects on the FSC heat generation and the normal force exerted on the substrate. The numerical and analytical models established were able to explain and confirm the trends observed experimentally. An FSC process window was determined based on the experiments performed and the various models developed.

The progress in the understanding of the FSC process achieved in this thesis can be incorporated in the FSC map, displayed in Chapter 1, and reproduced here, see Fig. 7.1. The exploratory work performed by Van der Stelt (2014) suggested that the relation between the cladding performance and the cladding conditions is mainly based on knowledge of the process temperature and the normal force. Knowing the cladding conditions in terms of the FSC setup and values of the process parameters, the process temperature and normal force were obtained from experiments. The relationship of the temperature and the force with the cladding performance in terms of the clad layer appearance and the hardness distributions 
was also established. This explains the arrows pointing from left to right between the balloons.

The experiments performed and the models developed in this thesis now also enable the FSC map to be gone through backwards. For example, upper and lower bounds of the temperature can be set to meet the requirements of the cladding performance such as substrate hardness, degree of mixing, etc. Then, the cladding conditions can be selected in terms of the setup and the process parameters with the help of the process window determined in the previous chapter. This direction is represented by the arrows pointing from right to left in the figure. The upper bound of the temperature follows from the onset of mixing of the clad layer with the substrate under specific experimental conditions, as observed in some of the experiments and models in Chapter 2. The lower bound is related to the lowest possible temperature to clad the AA2024 substrate with commercially pure aluminum based on experiments performed in Chapter 6. No model is yet available that predicts the onset of the formation of defect free clad layers in terms of FSC process parameters. Other remaining challenges will be discussed in the following sections.

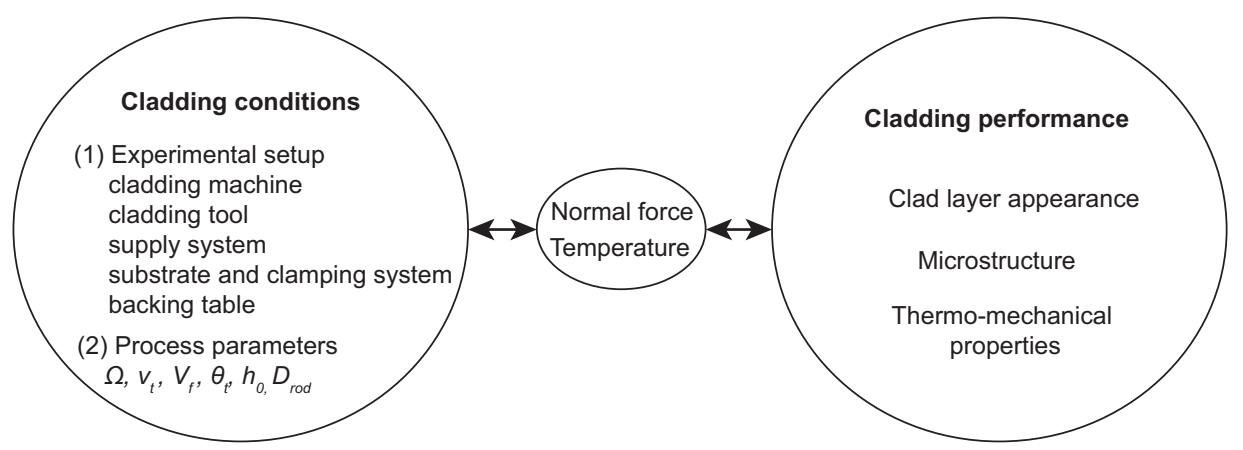

Fig. 7.1 An overview of the analyses involved in FSC.

\subsection{Remaining challenges}

\subsubsection{Experimental controllability}

The cladding experiments were performed on a modified planer machine equipped with a specially designed cladding tool. The presence of the tool provides a good control over the layer dimensions and the layer surface. The deposited layers are dense, defect free, continuous and well bonded to the substrate if proper process conditions are selected. No flash is observed near the layer edges and little material is wasted in the the cladding process. These are significant advantages of FSC over, for example, friction surfacing, see also Chapter 1. 
The tool rotation rate is a powerful and easily accessible parameter to control the FSC process. For example, it can be adjusted during the cladding phase to ensure the cladding process runs smoothly and at relatively low temperatures, which helps to retain the mechanical properties of the substrate being cladded. However, the cladding setup also has some shortcomings. For instance, the stiffness of the cladding machine is insufficient, leading to varying layer thicknesses as a function of the normal forces generated. Moreover, it is difficult to keep the supply rate of the clad material constant among different experiments. In the recommendation section of Chapter 8 these problems will be addressed and possible solutions will be provided.

\subsubsection{Numerical and analytical models}

The numerical and the analytical models developed in this thesis consider the clad material as a creeping fluid. The pressure distribution and the normal force exerted on the substrate are obtained by solving the Stokes equation. The calculations are computationally rather inexpensive, but a drawback of this CFD approach is the inability to provide the contact status at the tool-clad material interface. In fact, the status has to be provided as input information (see Chapter 5).

A more elegant solution would be obtained if the contact status is output of the calculations, based on a physical description of the behavior at the relevant contact surfaces with the clad material. Then, the sticking factor will become dependent on the local conditions (temperature, pressure, surface properties) both in time and place instead of being fixed priorly. The large amount of plastic deformation occurring within the clad material suggests modeling approaches based, for example, on the arbitrary Lagrangian-Eulerian method or mesh free finite elements that are in principle well capable of handling these conditions. These approaches are much more computationally expensive, but have been successfully employed for other solid state processes, such as complicated FSW computations including the prediction of welding defects, see He et al. (2014) and Fraser et al. (2016).

\subsubsection{Material flow and contact area}

The analysis of the FSC process parameters has been concentrated mainly on the influence of the tool rotation rate, the clad layer dimensions and the diameter of the FSC tool opening. The small inclination angle of the FSC tool axis with respect to the substrate normal has been neglected up to now.

The effect of the inclination angle has been explored with a $3 \mathrm{D}$ thermo-mechanical model that has been built as a combination of the 3D thermal model presented in Chapter 2 and the 2D thermo-mechanical model in Chapter 4. The cladding tool in the model is now inclined $1^{\circ}$ towards the trailing edge of the tool in line with the 
experimental FSC setup and full sticking is assumed at the interface between the clad material and the FSC tool.

The pressure distributions within the clad material calculated by the 3D thermomechanical model are shown in Fig. 7.2. The calculated pressure distribution is very different from the one calculated by the 2D axisymmetrical model, see also Fig. 5.9. The small inclination of the tool causes the presence of a region with high pressure on the retreating side, where the pressure values are even higher than the pressure required to press out the central clad rod. On the advancing side the pressure distribution indicates negative values, which seems physically unrealistic given the boundary conditions of the problem. Apparently, insufficient material is available here to fill up the space between the substrate and the FSC tool under the current conditions.

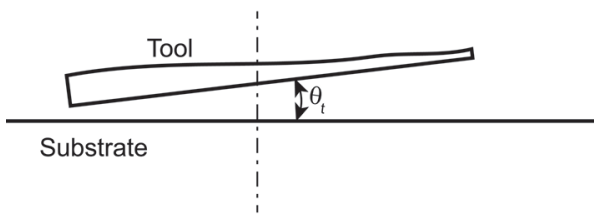

(a)

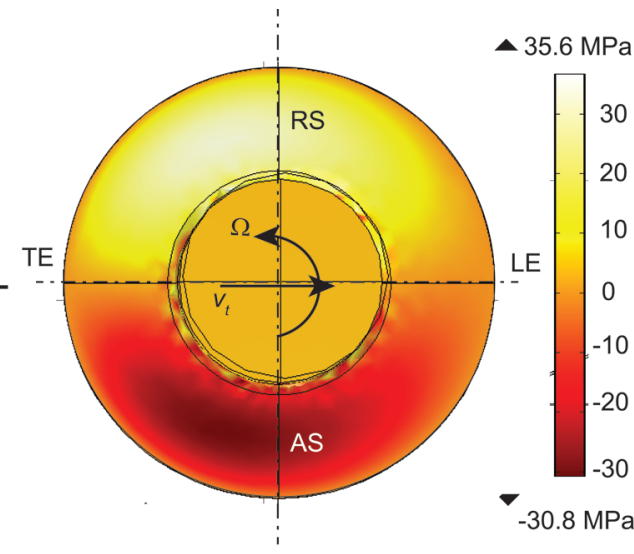

(b)

Fig. 7.2 (a) Orientation of the FSC tool with respect to the substrate; (b) the pressure distribution in the clad material calculated by the 3D thermo-mechanical model with a tool tilt angle of $1^{\circ}$.

Some evidence that the inclination angle may also have effect on the experimental results is visible in Fig. 7.3. Here, the top view at the end of the clad layer produced by experiment EH-02 is shown, along with a number of dashed lines to guide the eye. The cladding center line does not appear to be in the middle of the clad layer produced as the clad layer on the retreating side is somewhat less broad with respect to this line than on the advancing side. This holds for most experiments performed.

The markings left by the trailing edge of the tool at the surface of the clad layers compose arcs with a diameter which is larger than the approximate width of the layers, see the larger dashed circle. The smaller dashed circle represents the outside of the clad rod area, i.e. the region where the clad rod leaves the FSC tool opening. It is clear that the larger dashed circle and the smaller one are not concentric, i.e. they do not have a common center, which is believed to be caused by the inclination 
of the FSC tool axis with respect to the substrate normal.

Furthermore, a portion of the FSC tool at the outer edge was not in contact with clad material on the retreating side of the clad layer in the region in between both dashed circles. Hence, a non-circular contact zone is formed during the cladding phase. The exact shape of the contact region will probably not only depend on the tool rotation rate, tool translation speed and material deposited, but also on the tool tilt angle, the tool bottom profile and the stiffness of the FSC setup.

The above results and observations show once more how important knowledge on the interface conditions between the clad material and the FSC tool is in terms of the contact status (sticking vs slipping) and the contact area shape. The results also indicate that the pressure distribution at the clad material-substrate interface is likely to be very sensitive to these types of changes, which may serve as a possible explanation for the observed differences in the experimentally measured normal force values and the model results in Chapters 4 and 5 .

More work is required to elucidate the interaction between the process and design variables to determine exactly the contact region shape and dimensions and the influence on the contact status at the interfaces of the clad material with the tool and the substrate. As soon as a better description of the material and process behavior at these interfaces has been developed, a more accurate prediction of the influence of the various process and design variables is possible, although the currently developed models already provide significant insight into the role of the FSC process variables.

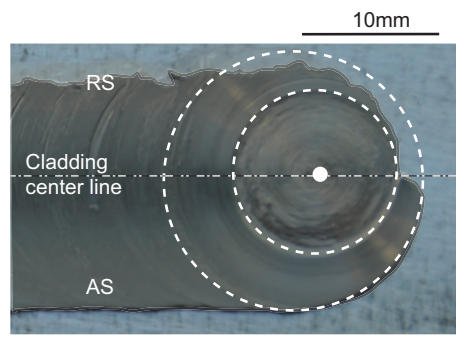

Fig. 7.3 The contact area between the tool and the clad layer observed from the top view of the layer in EH02. The cladding center line separates the advancing side (AS) from the retreating side (RS). The large and small circles indicate the shape of a trailing edge marking and the location of the clad rod area, respectively. The real tool-clad material contact zone clearly deviates from a circular zone. 


\section{References}

Fraser, K., St-Georges, L., and Kiss, L. (2016). Meshfree simulation of the entire FSW process on the GPU. In 11th Int. Symp. Frict. stir Weld., page 15, Cambridge.

$\mathrm{He}, \mathrm{X} ., \mathrm{Gu}, \mathrm{F}$., and Ball, A. (2014). A review of numerical analysis of friction stir welding. Prog. Mater. Sci., 65:1-66.

Van der Stelt, A. (2014). Friction surface cladding; development of a solid state cladding process. PhD thesis, University of Twente. 


\section{CHAPTER 8}

\section{Conclusions and recommendations}

Deposition of commercially pure aluminum AA1050 onto AA2024-T351 substrates employing FSC has been studied in detail in this thesis with the objectives of understanding the FSC process and determining an FSC process window. The work comprises both experimental work and modeling efforts as described in Chapters 2 - 6. The main conclusions drawn from this work are provided in the first section. A number of recommendations is given in the final section of this chapter.

\subsection{Conclusions}

- With the FSC process it is possible to deposit smooth and defect free clad layers of commercially pure AA1050 in the solid state and with a good bond to the AA2024-T351 substrates.

- Clad layers can be manufactured within a relatively broad process window. The layer width produced ranges from $16 \mathrm{~mm}$ to $24 \mathrm{~mm}$. Layers with a thickness between 0.2 and $0.8 \mathrm{~mm}$ can be produced well. Tools with different openings can also be employed, and the clad material can be deposited at different supply rates.

- Experiments performed at relatively low tool rotation rates, where the tool temperature is close to $300^{\circ} \mathrm{C}$, show only a small decrease in the substrate hardness.

- A 3D thermal model described in Chapter 2 provides a way to estimate the heat generation rate from the temperature data recorded during the experiments. The relative dimensions of the modeled ideal thermal contact area at the interface between the substrate and the underlying backing table are not dependent on the clad layer width, the clad layer thickness and the tool rotation rate.

- The thermo-mechanical FSC model introduced in Chapter 4 shows that higher tool rotation rates and larger layer widths raise the calculated heating rate nearly linearly. Larger diameters of the tool opening and layer thicknesses have a negligible effect on the heat generation rate. The normal force exerted on the substrate calculated by the model decreases with higher tool rotation 
rates, larger layer thicknesses and larger tool openings, whereas it increases with larger layer widths. These results are in line with the trends observed experimentally.

- Under full sticking conditions at the interfaces of the clad material to the tool and the substrate, the thermo-mechanical model overestimates the heat generation but it underestimates the recorded normal force. The ratio of the experimentally estimated heat generation to the model based one is observed to be a constant for all experiments performed. Such a ratio calculated for the normal force exerted on the substrate is shown to be non-uniform.

- If some degree of slipping is assumed at the tool-clad material interface, an average value of the apparent coefficient of friction of 2.1 is shown to reasonably describe the experimental results, a value which complies with the literature.

- In Chapter 5 an analytical model is presented to derive equations for the heat generation rate, the pressure and the normal force exerted on the substrate. The model considers the clad material isothermal with the temperature and strain rate dependence described by a power law. Under identical conditions this model gives the same results as the 2D axisymmetric thermo-mechanical model. The parameter study with the analytical model under full sticking condition shows similar trends as the 2D axisymmetric thermo-mechanical model.

- A better model description of the flow behavior within the clad material during the FSC process is obtained if spatially varying sticking conditions at the tool-clad material interface are considered as implemented in the analytical model. The transition from full sticking near the FSC tool opening to partial slipping typically occurs at an approximately fixed ratio with respect to the clad layer widths, as has been shown from an optimization study for the experiments performed with the $\varnothing 10$ tool. The predicted heat generation rate compares well with the corresponding experimental results if employing this ratio along with a fixed functional description of the slipping behavior towards the FSC tool outer edge. The prediction of the normal force is still off but the calculated forces are at the same level of magnitudes as the recorded ones.

- Dedicated experiments show that the substrate temperature should be above $317^{\circ} \mathrm{C}$ to deposit a continuous clad layer without defects. Mixing may occur when the substrate temperature is higher than $407^{\circ} \mathrm{C}$. The nonmixing/mixing occurrence can be predicted from the 3D thermal model utilizing the ratio of the effective stress applied to the substrate to the yield stress of the substrate at elevated temperature.

- A map of the process window has been established based on the thermal model, the analytical derivation of the heat generation and the observed temperature bounds. Proper tool rotation rates leading to continuous and defect free deposition can be selected directly from this map when certain layer dimensions are required. The effects of the temperature development over time during the manufacturing process on the mechanical properties of 
the substrate can be minimized choosing a temperature close to the lower temperature bound in the process window.

- Adjusting the tool rotation rate within the determined process window is an effective approach to control the cladding process; higher tool rotation rates can be used in the preheating phase to heat up the FSC system, the clad material and the substrate efficiently. Subsequently, lower rates can be employed in the cladding phase to keep the process temperature constant.

\subsection{Recommendations}

Further research is required to solve the remaining issues of FSC, to extend the current understanding of the process and to put FSC into practice. The following recommendations have been formulated on the basis of the findings in this work.

- The FSC setup currently lacks a torque measurement device which hampers modeling activities. The 3D thermal model developed to estimate the heat generation rate of the cladding process has been employed to estimate the total energy input. A direct comparison with the mechanical energy input from torque data would be highly recommended.

- It is recommended to increase the vertical stiffness of the FSC setup as variations in the normal force exerted on the substrate currently cause small, unwanted changes in the layer thickness.

- Deposition of clad layers at constant temperature requires accurate adjustment of the tool rotation rate. Currently, the temperature controlled cladding experiments are performed utilizing a manual feedback process, which has a relatively low level of accuracy and synchronization. A real time temperature acquisition system coupled with a tool rotation rate controller will lead to better temperature control during FSC experiments.

- Better temperature control during the FSC experiments is also obtained when the tool temperature remains constant during the cladding phase. However, during most FSC experiments it has been observed that the tool temperature slowly rises, which affects the FSC process performance. The FSC tool could be equipped with an additional cooling system that keeps the tool temperature at a fixed value independent of the process conditions.

- The layer width in this work is mainly controlled by the supply rate of the clad material at a given layer thickness. The layer edge is sometimes slightly wavy due to the material flow. A mechanical guide for the material flow can be designed, which can support the production of layers with a precise width and straight layer edges, although with the current FSC tool design this may be difficult to realize for relatively thin clad layers. An alternative solution is the following. Exploratory experiments carried out with AA2024 and AA6061 as clad material and AA2024 as substrate showed that these clad layers were always characterized with straight edges both at the advancing and retreating sides. In these cases also no clad material remained attached 
to the FSC tool as commonly occurred during experiments with AA1050 clad material. Hence, providing the FSC tool with a proper coating that decreases the sticking behavior of the AA1050 to the FSC tool may be beneficial to the quality of the clad layer edges.

- This work shows that the clad material is bonded well to the substrate and no debonding occurs, which may be sufficient for chemical protection of the substrates. However, the actual bonding strength remains unknown and future applications may be more demanding requiring a model based knowledge of the interface strength.

- Future applications of deposited clad layers will require minimal shape changes of the substrate due to the FSC process. It is therefore recommended to make dedicated studies of the relation between the cladding conditions and the development of the residual stresses as measured from hole drilling methods, X-ray diffraction and suchlike.

- The currently developed FSC models assume that the clad rod rotates with the same angular rotation rate as the tool. A microstructural study of the orientation and distribution of grains in the clad rod and the clad layer near the FSC tool opening may be helpful towards assessing the effective amount of slip taking place at this location, as plastic deformation of the clad material is linked to changes in the grain size, orientation and distribution.

- The lower bound of the process window was determined experimentally, where continuous clad layers were deposited at temperatures above this bound. Detailed studies of the deformation and bonding processes occurring at the interface need to be performed to thoroughly understand the behavior. Appropriate models should be developed to describe the processes to enable the determination of the temperature as a function of the process conditions and FSC tool design. The role of the oxide layers present at the surfaces of the substrate and the clad material should be included.

- Exploratory work has shown that the inclination angle of the tool is an important process parameter for FSC as it modifies the pressure distribution and the material flow. It should be investigated further and the influence of the tool design, especially the bottom profile of the tool, should be included in such a study.

- The influence of the tool translation speed on the FSC process has not been studied in this thesis. Nevertheless, it is an important process parameter to control the cladding efficiency. The influence of this parameter on the heat generation, the temperature distribution and the normal force should be studied systematically as well.

- The current cladding setup can deposit layers with dimensions of approximately $200 \mathrm{~mm} \times 20 \mathrm{~mm} \times 0.2 \mathrm{~mm}$. This may be insufficient for future industrial application of this technique. Therefore, the setup should be modified to one which can deposit material continuously. These new clad material supply solutions may also consider the use of other shapes than cylindrical rods (for example: powder, granulate, etc.).

- The current thesis has concentrated on the deposition of commercially pure 
aluminum onto AA2024 substrates. However, the FSC process can be applied to a broader range of materials. Exploratory experiments have shown that FSC of commercially pure aluminum on steel is feasible. Also, the deposition of AA6061 on an AA2024 substrate is possible and even the deposition of AA2024 on itself turned out to be successful. Also, in the latter case, multiple layers were deposited on top of each other, typical for additive manufacturing processes. The modeling efforts developed so far have been set up in a rather general way and may serve as a basis for exploration of these new applications and material combinations.

- Apart from surface protection and additive manufacturing, FSC can also be used to repair damaged layers such as worn Alclad workpieces. Moreover, some undesired features like grooves or holes on the surface of a workpiece can be filled by FSC. Finally, it can also be used in the post-welding process, for example to repair and/or cover welds. 



\section{Acknowledgement}

First of all, I would like to express my appreciation to my promoter Prof.dr.ir. R. Akkerman for his support. I highly appreciate that he accepted me as a Ph.D. candidate in the group of Production Technology. I would also like to thank Prof.dr.ir. L.E. Govaert for accepting to promote me together with Prof.dr.ir. R. Akkerman. In addition, I would like to extend my gratitude to the rest of the graduation committee: Prof.dr. I.M. Richardson, Prof.dr.ir. R. Benedictus, Prof.dr.ir. A.H. van den Boogaard and Prof.dr.ir. D.J. Schipper. Here, my special thanks goes to Prof.dr.ir. A.H. van den Boogaard for accepting me to join the group meeting of Nonlinear Solid Mechanism. His detailed suggestions brought various views and solutions to my work.

Secondly, I would like to sincerely thank my daily supervisor dr.ir. T.C. Bor for his sharp insight into this project, his scientific guidance, his kindness, and his overall support. During the last four years I experienced day by day what a qualified and responsible scientist he is. All experiments involved in this project have been done with his attendance even when the temperature dropped below $10^{\circ} \mathrm{C}$ in the workshop. He helped to solve the difficulties that occurred during the experiments, and also made many designs to make the experiments easier and more accurate. Besides this, he often worked until late in the night to correct my thesis. This work would not be finished on time without his help. Moreover, his full enthusiasm and spirit on research and his strong sense of responsibility for supervising his Ph.D. students gave me many good lessons. My sincere appreciation also goes to my second daily supervisor dr.ir. H.J.M. Geijselaers. His broad knowledge widens my prospective about research. His wise advice and comments always brought me to a new view about my research and writing. I would also like to thank Thijs Kok for the precious comments on my thesis he has provided during the reading meetings. I would like to thank Laura Vargas, Ivo Vrooijink and Bert Vos for their patient instruction and support in the lab. My thanks also goes to Axel Lok and Nico van Vliet for their support in measuring equipment and software programs. Within these four years, I have learned many things with their help: from operating the machines to preparing and analyzing the samples. I am also very grateful to the secretaries Belinda Schaap and Debbie Vrieze-Zimmerman van Woesik for helping me deal with the daily troubles. This made me able to fully focus on my research and finish my work on time. It is also them who bring the research groups together and this made me feel that I was not fighting alone.

I express my sincere gratitude to all the engineers in the metal workshop, Martin 
Sprenkeler, Norbert Spikker, Theo Pünt and Joop Tiehuis. They have taught me how to operate the machines and also prepared many samples together with me. I would like to specifically thank Martin Sprenkeler for the modification of the cladding tool and other designs. Here I also extend my appreciation to Eric De Vries for his help in the workshop.

My high appreciation goes to my senior office mates, Arnoud van der Stelt, Ted Ooijevaar, Emiel Drenth and Vitaly Koissin. Without their help, I would not be able to get adjusted and start my research fast. Here I would like to specifically thank Arnoud van der Stelt for the design of the cladding setup and the academic support in this project. I would extend my appreciation to my current office mates, Freek Deunk, Imrah Yosuf, Ozan Erartsin, Ramona Delphine Romian and Marijn de Leede, for their help and understanding and for the great working environment they have created together.

I would like to address my gratitude to the great colleagues and friends, Laurent Warnet, Roy Visser, Ismet Baran, Wouter Grouve, Ulrich Sachs, Bo Cornelissen, Iqbal Abdul Rasheed, Sybren Jansma, Johan van Ravenhorst, Francisco Sacchetti, Guillaume Vincent, Tjitse Slange, Jos Havinga, Ali Torkabadi, Sikander Naseem, Jurnan Schilder, Marieke Bezemer-Krijnen, Frans de Vries, Erkan Asik, Omid Nejadseyfi and Van Tung Tran. It is great to know them and work with them. I would also like to thank my Chinese friends Ya Wei, Bo Hou, Yibo Su, Wenqi Dang, Jincan Yan and Chao Wang and the American friend Shawn Zhang for making my life wonderful. I would especially thank Ya Wei for his technical and academic help in my research.

Here I would sincerely express my profound gratitude to my parents for the life and the great gene they gave me, the encouragement and support they provided, and for their great care and love. I would also thank my sisters Shaohua Liu and especially Shaohui Liu for the support they give me and for taking care of our parents. Here I would also like to thank my partner Peter Lanting for all his support. It is him who turned my Ph.D. life into a decent and colorful style by magic. Meanwhile I would like to thank other members in the Lanting's family for the daily life support.

Furthermore, I would like to address my special thanks to the China Scholarship Council for the financial support over years.

Finally I would like to thank everyone not mentioned above, but that have helped me in any way during the time of my Ph.D.

Lily Shaojie Liu

December 2016 


\section{Publications}

1. Liu, S., Bor, T.C., Van der stelt, A., Geijselaers, H., Kwakernaak, C., Kooijman, A., Mol, J., Akkerman, R., and Van Den Boogaard, A. (2016). Friction surface cladding: An exploratory study of a new solid state cladding process. J. Mater. Process. Technol., 229:769-784.

2. Ya, W., Pathiraj, B., and Liu, S. (2016). 2D modelling of clad geometry and resulting thermal cycles during laser cladding. J. Mater. Process. Technol., 230:217-232.

3. Liu, S., Bor, T.C., Geijselaers, H.J.M., Akkerman, R., (2016). Parameter Study for Friction Surface Cladding of AA1050 on AA2024-T351. Conference 11ISFSW 2016.05.17-16, Cambridge, UK.

4. Liu, S., Bor, T.C., Geijselaers, H.J.M., Akkerman, R., (2015). Thermal and Flow Analysis of Friction Surface Cladding with Varying Clad Layer Thickness. Conference IDDRG, 2015.05.31-06.03, Shanghai, China.

5. Liu, S., Bor, T.C., Geijselaers, H.J.M., Akkerman, R., (2015). Friction Surface Cladding of AA1050 on AA2024-T351; influence of clad layer thickness and tool rotation rate. Conference FSWP 2015.10.01-02, San Sebastian, Spain.

6. Liu, S., Bor, T.C., Geijselaers, H.J.M., Akkerman, R.. An analytical solution to the heat generation and normal force in friction surface cladding. In preparation, 2016 (Chapter 3 and 5 of this thesis). 



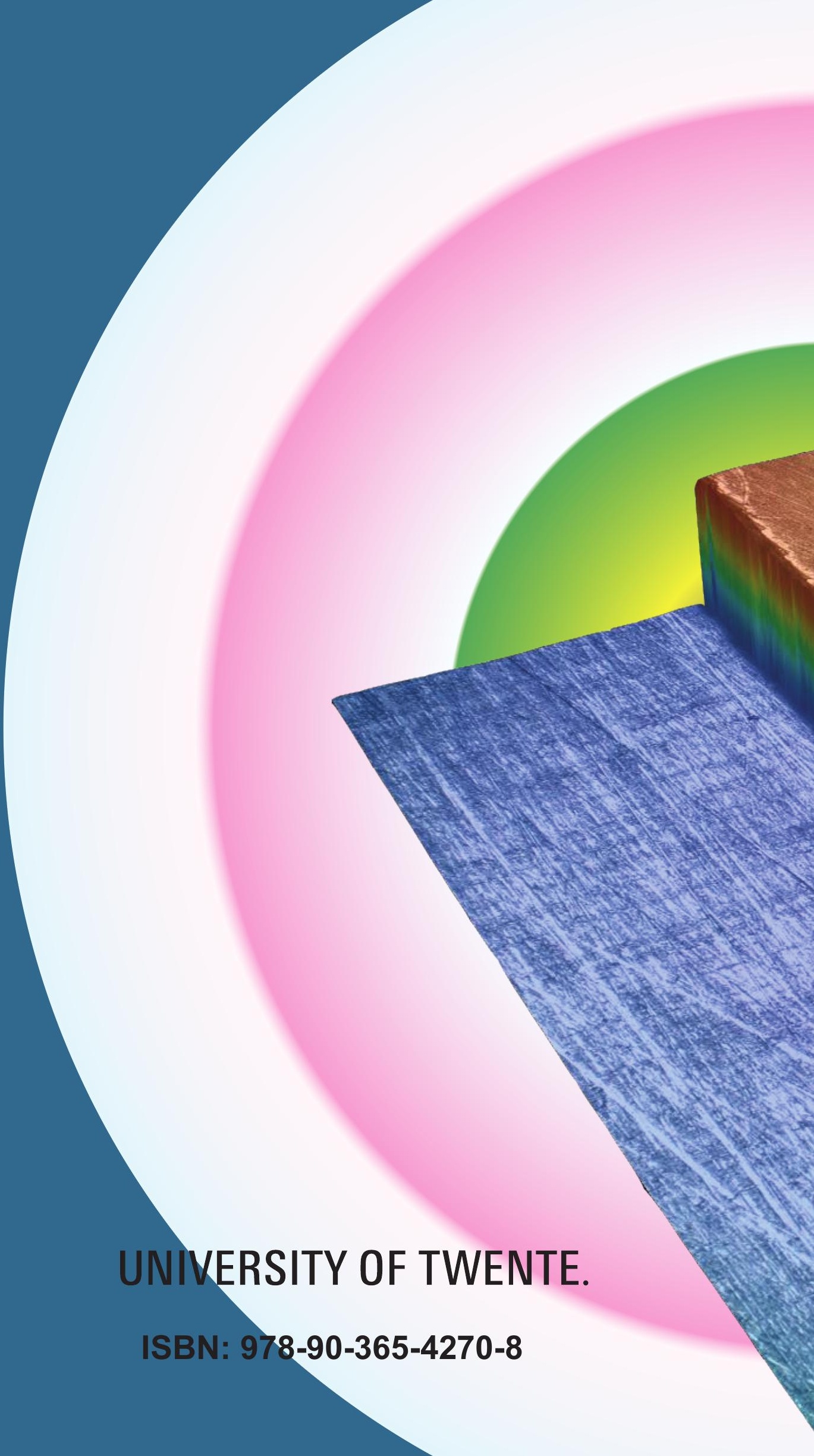

